\title{
A STUDY ON OZONATION AND OZONE BASED ADVANCED OXIDATION PROCESSES FOR THE REMOVAL OF NAPHTHENIC ACIDS FROM WATER: KINETIC STUDIES, MODELLING AND OPTIMAL CONTROL
}

\author{
by \\ Ali Kamel H. Al jibouri \\ M.A.Sc, Ryerson University, Toronto, Canada 2012 \\ M.Sc, Baghdad University, Baghdad, Iraq, 1998 \\ B.Sc, Baghdad University, Baghdad, Iraq, 1988
}

\begin{abstract}
A dissertation
presented to Ryerson University

in partial fulfillment of the

requirements for the degree of

Doctor of Philosophy

In the program of

Chemical Engineering
\end{abstract}

Toronto, Ontario

(C) Ali Kamel H. Al jibouri 2016 


\begin{abstract}
AUTHOR'S DECLARATION
I hereby declare that I am the sole author of this dissertation. This is a true copy of the dissertation, including any required final revisions, as accepted by my examiners.

I authorize Ryerson University to lend this dissertation to other institutions or individuals for the purpose of scholarly research.

I further authorize Ryerson University to reproduce this dissertation by photocopying or by other means, in total or in part, at the request of other institutions or individuals for the purpose of scholarly research.
\end{abstract}

I understand that my dissertation may be made electronically available to the public. 


\begin{abstract}
Ali Kamel H. Al jibouri

Doctor of Philosophy

Department of Chemical Engineering, Ryerson University, Toronto, 2016
\end{abstract}

Industrial wastewater is one of the largest environmental challenges of this century. Most of these wastewaters contain non-biodegradable pollutants which need special treatment methods. Advanced oxidation processes (AOP's), such as, ozonation, catalytic ozonation and ozone/ hydrogen peroxide have proved their effectiveness on the degradation of bio-recalcitrant pollutants. The main drawback in these processes is the high operating cost. The objective of this study was to develop innovative continuous ozonation and ozone based processes that can effectively degrade industrial non-biodegradable pollutants. Naphthenic acids (NAs) was used as the model pollutant in this study due to its importance as a major pollutant in oil and oil sands industries. The target was to convert bio-recalcitrant NAs into biodegradable substances with minimum consumption of ozone gas (operating cost). These processes can be followed by the biodegradation process to fully remove the rest of the pollutants. This research passed through several stages including screening of operating parameters, kinetic studies, and modeling, followed by optimal control of these processes. It was found that ozone concentration had the most significant effect on the NAs degradation compared to other parameters. The kinetics of direct and indirect (radical) ozonation of NAs were investigated and rate constants and activation energies of these reactions were determined. Catalytic ozonation of NAs was explored using alumina supported metal oxides and unsupported catalysts. Activated carbon was found to be the most effective catalyst. The addition of hydrogen peroxide into the ozonation systems significantly improved the removal of NAs compared with the ozonation only process. Models based on mass balance for the ozonation and ozone/ hydrogen peroxide processes were developed to predict the concentration profiles of reacting species. Optimal control policies of ozone/oxygen gas flow rate versus time were developed and validated to minimize NAs concentration in the liquid outlet stream from the continuous ozonation and ozone/ hydrogen peroxide processes. The experimental results demonstrated that the optimal control policies successfully minimized NAs concentration 
in the outlet stream. At the same time, ozone gas consumption was reduced to its minimum, i.e., just enough to minimize the concentration of NAs in the outlet stream. 


\section{ACKNOWLEDGEMENTS}

First, I would like to express my sincere appreciation to my supervisor Professor Jiangning Wu for her guidance and financial support throughout this research. Her exceptional support was amazing. She always gave me the right advice at the right time. She responded to my emails so quickly and sometimes even after midnight. I consider myself a very lucky person to had such a professional and nice supervisor. One day, a co-op student asked me at my final stages of my $\mathrm{PhD}$ study: If you had the chance to go back in time to choose a supervisor, who would you choose? My spontaneous answer was: Definitely Dr. Wu.

I am very grateful to Professor Simant R. Upreti (Chair of the Department of Chemical Engineering, Ryerson University) for his guidance and support in solving the optimal control problems. I appreciated his invaluable suggestions and support regarding my career development.

I would like also to thank all the faculty members in the Department of Chemical Engineering, Ryerson University for their support, especially Dr. Ginette Turcotte and Dr. Huu Doan for allowing me to use instruments in their laboratories.

I also extend my warm thanks to my examination committee members, Professor Ali Elkamel (external examiner, Department of Chemical Engineering, University of Waterloo), Professor Krishna Dev Kumar (Department of Aerospace Engineering, Ryerson University), Professor Simant R. Upreti, and Professor Chil-Hung Cheng for their time and consideration.

I would like to thank the engineering staff: Mr. Tondar Tajrobekar, Mr. Daniel Boothe, and Mr. Ali Hemmati, and the administration staff: Ms. Alanna McKnight, Ms. Elizabeth Hallowell, Ms. Leah Rogan, Ms. Isabella Fernandes, and Ms. Louise Lichacz, in the Department of Chemical Engineering, Ryerson University for all their assistance during my studies.

I would like to thank the Natural Sciences and Engineering Research Council of Canada (NSERC) for financial support. The Queen Elizabeth II Graduate Scholarship in Science and Technology (QEII - GSST) and Ontario Graduate Scholarship (OGS) offered by the Ontario government, and financial aid from Ryerson University are also acknowledged. Ryerson 
University Faculty of Engineering and Architectural Science Dean's Research Fund is highly appreciated.

Most importantly, none of this work would have been done without the support from my beloved wife, my sons and daughters. 


\section{TABLE OF CONTENTS}

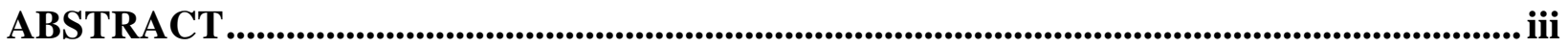

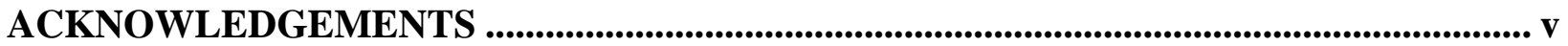

LIST OF TABLES ...........................................................................................................................

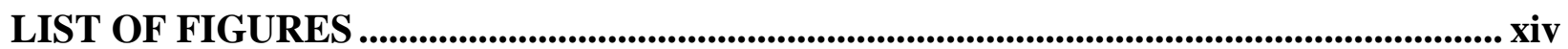

NOMENCLATURE................................................................................................................... xvii

CHAPTER 1: INTRODUCTION........................................................................................................... 1

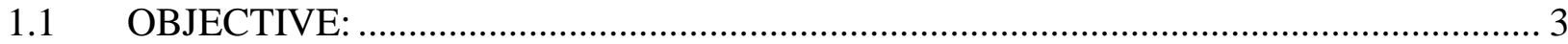

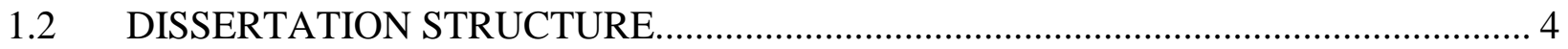

CHAPTER 2: LITERATURE REVIEW .................................................................................... 6

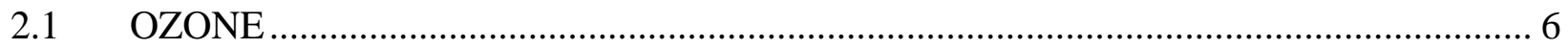

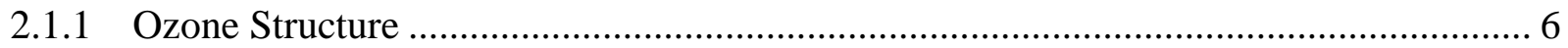

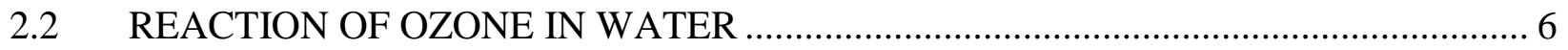

2.2.1 Direct Reactions of Ozone ..................................................................................... 7

2.2.2 Decomposition of Ozone in Water ...................................................................... 12

2.2.3 Indirect (Radical) reactions of Ozone ....................................................................... 13

2.3 HETEROGENEOUS CATALYTIC OZONATION ........................................................ 14

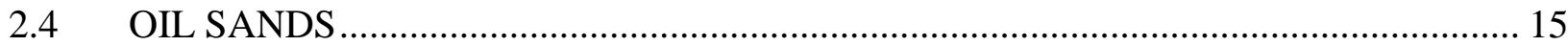

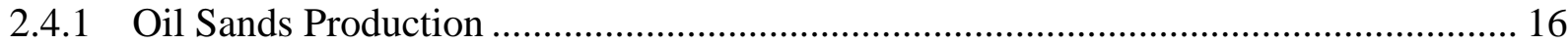

2.4.2 Oil Sands Process-Affected Water (OSPW) .......................................................... 18

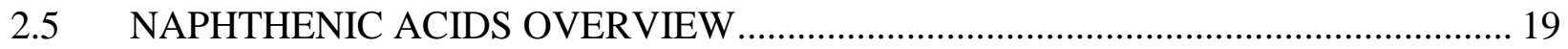




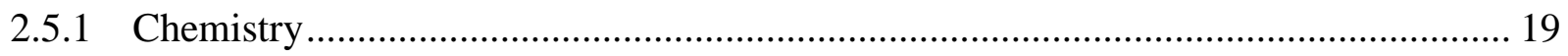

2.5.2 Naphthenic Acids Toxicity ……………………................................................ 20

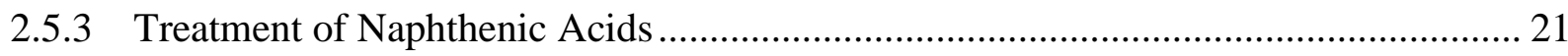

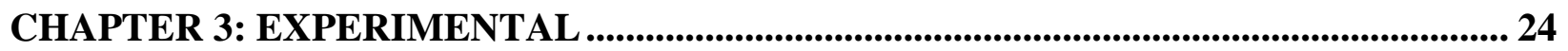

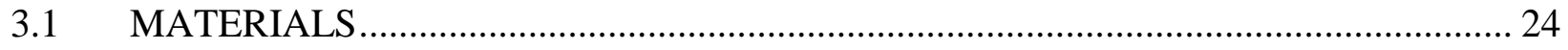

3.1.1 Preparation of Synthetic OSPW …………….................................................... 24

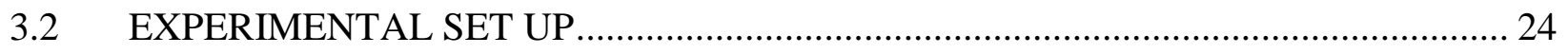

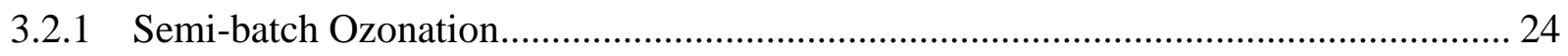

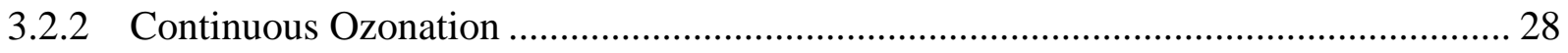

3.3 EXPERIMENTAL DESIGN FOR SCREENING OF OPERATING PARAMETERS ... 31

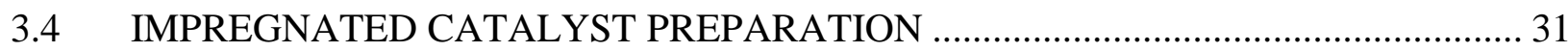

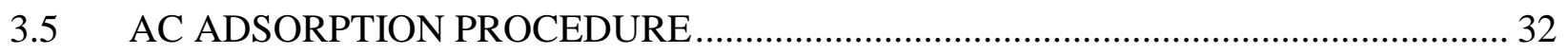

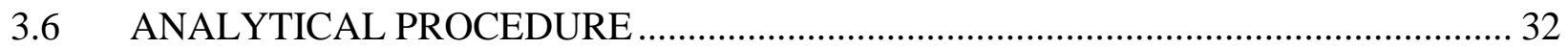

CHAPTER 4: MODEL DEVELOPMENT FOR NAPHTHENIC ACIDS OZONATION . 34

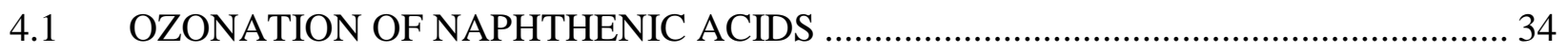

4.2 EFFECT OF OPERATING PARAMETERS ON NAPHTHENIC ACIDS REMOVAL 34

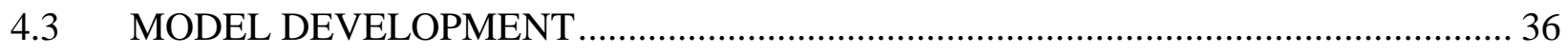

4.4 THEORETICAL ANALYSIS OF THE DEVELOPED MODEL ...................................... 37

\section{CHAPTER 5: OZONATION OF NAPHTHENIC ACIDS IN WATER: KINETIC STUDY}

5.1 DIRECT OZONATION OF NAPHTHENIC ACIDS ……………………................... 42

5.1.1 Effect of Operating Parameters on Naphthenic Acids Removal .................................. 42 
5.1.2 Determination of the Direct Reaction Rate Constant and Activation Energy ............. 45

5.1.3 Estimation of the Kinetic Regime of the Direct Reaction ...................................... 48

5.2 INDIECT (RADICAL) OZONATION OF NAPHTHENIC ACIDS ........................... 49

5.2.1 Determination of the hydroxyl radical concentration ........................................... 49

5.2.2 Determination of the indirect (radical) reaction rate constant ................................. 51

CHAPTER 6: APPLICATION OF MASS BALANCE MODELS IN THE PROCESS OF OZONE REMOVAL OF NAPHTHENIC ACIDS FROM WATER...................................... 54

6.1 EFFECT OF OPERATING PARAMETERS ON NAPHTHENIC ACIDS REMOVAL AND DISSOLVED OZONE CONCENTRATION ...................................................... 54

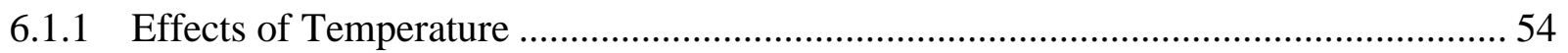

6.1.2 Effect of Inlet Gaseous Ozone Concentration ...................................................... 54

6.2 MODEL DEVELOPMENT FOR THE OZONATION OF NAPHTHENIC ACIDS

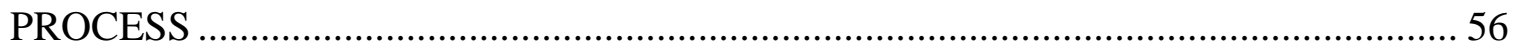

6.3 SOLVING THE DEVELOPED MASS BALANCE EQUATIONS ............................. 60

6.4 EVALUATION OF THE DEVELOPED MODELS ............................................... 62

CHAPTER 7: HETEROGENEOUS CATALYTIC OZONATION OF NAPHTHENIC

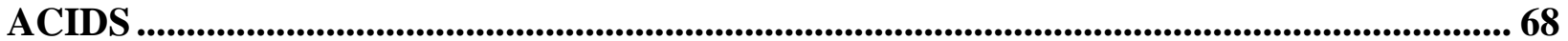

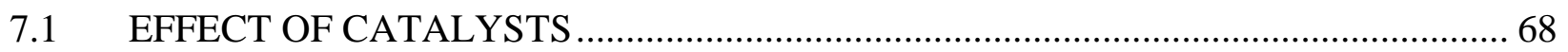

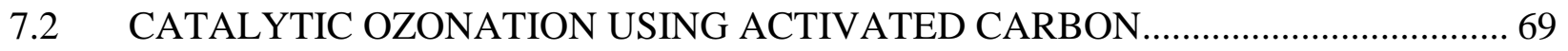

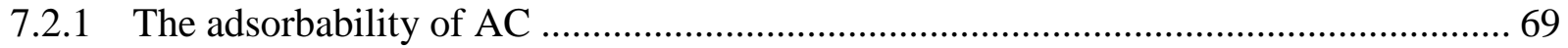

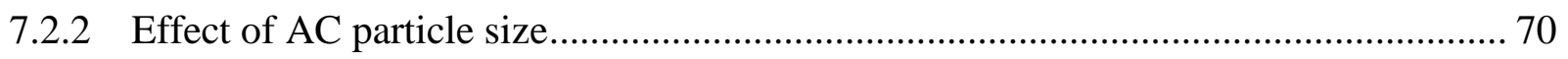

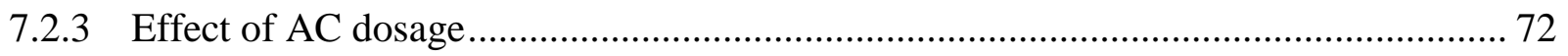

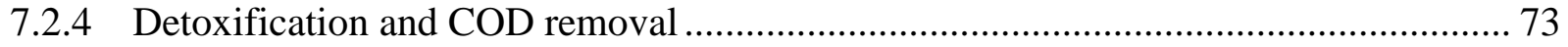

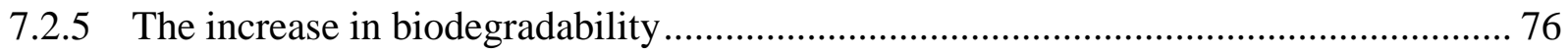




\section{CHAPTER 8: ADVANCED OXIDATION OF NAPHTHENIC ACIDS IN WATER BY}

OZONE AND HYDROGEN PEROXIDE.

8.1 INFLUENCE OF OPERATING PARAMETERS ON NAPHTHENIC ACIDS

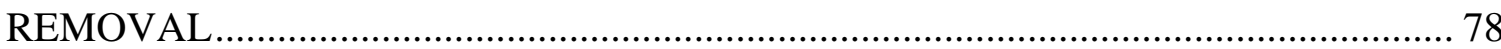

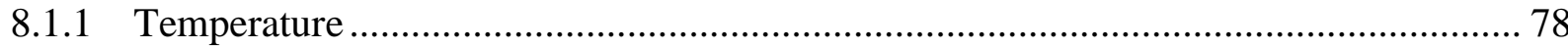

8.1.2 Initial Concentration of Hydrogen Peroxide ............................................................... 78

8.2 KINETICS OF ADVANCED OXIDATION OF NAPHTHENIC ACIDS........................ 81

8.3 MODELLING THE ADVANCED OXIDATION OF NAPHTHENIC ACIDS ............. 82

8.4 DETERMINATION OF THE OVERALL MASS TRANSFER COEFFICIENTS.......... 86

8.5 PREDICTION OF NAPHTHENIC ACIDS AND HYDROGEN PEROXIDE CONCENTRATIONS

\section{CHAPTER 9: OPTIMAL CONTROL FOR THE CONTINUOUS OZONATION OF}

NAPHTHENIC ACIDS IN WATER .......................................................................... 92

9.1 CONTINUOUS OZONATION OF NAPHTHENIC ACIDS MATHEMATICAL MODEL

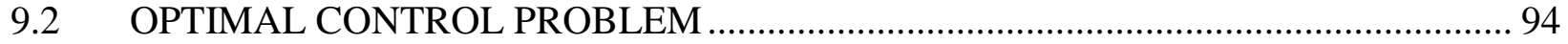

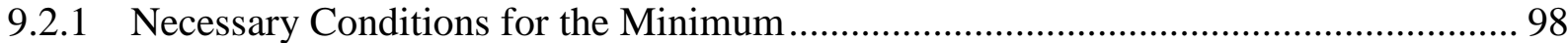

9.2.2 Computational Algorithm to Determine Optimal $(u)$.............................................. 100

9.2.3 Solving the optimal control problem ……………………......................................... 101

9.3 VALIDATION OF CONCENTRATION PROFILES USING OPTIMAL POLICY .... 106

9.4 BIODEGRADABILITY AND DETOXIFICATION …................................................ 108

CHAPTER 10: OPTIMAL CONTROL FOR CONTINUOUS ADVANCED OXIDATION OF NAPHTHENIC AIDS IN WATER.............................................................................................. 111 
10.1 CONTINUOUS ADVANCED OXIDATION OF NAPHTHENIC ACIDS MATHEMATICAL MODEL

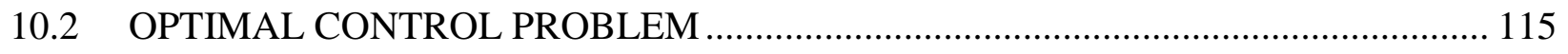

10.2.1 Necessary Conditions for the Minimum............................................................... 117

10.2.2 Computational Algorithm to Determine Optimal $(u)$............................................... 119

10.2.3 Solving the Optimal Control Problem ...................................................................... 119

10.3 VALIDATION OF CONCENTRATION PROFILES USING OPTIMAL POLICY .... 124

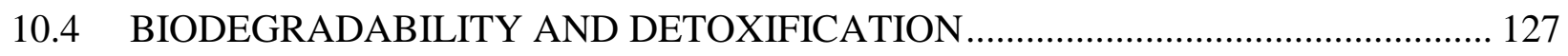

CHAPTER 11: CONCLUSIONS ................................................................................................... 131

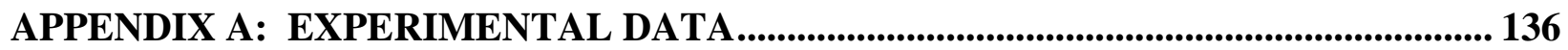

A.1 EXPERIMENTAL DATA FOR CHAPTER 4 ………………….................................. 136

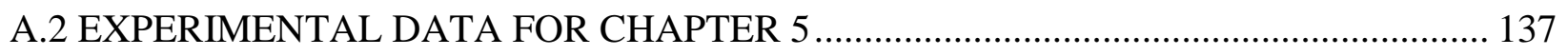

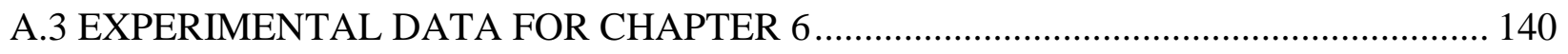

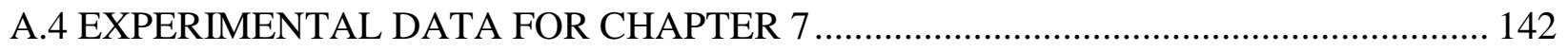

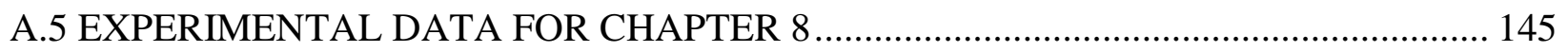

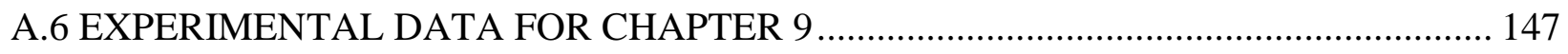

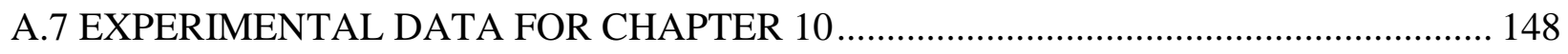

APPENDIX B: STANDARD CURVES ….................................................................................... 150

B.1 NAPHTHENIC ACIDS STANDARD CURVE ............................................................... 150

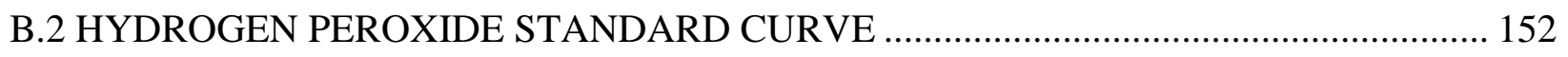




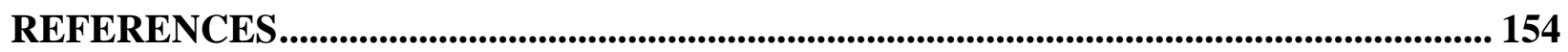




\section{LIST OF TABLES}

Table 2.1 Standard Redox Potential of Some Oxidant Species .................................................... 7

Table 2.2 Activating and deactivating Groups of the aromatic electrophilic substitution reaction

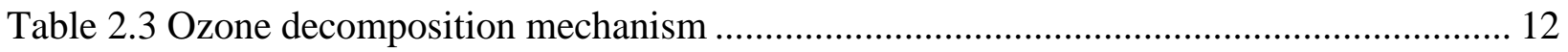

Table 2.4 Some researches on heterogeneous catalytic ozonation. ............................................ 15

Table 2.5 Canadian production of crude oil in Barrels/ day ...................................................... 16

Table 3.1. Experimental conditions applied in the screening of operating parameters, kinetic studies, modeling of ozonation, catalytic ozonation and advanced oxidation of NAs. ........ 26

Table 3.2 Experimental conditions applied in optimal control of continuous ozonation and AOP

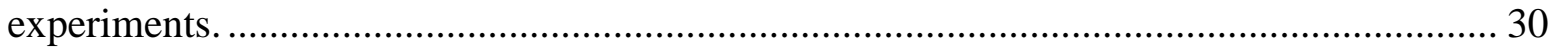

Table 3.3 Levels of operating parameters studied in the experimental design Parameter............ 31

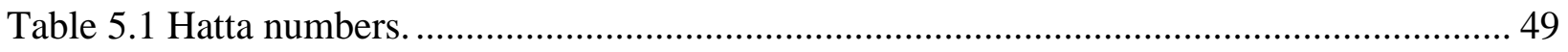

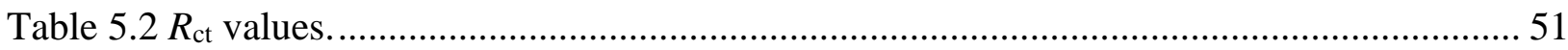

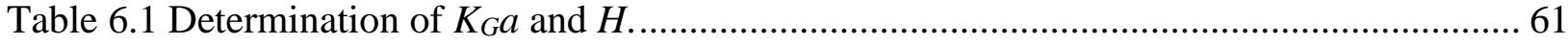

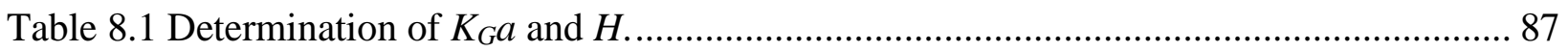

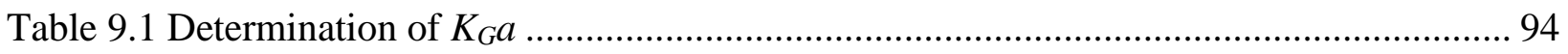

Table 9.2 Objective functional $\left[I=\hat{y}_{0}\left(t_{\mathrm{f}}\right) / \bar{y}_{0}\right]$ and gas consumption as functions of initial

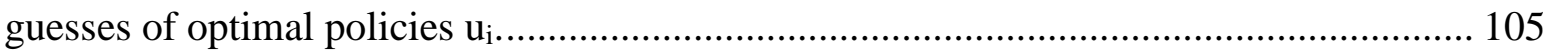

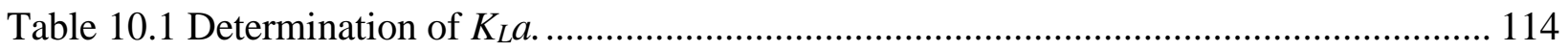

Table 10.2 Objective functional $\left[I=\hat{y}_{0}\left(t_{\mathrm{f}}\right) / \bar{y}_{0}\right]$ and gas consumption as functions of initial guesses of optimal policies $u_{i}$ 


\section{LIST OF FIGURES}

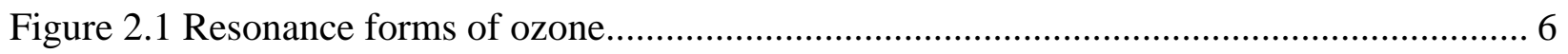

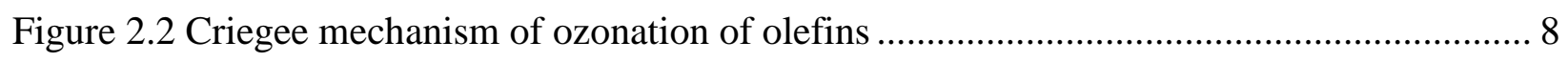

Figure 2.3 Reaction of zwitterion with water. ................................................................ 9

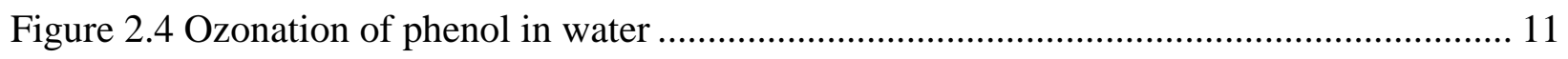

Figure 2.5 In-situ Oil Sands recovery using SAGD technology............................................ 17

Figure 2.6 block diagram for the oil sand production processes. .......................................... 18

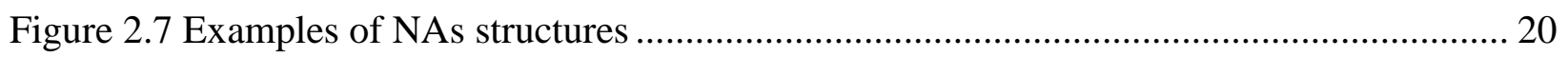

Figure 3.1 Schematic illustration of the ozone generation and reactor system used in model

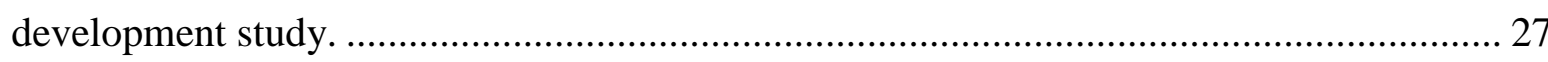

Figure 3.2 Schematic illustration of the ozone generation and semi-batch reactor system used for

kinetic studies, modeling, catalytic ozonation and AOP studies. ................................... 28

Figure 3.3 Continuous ozonation and AOP set up used in optimal control studies. .................. 30

Figure 4.1 Evolution of dimensionless concentration of naphthenic acids (NAs) with ozonation

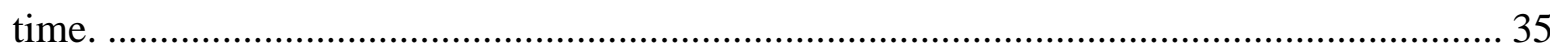

Figure 4.2 Standardized Pareto chart for the ozonation of NAs. .......................................... 36

Figure 4.3 Predicted response surfaces for the variation of NAs concentration with (a) inlet gaseous ozone concentration $\left(\mathrm{C}_{\mathrm{O} 3}\right)$ and ozone/oxygen flow rate $(F)$; (b) inlet gaseous ozone concentration $\left(C_{\mathrm{O} 3 \mathrm{Gi}}\right)$ and $\mathrm{pH}$, and $(\mathrm{c})$ ozone/oxygen flow rate $(F)$ and $\mathrm{pH}$...................... 39

Figure 4.4 Predicted concentration profile in the liquid film near a gas bubble....................... 41

Figure 5.1 Effect of scavenger concentration on the removal of NAs.................................... 43

Figure 5.2 Effects of temperature and the addition of scavenger on the removal of NAs........... 44

Figure 5.3 Effects of temperature and the addition of scavenger on the dissolved ozone

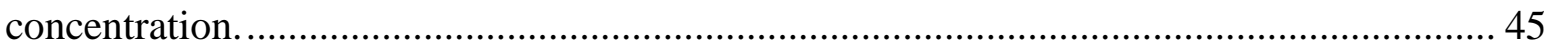

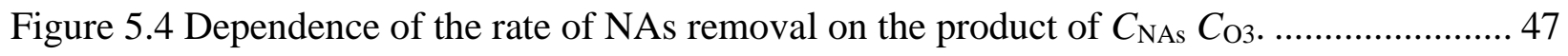

Figure 5.5 Graphical determination of the activation energy of direct ozonation of NAs. ......... 48

Figure 5.6 Plots of $\ln \left(C_{\mathrm{pCBA}} / C_{\mathrm{pCBA}, 0}\right)$ versus ozonation time............................................. 50

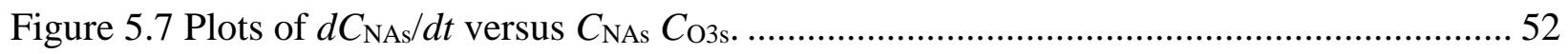

Figure 5.8 Graphical determination of the activation energy of indirect ozonation of NAs. ....... 53

Figure 6.1 Remaining of naphthenic acids (NAs) at different inlet ozone concentration. ........... 55 
Figure 6.2 Effect of inlet ozone concentration on dissolved ozone concentration.................... 56

Figure 6.3 Dependence of the Henry's law constant on temperature .................................... 61

Figure 6.4 Dependence of the overall mass transfer coefficient on temperature....................... 62

Figure 6.5 Validation of the mass transfer models developed at different temperature. (a) NAs,

(b) dissolved ozone, and (c) ozone in the gas phase at the outlet of the reactor. 65

Figure 6.6 Validation of the mass transfer models developed at different inlet ozone concentrations. (a) NAs, (b) dissolved ozone, and (c) ozone in the gas phase at the outlet of the reactor. 67

Figure 7.1 Effect of catalysts on the removal of NAs. 69

Figure 7.2 Removal of NAs by adsorption (Ads.), ozonation and catalytic ozonation (Cat.) using AC (0.25-0.841 mm). 71

Figure 7.3 Effect of AC particle sizes on the removal of NAs. 72

Figure 7.4 Effect of AC dosage on the removal of NAs at 5 and 15 min of catalytic ozonation time. 73

Figure 7.5 Toxicity removal in ozonation and catalytic ozonation of NAs processes. .............. 75

Figure 7.6 COD removal in ozonation and catalytic ozonation of NAs processes.................... 76

Figure 7.7 Degradability (BOD/COD ratio) in ozonation and catalytic ozonation of NAs processes. 77

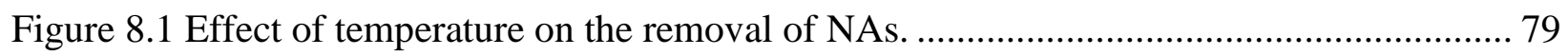

Figure 8.2 Effect of initial hydrogen peroxide concentration on the removal of NAs. .............. 80

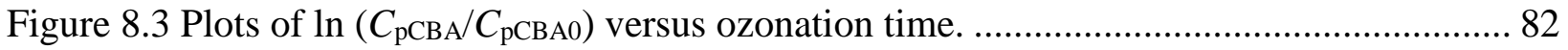

Figure 8.4 Validation of the original advanced oxidation kinetic model. Variation of the predicted (Mod.) and the experimental (Exp.) NAs concentrations with time at different temperatures.

Figure 8.5 Validation of the modified advanced oxidation kinetic model. Variation of the predicted (Mod.) and the experimental (Exp.) NAs concentrations with time at different initial hydrogen peroxide concentrations. 90

Figure 8.6 Variation of the predicted and experimental $\mathrm{H}_{2} \mathrm{O}_{2}$ concentration with time. 91

Figure 9.1 Concentration profiles of NAs using different optimal policies (gas flow rate) starting with different initial guesses for the control policies $\left(\mathrm{u}_{\mathrm{i}}\right)$. 103 
Figure 9.2 Optimal control policies (gas flow rates) starting with different initial guesses for these policies $\left(\mathrm{u}_{\mathrm{i}}\right)$

Figure 9.3 Concentration profiles of dissolved ozone using different optimal policies (gas flow rate) starting with different initial guesses for the control policies $\left(\mathrm{u}_{\mathrm{i}}\right)$........................ 105

Figure 9.4 Predicted (Pred.) and experimental (Exp.) control policies $\widehat{u}_{3}(t) \ldots \ldots \ldots \ldots \ldots \ldots \ldots \ldots . . . . . . . . . .106$

Figure 9.5 Predicted (Pred.) and experimental (Exp.) concentration profiles of NAs, dissolved ozone, and gaseous ozone obtained by using the optimal policy $\widehat{u}_{3}(t) \ldots \ldots \ldots \ldots \ldots \ldots \ldots \ldots \ldots . . . . . . . . . .108$

Figure 9.6 Biodegradability, as BOD/COD ratio, of ozonated NAs. ...................................... 109

Figure 9.7 Toxicity of ozonated NAs. ............................................................................... 110

Figure 10.1 Concentration profiles of NAs using different optimal policies (gas flow rate) starting with different initial guesses for the control policies $\left(\mathrm{u}_{\mathrm{i}}\right)$.

Figure 10.2 Optimal control policies (gas flow rates) starting with different initial guesses for these policies $\left(u_{i}\right)$

Figure 10.3 Concentration profiles of hydrogen peroxide using different optimal policies (gas flow rate) starting with different initial guesses for the control policies $\left(\mathrm{u}_{\mathrm{i}}\right)$ 123

Figure 10.4 Concentration profiles of gaseous ozone using different optimal policies (gas flow rate) starting with different initial guesses for the control policies $\left(u_{i}\right)$. 124

Figure 10.5 Predicted (Pred.) and experimental (Exp.) control policies $\widehat{u}_{3}(t)$ 125

Figure 10.6 Predicted (Pred.) and experimental (Exp.) concentration profiles of NAs, hydrogen peroxide, and gaseous ozone obtained by using the optimal policy $\widehat{u}_{3}(t)$. 127

Figure 10.7 Biodegradability, as BOD/COD ratio, of oxidized NAs with AOP time.............. 128

Figure 10.8 Toxicity of ozonated and advanced oxidized NAs. 


\section{NOMENCLATURE}

\begin{tabular}{|c|c|}
\hline $\mathrm{AOP}$ & advanced oxidation process \\
\hline$C_{\mathrm{HO}} \cdot$ & concentration of hydroxyl radicals $(\mathrm{M})$ \\
\hline$C_{\mathrm{H}_{2} \mathrm{O}_{2}}$ & concentration of hydrogen peroxide (M) \\
\hline$C_{\mathrm{H}_{2} \mathrm{O}_{2}, \mathrm{i}}$ & inlet concentration of hydrogen peroxide $(\mathrm{M})$ \\
\hline$C_{\mathrm{H}_{2} \mathrm{O}_{2}, 0}$ & initial total concentration of hydrogen peroxide (M) \\
\hline$C_{\mathrm{HPO}_{4}^{2-}}$ & concentration of phosphate buffer (M) \\
\hline$C_{\mathrm{NAs}}$ & concentration of naphthenic acids (M) \\
\hline$C_{\mathrm{NAs}, \mathrm{i}}$ & inlet concentration of naphthenic acids $(\mathrm{M})$ \\
\hline$C_{\mathrm{NAs}, 0}$ & initial concentration of naphthenic acids $(\mathrm{M})$ \\
\hline$C_{\mathrm{O}_{2}^{--}}$ & concentration of superoxide ion radical (M) \\
\hline$C_{\mathrm{O}_{3}}$ & concentration of dissolved ozone (M) \\
\hline$C_{\mathrm{O}_{3 \mathrm{~s}}}$ & stationary concentration of dissolved ozone (M) \\
\hline$C_{\mathrm{O}_{3 \mathrm{G}}}$ & concentration of ozone in the gas at the reactor outlet (M) \\
\hline$C_{\mathrm{O}_{3 \mathrm{Gi}}}$ & concentration of ozone in the gas at the reactor inlet $(\mathrm{M})$ \\
\hline$C_{\mathrm{O}_{3 \mathrm{Gs}}}$ & stationary concentration of ozone in the gas at the reactor outlet $(\mathrm{M})$ \\
\hline$C_{\mathrm{OH}}$ & concentration of hydroxyl radicals $(\mathrm{M})$ \\
\hline$C_{\mathrm{pCBA}}$ & concentration of $p$-chlorobenzoic acids $(\mathrm{M})$ \\
\hline$C_{\mathrm{pCBA}, 0}$ & initial concentration of $p$-chlorobenzoic acids $(\mathrm{M})$ \\
\hline$D_{\mathrm{O}_{3}}$ & diffusivity of dissolved ozone $\left(\mathrm{m}^{2} \mathrm{~s}^{-1}\right)$ \\
\hline$E_{a}$ & reaction activation energy $\left(\mathrm{KJ} \mathrm{mol}^{-1}\right)$ \\
\hline$F$ & gas volumetric flow rate $\left(\mathrm{L} \mathrm{min}^{-1}\right)$ \\
\hline$H$ & Henry law constant $\left(\mathrm{Pa} \mathrm{M}^{-1}\right)$ \\
\hline $\mathrm{Ha}$ & Hatta number (dimensionless) \\
\hline$k_{\mathrm{d}}$ & rate constant of the direct irreversible reaction between NAs and $\mathrm{o}$ \\
\hline
\end{tabular}




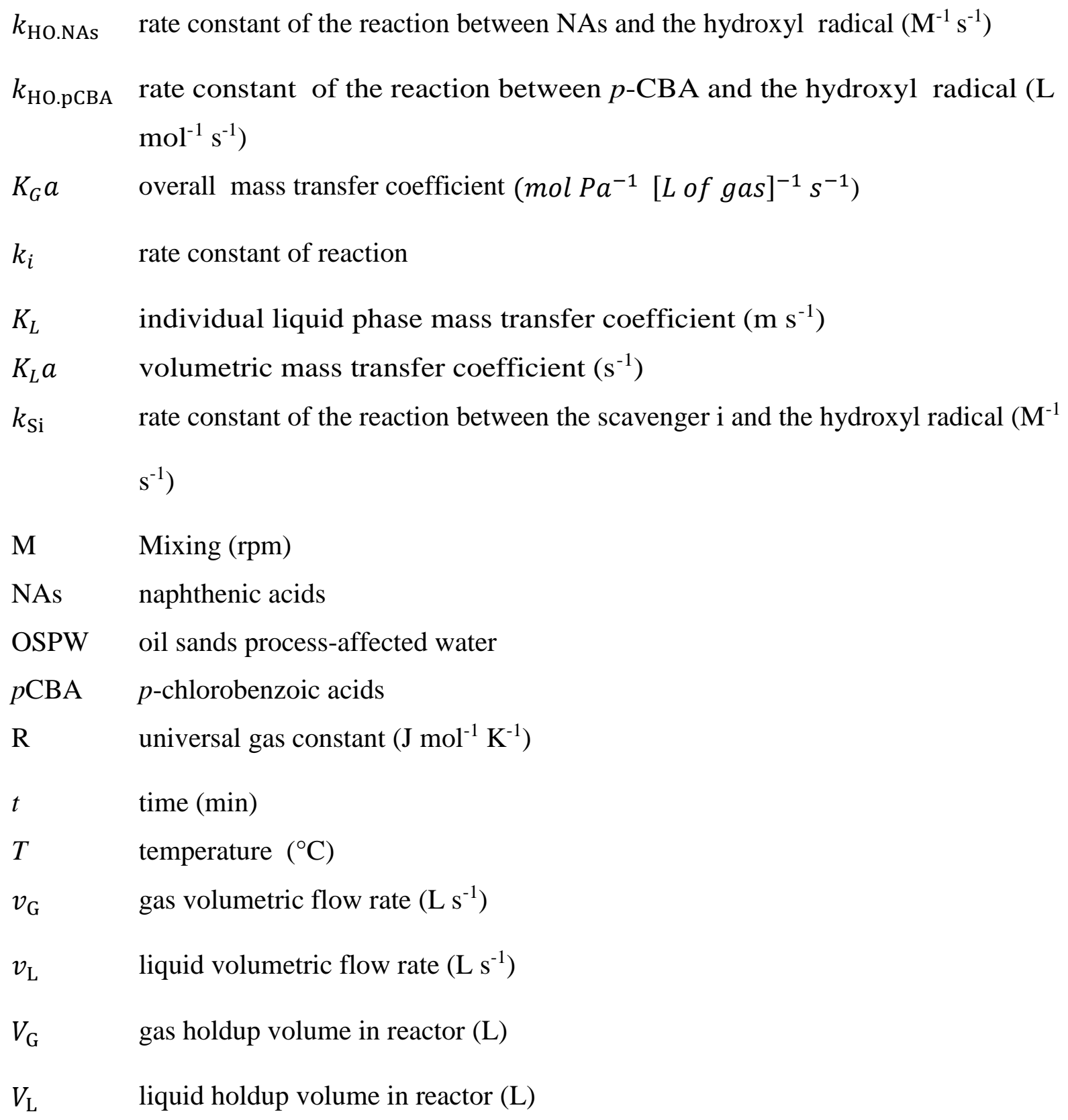




\section{CHAPTER 1: INTRODUCTION}

The Athabasca oil sands deposit in Alberta, Canada is one of the world's largest accumulations of heavy oils in shallow reservoirs. It covers around 75,000 $\mathrm{km}^{2}$ with approximately 900 billion barrels deposit of bitumen, which make up the third-largest proven oil reserves in the world (Zhou et al., 2008). Oil sands generally comprises $80-87 \%$ of inorganic materials (sand, silt and clay), 6-16\% of bitumen and 1-8\% of water by weights (Liu et al., 2005). Production of crude oil from oil sands is based on the alkaline hot water extraction process known as Clark process (Schramm et al., 2000). This process consumes a large volume of fresh water, approximately $3 \mathrm{~m}^{3}$ per $\mathrm{m}^{3}$ of oil produced, and produces approximately up to $4 \mathrm{~m}^{3}$ of wastewater of which $80-88 \%$ is recycled (Suncor Energy, 2010). The wastewater generated is known as oil sands processaffected water (OSPW).

The OSPW has been reported to cause both acute and chronic toxicity to a variety of organisms including fish, amphibians, phytoplankton, and mammals (Del Rio et al., 2006; Wang et al., 2013). The OSPW is toxic mainly because of the presence of the polar organic carboxylic acids known as "Naphthenic Acids" (NAs), which refer to a complex suite of alkyl-substituted acyclic and cycloaliphatic carboxylic acids having the general formula $\mathrm{C}_{n} \mathrm{H}_{2 n+Z} \mathrm{O}_{2}$; where $\mathrm{n}$ is the carbon number and $\mathrm{Z}$ is zero or a negative even integer that specifies the hydrogen deficiency resulting from ring formation (Clemente and Fedorak, 2005; Allen, 2008a; Headley and McMartin, 2004; Del Rio et al., 2006; Wang et al., 2013). The Alberta provincial government has imposed "zero discharge policy" prohibiting the release of OSPW to ground or surface waters (Government of Alberta, 2010). Under this policy, a large amount of OSPW must be held on site. It is estimated that over 1 billion $\mathrm{m}^{3}$ of OSPW will be accumulated in the Athabasca by the year 2025 (Lo et al. 2006). The oil companies are responsible for reclaiming this water and finding a way to release it back into the local environment; this mandate presents a major challenge for the industrial and academic communities.

Various technologies, such as biodegradation, adsorption, membrane filtration constructed wetlands, could affect the fate and toxicity of NAs in aquatic environments. Microbial degradation technology currently used by the industry, though the cheapest, is too slow to keep up with the fast expansion of the industries to meet the discharge policies, mainly because higher molecular weight 
NAs $(n \geq 22)$ are generally bio- recalcitrant (Han et al., 2009). Therefore, other methods are required to remove NAs in OSPW (Scott et al., 2008). Adsorption suffers from incomplete pollutant removal; fouling from oil; cleaning and regeneration costs; and low adsorption capacity (Adhoum and Monser, 2004). Membrane filtration can remove most of the solid pollutants in OSPW, but the following drawbacks make it impractical for the treatment of OSPW: fouling from oil, unremoved dissolved organics, algal growth, membrane replacement costs and brine disposal (Agenson et al., 2003; Peng et al., 2004). Performance of constructed wetlands suffers from: the significant impact of cold climate, toxic effects of naphthenic acids on wetland biota and long residence time required for complete detoxification of OSPW toxicity (Ji et al., 2002; Wallace, 2004).

On the other hand, ozonation is a promising technology used in oxidation and destruction of a wide variety of recalcitrant organic pollutants in water and wastewater. Ozone is a very powerful oxidizing agent which can selectively attack $\mathrm{C}=\mathrm{C}$ bonds of aromatic compounds $(\mathrm{Wu}$, 2005). This characteristic provides ozone with a significant advantage over other mentioned processes. Ozone can attack bio-recalcitrant organic compounds with large unsaturated molecules and degrade them to small and biodegradable organic compounds (Scott et al., 2008). In addition, ozone can decompose in water to produce even more powerful non-selective hydroxyl radicals (Rice and Browning, 1981). Accordingly, ozonation can reduce both concentration and toxicity of NAs in OSPW (Gamal El-Din et al., 2011; He et al., 2008; Scott et al., 2008). The main drawback of this process is the relatively long ozonation time to degrade some pollutants, resulting in relatively high operating cost (Allen, 2008b). This obstacle can be overcome by carefully design and control the ozonation and ozone based processes. Consequently, ozonation and ozone based processes can be used to convert bio-recalcitrant NAs into biodegradable substances so that the most cost-effective biodegradation process can follow ((He et al., 2012; Gamal El-Din et al., 2011; Perez-Estrada et al., 2011; Wang et al., 2013; Martin et al., 2010). Currently, there are several problems which need to be addressed to have efficient ozonation and ozone based processes:

- Effect of the operating parameters on the performance of the ozonation process has not been investigated previously. Knowing the impact of these parameters on the degradation of ANs is crucial to choose the best practical parameter to control the process. 
- Information on the ozonation of NAs kinetics is still absent in the literature. Lack of this information makes the reactor design impossible and hence hinders the development of ozone technology in OSPW treatment.

- Practical methods to predict the variations in concentration profiles of NAs, dissolved ozone and gaseous ozone during the ozonation processes are not yet readily available. In fact, these information is crucial for the better control of the processes.

- Heterogeneous catalytic ozonation has received much attention in wastewater treatment. However, to date, heterogeneous catalysis has not been applied to ozone treatment of OSPW. To overcome the application barrier of ozone technology in OSPW treatment, a study on heterogeneous catalytic ozonation of OSPW was initiated. It is hypothesized that addition of the catalysts would significantly increase the ozonation efficiency of OSPW, and thereby, reduce the ozonation cost to a level affordable for full scale application.

- Ozone can easily react with unsaturated aromatic and aliphatic compounds, but it has a low reaction rate with saturated organic compounds. This property restricts its application in chemical oxidation. This obstacle can be overcome by using advanced oxidation processes (AOPs), such as ozone/ hydrogen peroxide $\left(\mathrm{O}_{3} / \mathrm{H}_{2} \mathrm{O}_{2}\right)$. As far as kinetics is concerned, there are no results reported for the kinetics of NAs advanced oxidation using $\mathrm{O}_{3}$ and $\mathrm{H}_{2} \mathrm{O}_{2}$. The lack of such information made necessary further studies.

- Finally, ozonation and ozone based processes have not been optimally controlled by any research team in order to minimize the concentration of NAs in the outlet stream and/or ozone gas consumption during these processes.

\subsection{OBJECTIVE:}

The main objective of this study was to develop innovative continuous ozonation and ozone based processes that can effectively degrade industrial non-biodegradable pollutants. Naphthenic acids was used as the model pollutant in this study due to its importance as a major pollutant in oil and oil sands industries. The target was to convert bio-recalcitrant NAs into biodegradable substances with minimum consumption of ozone gas (operating cost). This process can be followed by the biodegradation process to fully remove the rest of the biodegradable pollutants. 
In order to satisfy this main objective, it was necessary to fulfill the following subobjectives:

- To study the effect of several operating parameters on the performance of the ozonation process.

- To conduct kinetic studies to determine necessary kinetic parameters.

- To model the ozonation process.

- To study the effectiveness of two powerful advanced oxidation processes (AOPs), i.e., catalytic ozonation and ozone/ hydrogen peroxide, on the removal of NAs compared to the ozonation only process.

- To optimally control the continuous ozonation process and the best performance AOP. The goal was to intensify these processes by minimizing both NAs concentration in the outlet stream and gaseous ozone consumption during the ozonation and zone based processes.

\subsection{DISSERTATION STRUCTURE}

Chapters of the dissertation are arranged according to the sub-objectives in the previous section. There are total eleven chapters including this chapter.

Chapter 2 consists of literature review to have a better understanding of the unique characteristics of ozone and its structure. The mechanism of ozone decomposition in water, in the presence of organic compounds, is explained. This is followed by a brief description of ozonation and catalytic ozonation of organic compounds in water. The second section of Chapter 2 is designated to describe the production of oil sands and the process effected water produces from this industry. Chemistry and toxicity of NAs, as a major pollutant in OSPW, and the emerging technologies for the removal of NAs are also briefly described in the same section.

Chapter 3 includes the materials used and the preparation of NAs solution. It also includes the experimental setup for semi-batch and continuous ozonation processes and the procedures for catalysts preparation and adsorption.

Chapter 4 is designated to explore the significance of the operating parameters in the ozonation process, which includes the ozone concentration in the feed gas $\left(C_{\mathrm{O}_{3 \mathrm{G}}}\right)$, oxygen/ozone feed gas flowrate $(F), \mathrm{pH}$ and mixing $(M)$. Screening for the significance of these operating parameters are described and statistically analyzed. 
In Chapter 5, kinetic studies, which were conducted to determine the rate constants and the activation energies of both direct and indirect ozonation of NAs, are described.

In Chapter 6, models for the prediction of the concentration profiles of commercial NAs and ozone in both the gas and liquid phases for a semi-batch ozonation of NAs are described.

Chapter 7 is designated to determine whether, and to which extent, the tested heterogeneous catalysts could enhance the ozonation process. The efficiencies of alumina and other impregnated catalysts are compared to the efficiency of activated carbon (AC). Toxicity and biodegradability of catalytic ozonated NAs by AC are described in this chapter. Adsorption of NAs by AC is also investigated.

Chapter 8 describes a kinetic model of the advanced oxidation of NAs using $\mathrm{O}_{3} / \mathrm{H}_{2} \mathrm{O}_{2}$ process. The model is then validated against the experimental results. Information obtained from this kinetic study is used later to optimal control a continuous AOP of NAs.

In Chapter 9, a continuous ozonation process of NAs is optimally control in order to intensify the process. A mathematical model is developed to formulate the optimal control problem. The necessary conditions for optimality are derived and used in a computational algorithm to determine the optimal gas flow rate versus time. This relationship is then converted into an optimal gas flow rate versus time policy. The optimal policies are experimentally validated.

In Chapter 10, a continuous AOP for NAs degradation, using ozone/ hydrogen peroxide, is optimally controlled. A mathematical model is developed to formulate the optimal control problem, that is, to find the gas flow rate versus time that minimizes NAs concentration in the outlet stream. The necessary conditions for optimality are derived and used in a computational algorithm to determine the optimal gas flow rate versus time. This relationship is then converted into an optimal gas flow rate versus time policy. The optimal policy is experimentally validated.

Chapter 11 reports the conclusions resulting from this study. 


\section{CHAPTER 2:}

\section{LITERATURE REVIEW}

\section{$2.1 \quad$ OZONE}

\subsubsection{Ozone Structure}

Ozone is formed from oxygen in a strongly endothermic reaction and decomposes easily into molecular and atomic oxygen. Most commonly, ozone is obtained by passing air or oxygen through a corona discharge. Some of the oxygen molecules are dissociated into oxygen atoms, which in turn combine with oxygen molecules to form ozone.

The ozone molecule is generally classified as a 1, 3 dipole (Fig. 2.1). In one resonance form, the central atom and one terminal atom possess full octets of electrons, while the other terminal oxygen atom has only a sextet of electrons. This electron deficiency in the terminal oxygen gives ozone an electrophilic character and is responsible for its electrophilic attack on electron rich substrates.

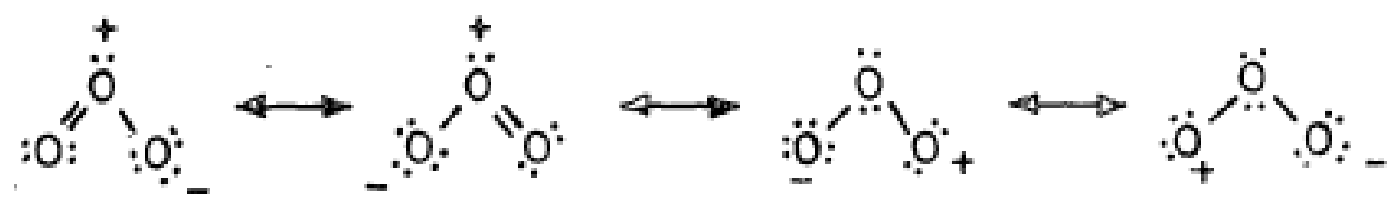

Figure 2.1 Resonance forms of ozone (Singh and Eckert, 1975).

\subsection{REACTION OF OZONE IN WATER}

Ozone reacts differently with organic compound in water due to its electronic configuration. There are three types of reactions between molecular ozone and organic compound as will be explained later. Free radicals are also formed from the decomposition of molecular ozone. These free radicals propagate themselves through mechanisms of elementary steps to yield hydroxyl radicals. These hydroxyl radicals are extremely reactive with any organic (and some inorganic) matter present in water (Staehelin and Hoigné, 1985). For this reason, ozone reactions in water can be classified as direct and indirect reactions. Direct reactions are the ozone molecule reaction with any other type of chemical species (molecular products, free radicals, etc.). Indirect 
reactions are those between the hydroxyl radical, formed from the decomposition of ozone or from other direct ozone reactions, with compounds present in water.

\subsubsection{Direct Reactions of Ozone}

Ozone reactions in water can be classified in three categories: oxidation-reduction reactions (redox); dipolar cycloaddition reactions and electrophilic substitution reactions

\subsubsection{Oxidation-Reduction Reactions (Redox)}

Redox reaction are characterized by the transfer of electrons from the redactor to the oxidant (Lin and Yeh, 1993). The oxidizing or reducing character of any chemical species is depending on their standard redox potential. Ozone has one of the highest standard redox potentials, exceeded only by fluorine atom, oxygen atom, and hydroxyl radical (see Table 2.1). Because of its high standard redox potential, ozone molecule reacts with numerous compounds by means of this reaction type. However, in most of these reactions there is no explicit electron transfer, but rather an oxygen transfer from the ozone molecule to the other compound. Examples of explicit electron transfer reactions is the reaction between ozone and the hydro peroxide ion can be classified in this group (Hoigné, 1998):

$$
\mathrm{O}_{3}+\mathrm{HO}_{2}^{-} \rightarrow \mathrm{O}_{3}^{-\bullet}+\mathrm{HO}_{2}^{\bullet}
$$

Table 2.1 Standard Redox Potential of Some Oxidant Species (Lin and Yeh, 1993).

\begin{tabular}{ccc} 
Oxidant Species & Redox Potential (Volts) & Relative Potential of Ozone \\
\hline Fluorine & 3.06 & 1.48 \\
Hydroxyl radical & 2.80 & 1.35 \\
Atomic oxygen & 2.42 & 1.17 \\
Ozone & 2.07 & 1.00 \\
Hydrogen peroxide & 1.77 & 0.85 \\
Hydroperoxide radical & 1.70 & 0.82 \\
Permanganate & 1.67 & 0.81 \\
Chlorine dioxide & 1.50 & 0.72 \\
Hypochlorous acid & 1.49 & 0.72 \\
Chlorine & 1.36 & 0.66 \\
Bromine & 1.09 & 0.53 \\
Hydrogen peroxide & 0.87 & 0.42 \\
Iodine & 0.54 & 0.26 \\
Oxygen & 0.40 & 0.19 \\
\hline
\end{tabular}




\subsubsection{Cycloaddition Reactions}

The reaction of ozone with carbon-carbon double bonds has been thoroughly studied and a great deal of experimental data has been accumulated for this particular reaction. The ozonation reaction proceeds by a three-step mechanism proposed by Criegee (1975). The Criegee mechanism of ozonation is outlined in Fig. 2.2. The olefins and ozone form an intermediate (initial ozonide). Next, the initial ozonide reverts to its corresponding carbonyl oxide (also called the Criegee zwitterion). The zwitterion serves as a reactive intermediate and can follow several pathways to produce reaction products. The most important pathway, from the standpoint of ozonation, is recombination of the zwitterion with the carbonyl fragment to form the final ozonide as shown in Fig. 2.2.

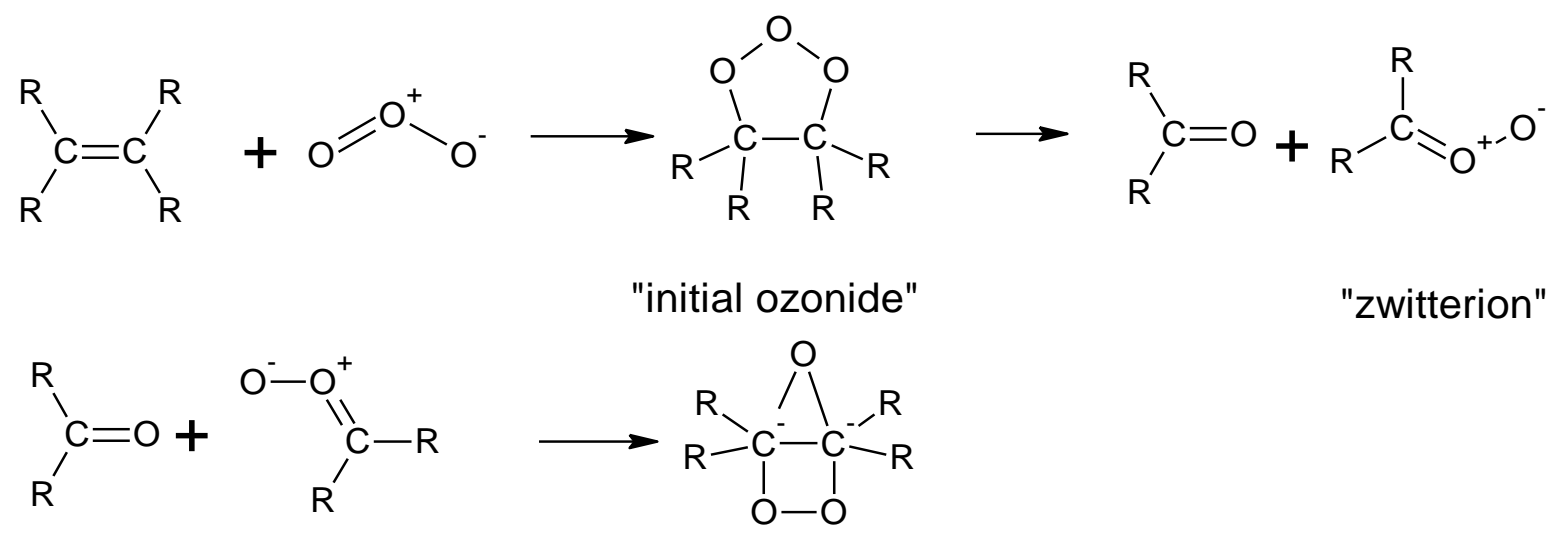

"final ozonide"

Figure 2.2 Criegee mechanism of ozonation of olefins (Criegee, 1975).

The second pathway involves reaction of the zwitterion with participating solvents. Fig. 2.3 illustrates a zwitterion reaction with water to form hydroxyhydroperoxide, which can in turn hydrolyze to formaldehyde and hydrogen peroxide. 


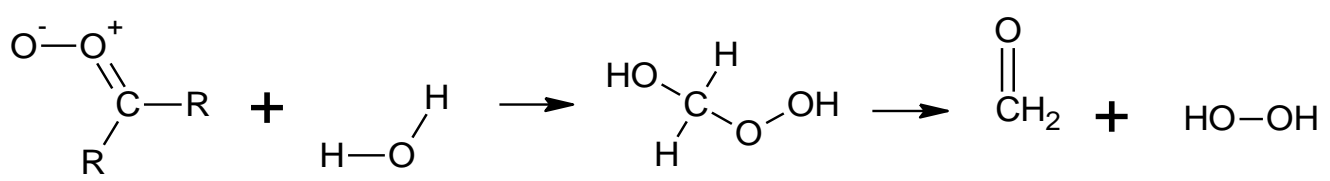

Figure 2.3 Reaction of zwitterion with water. (Criegee, 1975).

\subsubsection{Electrophilic Substitution Reactions}

In electrophilic substitution reactions, ozone (electrophilic agent) attacks one nucleophilic position of the organic molecule (i.e., an aromatic compound), resulting in the substitution of one part (e.g., atom, functional group, etc.) of the molecule (Morrison and Boyd, 1987). Aromatic compounds are usually undergo electrophilic substitution reactions rather than cycloaddition reactions because of the stability of the aromatic ring.

The reaction of ozone with aromatic compounds is more complicated than ozone reaction with olefins. For example, phenol was ozonated in water at $30{ }^{\circ} \mathrm{C}$ and it was found that approximately 17 mole-equivalents of ozone were needed to consume one mole of phenol and much more to use up the intermediates (Yamamoto et al., 1979). The major products were formic acid and carbon dioxide, several intermediates were detected such as catechol, hydroquinone, muconic acid, maleic aldehyde acid, glyoxalic acid, glyoxal, oxalic acid, and hydrogen peroxide (Fig. 2.4). In another study by Gould and Webber (1967), it was found that in an aqueous solution 4-6 moles of ozone per mole of phenol were sufficient to destroy phenol aromatic ring but that many more (about 150 moles or more) were required to destroy all organic materials completely to $\mathrm{CO}_{2}$. These results show the excess amount of ozone which is consumed by the intermediate compounds to reach the final products.

The presence of substituting groups in the aromatic molecule strongly affects the reactivity of the aromatic ring with electrophilic agents. Thus, groups such as $\mathrm{HO}^{-}, \mathrm{Cl}^{-}$, etc. activate or deactivate the aromatic ring for the electrophilic substitution reaction. Depending on the nature of the substituting group, the substitution reaction can take place in different nucleophilic points of the aromatic ring. Therefore, the deactivating groups facilitate the substitution in the meta position, while the activating groups promote the substitution of hydrogen atoms from their ortho and para positions with respect to these groups. Table 2.2 shows the effect of different substituting groups on the electrophilic reaction of aromatic molecule. 
Table 2.2 Activating and deactivating Groups of the aromatic electrophilic substitution reaction (Morrison and Boyd, 1987).

\begin{tabular}{ll}
\hline Group & Effect on Reaction \\
\hline $\mathrm{OH}^{-}, \mathrm{O}^{-}, \mathrm{NH}_{2}, \mathrm{NHR}, \mathrm{NR}_{2}$ & activate \\
$\mathrm{OR}, \mathrm{NHCOR}$ & activate \\
$\mathrm{NO}_{2}, \mathrm{NR}_{3}$ & activate \\
$\mathrm{C}_{6} \mathrm{H}_{5}, \mathrm{Alkyl}$ & deactivate \\
$\mathrm{C} \equiv \mathrm{N}, \mathrm{CHO}, \mathrm{COOH}$ & deactivate \\
$\mathrm{F}, \mathrm{Cl}, \mathrm{Br}, \mathrm{I}$ & deactivate \\
\hline
\end{tabular}

\subsubsection{Nucleophilic Reactions}

According to the resonance structures of the ozone molecule (see Figure 2.1), there is a negative charge on one of the terminal oxygen atoms. Thus, ozone could react with molecules containing electrophilic positions. These reactions are of the nucleophilic addition type, and theoretically molecules with double (and triple) bonds between atoms of different electronegativity could be involved. However, most of the information related to this type of reaction between ozone molecule and organic compounds has been obtained in an organic medium, and there is little information on this subject when water is the solvent (Riebel et al., 1960). 


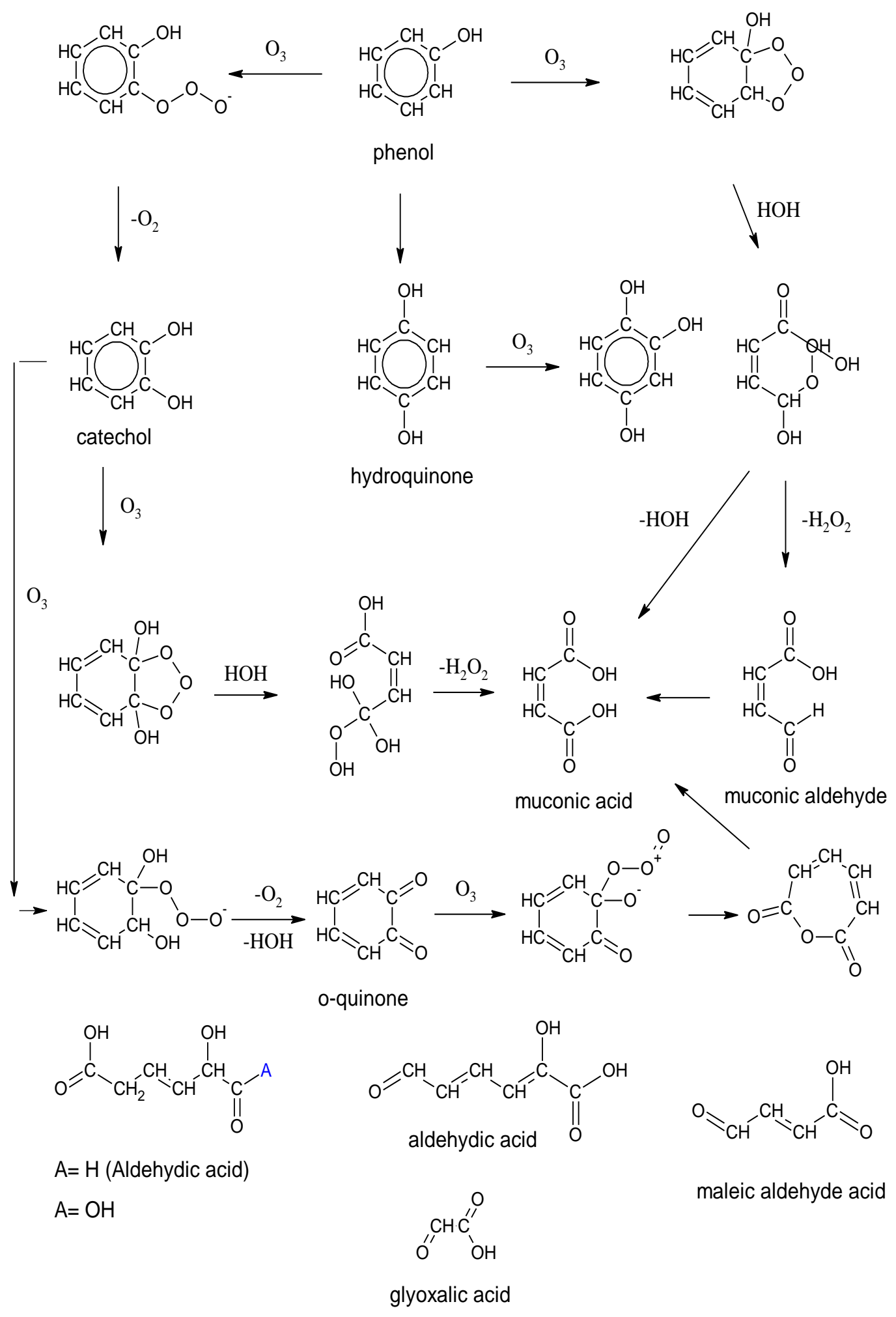

Figure 2.4 Ozonation of phenol in water (Yamamoto et al., 1979). 


\subsubsection{Decomposition of Ozone in Water}

Ozone can self-decompose in water to form free radicals. Numerous studies have been developed to clarify the mechanism of decomposition of ozone in water (Staehelin and Hoigné, 1982; Staehelin and Hoigné, 1985; Buhler et al., 1984; Staehelin et al., 1984; Tomiyasu et al., 1984). The mechanism of Staehelin and Hoigné, is the most acceptable mechanism of ozone decomposition in water in the presence of organic solutes acting as promotors and inhibitors of radical chain reactions (Staehelin and Hoigné, 1985). This mechanism is shown in Table 2.3.

Table 2.3 Ozone decomposition mechanism according to Staehelin, and Hoigné (1985).

\begin{tabular}{|c|c|c|}
\hline Reaction & \multicolumn{2}{|l|}{ Rate constant } \\
\hline \multicolumn{3}{|c|}{ Initiation Reaction } \\
\hline $\mathrm{O}_{3}+\mathrm{OH}^{-} \stackrel{k_{i}}{\rightarrow} \mathrm{HO}_{2}^{\cdot}+\mathrm{O}_{2}^{-\bullet}$ & $k_{i}=70 M^{-1} s^{-1}$ & $(2.2)$ \\
\hline \multicolumn{3}{|c|}{ Propagation Reactions } \\
\hline $\mathrm{HO}_{2}^{\circ} \rightleftharpoons \mathrm{O}_{2}^{-\bullet}+\mathrm{H}^{+}$ & $p K=4.8$ & $(2.3)$ \\
\hline$O_{3}+O_{2}^{-\cdot} \stackrel{k_{1}}{\rightarrow} O_{3}^{-\cdot}+O_{2}$ & $k_{1}=1.9 \times 10^{9} M^{-1} s^{-1}$ & (2.4) \\
\hline $\mathrm{O}_{3}^{-\cdot}+H^{+} \stackrel{k_{2}}{\rightarrow} \mathrm{HO}_{3}^{\cdot}$ & $k_{2}=5.0 \times 10^{10} M^{-1} S^{-1}$ & $(2.5)$ \\
\hline $\mathrm{HO}_{3}^{\cdot} \stackrel{k_{3}}{\rightarrow} \mathrm{HO}^{\bullet}+\mathrm{O}_{2}$ & $k_{3}=1.4 \times 10^{5} M^{-1} S^{-1}$ & (2.6) \\
\hline $\mathrm{O}_{3}+\mathrm{HO}^{\cdot} \stackrel{k_{4}}{\rightarrow} \mathrm{HO}_{2}^{\cdot}+\mathrm{O}_{2}^{\cdot}$ & $k_{4}=2.0 \times 10^{9} \mathrm{M}^{-1} \mathrm{~S}^{-1}$ & $(2.7)$ \\
\hline \multicolumn{3}{|c|}{ Termination Reactions } \\
\hline$H O^{\bullet}+S_{i} \stackrel{k_{s i}}{\rightarrow}$ product & $k_{\mathrm{Si}}=? M^{-1} s^{-1}$ & $(2.8)$ \\
\hline
\end{tabular}

where $S_{i}$ in Equation (2.8) is a hydroxyl radical scavenger such as bicarbonate or carbonate ions. Reaction between ozone and hydroperoxide ions (the ionic form of hydrogen peroxide) is also considered as a main initiation reactions of the ozone decomposition mechanism in water as will be explained in Chapter 8. However, other initiation reactions could develop when other agents, such as solid catalysts, are also present. Thus, the ozone adsorption and decomposition on a catalyst surface could yield active species such as hydroxyl radicals. The reaction of ozone and the 
superoxide ion radical $\left(\mathrm{O}_{2}^{-\bullet}\right)$ in Equation (2.4) is one of the main propagating reactions of the ozone decomposition mechanism.

There are other substances of different nature that can also contribute to the generation or disappearance of free radicals. These substances are called initiators, inhibitors, and promoters (Staehelin and Hoigné, 1985). The initiators, such as the hydroperoxide ion, react directly with ozone to yield the superoxide ion radical [Equation (2.4)] which is rapidly reacts with ozone to yield free radicals, such as the ozonide ion radical $\left(\mathrm{O}_{3}^{-\bullet}\right)$ that eventually leads to the hydroxyl radical $\left(H O^{\circ}\right)$ as shown in Equations (2.5) and (2.6). On the other hand, promoters are those species that react with the hydroxyl radical to propagate radical chain that yield the superoxide ion radical. Examples of these substances are, formic acid and methanol (Staehelin and Hoigné, 1985).

Hydrogen peroxide, if present, plays an important role in the mechanism of ozone decomposition. Hydrogen peroxide can act either as an initiator and promotor of ozone decomposition or as an inhibitor of ozone decomposition as will be explained in Chapter 8 .

Finally, inhibitors are those species that react with the hydroxyl radical to terminate the radical chain. In this group, one can cite carbonate, and bicarbonate ions and tert-butanol (Staehelin and Hoigné, 1985). These species are called hydroxyl-free radical scavengers. Sodium bicarbonate was used as a hydroxyl-free radical scavenger in the kinetic study of direct ozonation of NAs as will be shown in Chapter 5.

\subsubsection{Indirect (Radical) reactions of Ozone}

Indirect reactions are due to the action of free radical species resulting from the decomposition of ozone in water. The free radical species are formed in the initiation or propagation reactions of the mechanisms of advanced oxidation processes involving ozone and other agents, such as hydrogen peroxide or UV radiation, among others (Glaze et al., 1987). AOPs are defined as the processes producing hydroxyl radicals. Hydroxyl radicals are classified as an extremely reactive species and they can react with any organic (and some inorganic) matter present in water (Buxton et al., 1988).

The reactions of ozone with the hydroxyl and hydroperoxide ions can be considered the main initiation reactions of the ozone decomposition mechanism in water. However, other initiation reactions can be developed when other agents, such as solid catalysts or UV radiation, 
are present. Thus, ozone adsorption and decomposition on a catalyst surface to yield active species are also examples of initiation reactions (Jans and Hoigné, 1998).

\subsection{HETEROGENEOUS CATALYTIC OZONATION}

Numerous research studies in the mid-1990s were conducted using combined application of ozone and solid catalysts in an attempt to improve the performance of advanced oxidation of water contaminants. These processes are called the catalytic ozonation of water pollutants (Legube et al., 1999). One should distinguish the homogeneous and the heterogeneous processes when dealing with catalytic ozonation, based on the water solubility of the catalyst. In 1967, Phenol was successfully degraded using heterogeneous catalytic ozonation process with a $\mathrm{Fe}_{2} \mathrm{O}_{3}$ type catalyst Chen et al., 1967).

Generally, catalysts can accelerate ozonation rate, reduce ozone consumption, and thus significantly cut down the cost (Kasprzyk-Horderna et al., 2003; Yong et al., 2005). Heterogeneous catalysts have an advantage over the homogeneous catalysts because they can be easily separated and recovered from water for reuse. Heterogeneous catalytic ozonation has thus received much attention in wastewater treatment. However, to date, heterogeneous catalysis has not been applied to ozone treatment of OSPW. To overcome the application barrier of ozone technology in OSPW treatment, we initiated a study on heterogeneous catalytic ozonation of OSPW.

It is known that supported and unsupported metals and metal oxides are the most commonly used catalysts for ozonation of organic compounds in water (Kasprzyk-Horderna et al., 2003). Among them, alumina and alumina-supported metal oxides show high activity for the destruction of pollutants with ozone at ambient temperature (Kasprzyk-Horderna et al., 2003; Li et al., 2010; Yang et al., 2009). Table 2.4 shows some studies on heterogeneous catalytic ozonation.

It was noticeable that many researchers have focused on the use of manganese and cobalt supported on alumina or other carriers, as can be seen in Table 2.4. This gave us a motivation to test these catalysts in the catalytic ozonation of NAs. Accordingly, catalysts investigated in this study were alumina and alumina-supported metal oxides including manganese dioxide $\left(\mathrm{MnO}_{2}\right)$, manganese dioxide/cobalt oxide $\left(\mathrm{MnO}_{2} / \mathrm{Co}_{3} \mathrm{O}_{4}\right)$ and manganese dioxide/lithium oxide $\left(\mathrm{MnO}_{2} / \mathrm{Li}_{2} \mathrm{O}\right)$. The efficiencies of the impregnated catalysts were compared to the efficiency of activated carbon (AC), which was also examined as a catalyst. 
Table 2.4 Some researches on heterogeneous catalytic ozonation.

\begin{tabular}{|c|c|c|c|c|}
\hline $\begin{array}{l}\text { Ozonation } \\
\text { System }\end{array}$ & Catalyst & $\begin{array}{l}\text { Reactor } \\
\text { Style }\end{array}$ & Observations & Reference \\
\hline $\begin{array}{l}\text { Pndhenol, Ethyl } \\
\text { acetoacetate, } \\
\text { wastewater }\end{array}$ & $\mathrm{Fe}_{2} \mathrm{O}_{3}$ & $\begin{array}{l}\text { Packed-bed } \\
\text { reactor }\end{array}$ & $\begin{array}{l}100 \% \text { phenol conversion } \\
\text { in } 40 \text { min Significant } \\
\text { removals of COD }\end{array}$ & $\begin{array}{l}\text { (Chen et } \\
\text { al., 1967) }\end{array}$ \\
\hline $\begin{array}{l}\text { Chloro and nitro } \\
\text { aromatic } \\
\text { compounds }\end{array}$ & $\begin{array}{l}\text { Mn/Co modified } \\
\text { porous } \\
\text { diatomaceous } \\
\text { ceramic fillings }\end{array}$ & Semi-batch & $\begin{array}{l}\text { enhanced removal } \\
\text { efficiencies of TOC and } \\
\text { COD; increased the } \\
\text { biodegradability with } \\
\text { toxicity reduction }\end{array}$ & $\begin{array}{l}\text { (Li et al., } \\
\text { 2010) }\end{array}$ \\
\hline Fenofibric acid & $\begin{array}{l}\text { alumina- } \\
\text { supported } \\
\text { manganese oxide }\end{array}$ & $\begin{array}{l}\text { glass } \\
\text { jacketed } \\
\text { reactor }\end{array}$ & $\begin{array}{l}\text { considerable increase in } \\
\text { the generation of hydroxyl } \\
\text { radicals due to the use of } \\
\text { catalysts }\end{array}$ & $\begin{array}{l}\text { (Rosal et } \\
\text { al., 2010) }\end{array}$ \\
\hline Ciprofloxacin & $\begin{array}{l}\text { Carbon nanotube- } \\
\text { supported } \\
\text { manganese } \\
\text { oxides }\end{array}$ & Semi-batch & $\begin{array}{l}\text { Catalyst significantly } \\
\text { elevated the degradation } \\
\text { and mineralization } \\
\text { efficiency and promoted } \\
\text { the generation of hydroxyl } \\
\text { radicals. }\end{array}$ & $\begin{array}{l}\text { (Sui et al., } \\
\text { 2012) }\end{array}$ \\
\hline $\begin{array}{l}\text { Pharmaceutical } \\
\text { compounds }\end{array}$ & $\begin{array}{l}\text { alumina- } \\
\text { supported } \\
\text { manganese oxide }\end{array}$ & Semi-batch & $\begin{array}{l}\mathrm{MnO}_{\mathrm{x}} \text { enhanced the } \\
\text { formation and activation } \\
\text { of surface hydroxyl } \\
\text { groups, causing higher } \\
\text { catalytic reactivity. }\end{array}$ & $\begin{array}{l}\text { (Yang et } \\
\text { al., 2009) }\end{array}$ \\
\hline 4-chlorophenol & $\begin{array}{l}\text { alumina- } \\
\text { supported } \\
\text { manganese oxide }\end{array}$ & $\begin{array}{l}\text { Fluidized } \\
\text { bed }\end{array}$ & $\begin{array}{l}\text { Faster degradation; } \\
\text { temperature influenced the } \\
\text { degradation }\end{array}$ & $\begin{array}{l}\text { (Qi et al., } \\
\text { 2011) }\end{array}$ \\
\hline
\end{tabular}

\subsection{OIL SANDS}

Oil sands (also called tar sands) are mixtures of organic matter, quartz sand, bitumen, and water that can either be mined or extracted in-situ using thermal recovery techniques. Typically, oil sands contain about $75 \%$ inorganic matter, $10 \%$ bitumen, $10 \%$ silt and clay, and 5\% water (National Energy Board, 2006). Bitumen is heavy crude that does not flow naturally because it has high density, high viscosity, and high metal concentration. There is also a high carbon-to-hydrogen molecule count (i.e. oil sands are low in hydrogen). This thick, black, tar-like substance must be upgraded with an injection of hydrogen or by the removal of some of the carbon before it can be processed. 
Canadian oil sand resources are located almost entirely in the province of Alberta. In 2010, Alberta produced about 1.6 million barrels per day. This representes about $72 \%$ of Alberta's and $52 \%$ of Canada's total crude oil and equivalent production (Energy Resources Conservation Board, 2010). Reservoirs at the surface account for 35 billion barrels (20\%) and in-situ reserves at 141 billion barrels (80\%). Table 2.5 shows the production of crude oil in Canada including the forecast in the future. It can be seen from Table 2.5 that oil sands will have the major portion of the oil production in the near future. It is estimated that the ultimate amount to be discovered is 2.5 trillion barrels: about 2.4 trillion in-situ and 140 billion surface-mineable (National Energy Board, 2004).

Table 2.5 Canadian production of crude oil in Barrels/ day (Canadian Association of Petroleum Producers, 2012).

\begin{tabular}{lllll}
\hline \multicolumn{5}{c}{ Oil Production in million Barrels/day } \\
\hline Year & 1980 & 2010 & 2025 & 2030 \\
Crude Oil (Including oil sands) & 1.5 & 3.0 & 5.6 & 6.2 \\
Oil Sands & 0.1 & 1.6 & 4.2 & 5.0 \\
\hline
\end{tabular}

\subsubsection{Oil Sands Production}

Oil sands are either surface-mined or produced in-situ. Mining works best for deposits with overburden less than 75 meters thick. Mining requires a hydraulic or electric shovel that loads the sand into 400-ton trucks, which carry the material to a crusher to be mixed into slurry. Using pumps and pipelines, the slurry is "hydro transported" to an extraction facility to extract bitumen. This process recovers about 90\% of the bitumen (Aberta Chamber of Resources, 2004). One-third of the Alberta's oil sand was produced using the cold production method in which oil sands are light enough to flow without heat.

For in-situ thermal recovery (Fig. 2.5), wells are drilled, and then steam is injected to heat the bitumen so it flows like conventional oil. In-situ production involves using various techniques. One technique is the Cyclic Steam Stimulator (CSS), also known as "huff and puff." CSS is the most widely used in-situ technology. In this process, steam is added to the oil sands via vertical wells, and the liquefied bitumen is pumped to the surface using the same well. But a relatively new technology: steam-assisted gravity drainage (SAGD), has demonstrated that its operations can 
recover as much as $70 \%$ of the bitumen in place. Using SAGD, steam is added to the oil sands using a horizontal well, then the liquefied bitumen is pumped simultaneously using another horizontal well located below the steam injection well.

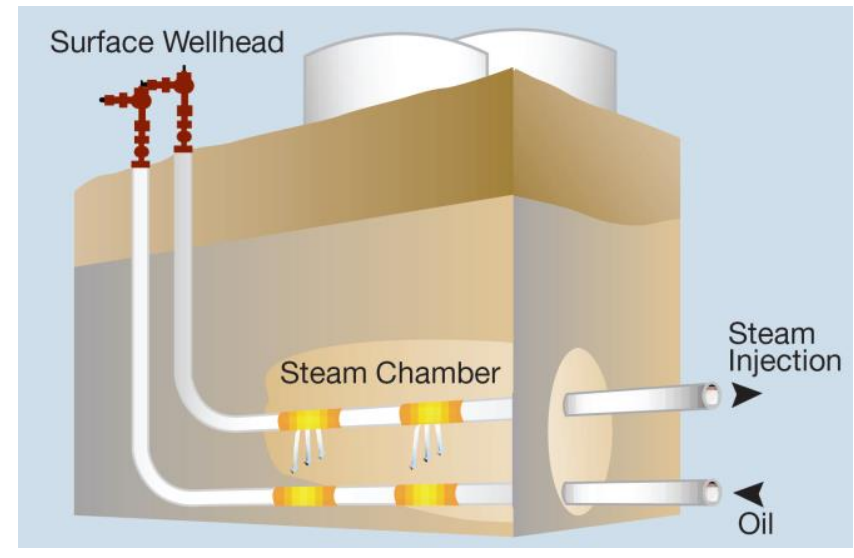

Figure 2.5 In-situ Oil Sands recovery using SAGD technology (Alberta Chamber of Resources, 2004).

The emerging Vapor Extraction Process (VAPEX) technology operates similarly to SAGD. But instead of steam, ethane, butane, or propane is injected into the reservoir to mobilize the hydrocarbons towards the production well. This process claimed to eliminate the cost of steam generators and natural gas. This method is expected to reduce the operating costs by half to that of the SAGD process (National Energy Board, 2013). Although researchers are claiming many advantages, the process is still at an experimental stage (Banerjee, 2012).

A fourth technique is cold production, suitable for oil sands lighter than those recovered using thermal assisted methods or mining. This process involves the coproduction of sand with the bitumen and allows the oil sands to flow to the well bore without heat.

The extraction process separates the bitumen from oil sands using warm water and chemicals. Extracting the oil from the sand after it is slurred consists of two main steps. The first step is the separation of bitumen in a primary separation vessel. Secondly, the material is sent to the froth tank for diluted froth treatment to recover the bitumen and reject the residual water and solids. 
Upgrading the bitumen uses the process of coking for carbon removal or hydro-cracking for hydrogen addition. Coking is a common carbon removal technique that "cracks" the bitumen using heat and catalysts, producing light oils, natural gas, and coke (a solid carbon by-product). The coking process is highly aromatic and produces a low quality product. The product must be converted in a refinery to a lighter gas and distillate. Hydro-cracking also cracks the oil into light oils but produces no coke by-product. Hydro-cracking requires natural gas for conversion to hydrogen. Fig. 2.6 shows a block diagram for the oil sand production processes.

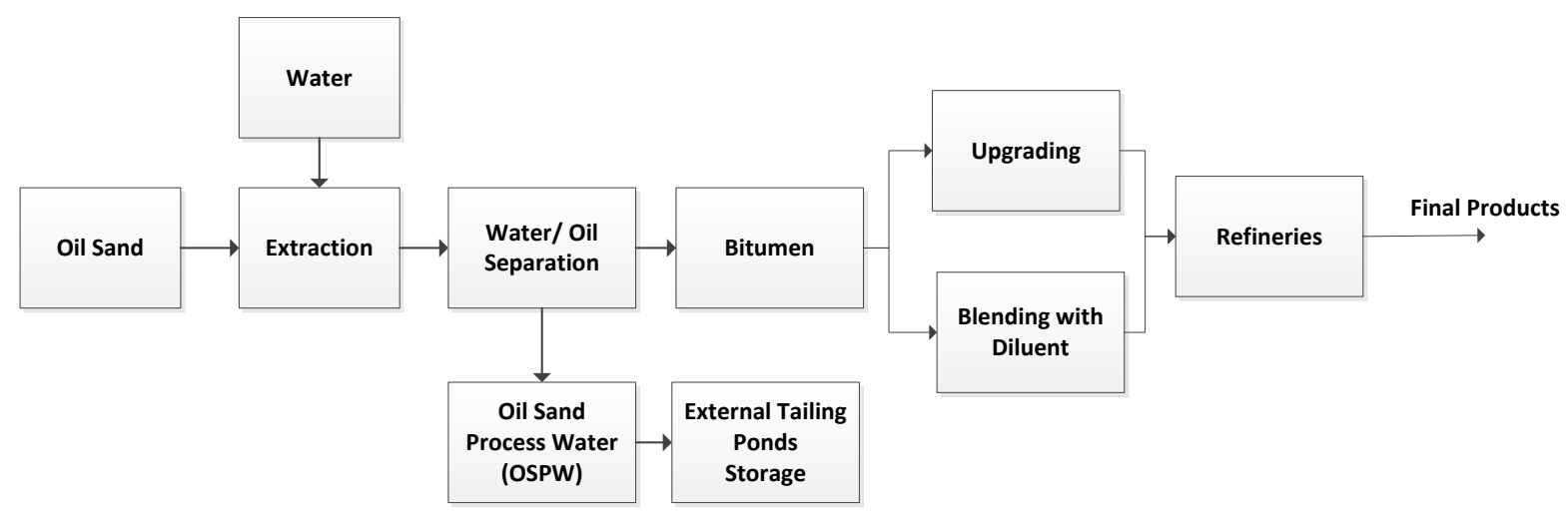

Figure 2.6 block diagram for the oil sand production processes.

\subsubsection{Oil Sands Process-Affected Water (OSPW)}

Every $1 \mathrm{~m}^{3}$ of mined oil sand requires approximately $3 \mathrm{~m}^{3}$ of water and produces on average $4 \mathrm{~m}^{3}$ of waste (Clemente et al., 2003). The tailings slurry consists mainly of solids (sand and clays), recycled water, organics, process additives and residual bitumen. Current practice by the oil sands companies is to release extraction wastes to external tailing ponds. Consequently, all processaffected waters and fluid tailings are contained on-site for an indeterminate time until they are successfully remediated and reclaimed. As an example, the volume of impounded process water at Syncrude's Lease 17/22 was approaching 1 billion $\mathrm{m}^{3}$ in 2004 and the industry-wide tailings volumes will continue to increase due to the rapid expansion of the oil sands industry (Allen, 2008a). One of the major reclamation plans for fine tailings is a wet landscape approach (List and Lord, 1997). With this approach, the fine tailings would be transferred into an abandoned mined- 
out pit, over which a layer of water would be placed, establishing a water-cap over the fine tailings base, thus creating end pit lakes (Boerger et al., 1992).

Oil sands process-affected water (OSPW) is mildly caustic and saline. It contains organic contaminants such as polycyclic aromatic hydrocarbons and a complex mixture of naturally occurring aliphatic and alicyclic carboxylic acids known as naphthenic acids (NAs). Concentration of NAs in fresh OSPW normally exceeds $50 \mathrm{mg} \mathrm{L}^{-1}$ and may reach up to $120 \mathrm{mg} \mathrm{L}^{-1}$ in tailings ponds. The toxicity of fluid tailings has largely been attributed to NAs (Scott et al., 2005). Though it is well known that NAs experience biodegradation in tailings pond to some extent, decades of storage in tailings ponds under various conditions have not proven effective at decreasing NAs to below $20 \mathrm{mg} \mathrm{L}^{-1}$ (Quagraine et al., 2005). Owing to the inherent persistence of NAs, complete remediation of OSPW has yet to be achieved.

\subsection{NAPHTHENIC ACIDS OVERVIEW}

\subsubsection{Chemistry}

Naphthenic acids are acids, chiefly monocarboxylic, derived from naphthenes. Naphthenes are primarily cycloalkanes especially cyclopentane, cyclohexane and their alkyl derivatives (McNaught and Wilkinson, 1997). This definition recognizes NAs as a family of carboxylic acid surfactants composed predominantly of alkyl-substituted cycloaliphatic carboxylic acids with smaller amounts of acyclic aliphatic acids. The carboxyl group is usually bonded or attached to a side chain rather than directly to a cycloaliphatic ring (Fan, 1991). It is widely accepted that the complex compounds are represented by the general formula $\mathrm{C}_{n} \mathrm{H}_{2 n+Z} \mathrm{O}_{2}$ (Dzidic et al., 1988), where $\mathrm{n}$ represents the carbon number and $\mathrm{Z}$ is an even, negative integer corresponding to hydrogen deficiency mainly due to ring formation in the structure. Thus the absolute value of $\mathrm{Z}$ divided by 2 gives the number of the rings in the compounds. A Z-value of 0 means acyclic acids, which are believed to be highly branched (Rudzinski et al., 2002) rather than linear natural fatty acids. A Zvalue of -2 represents monocyclic or mono-unsaturated NAs; -4 represents bicyclic and so on. The Z-value may also include unsaturation in the chemical structure. The generality of the formula allows for a vast array of isomers for each value of $n$ and Z. Fig. 2.7 shows structural examples of NAs. 


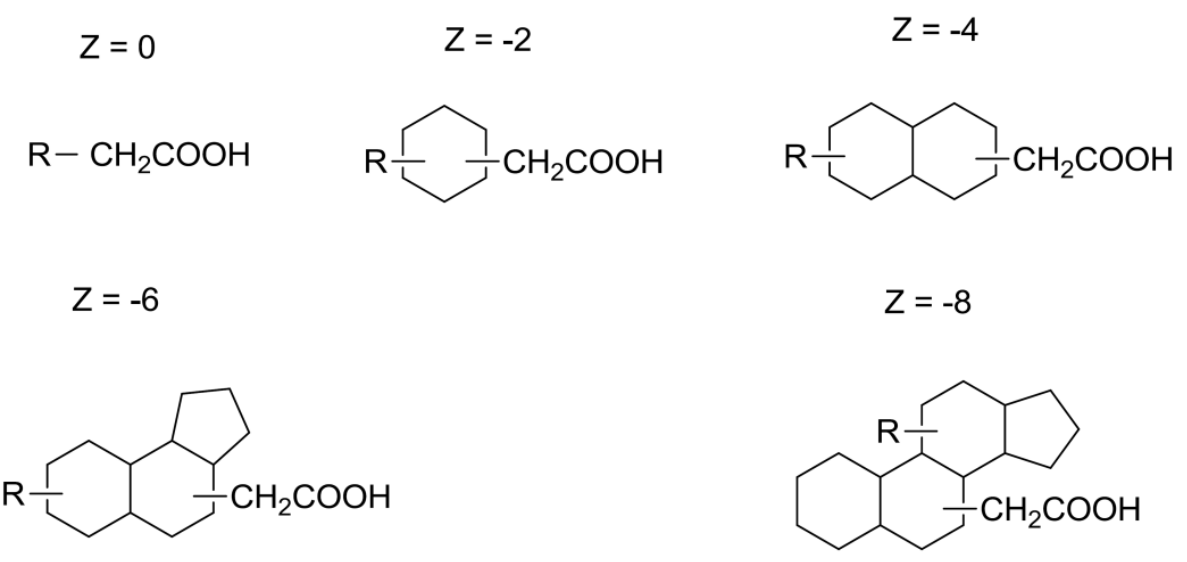

Figure 2.7 Examples of NAs structures (Grewer et al., 2010).

\subsubsection{Naphthenic Acids Toxicity}

NAs are toxic to aquatic algae and other micro-organisms. NAs molecules possess hydrophilic and hydrophobic functional groups which allow these molecules to penetrate into cell membranes and disrupt cellular function, eventually resulting in cell death (Frank et al., 2008). NAs in fresh fluid tailings can cause an acutely toxic effect to aquatic organisms (LC50 $<10 \% \mathrm{v} / \mathrm{v}$ for rainbow trout) and to mammals (oral LC50 $=3.0 \mathrm{~g} / \mathrm{kg}$ body weight) (MacKinnon and Boerger, 1986). Studies referenced by Herman et al. (1994) show that acute toxicity of OSPW by natural processes is reduced within one year while the removal of chronic toxicity requires 2 to 3 years. A later study showed that the degradation of NAs in isolated tailings pond water occur at a rate of $16 \%$ per year over the first 5 years (from 130 to $24 \mathrm{mg} \mathrm{L}^{-1}$ ), but further degradation of NAs beyond 5 years become negligible (MacKinnon, 2004). Han et al. (2009) reported that the degradation and detoxification rates are related to the structure of NAs. The most rapidly degraded NAs are the least cyclic $(Z=0$ and $Z=-2)$; whereas some of the more complex NAs can have half-lives in the order of 12.3 to 13.6 years. Thus, toxic effects do not relate to the NAs concentration directly but are more a function of content and complexity of NAs (Brient et al., 1995). Unfortunately, it is not well established which specific NAs are the most toxic due mainly to the presence of hundreds of these compounds in oil sands. Although the acutely toxic fraction of NAs can degrade naturally in 
experimental pits and wetlands, the lengthy residence time required makes it impractical for a direct environmental discharge of water. Since concentration-based limits have not been established in Canada, background concentrations in local surface- and groundwater (i.e., 1-5 $\mathrm{mg} \mathrm{L}^{-1}$ ) are suggested as a target for NAs removal. Given typical NAs concentrations of 50-70 mg $\mathrm{L}^{-1}$ in OSPW, the corresponding water treatment objective would be $90 \%-99 \%$ removal (Allen, 2008b).

\subsubsection{Treatment of Naphthenic Acids}

It was shown in the previous section that the mechanism of in-situ remediation through natural attenuation alone does not seem sufficient to treat the volumes of OSPW currently in containment. In order to effectively reduce or eliminate toxicity of OSPW, a treatment approach that can directly target NAs is required. Several researchers explored the effectiveness of using different technologies in the treatment of OSPW, such as: adsorption (Hansen and Davies, 1994; Marr et al., 1996; Adhoum and Monser, 2004), micro- and ultrafiltration (Bilstad and Espedal, 1996; Lin and Lan, 1998; Campos et al., 2002), nanofiltration, reverse osmosis, and electrodialysis (Dyke and Bartels, 1990; Agenson et al., 2003; Peng et al., 2004), biological treatment (Doran et al., 1998; Tellez et al., 2002; Campos et al., 2002), and advanced oxidation (Bettle and Tittlebaum, 1995; Li et al., 2006; Scott et al., 2008; Martin et al., 2010; He et al., 2012, 2010; Garcia-Garcia et al., 2011; Gamal El-Din et al., 2011; Pérez-Estrada et al., 2011; Anderson et al., 2012; Wang et al., 2013; Pereira et al., 2013; Hwang et al., 2013).

Allen (2008b) had reviewed the above emerging technologies in the treatment of the OSPW. He pointed out that all the above processes need further development to be practical to be used in industry. Of particular interest is the advanced oxidation processes (AOP), where he quoted "with the exception of a few studies cited above, recently published research on the use of advanced technologies to treat oil sands process water is relatively scarce. As a result, there are considerable knowledge gaps regarding the effectiveness of the numerous state-of-the-art technologies currently being tested and deployed for produced water treatment in the oil and gas industry". This quote ignited the motivation to conduct this research. In this research we focused on the development of ozonation and ozonation based technologies, i.e., catalytic ozonation and ozone/ hydrogen peroxide processes. 
Scott et al. (2008) was the first researching group to use dissolved ozone in the treatment of OSPW. The sediment-free OSPW was ozonated for $50 \mathrm{~min}$ to generate a non-toxic effluent (based on the Microtox bioassay). Naphthenic acids concentration was decreased by $70 \%$. After $130 \mathrm{~min}$ of ozonation, the residual NAs concentration was $2 \mathrm{mg} \mathrm{L}^{-1}$ : $<5 \%$ of the initial concentration in the filtered OSPW. Total organic carbon did not change with 130 min of ozonation, whereas chemical oxygen demand decreased by 50\% and 5-d biochemical oxygen demand increased from an initial value of $2 \mathrm{mg} \mathrm{L}^{-1}$ to a final value of $15 \mathrm{mg} \mathrm{L}^{-1}$. GC-MS analysis showed that ozonation resulted in an overall decrease in the proportion of high molecular weight naphthenic acids $(n \geq 22)$.

The work of Scott et al. (2008) was followed by several researches (Gamal El-Din et al., 2011; Pérez-Estrada et al., 2011; Wang et al., 2013). It was concluded that ozone degraded NA compounds with high carbon numbers and aromatic rings and there was an increase in low molecular weight NA compounds, and other organics following ozone treatment (Gamal El-Din et al., 2011; Pereira et al., 2013). They also concluded that ozonated OSPW NAs may be more susceptible to biodegradation (Scott et al., 2008; Gamal El-Din et al., 2011; Pérez-Estrada et al., 2011; Wang et al., 2013; Pereira et al., 2013). It has also been found while ozone significantly degraded NAs to the largest extent, it also reduced the concentration of other organic compounds in OSPW (Martin et al., 2010; Gamal El-Din et al., 2011; Garcia-Garcia et al., 2011; Anderson et al., 2012; He et al., 2012, 2010; Wang et al., 2013; Pereira et al., 2013; Hwang et al., 2013).

Ozone treatment has reduced, but not completely eliminated, toxicity for various aquatic life forms (He et al., 2012; Anderson et al., 2012; Hagen et al., 2014) and mammals (He et al., 2010; Garcia-Garcia et al., 2011; Wang et al., 2013). Ozonation, which reduces the total concentration of NAs and changes the relative proportions of the different fractions of NAs in OSPW, also reduces toxicity as measured by the Microtox assay and attenuates endocrine disrupting effects on eukaryotic cells in-vitro (He et al., 2010). Increasing ozone dose was found to reduced toxicity to V. fischeri (Scott et al., 2008; Gamal El-Din et al., 2011). Wang et al. (2013) also noticed a reduction in toxicity effect on V. fischeri after ozonation of OSPW.

Biochemical oxygen demand (BOD), which represents the amount of dissolved oxygen needed (i.e., demanded) by aerobic biological organisms to break down organic material present in a given water sample at certain temperature over a specific time period (APHA, 2005), was increased for ozonated OSPW from 8 to $25 \mathrm{mg} \mathrm{L}^{-1}$ with an ozone dose of $150 \mathrm{mg} \mathrm{L}^{-1}$ (Gamal El- 
Din et al., 2011), and from 3 to $15 \mathrm{mg} \mathrm{L}^{-1}$ with an ozone dose of $360 \mathrm{mg} \mathrm{L}^{-1}$ (Wang et al., 2013). Coupling ozone treatment with biodegradation to treat OSPW from an active Syncrude tailings pond was found to increase the biodegradability of the organic fraction of OSPW (Martin et al., 2010; Wang et al., 2013; Hwang et al., 2013; Brown et al., 2013).

From the above, it can be concluded that the best practice is to ozonize or advanced oxidize NAs to a point where it becomes easy or rapid biodegradable. This can be followed by natural biodegradation of the ozonated NAs. This was what have been achieved in this work as will be shown in the subsequent chapters. 


\section{CHAPTER 3: \\ EXPERIMENTAL}

\subsection{MATERIALS}

Commercial NAs (density $=0.92 \mathrm{~g} / \mathrm{cm}^{3}$ and average molecular weight $=245 \mathrm{~g} \mathrm{~mol}^{-1}$ ) was purchased from Sigma-Aldrich and was used as a model compound. Alumina $\left(\gamma-\mathrm{Al}_{2} \mathrm{O}_{3}\right)$ with total pore volume of $0.62 \mathrm{~cm}^{3} \mathrm{~g}^{-1}$ and surface area $220 \mathrm{~m}^{2} \mathrm{~g}^{-1}$ was obtained from VWR (Mississauga, Ontario, Canada). Untreated, granular AC was purchased from Sigma-Aldrich with particle sizes ranges $0.037-2.38 \mathrm{~mm}$ and it was used as received without any further treatment. The AC surface area (BET) from nitrogen adsorption expressed on a dry basis was $600-800 \mathrm{~m}^{2} \mathrm{~g}^{-1}$ according the manufacturing company (Sigma-Aldrich). Hydrogen peroxide (30 wt. \%) was purchased from Sigma-Aldrich. All other chemicals used in this study were reagent grade and obtained either from either Sigma-Aldrich (Oakville, Ontario, Canada) or VWR (Mississauga, Ontario, Canada).

\subsubsection{Preparation of Synthetic OSPW}

The initial concentration of the NAs solutions was $100 \mathrm{mg} \mathrm{L}^{-1}\left(4.1 \times 10^{-4} \mathrm{M}\right)$. This concentration simulated the NAs concentration in real OSPW, which typically ranges between 40 and $120 \mathrm{mg} \mathrm{L}^{-1}$ (Holowenko et al., 2001). The solutions were buffered with $5 \times 10^{-3} \mathrm{M}$ phosphate to maintain the specific $\mathrm{pH}$.

In some experiments, $p$-chlorobenzoic acid (Aldrich) was used as a hydroxyl radical's probe. It was added to NAs solution at a concentration of $1 \mathrm{mg} \mathrm{L}^{-1}\left(6.4 \times 10^{-6} \mathrm{M}\right)$.

In advanced oxidation (ozone/ hydrogen peroxide) experiments, the stock hydrogen peroxide (30 wt. \%) was added to the reaction solution immediately before the start of the experiments. Initial hydrogen peroxide concentration in NAs solution was between $10^{-4}-0.1 \mathrm{M}$.

\subsection{EXPERIMENTAL SET UP}

\subsubsection{Semi-batch Ozonation}

Fig. 3.1 shows the schematic diagram of the semi-batch ozonation setup used in the screening of operating parameters and model development study. A cylindrical bubbling glass reactor (diameter $=6.5 \mathrm{~cm}$ and height $=21.5 \mathrm{~cm}$ ) was used with $500 \mathrm{~mL}$ of NAs solution added to 
the reactor in each experiment. Compressed oxygen gas from a cylinder was fed to a Model GL-1 ozone generator (PCI-WEDECO Environmental Technologies, Charlotte, NC). Ozone concentration was controlled by varying the power supply to the generator. Ozone concentration in the feed to the reactor was measured by an OZOCAN analyzer (OZOCAN Corporation, Toronto, Canada). Un-reacted ozone in the outlet gas from the top of the reactor and in the bypass streams was destructed by passing the gas through a catalytic ozone-destruct unit filled with Carulite catalyst (Carus Chemical Company, Peru, IL). Experiments were conducted at room temperature $\left(25^{\circ} \mathrm{C}\right)$. The reactor was mounted on a magnetic stirrer to control the mixing speed of the solution in the reactor.

Fig. 3.2 shows the schematic diagram of the semi-batch set-up used in the kinetic study, modeling, catalytic ozonation and advanced oxidation studies. Ozone generation system was the same as above. A glass reactor $(680 \mathrm{~mL})$, equipped with a porous diffuser of $16 \mu \mathrm{m}$ mean porosity was used in this study. $500 \mathrm{~mL}$ of NAs solution was added to the reactor. In the case of direct kinetic study, the required amount of sodium bicarbonate (hydroxyl radical scavenger) was dissolved in NAs solution prior to the addition of NAs solution to the reactor. While in the case of indirect kinetic study, the required amount of $p$-chlorobenzoic acid was added to NAs prior to the addition of NAs solution to the reactor. The reactor was submerged in a thermostatic bath to keep the temperature constant within $\pm 0.1^{\circ} \mathrm{C}$. The reaction started when an ozone-oxygen mixture was fed to the reactor. The reactor was operated in a semi-batch mode with the gas running continuously and the solution staying in the reactor.

In modeling of the semi-batch ozonation process, the gas holdup was determined by measuring the increase in liquid heights after the gas was introduced into the liquid at the given gas flowrate.

In catalytic ozonation experiments, required amount of catalyst was added to NAs solution immediately before starting the experiment. In addition to the catalytic ozonation experiments, ozonation only (without adding the catalyst) experiments were also carried out to compare the improvement achieved in the NAs removal rate.

In advanced oxidation experiments, the required amount of $\mathrm{H}_{2} \mathrm{O}_{2}$ was added to NAs solution with mixing for $5 \mathrm{~min}$ immediately before starting the experiment. Once the aqueous solution with the required concentration of $\mathrm{H}_{2} \mathrm{O}_{2}$ was charged and reaction temperature achieved, 
an ozone/ oxygen $\left(\mathrm{O}_{3 /} \mathrm{O}_{2}\right)$ mixture, with an $\mathrm{O}_{3}$ concentration of $9.3 \times 10^{-4} \mathrm{M}$, was fed to the reactor through the diffuser.

The experimental conditions for screening of operating parameter, kinetic, modeling, catalytic ozonation and advanced oxidation studies are given in Table 3.1.

Table 3.1. Experimental conditions applied in the screening of operating parameters, kinetic studies, modeling of ozonation, catalytic ozonation and advanced oxidation of NAs.

\begin{tabular}{lccc}
\hline Parameters & $\begin{array}{c}\text { Screening of } \\
\text { operating parameters }\end{array}$ & $\begin{array}{c}\text { Kinetic, Modeling, } \\
\text { Catalytic ozonation }\end{array}$ & AOP \\
\hline$C_{N A s, 0}$ & 100 & 100 & 100 \\
$\left(\mathrm{mg} \mathrm{L}^{-1}\right)$ & $4.1 \times 10^{-4}$ & $4.1 \times 10^{-4}$ & $4.1 \times 10^{-4}$ \\
$C_{N A s, 0}(\mathrm{M})$ & - & $6.4 \times 10^{-6}$ & $6.4 \times 10^{-6}$ \\
$C_{p C B A, 0}(\mathrm{M})$ & - & - & $10^{-4}-10^{-2}$ \\
$C_{H_{2} O_{2,0}}(\mathrm{M})$ & $0.5-4 \mathrm{wt} . \%$ & $(3.1-9.3) \times 10^{-4} \mathrm{M}$ & $(3.1-9.3) \times 10^{-4} \mathrm{M}$ \\
$C_{O_{3 G i}}$ & 25 & 5,15, and 25 & 5,15 and 25 \\
$\mathrm{~T}\left({ }^{\circ} \mathrm{C}\right)$ & $8-12$ & 8.5 & 8.5 \\
$\mathrm{pH}$ & $1-3$ & 1 & 1 \\
Gas flow rate $\left(\mathrm{Lmin}^{-1}\right)$ & & & \\
\hline
\end{tabular}




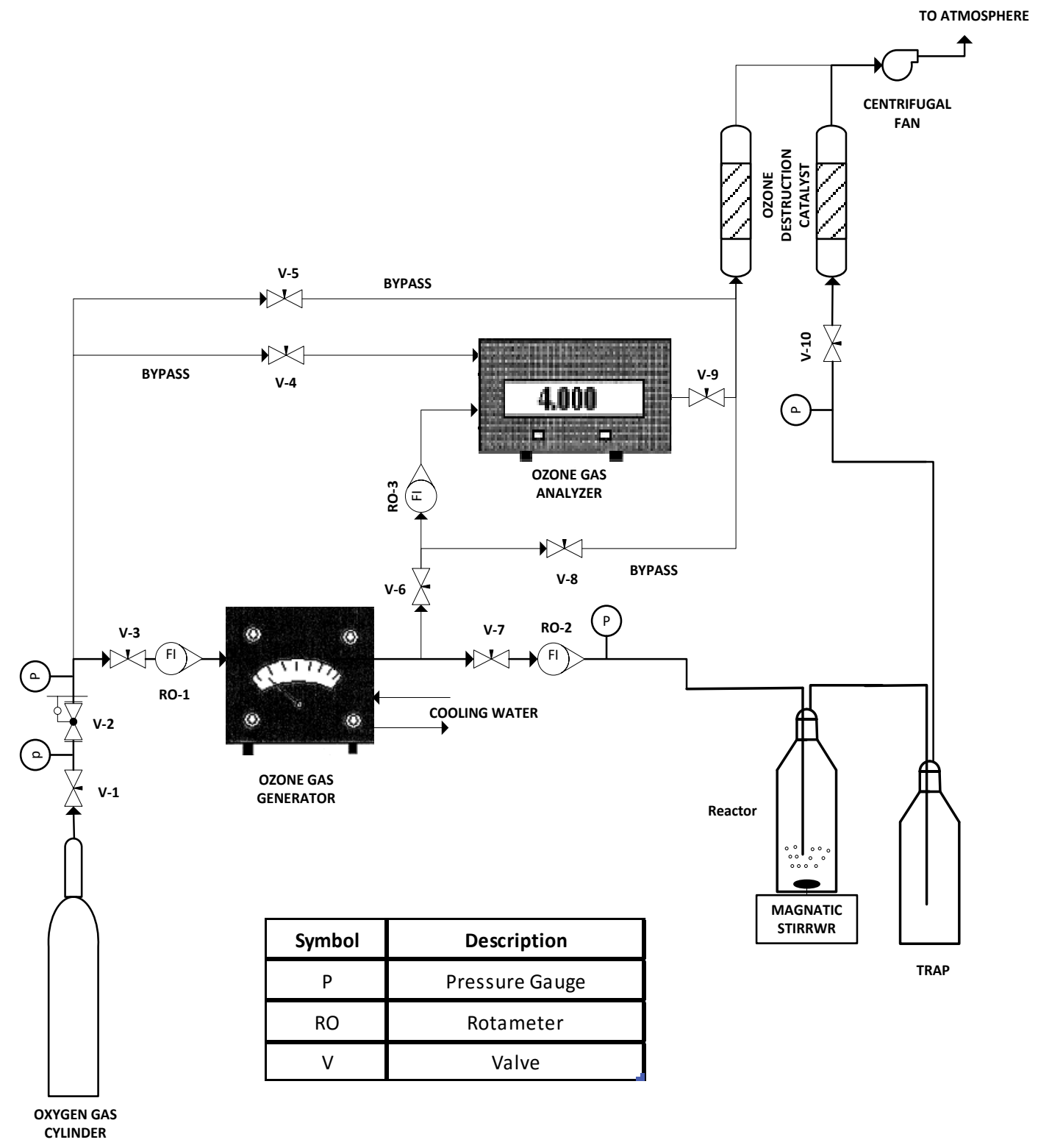

Figure 3.1 Schematic illustration of the ozone generation and reactor system used in model development study. 


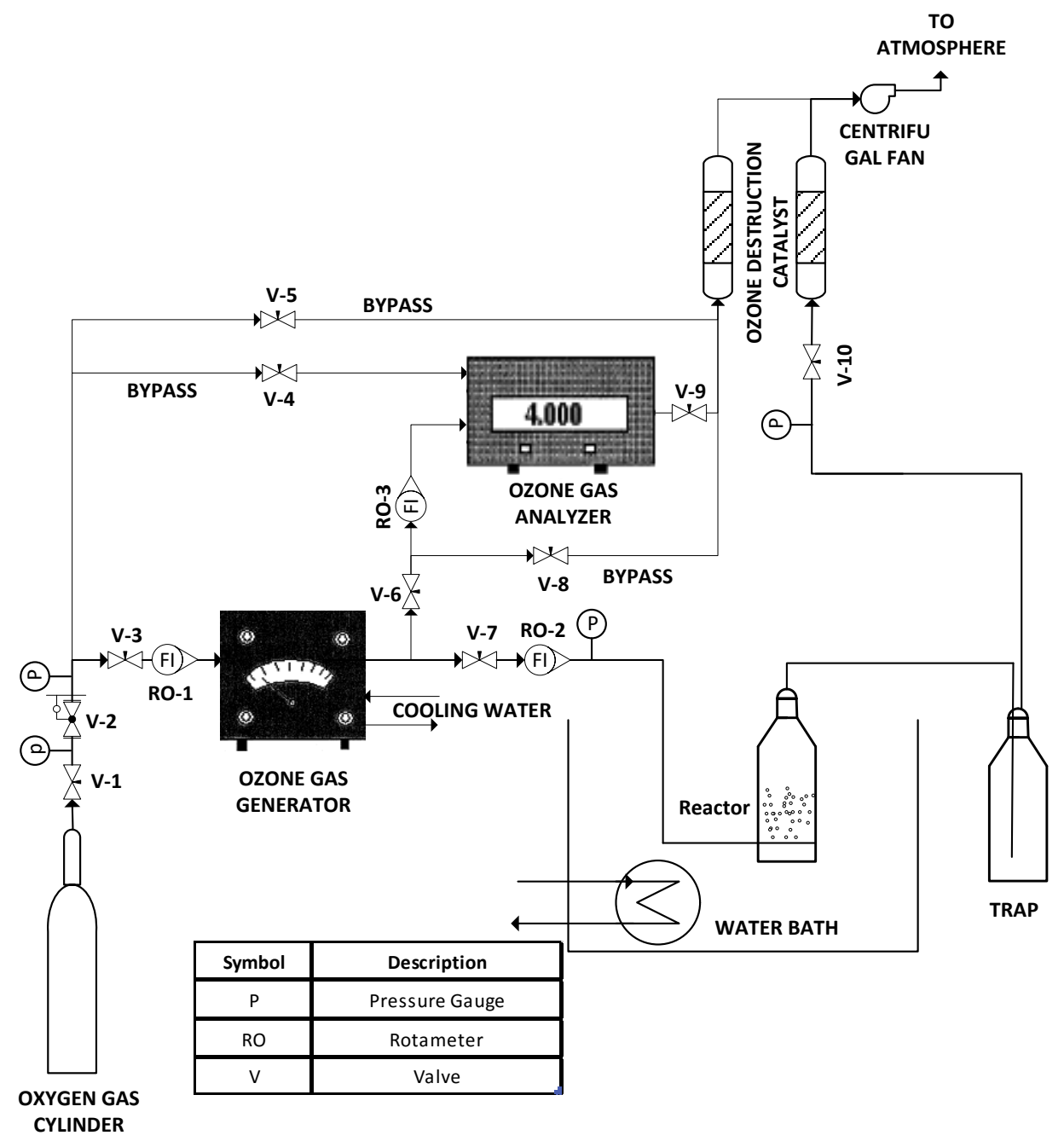

Figure 3.2 Schematic illustration of the ozone generation and semi-batch reactor system used for kinetic studies, modeling, catalytic ozonation and AOP studies.

\subsubsection{Continuous Ozonation}

Fig. 3.3 shows the experimental setup for the continuous ozonation and advanced oxidation experiments which were applied for optimal control studies. Ozone generation system was similar to the semi-batch set up described above. The reactor system consisted of a $3 \mathrm{~L}$ lower reservoir and a packed column. The packing of the column was $1 \mathrm{~cm}$ polyvinyl chloride (PVC) balls which were supported by a glass-filled TFE packing support disc. The total volume of the reservoir and the void volume of the column was $4.99 \mathrm{~L}$. 
Initially, 2.5 L of NAs solution was pumped from the feeding tank to the reservoir and circulated through the heat exchanger and the packed column to reach the desired temperature. Then 0.025 or $0.05 \mathrm{~L} \mathrm{~min}^{-1}$ of NAs solution was fed to the reactor system continuously. Once the NAs solution reached steady state flow, the reaction started by bubbling the ozone containing gas into the reservoir through the diffuser. As flow rate was controlled through proportional control valve and flow meter arrangement. The control policies (gas flow rate vs. time) were implemented as a text file using Labview 7.1 software as a graphical user interface. The proportional-integralderivative controller (PID controller) coefficients were: $K_{\mathrm{p}}=0.15, K_{\mathrm{i}}=0.015, K_{\mathrm{d}}=0.001$.

Optimum liquid circulation flow rate and gas and liquid hold ups were determined by pulse injection of concentrated methylene blue in a steady flow of pure water through the system (Fogler, 2006). The experiment was conducted with liquid circulation flow rate of $2 \mathrm{~L} \mathrm{~min}^{-1}$. A specific portion of liquid would be pumped back to the reservoir through the heat exchanger and the column. The remaining portion (equal to the inlet liquid flow rate) was discharged to the receiving tank. During the continuous operation, samples were collected at specific intervals from the outlet liquid stream to determine NAs and dissolved ozone concentrations.

In advanced oxidation experiments, NAs solution in the feeding tank was spiked with concentrated $\mathrm{H}_{2} \mathrm{O}_{2}$, to achieve the required inlet concentration of $\mathrm{H}_{2} \mathrm{O}_{2}$, with mixing for 5 min immediately before starting the AOP experiment.

Table 3.2 shows the experimental conditions which were used in the optimal control of continuous ozonation and advanced oxidation of NAs. 


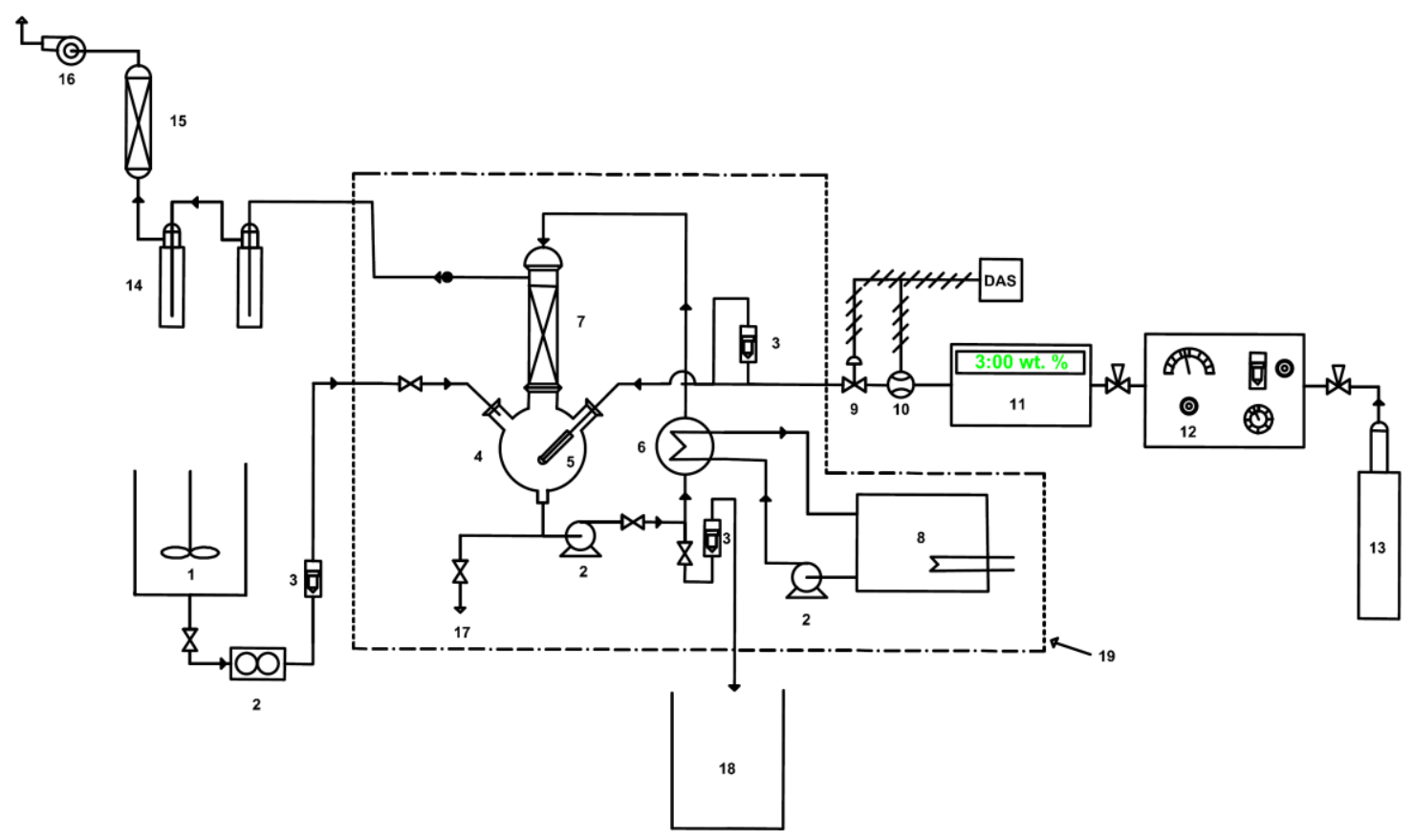

Figure 3.3 Continuous ozonation and AOP set up used in optimal control studies. 1. Feeding tank 2. Pump 3. Rotameter, 4. Reservoir 5. Diffuser 6. Heat exchanger 7. Absorption packed column 8. Controlled temperature water bath 9. Proportional control valve 10. Flow meter 11. Ozone gas analyzer 12. Ozone generator 13. Oxygen gas cylinder 14. Ozone trap 15. Ozone destruction catalyst 16. Blower 17. Drain 18. Receiving tank 19. System boundary. DAS = Data Acquisition System.

Table 3.2 Experimental conditions applied in optimal control of continuous ozonation and AOP experiments.

\begin{tabular}{lcc}
\hline Parameter & Ozonation & AOP \\
\hline & & \\
$C_{\mathrm{NAs}, 0}(\mathrm{M})$ & $4.1 \times 10^{-4}$ & $4.1 \times 10^{-4}$ \\
$C_{\mathrm{H}_{2} \mathrm{O}_{2}}(\mathrm{M})$ & - & $1.0 \times 10^{-3}$ \\
$C_{\mathrm{O}_{3} \mathrm{Gi}}(\mathrm{M})$ & $9.3 \times 10^{-4}$ & $9.3 \times 10^{-4}$ \\
$\mathrm{~T}\left({ }^{\circ} \mathrm{C}\right)$ & 25 & 25 \\
$\mathrm{pH}$ & 8.5 & 8.5 \\
$\mathrm{Gas}$ flow rate $\left(\mathrm{L} \mathrm{min}^{-1}\right)$ & $0.25-4.0$ & $0.25-4.0$ \\
Liquid flow rate $\left(\mathrm{L} \mathrm{min}^{-1}\right)$ & 0.025 & 0.05 \\
Liquid circulation flow rate $\left(\mathrm{L} \mathrm{min}^{-1}\right)$ & 2 & 2 \\
\hline
\end{tabular}




\subsection{EXPERIMENTAL DESIGN FOR SCREENING OF OPERATING PARAMETERS}

Experiments were designed to examine the influence of the operating parameters on the ozonation of NAs. Parameters investigated were gaseous ozone concentration $\left(C_{\mathrm{O}_{3 \mathrm{G}}}\right)$, ozone/oxygen flowrate $(F), \mathrm{pH}$, and mixing at $200 \mathrm{rpm}(M)$. Experiments were conducted according to a $2^{4}$ factorial design with two center points to improve the accuracy, in which the variables were evaluated at two levels. Table 3.3 shows the design of experiments. Each experiment was run in duplicate and the average NAs concentration was recorded.

Table 3.3 Levels of operating parameters studied in the experimental design Parameter.

\begin{tabular}{lll}
\hline \multirow{2}{*}{ Parameter } & \multicolumn{2}{c}{ Level } \\
\cline { 2 - 3 } & $\begin{array}{c}\text { Lower } \\
(-1)\end{array}$ & Upper (1) \\
\hline Gaseous ozone concentration (wt. \%) & 0.5 & 4 \\
Ozone/oxygen flow are $\left(\mathrm{L} \min ^{-1}\right)$ & 1 & 3 \\
pH & 8 & 12 \\
Mixing (200 rpm) & $\mathrm{N}$ & $\mathrm{Y}$ \\
\hline
\end{tabular}

\subsection{IMPREGNATED CATALYST PREPARATION}

Both supported and unsupported heterogeneous catalysts were used in this study. The unsupported catalysts used were alumina and AC. The supported catalysts were alumina supported metal oxides including $\mathrm{MnO}_{2}, \mathrm{MnO}_{2} / \mathrm{Co}_{3} \mathrm{O}_{4}$, and $\mathrm{MnO}_{2} / \mathrm{Li}_{2} \mathrm{O}$.

The supported catalysts were prepared by incipient wetness impregnation (Yang et al., 2009; Bartholomew and Farrauto, 2006; Rosal et al., 2010). The metal precursors used were acetate salts (tetrahydrate) of manganese $(\mathrm{Mn})$, cobalt $(\mathrm{Co})$ and lithium $(\mathrm{Li})$. The catalyst support (catalyst carrier) was alumina. Briefly, alumina was dried for $2 \mathrm{hrs}$ at $110{ }^{\circ} \mathrm{C}$ to a constant weight and allowed to cool to room temperature. A specific amount of the metal precursor was dissolved in a volume of distilled water equal to the pore volume of the support (Bartholomew and Farrauto, 2006), then this solution was added slowly to alumina. After impregnation, the catalyst was dried at $110{ }^{\circ} \mathrm{C}$ for $2 \mathrm{~h}$ and finally calcined in a muffle furnace (exposed to static air) at $500{ }^{\circ} \mathrm{C}$ for $3 \mathrm{~h}$ at a heating rate of $10{ }^{\circ} \mathrm{C} \mathrm{min}-1$. The prepared catalysts were washed twice with $2 \mathrm{~mL}$ of $0.1 \mathrm{M}$ sodium phosphate to prevent the leaching of the catalyst (Yang et al., 2009; Rosal et al., 2010). 
The weight percentage of the catalytic metals was calculated in terms of the metal oxides, i.e., $\mathrm{MnO}_{2}, \mathrm{Co}_{3} \mathrm{O}_{4}$, and $\mathrm{Li}_{2} \mathrm{O}$, respectively, which was the ratio of the weight of the deposited metal oxide to the total weight of alumina plus the deposited metal oxide (Yang et al., 2009).

\subsection{AC ADSORPTION PROCEDURE}

The adsorption tests were conducted by putting $250 \mathrm{~cm}^{3}$ of NAs solution in an Erlenmeyer flasks. AC was added in a dosage of $1 \mathrm{~g} \mathrm{~L}^{-1}$. The flasks were stopped using a sponge stopper. Flasks were placed in an air incubator (New Brunswick, model INNOVA 40), shaken at a speed of $100 \mathrm{rpm}$ and controlled temperature of $25^{\circ} \mathrm{C}$. The concentration of NAs were determined before and after the adsorption test.

\subsection{ANALYTICAL PROCEDURE}

NAs sample was quantified by the Fourier transform infrared (FTIR) spectrometer (Spectrum One, Perkin Elmer, Woodbridge, ON, Canada). The spectral resolution was $4 \mathrm{~cm}^{-1}$ and the spectral range was $4000-400 \mathrm{~cm}^{-1}$. The quantification was performed using the method developed by Jivraj et al. (1995) and outlined by Holowenko et al. (2001). Before quantification, the residual ozone in the testing sample was quenched with $0.1 \mathrm{~mL}$ of $1 \mathrm{~N}$ sodium thiosulfate to ensure the absence of ozone interference in the FTIR analysis. The sample $(250 \mathrm{~mL})$ was acidified to $\mathrm{pH}$ 2-2.5 with $\mathrm{H}_{2} \mathrm{SO}_{4}$ and extracted twice with $25 \mathrm{~mL}$ of dichloromethane (DCM). The DCM extracts were combined and the solvent was evaporated overnight to dryness. Then the dried extract was dissolved in $5 \mathrm{~mL}$ of DCM and filled into a $\mathrm{KBr}$ cell for quantification. The DCM background was used for all spectra. The NAs showed absorbance peaks at 1737 (for monomers) and $1698 \mathrm{~cm}^{-1}$ (for hydrogen-bonded dimers). These two peaks deviated slightly from the reported values (1743 and $1705 \mathrm{~cm}^{-1}$ ) by Holowenko et al. (2001). Appendix B shows the standard curve which was used to determine the concentration of NAs in all experiments.

The ozone concentration in the gas entering to the reactor was measured by an ozone monitor ((Model HC-400, PCI-WEDECO Environmental Technologies, Charlotte NC). The ozone concentration in the gas leaving the reactor was measured by the standard iodometric titration method (APHA, 2005). Dissolved ozone was determined using the standard indigo method (APHA, 2005). Hydrogen peroxide was analyzed using the titanium oxalate method (WRF, 2009). 
Appendix B shows the standard curve which was used to determine the concentration of hydrogen peroxide.

To conduct kinetic studies for the indirect reactions, some experiments were carried out in the presence of known concentrations of $p$-chlorobenzoic acid ( $p$ CBA, Sigma-Aldrich) which was used as a probe compound for the determination of $\mathrm{HO}^{\bullet}$ concentration (Elovitz and von Gunten, 1999). The concentration of $p$ CBA was analyzed using a HPLC (Agilent 1100 Series) equipped with a diode array detector. A Supelco Discovery C18 column of $4.6 \times 250 \mathrm{~mm}$ was used. The mobile phase consisted of water and acetonitrile. The column temperature and flow rate were $28^{\circ} \mathrm{C}$ and $0.5 \mathrm{~mL} \mathrm{~min}^{-1}$, respectively (Elovitz and von Gunten, 1999; Lester et al., 2010).

Chemical and biochemical oxygen demands (COD \& BOD) of the samples was determined according to the standard method (APHA, 2005). The toxicity of NAs sample was determined by Microtox acute toxicity test (Gamal El-Din et al., 2011; Scott et al., 2008). The test exposed luminescent organisms in Microtox Acute Reagent to aqueous samples, and measured the increase or decrease in light output by the test organisms. In this study, a DeltaTox II toxicity analyzer (Modern Water Inc., New Castle, DE, USA) was used to measure the luminescence of reconstituted Vibrio fischeri before and after addition of the sample. The reduction in intensity of light emitted from the bacteria after 15 min exposure to the sample was a measure of the toxicity of the sample (Modren Water Inc., 2013).

All measurements were duplicated and the averages were recorded. 


\section{CHAPTER 4:}

\section{MODEL DEVELOPMENT FOR NAPHTHENIC ACIDS OZONATION*}

\subsection{OZONATION OF NAPHTHENIC ACIDS}

To determine an appropriate length of ozonation time to conduct the factorial experiments, solutions of NAs were ozonated for different length of time. All experiments were carried out with ozone concentration of $3 \mathrm{wt}$. \%, ozone/oxygen flow rate $1 \mathrm{~L} \mathrm{~min}^{-1}, \mathrm{pH} 10$ and with mixing at a speed of $200 \mathrm{rpm}$. Fig. 4.1 shows the results, where $C_{\mathrm{NAs} 0}$ and $C_{\mathrm{NAs}}$ are the concentration of NAs at time zero and $t$, respectively. As can been seen from Fig. 4.1, NAs concentration dropped relatively fast from $100 \mathrm{mg} \mathrm{L}^{-1}$ to $70.3 \mathrm{mg} \mathrm{L}^{-1}$ in the first $15 \mathrm{~min}$. After $15 \mathrm{~min}$, the rate of NAs degradation slowed down gradually. It decreased to $52.4 \mathrm{mg} \mathrm{L}^{-1}$ after $30 \mathrm{~min}$, to $29 \mathrm{mg} \mathrm{L}^{-1}$ after $60 \mathrm{~min}$ and to $4 \mathrm{mg} \mathrm{L}^{-1}$ after $120 \mathrm{~min}$ of ozonation. This slowdown was expected since carboxylic acids with high molecular weight were degraded much easier while the low molecular weight carboxylic acids needed much effort to degrade (Scott et al., 2008). Based on the results shown in Fig. 4.1, ozonation time of 15 min was selected for the subsequent experiments, simply because at this time relatively significant degradation of NAs was observed and the rate of degradation was still at the fast region.

\subsection{EFFECT OF OPERATING PARAMETERS ON NAPHTHENIC ACIDS REMOVAL}

To have a statistical understanding of the effect of the operating parameters on the removal of NAs, results of the $2^{4}$ factorial experiments were used to establish a standardized Pareto chart (Fig. 4.2). This chart shows that each parameter and their interactions had either a positive or a negative effect on NAs concentration reduction while their values were changed from the lower level value (-1) to the upper level value (+1). It can be observed from Fig. 4.2 that the upper level values of all the parameters and their interactions, except for the interaction of $\mathrm{pH}$ and mixing $(p H \times M)$, had positive effects on the removal of NAs. In other words, increasing the gaseous ozone

* Al jibouri A. K. H., Wu J. (2015). Model development for naphthenic acids ozonation process. Environ. Sci. Poll. Res. 22: 2558-2565. 


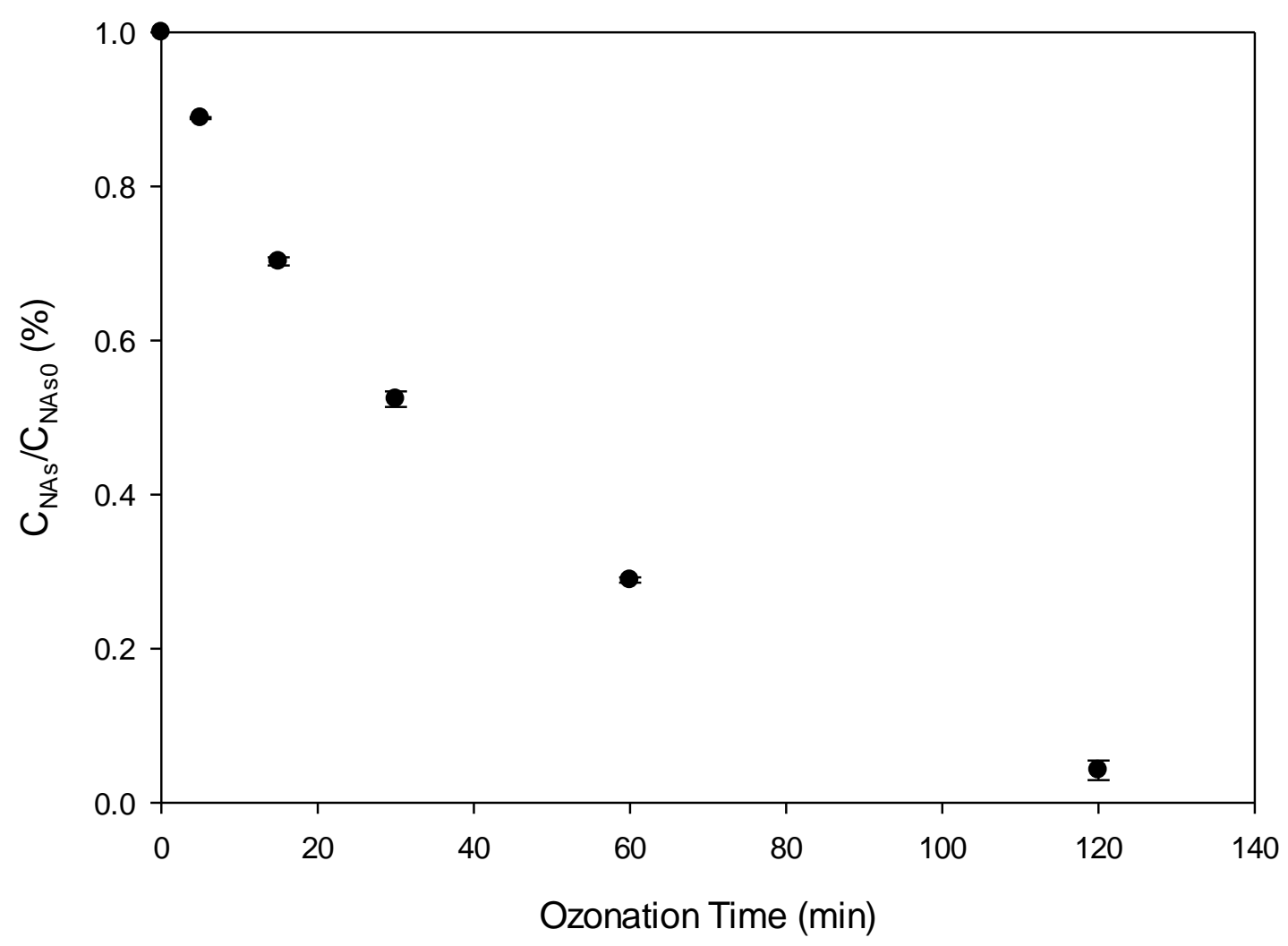

Figure 4.1 Evolution of dimensionless concentration of naphthenic acids (NAs) with ozonation time. Experimental conditions: liquid volume $=500 \mathrm{~mL}, C_{\mathrm{NAs} 0}=100 \mathrm{mg} \mathrm{L}^{-1}, C_{\mathrm{O} 3}=3 \mathrm{wt} . \%, F=$ $1 \mathrm{~L} \mathrm{~min}{ }^{-1}$, mixing $(\mathrm{M})=200 \mathrm{rpm}, T=25^{\circ} \mathrm{C}$, and $p H=10$.

concentration, ozone/oxygen flow rate, $\mathrm{pH}$ and adding mixing will enhance the removal of NAs.

Experiments were conducted to further examine the above conclusion. Samples of NAs were ozonated for $15 \mathrm{~min}$ using the highest parameter values: $4 \mathrm{wt}$. \% for gaseous ozone concentration, $3 \mathrm{~L} \mathrm{~min}^{-1}$ for ozone/oxygen flow rate, 12 for $\mathrm{pH}$ and $200 \mathrm{rpm}$ for mixing. Consequently, the remaining NAs concentration after ozonation was $8 \mathrm{mg} \mathrm{L}^{-1}$. This result was considered as a significant improvement in NAs concentration reduction when compared to results shown in Fig. 4.1, in which the NAs concentration was reduced to $70 \mathrm{mg} \mathrm{L}^{-1}$ after $15 \mathrm{~min}$ ozonation. The conclusion drawn from Fig. 4.2 thus verified experimentally. Fig. 4.2 also shows that ozone concentration had a statistically significant effect on the NAs concentration because it passed the vertical line in Fig. 4.2. The vertical line represents the threshold of the statistically 
significant effect (StatPoint Technologies Inc., 2010). It can also be observed from Fig. 4.2 that although mixing had positive effect on NAs concentration, this effect was relatively small.

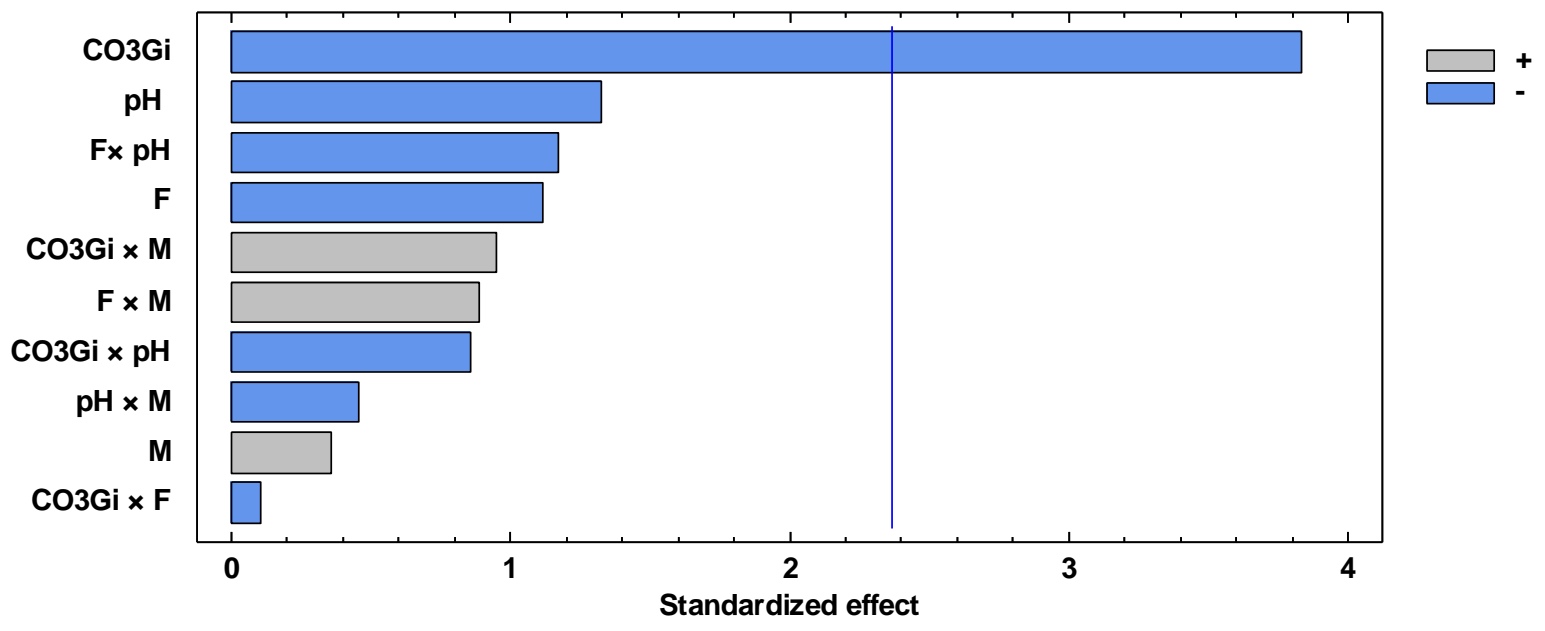

Figure 4.2 Standardized Pareto chart for the ozonation of NAs. Co3Gi $_{\text {O }}$ inlet gaseous ozone concentration, $\mathrm{F}=$ ozone/oxygen flow rate, and $\mathrm{M}=$ mixing.

\subsection{MODEL DEVELOPMENT}

Results of the factorial experiments were also used to develop a model for effects of operating parameters on the removal of NAs with the STATGRAPHICS ${ }^{\circledR}$ Centurion XVI software (StatPoint Technologies Inc. Warrenton, VA) being applied. The effect of mixing was not included because firstly, it was not significant and secondly, only yes and no levels were tested. The model developed is:

$$
\begin{gathered}
C_{N A s}=38.7855+1.8114 C_{O_{3 G i}}+23.5252 \mathrm{~F}+5.1159 p H-0.2879 C_{O_{3 G i}} \times F \\
-1.1768 C_{O_{3 G i}} \times p H-2.8256 \mathrm{~F} \times p H
\end{gathered}
$$

where $C_{\mathrm{NAs}}$ is in $\mathrm{mg} \mathrm{L}^{-1}, C_{\mathrm{O}_{3 \mathrm{Gi}}}$ is the inlet gaseous ozone concentration in wt. $\%$ and $F$ is the ozone/oxygen flow rate in $\mathrm{L} \mathrm{min}^{-1}$. It was found that the model represents the experimental results at a confidence level of $97.5 \%$ (see Table A.2, Appendix A). This model provided for the first time the information on the dependence of ozone removal of NAs on the operation parameters. 
Equation (4.1) was also plotted in Fig. 4.3 to show graphically the relationship between NAs concentration and each of the above three parameters. In each plot, two parameters were changing while the third one was fixed at the middle value between the minimum and the maximum. The response surface plots provided a better visualization for the dependence of removal of NAs on ozone concentration, ozone/oxygen flow rate and $\mathrm{pH}$.

Fig. 4.3a and $4.3 \mathrm{~b}$ show that the removal of NAs depended significantly on the ozone concentration. In fact, when the bubbles of ozone/oxygen gas mixture transferred through the aqueous solution of NAs, the concentration difference (driving force) between the gas and liquid phases controlled the rate of ozone absorption into the liquid phase and subsequently, the rate of reaction between dissolved ozone and NAs in the bulk of the liquid. Therefore, as the ozone concentration increased in the gas phase, the rate of ozone absorption increased as well, resulting in an increase in the rate of oxidation of NAs.

Increasing ozone/oxygen mixture flow rate could increase the mass transfer surface area between the gas and liquid phases which in turn could increase the rate of ozone absorption and the rate of reaction with NAs. However, it is observed from Fig. 4.3a and 4.3c that increasing the mass transfer surface area had much less effect than the concentration difference had.

As shown in Fig. 4b and 4c, increase in $\mathrm{pH}$ enhanced the removal of NAs. This result was in agreement with a reported work by Perez-Estrada et al. (2011). The reason is that higher $\mathrm{pH}$ resulted in the generation of more hydroxyl radicals from ozone self-decomposition, which increased the rate of oxidation of recalcitrant carboxylic acids in NAs.

\subsection{THEORETICAL ANALYSIS OF THE DEVELOPED MODEL}

Equation (4.1) is an empirical model. To understand the characteristics of this model better, ozonation process was further analyzed. It is known that theoretically, for reactions between dissolved ozone and the solute in water, the reaction is first order with respect to ozone and the solute, respectively. Overall, the reaction is second order $(\mathrm{Wu}, 2005)$. In the case the solute is NAs:

$$
\frac{-d C_{\mathrm{O}_{3}}}{d t}=k_{\mathrm{O}_{3}} C_{\mathrm{O}_{3}} C_{\mathrm{NAs}}
$$

where $k_{O_{3}}$ is the rate constant. At the beginning of our semi-batch reaction, the concentration of NAs was in excess compared to the dissolved ozone concentration. Therefore, the 


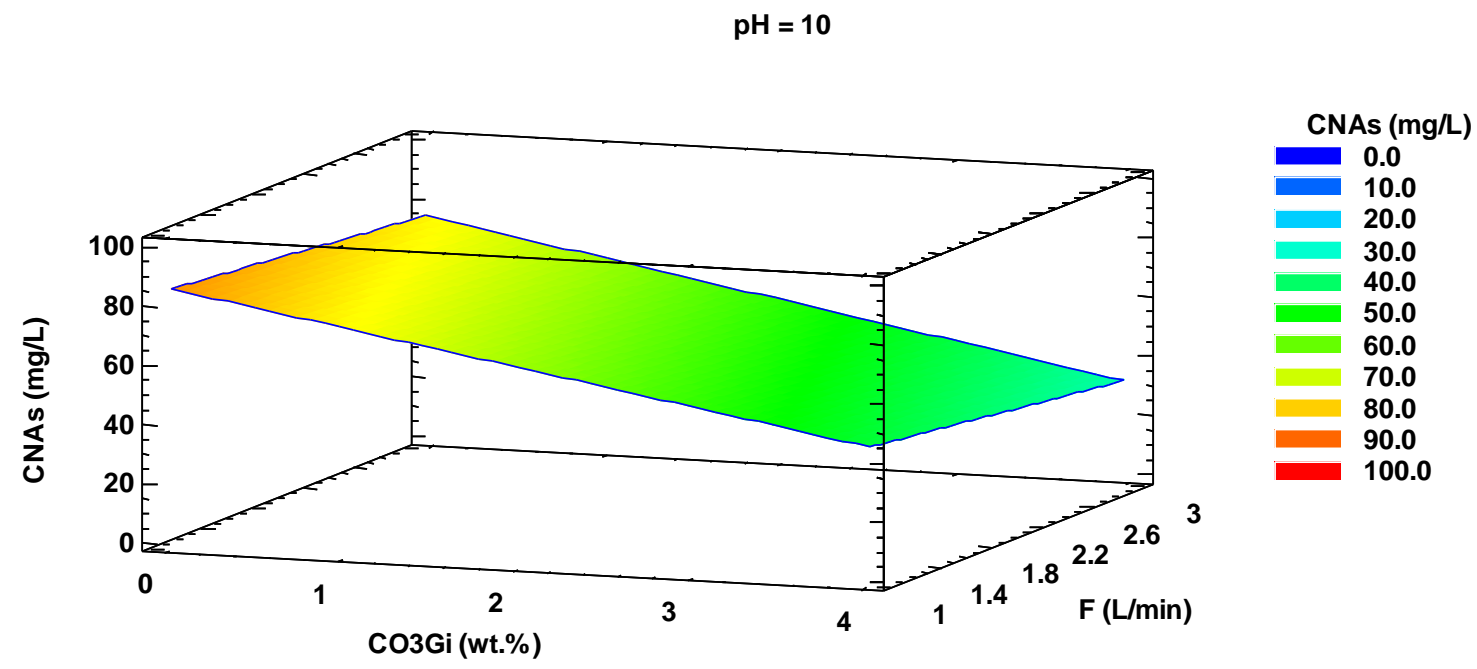

(a)

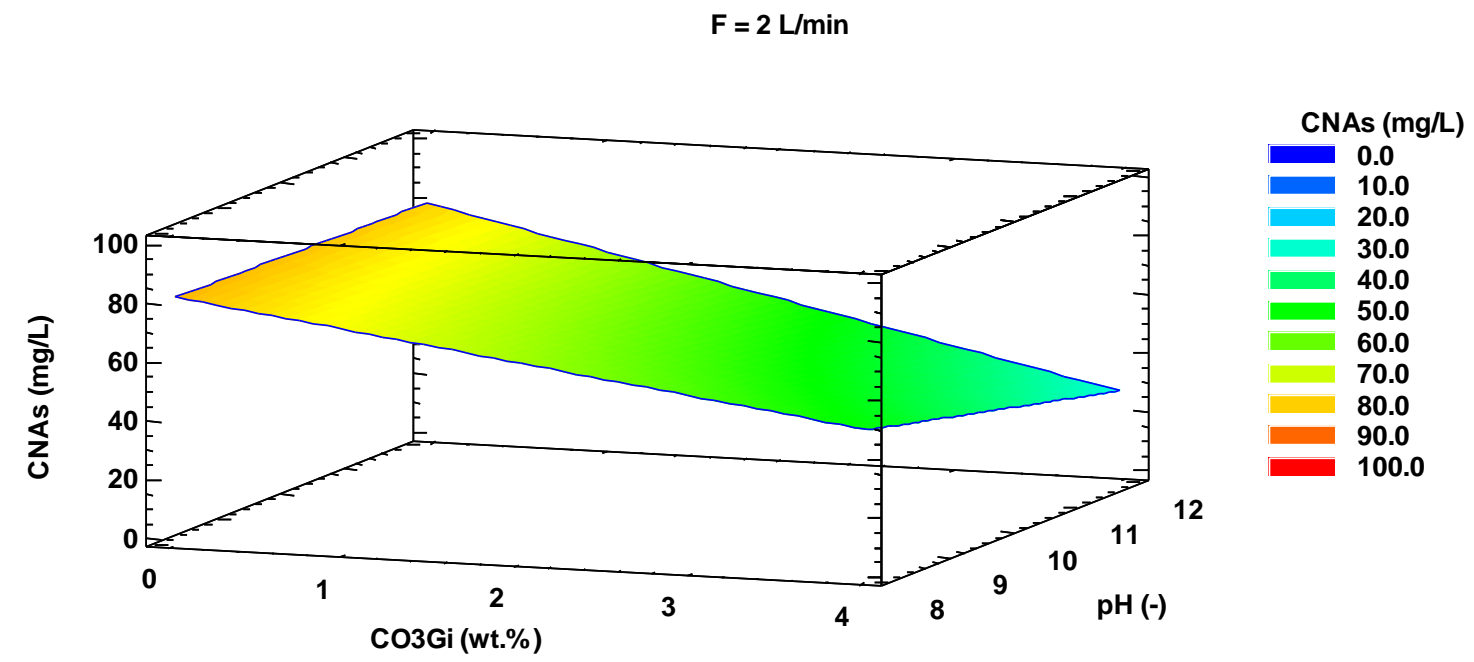

(b) 


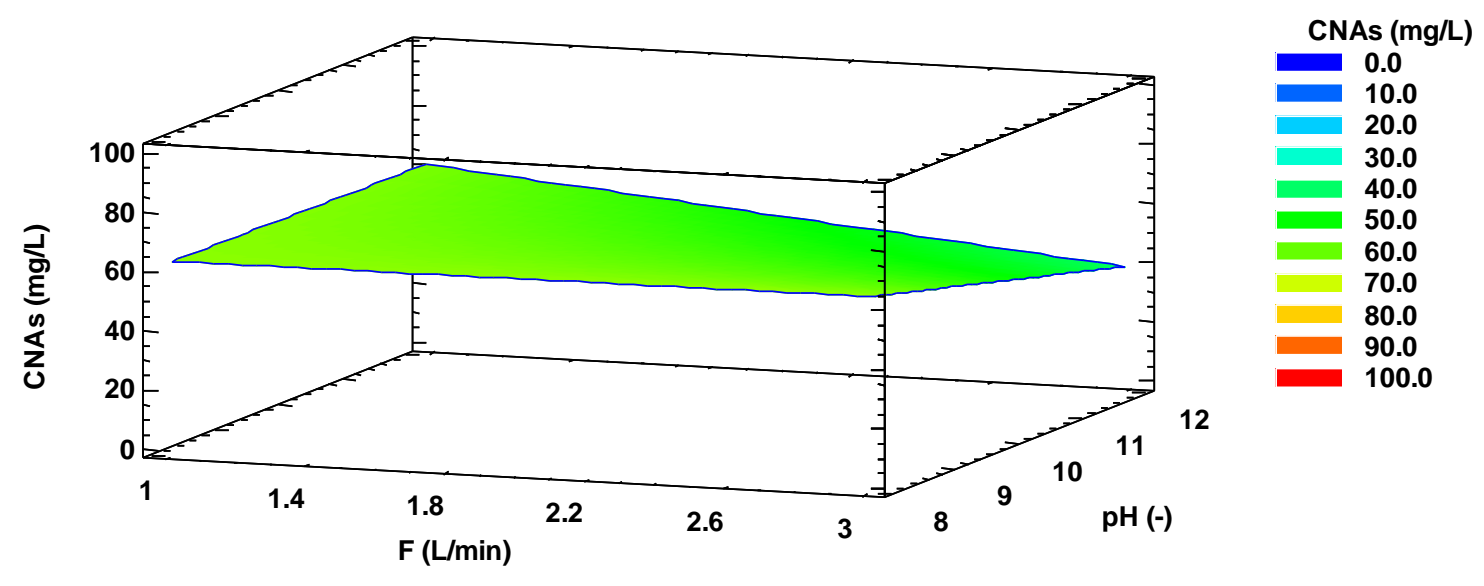

(c)

Figure 4.3 Predicted response surfaces for the variation of NAs concentration with (a) inlet gaseous ozone concentration $\left(C_{\mathrm{O} 3}\right)$ and ozone/oxygen flow rate $(F)$; (b) inlet gaseous ozone concentration $\left(C_{\mathrm{O} 3 \mathrm{Gi}}\right)$ and $\mathrm{pH}$, and $(\mathrm{c})$ ozone/oxygen flow rate $(F)$ and $\mathrm{pH}$. Experimental conditions: liquid volume $=500 \mathrm{~mL}, C_{\mathrm{NAs} 0}=100 \mathrm{mg} \mathrm{L}^{-1}, \mathrm{~T}=25^{\circ} \mathrm{C}$, and ozonation time $=15 \mathrm{~min}$.

concentration of NAs can be assumed as a constant during that short period of time and the reaction became pseudo-first order with respect to ozone:

$$
\frac{-d C_{\mathrm{O}_{3}}}{d t}=k_{\mathrm{O}_{3}}^{\prime} C_{\mathrm{O}_{3}}
$$

where $k_{\mathrm{O}_{3}}^{\prime}=k_{\mathrm{O}_{3}} C_{\mathrm{NAs}}$. This assumption was also applied by previous researchers when a wide range of organic compounds were ozonated (Hoigné and Bader, 1983a; 1983b).

An exact analysis of the absorption of ozone in water with chemical reaction (oxidation of NAs) is not possible because of the complexity of the gas-absorption process. However, by using a relatively simple model (Bird et al., 2002), pseudo-quantitative insight can be obtained. The model used involves the following assumptions: (i) each gas bubble was surrounding by a stagnant liquid film of thickness $\delta$, which was small relative to the bubble diameter; (ii) a quasi-steady 
concentration profile was quickly established in the liquid film after the bubble was formed; (iii) the ozone gas was sparingly soluble in the liquid, so that convection mass transfer could be neglected; and (iv) the liquid outside the stagnant film was at a concentration $C_{O_{3 \delta}}$, which changed so slowly with respect to time that it could be considered as constant. A mass balance in the gasliquid interface around the ozone/oxygen mixture bubble (Fig. 4.4) gives the following differential equations which describe the absorption of ozone in water with chemical reaction:

$$
\begin{aligned}
& D_{\mathrm{O}_{3}} \frac{d^{2} C_{\mathrm{O}_{3}}}{d z^{2}}-k_{\mathrm{O}_{3}}^{\prime} C_{\mathrm{O}_{3}}=0 \\
& -\left.S D_{\mathrm{O}_{3}} \frac{d C_{\mathrm{O}_{3}}}{d z}\right|_{z=\delta}=V k_{\mathrm{O}_{3}}^{\prime} C_{\mathrm{O}_{3 \delta}}
\end{aligned}
$$

where $D_{\mathrm{O}_{3}}$ is the diffusivity of ozone in water, $S$ is surface area of all gas bubbles and $V$ is the volume of the liquid phase in the reactor. Solving Equations (4.4) and (4.5) using the boundary conditions shown in Fig. 4.4: B.C.1: at $\mathrm{z}=0, C_{O_{3}}=C_{O_{30}}$ and B.C.2: at $\mathrm{z}=\delta, C_{O_{3}}=C_{O_{3 \delta}}$, an expression for the total rate of ozone absorption with chemical reaction can be obtained:

$$
\left.N_{\mathrm{O}_{3_{\mathrm{Z}}}}\right|_{z=\delta}=-\left.D_{\mathrm{O}_{3}} \frac{d C_{\mathrm{O}_{3}}}{d z}\right|_{z=\delta}=\frac{C_{\mathrm{O}_{30} D_{\mathrm{O}_{3}}}}{\delta} \frac{\phi}{\sinh \phi}\left(\cosh \phi-\frac{1}{\cosh \phi+\left(\frac{V}{S \delta}\right) \phi \sinh \phi}\right)
$$

where $\emptyset=\sqrt{k_{A}^{\prime} \delta^{2} / D_{\mathrm{O}_{3}}}$. It has to be emphasized that in developing Equation (4.6), the convection mass transfer for ozone absorption had been neglected because ozone is sparingly soluble in water (Roth and Sullivan, 1981). According to Equation (4.6), doubling ozone concentration in the gas phase will double the absorption rate and subsequently double the rate of NAs reaction. On the other hand, Equation (4.6) also indicates that increasing the mass transfer area by increasing gas flowrate and mixing only has very limited impact on the absorption rate of ozone in water. For example, if $(V / S \delta)$ decreases from $10^{-2}$ to $10^{-4}$ by increasing $S 100$ times, while keeping other variables constant and $\emptyset$ at $10^{-2}$, then the rate of absorption will only increase approximately $1 \times 10^{-}$ ${ }^{6}$ mole $\mathrm{cm}^{-2} \cdot \mathrm{s}^{-1}$. Therefore, Equation (4.6) revealed that for ozonation of NAs, the effect of ozone concentration was significant whereas that of the gas flow rate and mixing was not. These revelations are in agreement with our results shown in Fig. 4.3, which was plotted according to 
Equation (4.1), the model developed in this study. Thus, Equation (4.6) provided theoretical background for the proposed empirical model.

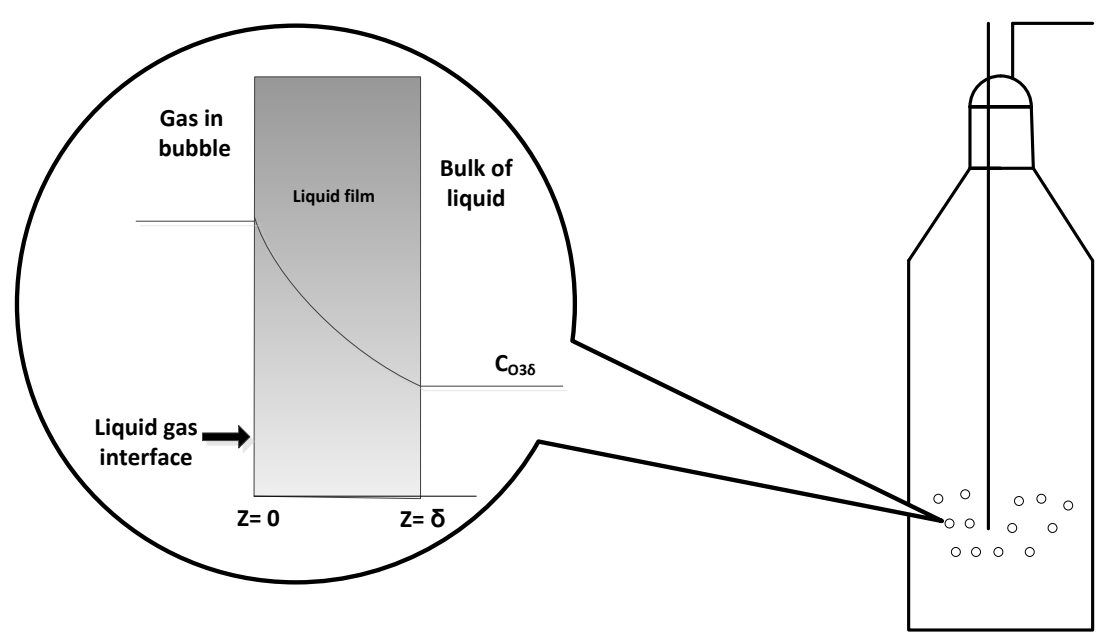

Figure 4.4 Predicted concentration profile in the liquid film near a gas bubble. 


\section{CHAPTER 5:}

\section{OZONATION OF NAPHTHENIC ACIDS IN WATER: KINETIC STUDY ${ }^{\dagger}$}

\subsection{DIRECT OZONATION OF NAPHTHENIC ACIDS}

\subsubsection{Effect of Operating Parameters on Naphthenic Acids Removal}

\subsubsection{Effect of the Scavenger Concentration}

To study the direct ozonation of NAs, the radical reactions in the system must be eliminated. A commonly used radical scavenger, sodium bicarbonate, was applied to serve the purpose (Staehelin and Hoigné, 1982). Radical scavengers are chemicals which consume the radicals generated during the reaction (Hoigne and Bader, 1983a; 1983b). Experiments were conducted at different bicarbonate concentrations. Fig. 5.1 shows the results at $25^{\circ} \mathrm{C}$, where $C_{N A s}$ is the concentration of NAs at time $t$ and $C_{\mathrm{NAs}, 0}$ is the initial concentration of NAs. It can be observed from Fig. 5.1 that ozonation of NAs did go through both direct and indirect pathways, simply because the removal of NAs with scavenger added was always less than that without the use of the scavenger. For example, after 30 min ozonation, the NAs remaining was $28.9 \%$ in the absence of the scavenger, whereas the NAs remaining increased to $42.2 \%$ when $0.02 \mathrm{M}$ sodium bicarbonate was added to suppress the radical oxidation. Fig. 5.1 also shows that the removal of NAs decreased with the increase in carbonate concentration until the carbonate concentration reached $0.02 \mathrm{M}$. Increase in carbonate concentration beyond this point only resulted in negligible changes in the removal of NAs. Similar results were obtained at other temperatures (data not shown). Therefore, $0.02 \mathrm{M}$ sodium carbonate was considered as the scavenger concentration which could eliminate all radical reactions. However, to ensure the direct ozonation to be in the radicalfree condition, we chose to use $0.075 \mathrm{M}$ sodium bicarbonate for all the subsequent direct ozonation experiments.

\footnotetext{
${ }^{\dagger}$ Al jibouri A. K. H., Wu J., Upreti S. R. (2015). Ozonation of Naphthenic Acids in Water: Kinetic Study. Water Air Soil Pollut. 226(10):338.
} 


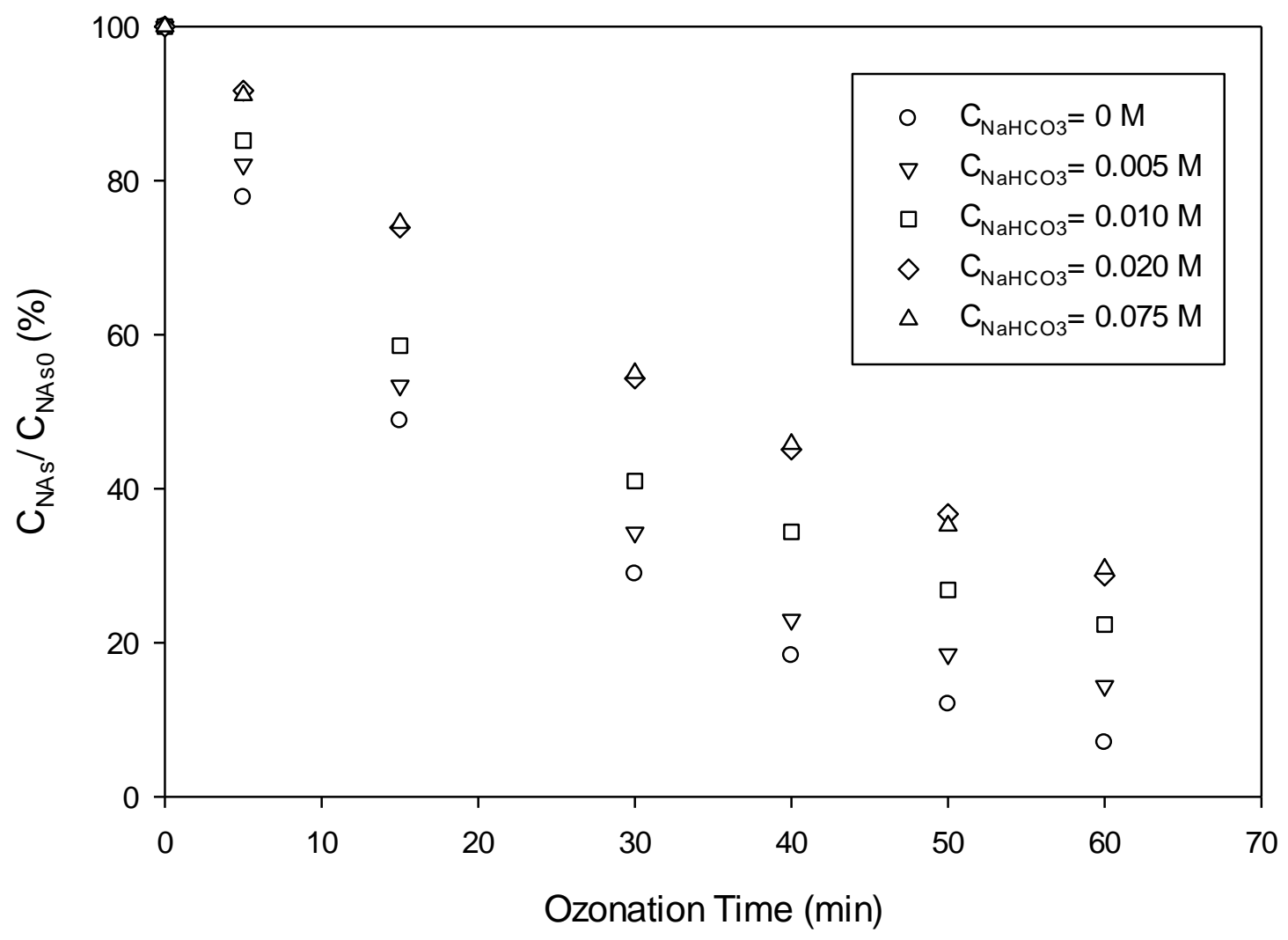

Figure 5.1 Effect of scavenger concentration on the removal of NAs. $C_{\mathrm{NAs} 0}=4.1 \times 10^{-4} \mathrm{M} ; \mathrm{T}=$ $25^{\circ} \mathrm{C} ; \mathrm{pH}=8.5$.

\subsubsection{Effect of Temperature}

The effects of operating parameters including ozone inlet concentration, $\mathrm{pH}$, gas flowrate and mixing on the removal of NAs have been reported in our previous work ( $\mathrm{Al}$ jibouri and $\mathrm{Wu}$, 2015). To explore the temperature effect, ozonation of NAs was conducted at different temperatures in the presence and absence of the radical scavenger, respectively. Experiments were conducted at three temperature levels $\left(5,15\right.$ and $\left.25^{\circ} \mathrm{C}\right)$. Fig. 5.2 shows the results. As temperature increased, the removal of NAs increased as well. It is known that ozonation is a gas liquid reaction, the oxidation rate of NAs should also depend on the ozone solubility which decreases with the increasing temperature (Sotelo et al., 1989). Thus, the increase in the rate of oxidation and decrease in dissolved ozone concentration are two opposite effects on the removal of NAs. However, it can 
be observed from Fig. 5.2 that overall, the increase in temperature had a positive effect on the removal of NAs.

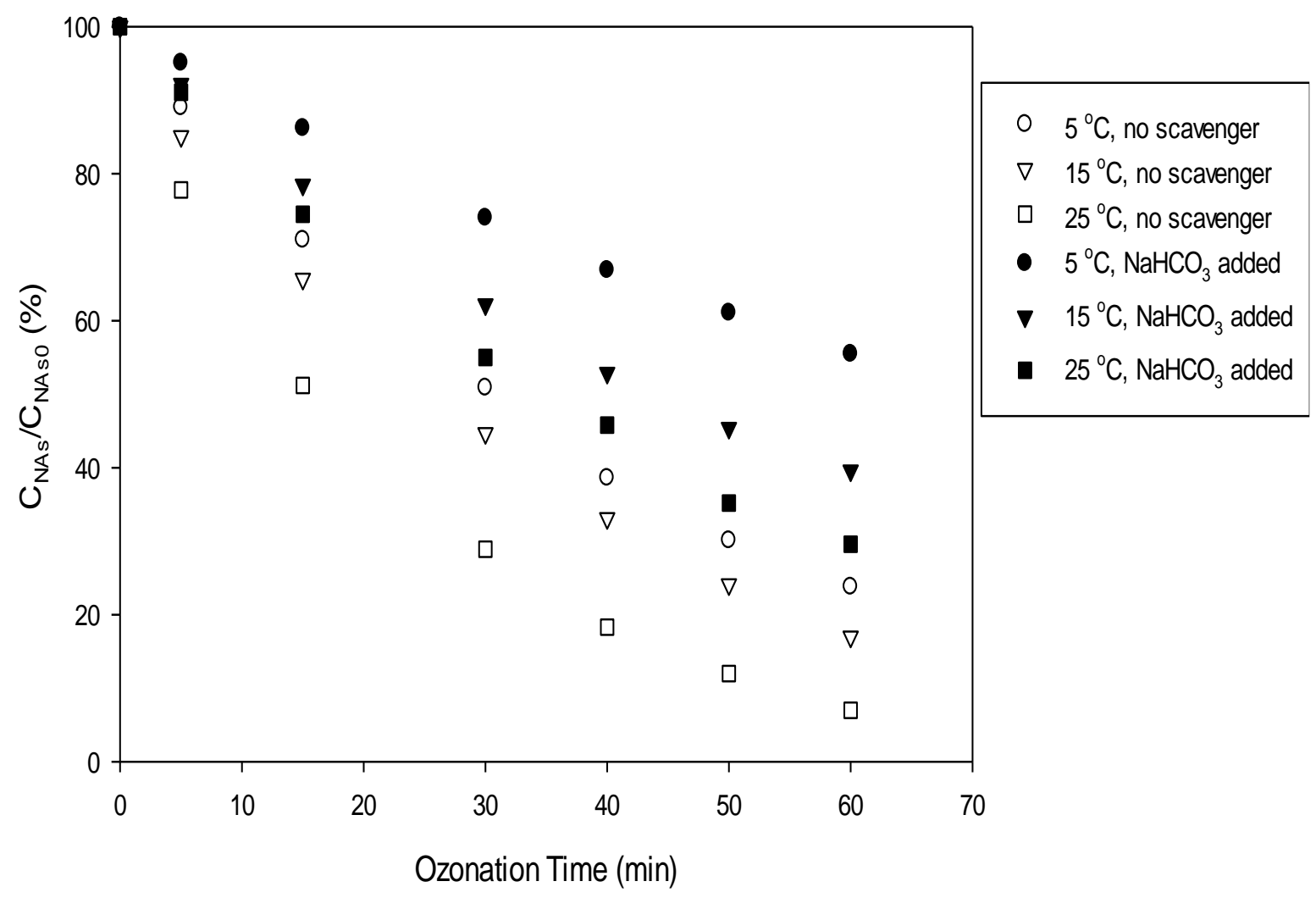

Figure 5.2 Effects of temperature and the addition of scavenger on the removal of NAs. $C_{\text {NAs0 }}=$ $4.1 \times 10^{-4} \mathrm{M} ; \mathrm{pH}=8.5$; Scavenger concentration: $C_{\mathrm{NaHCO} 3}=0.075 \mathrm{M}$.

During the ozonation of NAs, the dissolved ozone concentration was also measured and results are shown in Fig. 5.3. It is observed that the dissolved ozone concentration decreased with the increase in temperature. Also, the dissolved ozone concentration increased with ozonation time until an equilibrium value was reached at approximately $15 \mathrm{~min}$. At all temperatures, the dissolved ozone was always present. Obviously, ozone solubility under this circumstance had no influence on the NAs removal, and therefore, temperature had a positive effect on the removal of NAs. As a matter of fact, the presence of important amount of dissolved ozone also suggested that ozonation 
of NAs could be a slow gas-liquid reactions (Danckwerts, 1970; Charpentier, 1981). Further discussion on the kinetic regime will follow.

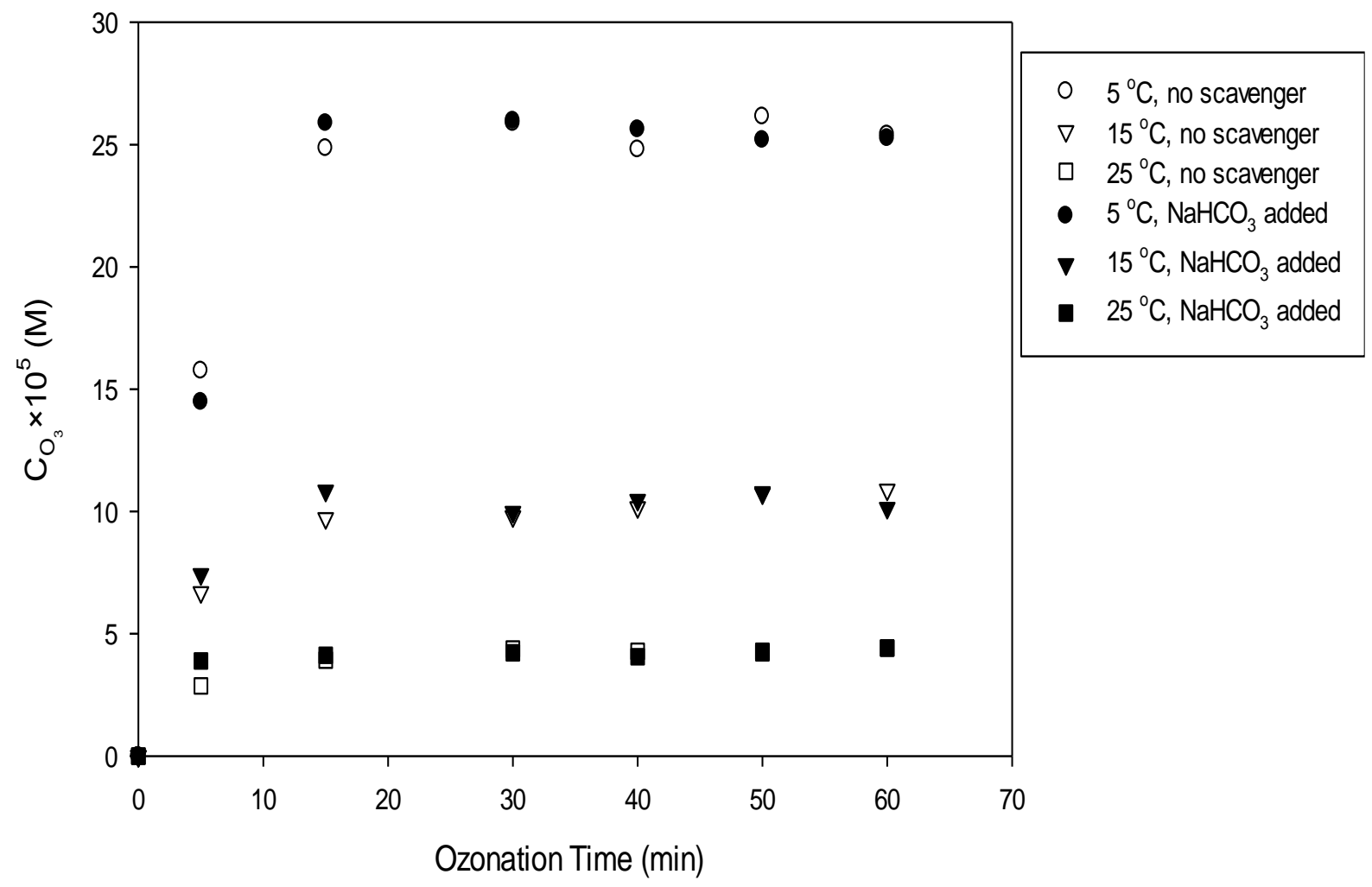

Figure 5.3 Effects of temperature and the addition of scavenger on the dissolved ozone concentration. $C_{\mathrm{NAs} 0}=4.1 \times 10^{-4} \mathrm{M}, \mathrm{pH}=8.5$, Scavenger concentration: $C_{\mathrm{NaHCO} 3}=0.075 \mathrm{M}$.

\subsubsection{Determination of the Direct Reaction Rate Constant and Activation Energy}

As mentioned earlier, ozone oxidizes organic pollutants in water with two pathways: direct and indirect reactions. For ozonation of organic pollutants in water, the mechanism proposed by Staehelin and Hoigné (1985) was generally accepted. In the case of ozonation of NAs, the mechanism is as follows:

For direct ozonation of NAs: 


$$
O_{3}+N A s \stackrel{k_{d}}{\rightarrow} \text { Intermediates }
$$

where $k_{d}$ is the rate constant for the direct ozonation between molecular ozone and NAs.

For indirect (radical) reaction:

$$
\mathrm{NAs}+\mathrm{HO} \cdot \stackrel{k_{H O^{*} N A S}}{\longrightarrow} \text { Intermediates }
$$

where $k_{H O}{ }^{*} A s$ is the indirect (radical) rate constant for the reaction between NAs and the hydroxyl radicals.

To investigate the kinetics of the direct ozonation of NAs, reactions were conducted in the presence of $0.075 \mathrm{M}$ sodium bicarbonate to eliminate radical reactions. Results of removal of NAs and dissolved ozone concentration with the scavenger added are also shown in Figs. 5.2 and 5.3, respectively. As can be observed from the two figures, addition of sodium bicarbonate decreased the rate of reaction, indicating the elimination of the radical reactions. However, dissolved ozone concentration was almost unaffected by the scavenger.

According to the mechanism, the rate of direct ozonation of NAs can be expressed as:

$$
-\frac{d C_{\mathrm{NAs}}}{d t}=k_{d} C_{\mathrm{NAs}} C_{\mathrm{O}_{3}}
$$

where $C_{N A s}$ and $C_{O_{3}}$ are the concentration of NAs and dissolved ozone, respectively. According to Equation (5.3), a plot of $-d C_{\mathrm{NAs}} d t$ versus the product of $C_{\mathrm{NAs}} C_{\mathrm{O}_{3}}$ should yield a straight line and the slope of this line equals $k_{\mathrm{d}}$ (Beltran, et al., 1995). The disappearance rates of NAs, $-d C_{\mathrm{NAs}} d d t$, were obtained by differentiating the experimental data of $C_{N A s}$ with respect to $t$ in the presence of $0.075 \mathrm{M}$ sodium bicarbonate in Fig. 5.2. The $C_{\mathrm{NAs}}$ and $C_{O_{3}}$ were obtained from Figs 5.2 and 5.3, respectively. The curve fittings results are shown in Fig. 5.4 and it is obvious that the data fit the straight lines very well. From the slopes of the lines, the rate constants of the direct reaction of NAs and ozone were determined to be $0.67,2.71$ and $8.85 \mathrm{M}^{-1} \mathrm{~s}^{-1}$ at 5,15 and $25^{\circ} \mathrm{C}$, respectively. According to the Arrhenius law:

$$
k_{\mathrm{d}}=A e^{-\frac{-E}{R T}}
$$

where $\mathrm{A}$ is the frequency factor, $\mathrm{E}$ the activation energy and $\mathrm{R}$ the gas constant. Taking the natural logarithm of Equation (5.4) and plotting $\ln k_{d}$ versus 1/T in Fig. 5.5, the following equation was obtained:

$$
\ln k_{\mathrm{d}}=-10,687\left(\frac{1}{T}\right)+38.05, M^{-1} S^{-1}
$$


Calculating the activation energy from the slope and the frequency factor from the interception of the straight line, the Arrhenius equation for direct ozonation of NAs is:

$$
k_{\mathrm{d}}=3.34 \times 10^{16} \exp \left(-\frac{88.85}{\mathrm{R} T}\right), M^{-1} S^{-1}
$$

where the temperature (T) is in K and the activation energy of the direct ozonation of NAs is 88.85 $\mathrm{kJ} \mathrm{mol}^{-1}$.

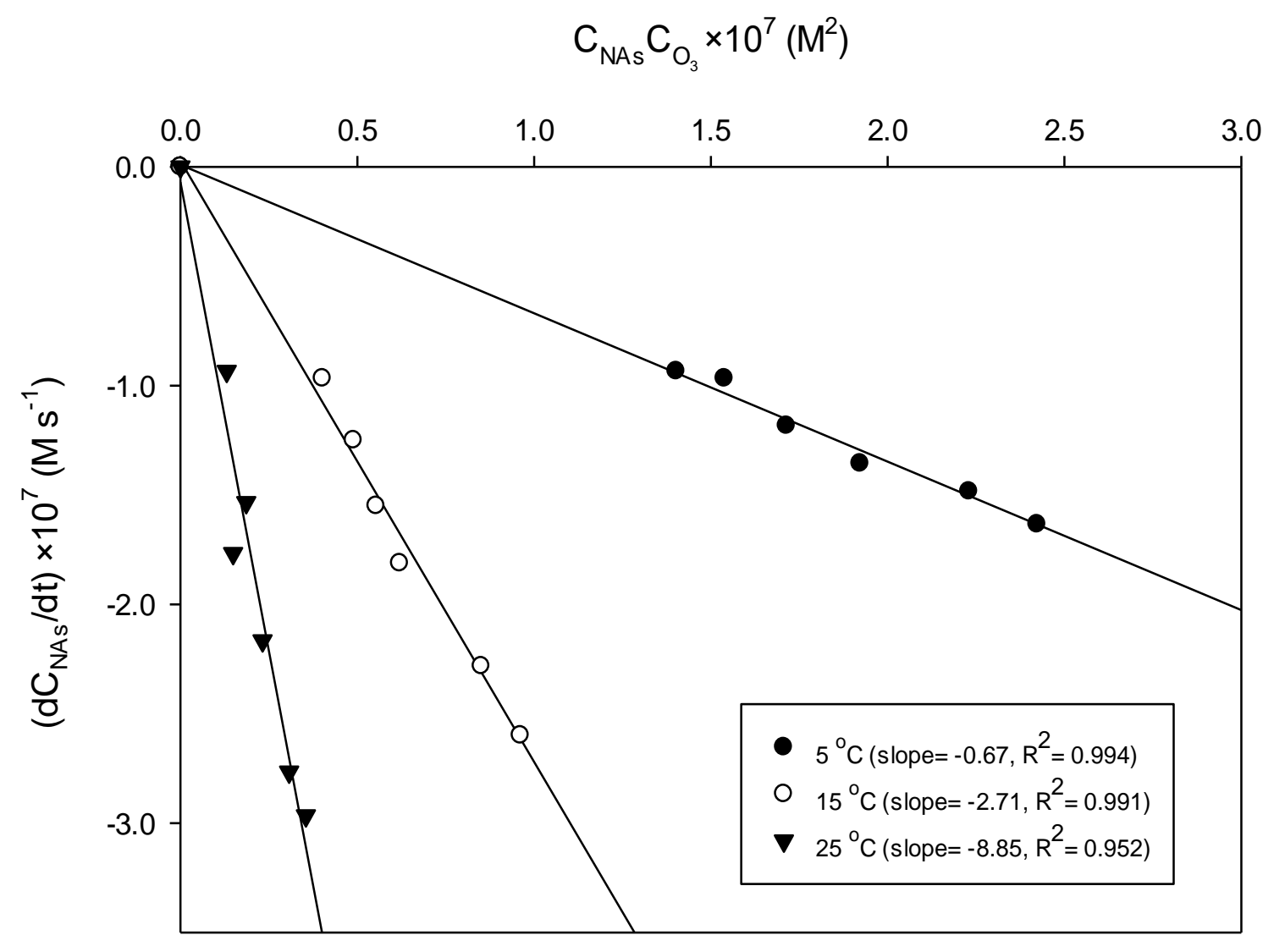

Figure 5.4 Dependence of the rate of NAs removal on the product of $C_{\mathrm{NAs}} C_{\mathrm{O} 3} . \mathrm{pH}=8.5$; Scavenger concentration: $C_{\mathrm{NaHCO} 3}=0.075 \mathrm{M} ; C_{\mathrm{NAs} 0}=4.1 \times 10^{-4} \mathrm{M}$. 


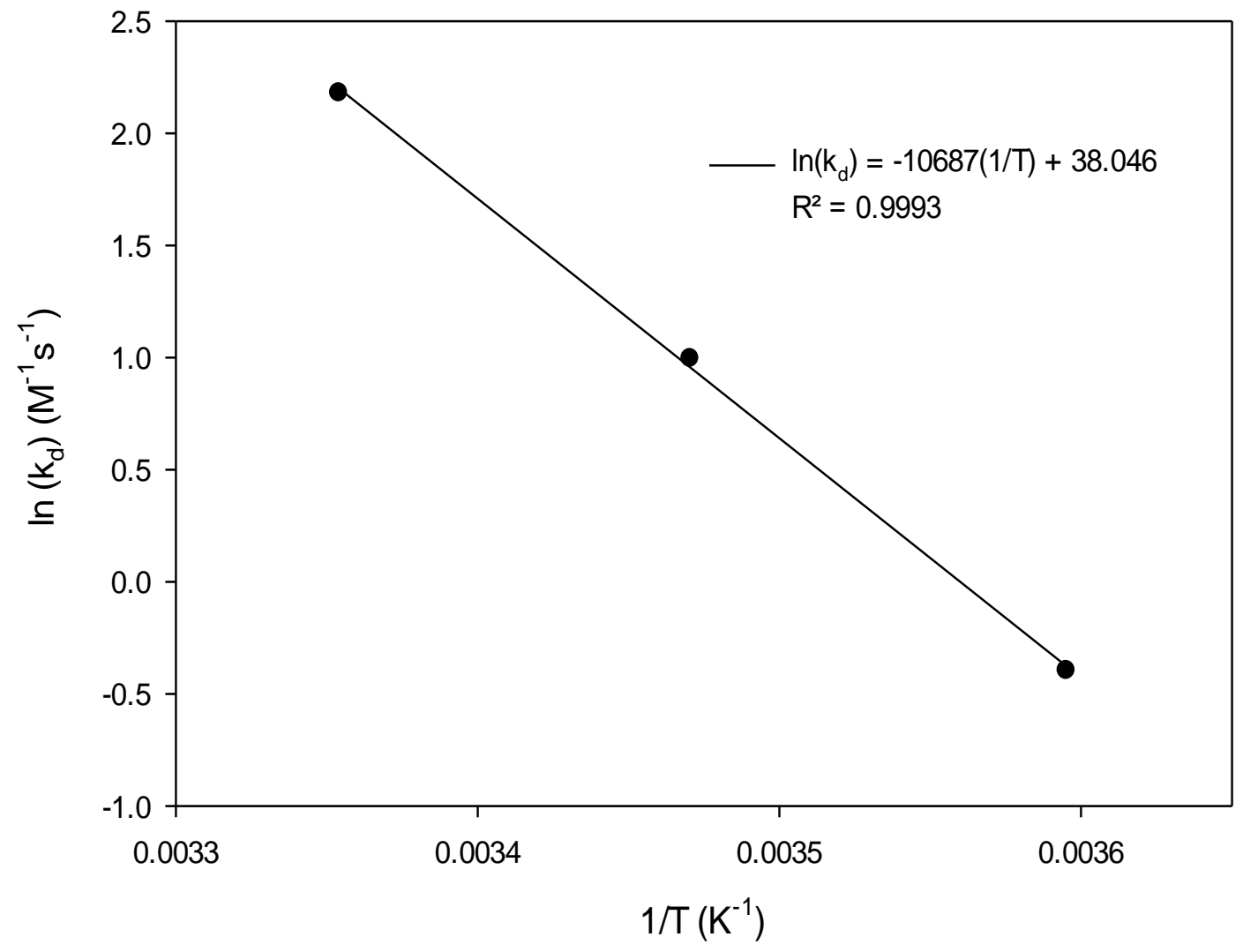

Figure 5.5 Graphical determination of the activation energy of direct ozonation of NAs.

\subsubsection{Estimation of the Kinetic Regime of the Direct Reaction}

To confirm if the direct ozonation of NAs was a slow reaction as mentioned in Section 5.1.1.2, the Hatta number $(\mathrm{Ha})$ of the reaction was calculated to estimate the kinetic regime. $\mathrm{Ha}$ is a dimensionless parameter that compares the rate of reaction in a liquid film to the rate of diffusion through the film (Levenspiel, 1999). For an irreversible second-order reaction, Ha was defined as (Charpentier, 1981):

$$
H a=\frac{\sqrt{k_{\mathrm{d}} D_{\mathrm{O}_{3}} C_{\mathrm{NAs}}}}{K_{\mathrm{L}}}
$$

where $D_{O_{3}}$ is the diffusivity of the dissolved ozone in water and $K_{\mathrm{L}}$ is the liquid phase mass transfer coefficient. To calculate Ha from Equation (5.7), $K_{\mathrm{L}}$ was taken to be $2 \times 10^{-4} \mathrm{~m} \mathrm{~s}^{-1}$, which is a typical value for the type of gas-liquid contactor used in this study, and $D_{O_{3}}$ was taken to be $1.3 \times 10^{-9} \mathrm{~m}^{2}$ 
$\mathrm{s}^{-1}$ (Beltrán, 1997). For the concentration of NAs at $4.1 \times 10^{-4} \mathrm{M}$, calculated values of $\mathrm{Ha}$ are listed in Table 5.1. As can be seen from Table 5.1, all the $H a$ values are less than 0.02 , therefore, the direct ozonation of NAs is a very slow reaction in bulk liquid (Charpentier, 1981; Levenspiel, 1999). This conclusion was also evidenced by the presence of the important amount of dissolved ozone in the reactor as shown in Fig. 5.3.

Table 5.1 Hatta numbers.

\begin{tabular}{ccc}
\hline Temperature $\left({ }^{\circ} \mathrm{C}\right)$ & $k_{\mathrm{d}}\left(\mathrm{M}^{-1} \mathrm{~s}^{-1}\right)$ & $H a$ \\
\hline 5 & 0.67 & 0.003 \\
15 & 2.71 & 0.006 \\
25 & 8.85 & 0.011 \\
\hline
\end{tabular}

\subsection{INDIECT (RADICAL) OZONATION OF NAPHTHENIC ACIDS}

\subsubsection{Determination of the hydroxyl radical concentration}

To conduct kinetic study of the indirect ozonation of NAs, the concentration of the hydroxyl radicals should be known. The hydroxyl radical concentration was determined by using pCBA as a hydroxyl radical probe compound (Elovitz and von Gunten, 1999). It is known that $p$ CBA has a very low reactivity with $\mathrm{O}_{3}$ or secondary oxidants, but reacts readily with $\mathrm{HO}^{\bullet}$. Within the $\mathrm{pH}$ range of 6 to 9.4, the rate constant of the reaction between hydroxyl radicals and $p \mathrm{CBA}$, $k_{H O} \cdot p C B A$, is $5 \times 10^{9} \mathrm{M}^{-1} \mathrm{~s}^{-1}$ (Neta and Dorfman, 1968; Yao and Haag, 1991; Elovitz and von Gunten, 1999). Therefore, the disappearance of it is an indirect measure of the $H O^{\bullet}$ concentration.

Experiments were conducted at the same conditions as those of ozonation of NAs, but in the absence of scavengers and in the presence of a small amount of $p$ CBA $\left(6.4 \times 10^{-6} \mathrm{M}\right)$ (Elovitz and von Gunten, 1999).

The rate of the degradation of the reference compound, $p \mathrm{CBA}$, is:

$$
-\frac{d C_{\mathrm{pCBA}}}{d t}=k_{\mathrm{HO} \cdot{ }_{\mathrm{pCBA}}} C_{\mathrm{pCBA}} C_{\mathrm{HO}} \cdot
$$

where $C_{\mathrm{pCBA}}$ is the concentrations of $p \mathrm{CBA}$.

Integration of Equation (5.8) with the limits 


$$
t=0 \quad C_{\mathrm{pCBA}}=C_{\mathrm{pCBA}_{0}} ; t=\mathrm{t} \quad C_{\mathrm{pCBA}}=C_{\mathrm{pCBA}}
$$

yields

$$
\ln \frac{C_{\mathrm{pCBA}}}{C_{\mathrm{pCBA}_{0}}}=k_{\mathrm{HO}} \cdot \mathrm{pCBA} C_{\mathrm{HO}} \cdot t
$$

The left hand side of Equation (5.9), $\ln C_{\mathrm{pCBA}} / C_{\mathrm{pCBA}_{0}}$, was plotted against the ozonation time at $25^{\circ} \mathrm{C}$ in Fig. 5.6. It is observed from Fig. 5.6 that a straight line was obtained. The slope of the straight line is the product of $k_{\mathrm{HO}}{ }^{\mathrm{pCBA}}$ and $C_{\mathrm{HO}} \cdot$. With the known value of $k_{\mathrm{HO}} \cdot \mathrm{pCBA}=5 \times 10^{9}$ $\mathrm{M}^{-1} \mathrm{~S}^{-1}$ ((Neta and Dorfman, 1968; Yao and Haag, 1991; Elovitz and von Gunten, 1999), the hydroxyl radical concentrations was found to be $1.5 \times 10^{-12} \mathrm{M}$.

Ozonation Time (min)

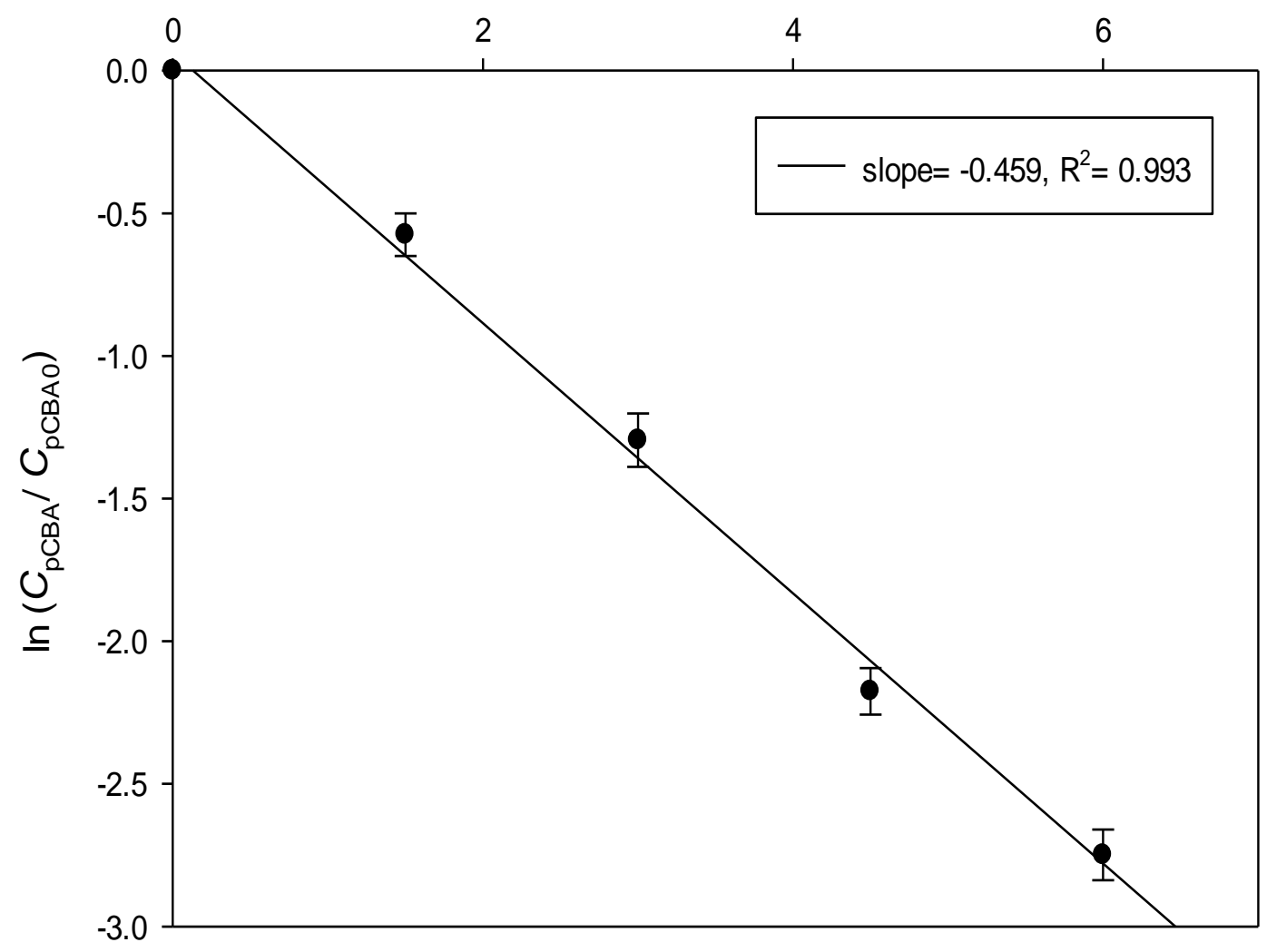

Figure 5.6 Plots of $\ln \left(\mathrm{C}_{\mathrm{pCBA}} / \mathrm{C}_{\mathrm{pCBA}, 0}\right)$ versus ozonation time. $C_{\mathrm{NAs} 0}=4.1 \times 10^{-4} \mathrm{M} ; \mathrm{T}=25^{\circ} \mathrm{C} ; \mathrm{pH}=$ $8.5 ; C_{\mathrm{pCBA} 0}=6.4 \times 10^{-6} \mathrm{M}$. 


\subsubsection{Determination of the indirect (radical) reaction rate constant}

As mentioned earlier, ozonation of aqueous NAs is carried out through direct reaction with ozone and via radicals (hydroxyl radicals) formed from the decomposition of ozone in water (Hoigne and Bader, 1976). Therefore, the overall rate of NAs degradation is

$$
-\frac{d C_{\mathrm{NAs}}}{d t}=k_{\mathrm{d}} C_{\mathrm{NAs}} C_{\mathrm{O}_{3}}+k_{\mathrm{HO}} \cdot \mathrm{NAs}_{\mathrm{NAs}} C_{\mathrm{HO}} \cdot
$$

To determine the indirect reaction rate constant, we introduced the $R_{\mathrm{ct}}$ concept, which was defined as the ratio of hydroxyl radical concentration to dissolved ozone concentration (Elovitz and von Gunten, 1999):

$$
R_{\mathrm{ct}}=\frac{C_{\mathrm{HO}}}{C_{\mathrm{O}_{3}}}
$$

According to Elovitz et al. (2000), the concentration of hydroxyl radicals was independent of the water temperature. Using the equilibrium concentrations of dissolved ozone, $C_{\mathrm{O}_{3 s}}$, at $5{ }^{\circ} \mathrm{C}$, $15^{\circ} \mathrm{C}$, and $25^{\circ} \mathrm{C}$ (Fig. 5.3) in the absence of scavenger, and the hydroxyl radical concentration of $1.5 \times 10^{-12} \mathrm{M}$, the calculated $R_{c t}$ values are listed in Table 5.2.

Table $5.2 R_{\mathrm{ct}}$ values.

\begin{tabular}{ccc}
\hline Temperature $\left({ }^{\circ} \mathrm{C}\right)$ & $C_{\mathrm{O}_{3 \mathrm{~s}}} \times 10^{4}(\mathrm{M})$ & $R_{\mathrm{ct}} \times 10^{8}$ \\
\hline 5 & 2.5 & 0.6 \\
15 & 1.0 & 1.5 \\
25 & 0.4 & 3.8 \\
\hline
\end{tabular}

Substituting Equation (5.11) into Equation (5.10) yields

$$
-\frac{d C_{\mathrm{NAs}}}{d t}=\left(k_{\mathrm{d}}+R_{\mathrm{ct}} \times k_{\mathrm{HO} \cdot \mathrm{NAs}}\right) C_{\mathrm{NAs}} C_{O_{3}}
$$

It is observed from Fig. 5.3 that the dissolved ozone concentration reached an equilibrium concentration in about $15 \mathrm{~min}$ with and without scavenger. Also, the ozone removal of NAs continued after $15 \mathrm{~min}$ (Fig. 5.2). In fact, the presence of important amount of dissolved ozone (Fig. 5.3) suggests undoubtedly that the chemical reactions is in the slow regime developed in the bulk water (Danckwerts, 1970; Charpentier, 1981). Because of the continuation of the reaction 
after the equilibrium concentration of dissolved ozone was reached, we applied Equation (5.12) for the ozonation processes after $15 \mathrm{~min}$ to get the following equation:

$$
-\frac{d C_{\mathrm{NAs}}}{d t}=\left(k_{\mathrm{d}}+R_{\mathrm{ct}} \times k_{\mathrm{HO} \cdot \mathrm{NAs}}\right) C_{\mathrm{NAs}} C_{\mathrm{O}_{3 \mathrm{~s}}}
$$

According to Equation (5.13), a plot of $-d C_{\mathrm{NAs}} / d t$ versus the product of $C_{\mathrm{NAs}}$ and $C_{\mathrm{O}_{3 \mathrm{~s}}}$ should lead to a straight line, and the slope of the straight line gives the value of $\left(k_{\mathrm{d}}+R_{\mathrm{ct}} \times k_{\mathrm{HO}}{ }^{\mathrm{N} A s}\right)$. The disappearance rates of NAs, $-d C_{\mathrm{NAs}} / d t$, can be obtained from the data in Fig. 5.2 by differentiating the concentration of $N A s$ with respect to ozonation time in the absence of scavenger. Fig. 5.7 shows those plots and it is observed that the data fit to the straight lines well. By calculating $k_{\mathrm{d}}$ from Equation (5.6), the indirect rate constants for the reaction between NAs and hydroxyl radicals were determined to be $1.12 \times 10^{8}, 1.78 \times 10^{8}$ and $2.33 \times 10^{8} \mathrm{M}^{-1}$ $\mathrm{s}^{-1}$ at 5,15 and $25^{\circ} \mathrm{C}$, respectively.

$$
\mathrm{C}_{\mathrm{NAs}} \mathrm{C}_{\mathrm{O}_{3 \mathrm{~s}}} \times 10^{8}\left(\mathrm{M}^{2}\right)
$$

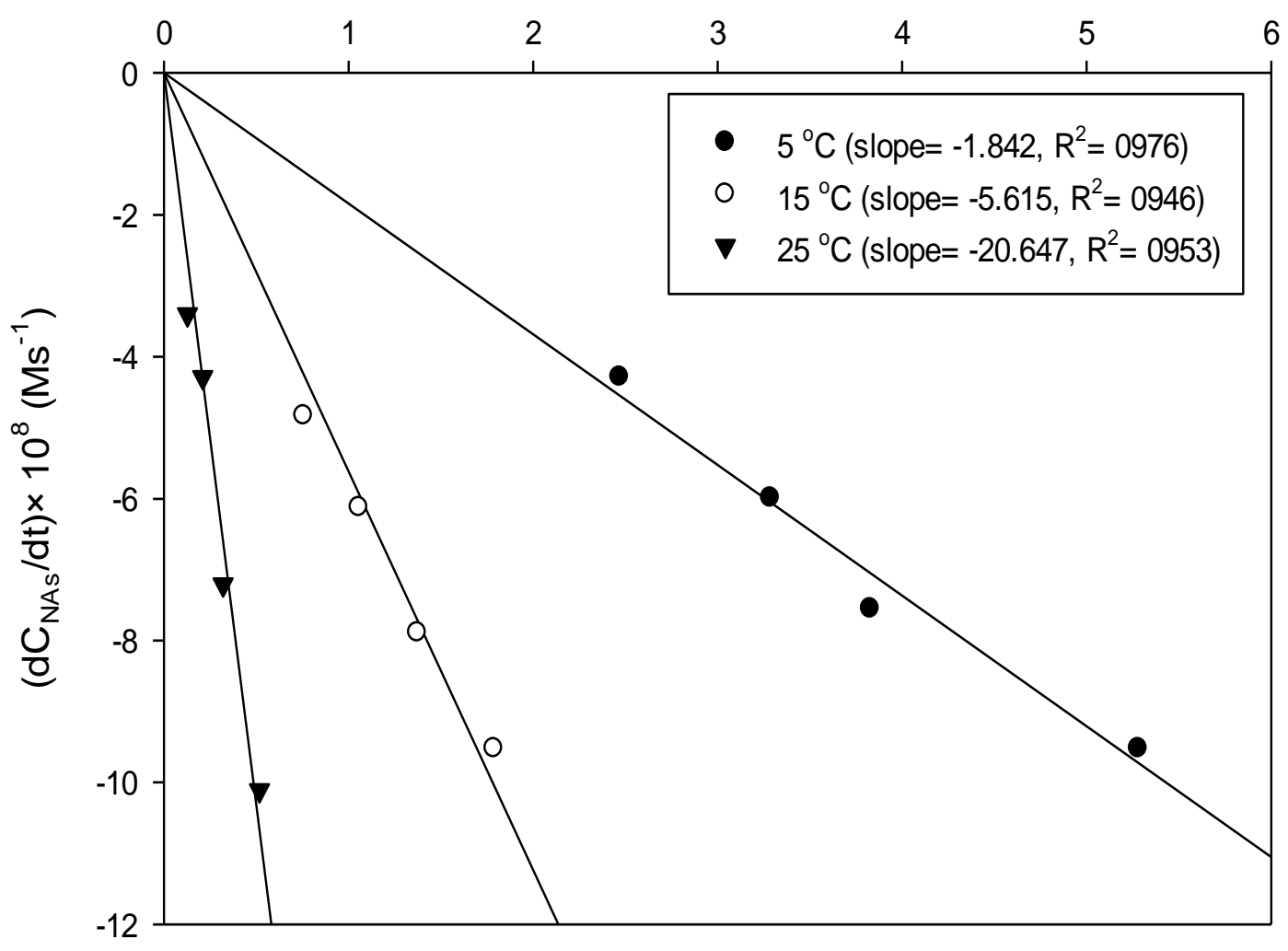

Figure 5.7 Plots of $d C_{\mathrm{NAs}} / d t$ versus $C_{\mathrm{NAs}} C_{\mathrm{O} 3 \mathrm{~s} .} \mathrm{C}_{\mathrm{NAs} 0}=4.1 \times 10^{-4} \mathrm{M} ; \mathrm{T}=25^{\circ} \mathrm{C} ; \mathrm{pH}=8.5$. 
Further, Fig. 5.8 shows the Arrhenius plot of the indirect ozonation of NAs. Calculating the activation energy from the slope and the frequency factor from the interception of the straight line, the Arrhenius equation of the indirect ozonation of NAs is:

$$
k_{\mathrm{HO}}{ }_{\mathrm{NAs}}=6.79 \times 10^{12} \exp \left(-\frac{25.41}{\mathrm{R} T}\right), M^{-1} s^{-1}
$$

where the temperature ( $\mathrm{T}$ ) is in $\mathrm{K}$ and the activation energy of the indirect ozonation of NAs is $25.41 \mathrm{~kJ} \mathrm{~mole}^{-1}$.

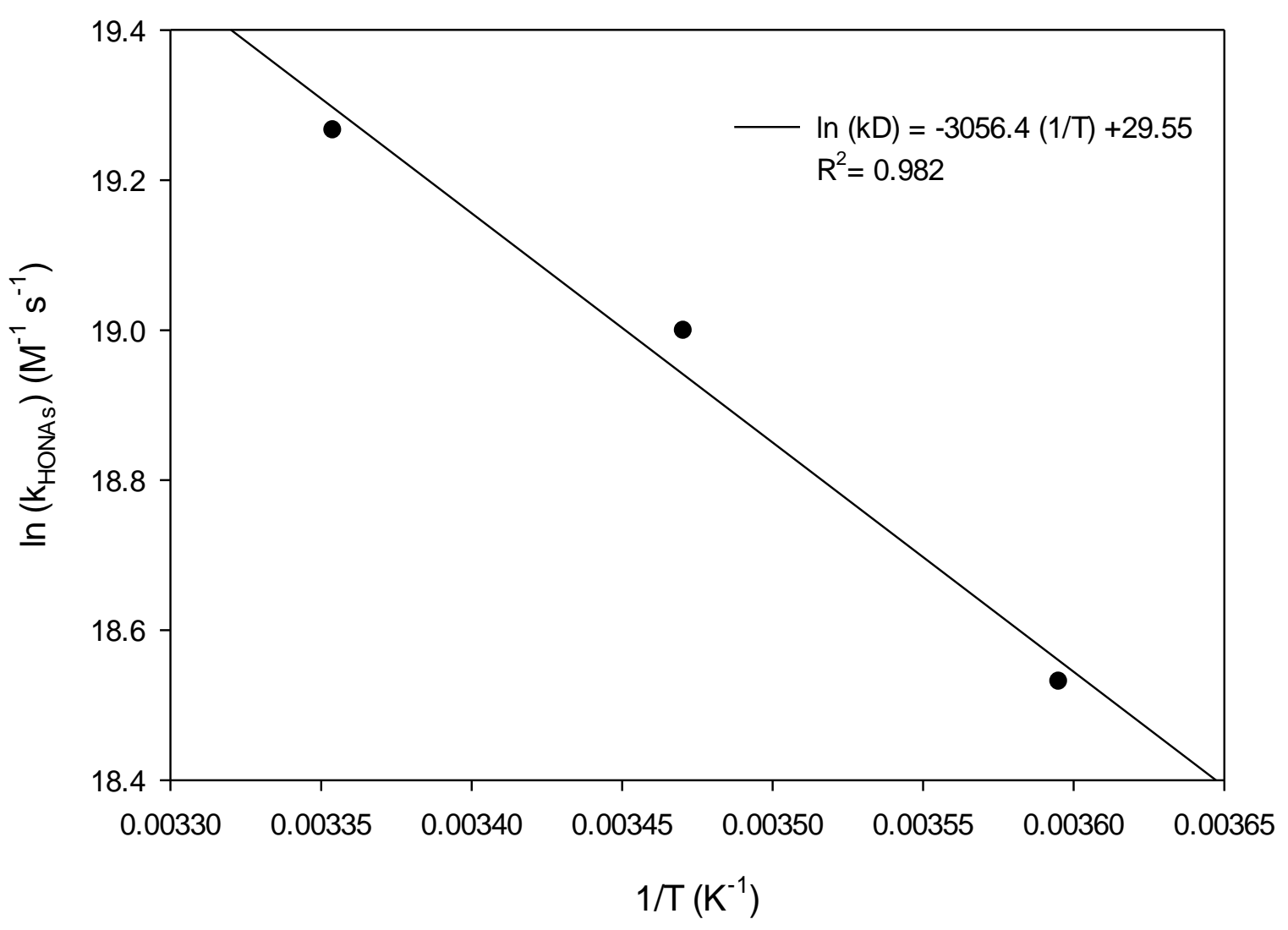

Figure 5.8 Graphical determination of the activation energy of indirect ozonation of NAs. 


\section{CHAPTER 6:}

\section{APPLICATION OF MASS BALANCE MODELS IN THE PROCESS OF OZONE REMOVAL OF NAPHTHENIC ACIDS FROM WATER:}

\subsection{EFFECT OF OPERATING PARAMETERS ON NAPHTHENIC ACIDS REMOVAL AND DISSOLVED OZONE CONCENTRATION}

\subsubsection{Effects of Temperature}

Effects of temperature on the removal of NAs and on the dissolved ozone concentration were plotted in two figures (Figs. 5.2 and 5.3) in our previous work (Al jibouri et al., 2015a). It was concluded that the removal of NAs increased with the temperature while the dissolved ozone concentration decreased with the temperature. It was also concluded that the ozonation of NAs is in the kinetic regime of slow reaction (Al jibouri et al., 2015a).

\subsubsection{Effect of Inlet Gaseous Ozone Concentration}

The effects of inlet gaseous ozone concentration into the reactor on the removal of NAs and dissolved ozone concentration were also examined at $\mathrm{pH}$ 8.5. Results of removal of NAs are shown in Fig. 6.1. It is observed that increase in inlet ozone concentration enhanced the removal of NAs. After 30 min ozonation, with the inlet ozone concentration of $3.1 \times 10^{-4} \mathrm{M}, 6.2 \times 10^{-4} \mathrm{M}$ and $9.3 \times 10^{-4} \mathrm{M}$, the remaining of NAs were $69.9 \%, 52.7 \%$, and $28.9 \%$, respectively. In fact, increasing the inlet ozone concentration increased the dissolved ozone concentration so that the removal rate of NAs by the dissolved molecular ozone and by free radicals generated from self-decomposition of ozone in water was increased (Al jibouri and Wu, 2015; Al jibouri et al., 2015a). The increase in the concentration of dissolved ozone in the presence of NAs with the inlet ozone concentration was confirmed experimentally and is shown in Fig. 6.2. It should be pointed out that the concentration of dissolve ozone in real OSPW is expected to be lower than in the synthetic wastewater used in this study due to the higher consumption of ozone by organic and inorganic constituents of OSPW other than NAs.

\footnotetext{
* Al jibouri A. K. H., Wu J., Upreti S. R. (2016). Application of mass balance models in the process of ozone removal of naphthenic acids from water. Can. J. Chem. Eng. Accepted.
} 


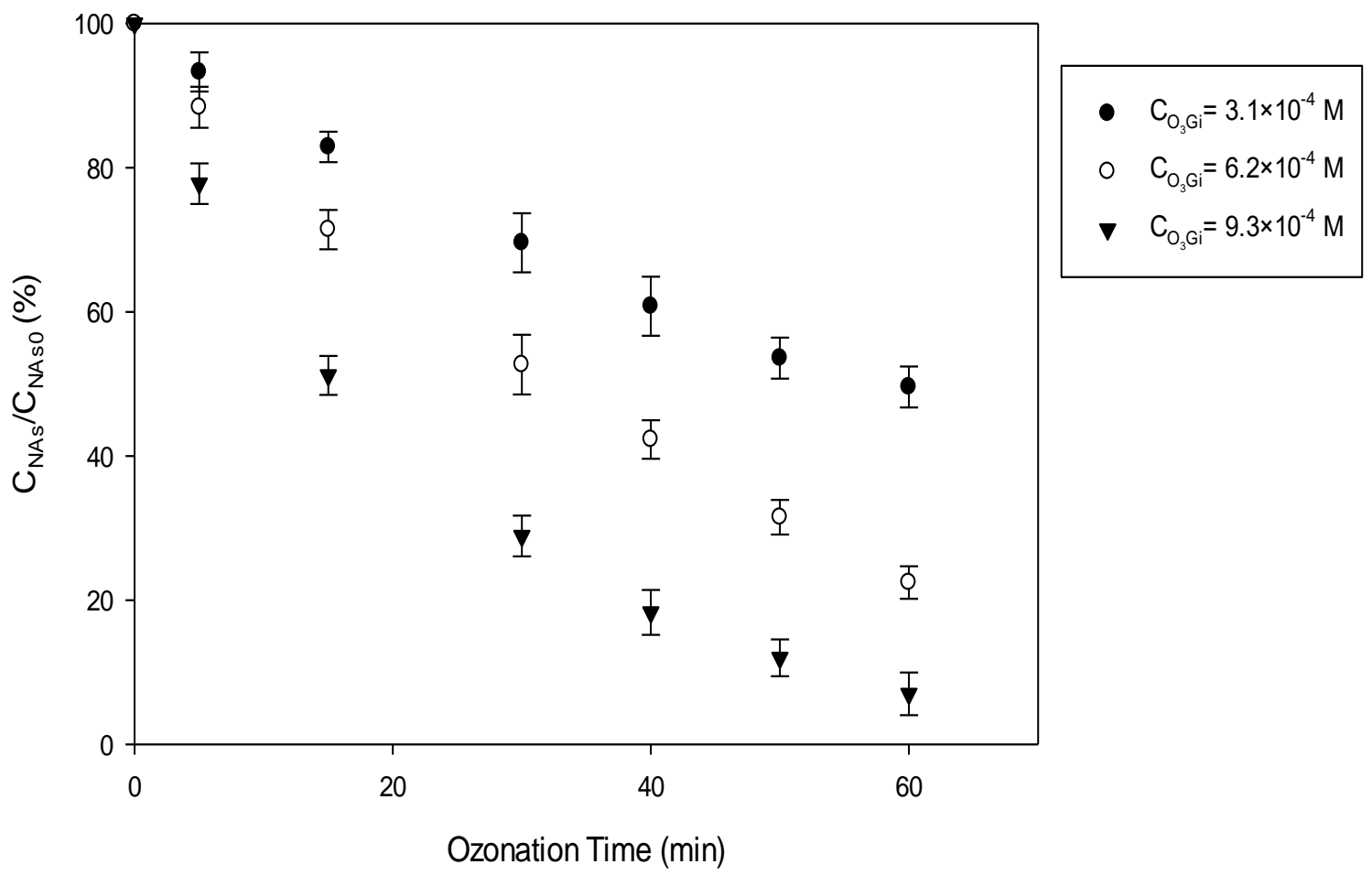

Figure 6.1 Remaining of naphthenic acids (NAs) at different inlet ozone concentration. $C_{\mathrm{NAs} 0}=$ $4.1 \times 10^{-4} \mathrm{M} ; \mathrm{T}=25^{\circ} \mathrm{C} ; \mathrm{pH}=8.5$. 


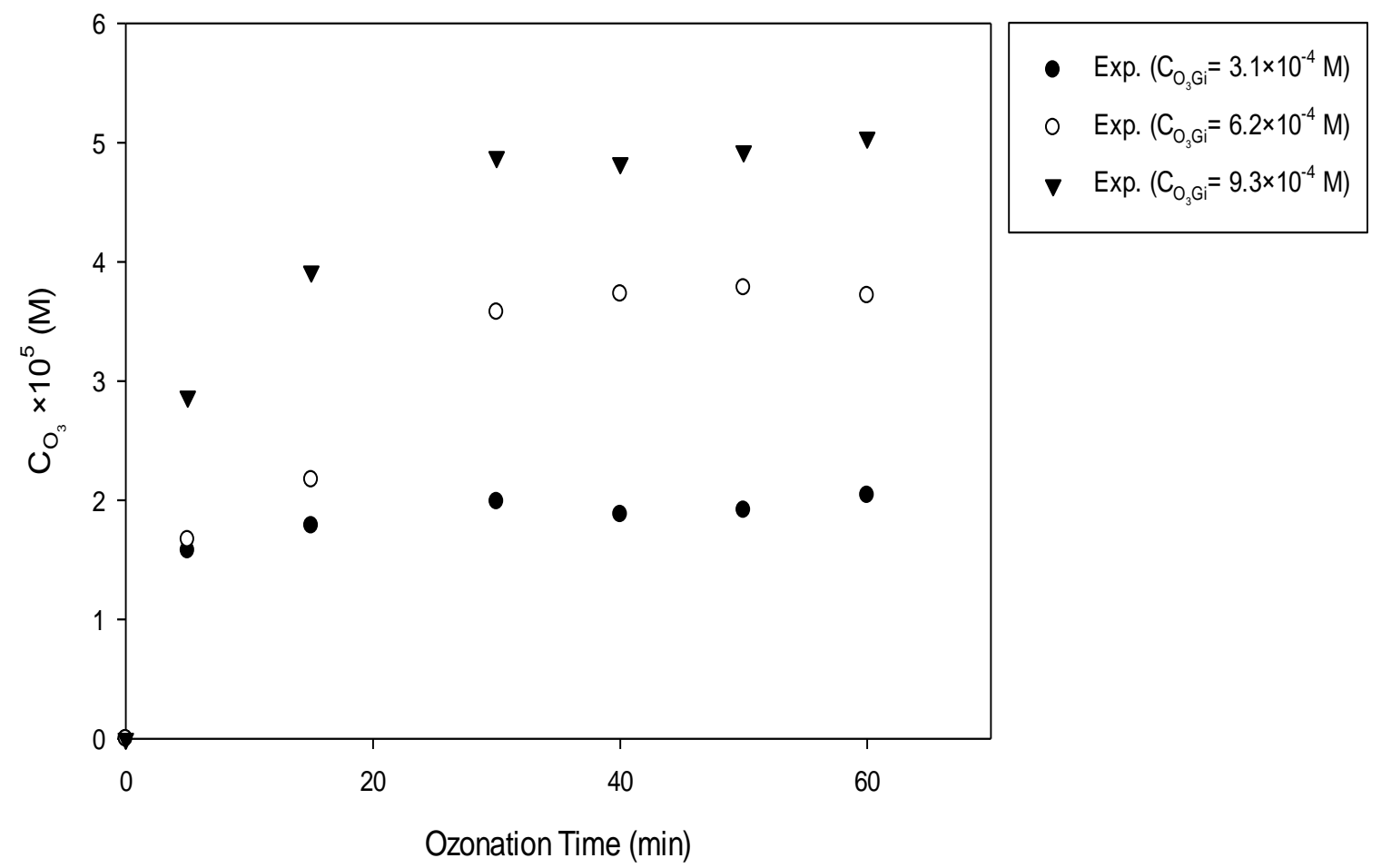

Figure 6.2 Effect of inlet ozone concentration on dissolved ozone concentration. $T=25{ }^{\circ} \mathrm{C} ; C_{\mathrm{NAs}} 0$ $=4.1 \times 10^{-4} \mathrm{M} ; \mathrm{pH}=8.5$.

\subsection{MODEL DEVELOPMENT FOR THE OZONATION OF NAPHTHENIC ACIDS PROCESS}

Our previous results showed that ozone removal of NAs was carried out through two pathways: direct oxidation of NAs by molecular ozone, and indirect oxidation by hydroxyl radicals formed from the self-decomposition of ozone in water (Al jibouri et al., 2015a). On the other hand, to develop the mass balance models for the ozonation of NAs process, the kinetic regime of the reactions has to be known, fast reaction is generally controlled by mass transfer but slow reaction is not. Whether or not the reactions are controlled by the mass transfer of ozone results in different mass balance models. It is known that the Hatta number $\mathrm{Ha}$ ) can be used to estimate the kinetic regime of a gas-liquid reaction such as the one in this study. $\mathrm{Ha}$ is a dimensionless parameter that compares the rate of reaction in a liquid film to the rate of diffusion through the film. If Ha is less than 0.02 , then a very slow reaction is expected (Levenspiel, 1999). Results of our previous study 
revealed that for the direct ozonation of NAs, the values of $\mathrm{Ha}$ under different reaction conditions ranged from 0.003 to 0.011 (Al jibouri et al., 2015a). Obviously, the direct reaction is very slow. At the same time, as can be observed from Fig. 6.2, a considerable amount of dissolved ozone was present in the reactor, which is a strong indication that the overall reactions between ozone and NAs were also very slow and occurred in the bulk water instead of in the film (Charpentier, 1981; Danckwerts, 1970; Beltrán et al., 1994).

Assuming that the ozonation of NAs follows the mechanism of Staehelin and Hoigné, NAs was oxidized as follows (Al jibouri et al., 2015a; Staehelin and Hoigné, 1985):

The direct reaction with ozone:

$$
O_{3}+N A s \stackrel{k_{d}}{\rightarrow} \text { Intermediates } \quad k_{\mathrm{d}}=3.34 \times 10^{16} \exp \left(-\frac{88.85}{\mathrm{RT}}\right)
$$

The indirect reaction with hydroxyl radicals:

$$
N A s+H O^{\bullet} \stackrel{k_{H O}{ }^{*} A s}{\longrightarrow} \text { Intermediates } \quad k_{\mathrm{HO} \cdot \mathrm{NAs}}=6.79 \times 10^{12} \exp \left(-\frac{25.41}{\mathrm{RT}}\right)
$$

The equations of calculating direct and indirect rate constants $\left(k_{d}\right.$ and $\left.k_{H O}{ }^{*} N A s\right)$ were derived in our previous study ( $\mathrm{Al}$ jibouri et al., 2015a).

Combining the above information with mass balances of NAs and ozone, models can be developed to predict the concentration profiles of NAs and ozone.

Mass balance of NAs

The disappearance of NAs is due to the direct and indirect ozonation:

$$
-\frac{d C_{\mathrm{NAs}}}{d t}=k_{\mathrm{d}} C_{\mathrm{NAs}} C_{\mathrm{O}_{3}}+k_{\mathrm{HO} \cdot{ }_{\mathrm{NAs}}} C_{\mathrm{NAs}} C_{\mathrm{HO}} \cdot
$$

The reason that only hydroxyl radicals were counted in the reactions is because they play a central role in the ozonation processes due to their high reactivity (Wang and $\mathrm{Xu}, 2012$ ).

\section{Mass balance of dissolved ozone}


Based on the fact that the overall reaction between ozone and NAs is a slow reaction and assuming that gas and liquid phases are well mixed in the reactor, i.e., the establishment of gas-liquid equilibrium, the mass balance of dissolved ozone is as follows:

$$
\frac{d C_{\mathrm{O}_{3}}}{d t}=\left(\frac{V_{\mathrm{G}}}{V_{\mathrm{L}}}\right) K_{G} a\left(C_{\mathrm{O}_{3} \mathrm{G}} \mathrm{R} T-H C_{\mathrm{O}_{3}}\right)-\sum_{i=1}^{4} r_{i}
$$

where $V_{\mathrm{L}}, V_{\mathrm{G}}, K_{G} a, C_{O_{3} G}, \mathrm{R}, H$ and $T$ are the volume of liquid within the reactor $(0.5 \mathrm{~L})$, the gas holdup $(0.05 \mathrm{~L})$, the overall mass transfer coefficient referred to the gas phase, the concentration of ozone in the gas leaving the reactor, the universal gas constant, the Henry's law constant and temperature, respectively. The changes in dissolved ozone concentration are due to mass transfer of ozone to the water, direct oxidation of NAs and ozone self-decomposition in water. The first term in the right hand side of Equation (6.4) is the driving force for the absorption of ozone from the gas to the liquid phases. The term $\sum r_{i}$ represents the rate of consumption of dissolved ozone due to the direct reaction of ozone with NAs and due to the self-decomposition of ozone in water as shown below (Beltrán et al., 1994; Staehelin and Hoigné, 1985):

$$
\begin{aligned}
& \mathrm{O}_{3}+\mathrm{OH}^{-} \stackrel{k_{i}}{\rightarrow} \mathrm{HO}_{2 \cdot}+\mathrm{O}_{2}^{-} \\
& O_{3}+O_{2 \cdot}^{-} \stackrel{k_{1}}{\rightarrow} O_{3 \cdot}^{-}+O_{2} \\
& \mathrm{O}_{3}+\mathrm{OH} \cdot \stackrel{k_{2}}{\rightarrow} \mathrm{HO}_{2}+\mathrm{O}_{2}
\end{aligned}
$$

where $k_{i}, k_{1}$, and $k_{2}$ are the rate constants of the above three ozone decomposition reactions. Therefore, the rate of disappearance of dissolved ozone can be written as (Beltrán et al., 1994):

$$
\sum_{i=1}^{4} r_{i}=\left(k_{\mathrm{d}} C_{\mathrm{NAs}}+k_{i} 10^{(p H-14)}+k_{1} C_{\mathrm{O}_{2}^{-}}+k_{2} C_{\mathrm{HO}^{\cdot}}\right) C_{\mathrm{O}_{3}}
$$

The radical concentrations in Equation (6.5) can be determined by applying the pseudosteady-state-hypothesis (PSSH) to the active radicals (Fogler, 2006). The expressions thus obtained are (Beltrán et al., 1994; Staehelin and Hoigné, 1985):

$$
C_{\mathrm{HO}} \cdot=\frac{2 k_{i} 10^{(p H-14)} C_{\mathrm{O}_{3}}}{k_{\mathrm{HO} \cdot \mathrm{NAs}} C_{\mathrm{NAs}}+\sum k_{\mathrm{Si}} C_{\mathrm{S}_{\mathrm{i}}}}
$$




$$
C_{\mathrm{O}_{2}^{-\cdot}}=\frac{2 k_{i} 10^{(p H-14)}+k_{2} C_{\mathrm{HO}}}{k_{1}}
$$

According to Staehelin and Hoigné, (1985), the rate constants in Equations (6.6) and (6.7) are: $k_{i}=70 \mathrm{M}^{-1} \mathrm{~S}^{-1}, k_{1}=1.9 \times 10^{9} \mathrm{M}^{-1} \mathrm{~S}^{-1}$, and $k_{2}=2.0 \times 10^{9} \mathrm{M}^{-1} \mathrm{~S}^{-1}$. On the other hand, $C_{S_{i}}$ in Equation (6.6) is the concentration of the scavengers. In the phosphate-buffered system at $\mathrm{pH} 8.5$ in this study, the scavenger should be $\mathrm{HPO}_{4}^{2-}$ (Grabner et al., 1973). Therefore, the scavenger term in the denominator of Equation (6.6) can be expressed as follows:

$$
\sum k_{\mathrm{Si}} C_{\mathrm{S}_{\mathrm{i}}}=k_{\mathrm{s} 1} C_{\mathrm{HPO}_{4}^{2-}}
$$

where $k_{s 1}$ is the rate constant for the reaction between the hydroxyl radical and the phosphate ions and has the value of $7.9 \times 10^{5} \mathrm{M}^{-1} \mathrm{~s}^{-1}$ (Grabner et al., 1973).

It should be mentioned that the intermediates of the ozonation of NAs can also compete with NAs to consume ozone in the form of either molecular ozone or hydroxyl radicals, resulting in the decrease in dissolved ozone. This part of dissolved ozone consumption was not counted in the mass balance model of dissolved ozone because of the nature of NAs mixtures. Naphthenic acids (NAs) refer to a complex suite of alkyl-substituted acyclic and cycloaliphatic carboxylic acids (Clemente and Fedorak, 2005; Ahad, et al., 2013). The analytical studies showed that approximately 1500 acids were detected in the NAs mixtures (Seifert and Teeter, 1969). The complexity of NAs mixtures makes the detection of all the ozonation intermediates almost an impossible task. As a consequence, the ozone consumption by the intermediates was not considered

Mass balance of ozone in the gas phase

$$
\frac{d C_{\mathrm{O}_{3} \mathrm{G}}}{d t}=\left(\frac{v_{\mathrm{G}}}{V_{\mathrm{G}}}\right)\left(C_{\mathrm{O}_{3} \mathrm{Gi}}-C_{\mathrm{O}_{3} \mathrm{G}}\right)-K_{G} a\left(C_{\mathrm{O}_{3} \mathrm{G}} \mathrm{R} T-H C_{\mathrm{O}_{3}}\right)
$$

where $v_{\mathrm{G}}$ and $C_{\mathrm{O}_{3} \mathrm{Gi}}$ are the gas volumetric flow rate and ozone gas concentration at the reactor inlet, respectively. The first term in the right side of Equation (6.9) represents the driving force of 
ozone mass transfer in the gas phase while the second term represents the driving force for the absorption of ozone from the gas to the liquid phases.

\subsection{SOLVING THE DEVELOPED MASS BALANCE EQUATIONS}

The solutions for Equations (6.3), (6.4), and (6.9) can provide the concentration profiles of NAs, dissolved ozone and gaseous ozone during the reaction. However, to solve the three equations, it is necessary to determine the overall mass transfer coefficient $\left(K_{G} a\right)$ and the Henry's law constant $(H)$.

According to Equation (6.9), when the gaseous and dissolved ozone concentrations approached equilibrium conditions given the reaction is very slow, the ozone accumulation term is zero and the concentrations of dissolved ozone and ozone in the gas phase leaving the reactor are $C_{O_{3} S}$ and $C_{O_{3} G s}$, respectively. Thus, Equation (6.9) becomes:

$$
0=\left(\frac{\nu_{\mathrm{G}}}{V_{\mathrm{G}}}\right)\left(C_{\mathrm{O}_{3} \mathrm{Gi}}-C_{\mathrm{O}_{3} \mathrm{Gs}}\right)-K_{G} a\left(C_{\mathrm{O}_{3} \mathrm{Gs}} \mathrm{RT}-\mathrm{HC}_{\mathrm{O}_{3} \mathrm{~S}}\right)
$$

$K_{G} a$ and $H$ can be calculated from Equation (6.10). Two different inlet ozone gas concentrations were applied at each temperature in order to get two nonlinear equations. The nonlinear equations can be expressed in the general form:

$$
\sum_{i=1}^{2} f(i)=\left(\frac{v_{\mathrm{G}}}{V_{\mathrm{G}}}\right)\left[C_{\mathrm{O}_{3} \mathrm{Gi}}(i)-C_{\mathrm{O}_{3} \mathrm{Gs}}(i)\right]-K_{G} a\left[C_{\mathrm{O}_{3} \mathrm{Gs}}(i) \mathrm{R} T-H C_{\mathrm{O}_{3} \mathrm{~s}}(i)\right]
$$

The Newton-Raphson non-linear numerical method was used to solve the two equations to get $K_{G} a$ and $H$ at each temperature (Chapra and Canale, 2009). Table 6.1 shows the results.

Further, values of $K_{G} a$ and $H$ in Table 6.1 were plotted versus temperature in Figs. 6.3 and 6.4 , respectively, to get the temperature dependence of the two parameters. From the slopes and interceptions of the straight lines in the figures, temperature dependence of $K_{G} a$ and $H$ were obtained:

$$
\begin{aligned}
& H=1.33 \times 10^{17} \exp \left(-\frac{6563.1}{T}\right), \quad \mathrm{Pa} \mathrm{M}^{-1} \\
& K_{G} a=2.18 \times 10^{-9} \exp \left(\frac{791.3}{T}\right), \quad \mathrm{mol} \mathrm{Pa}^{-1}(\mathrm{~L} \text { of gas })^{-1} \mathrm{~s}^{-1}
\end{aligned}
$$

where the temperature (T) is in Kelvin. 
Table 6.1 Determination of $K_{G} a$ and $H$.

\begin{tabular}{|c|c|c|c|c|c|}
\hline $\begin{array}{c}\mathrm{T} \\
(\mathrm{K})\end{array}$ & $\begin{array}{c}C_{\mathrm{O}_{3} \mathrm{Gi}} \\
(\mathrm{M})\end{array}$ & $\begin{array}{c}C_{\mathrm{O}_{3} \mathrm{Gs}} \\
(\mathrm{M})\end{array}$ & $\begin{array}{l}C_{\mathrm{O}_{3}} \\
(\mathrm{M})\end{array}$ & $\begin{array}{l}\quad H \\
\left(\mathrm{~Pa} \mathrm{M}^{-1}\right) \\
\times 10^{-6}\end{array}$ & $\begin{array}{c}K_{G} a \\
\left(\mathrm{~mol} \mathrm{~Pa}^{-1}[\mathrm{~L} \text { of gas }]^{-1} \mathrm{~s}^{-1}\right) \times 10^{8}\end{array}$ \\
\hline \multirow{2}{*}{278} & $6.2 \times 10^{-4}$ & $6.04 \times 10^{-4}$ & $1.72 \times 10^{-4}$ & \multirow{2}{*}{7.30} & \multirow{2}{*}{3.74} \\
\hline & $9.3 \times 10^{-4}$ & $9.01 \times 10^{-4}$ & $2.5 \times 10^{-4}$ & & \\
\hline \multirow{2}{*}{288} & $6.2 \times 10^{-4}$ & $6.18 \times 10^{-4}$ & $8.0 \times 10^{-5}$ & \multirow{2}{*}{18.24} & \multirow{2}{*}{3.4} \\
\hline & $9.3 \times 10^{-4}$ & $8.97 \times 10^{-4}$ & $1.0 \times 10^{-4}$ & & \\
\hline \multirow{2}{*}{298} & $6.2 \times 10^{-4}$ & $6.03 \times 10^{-4}$ & $3.7 \times 10^{-5}$ & \multirow{2}{*}{35.46} & \multirow{2}{*}{3.09} \\
\hline & $9.3 \times 10^{-4}$ & $8.9 \times 10^{-4}$ & $5.0 \times 10^{-5}$ & & \\
\hline
\end{tabular}

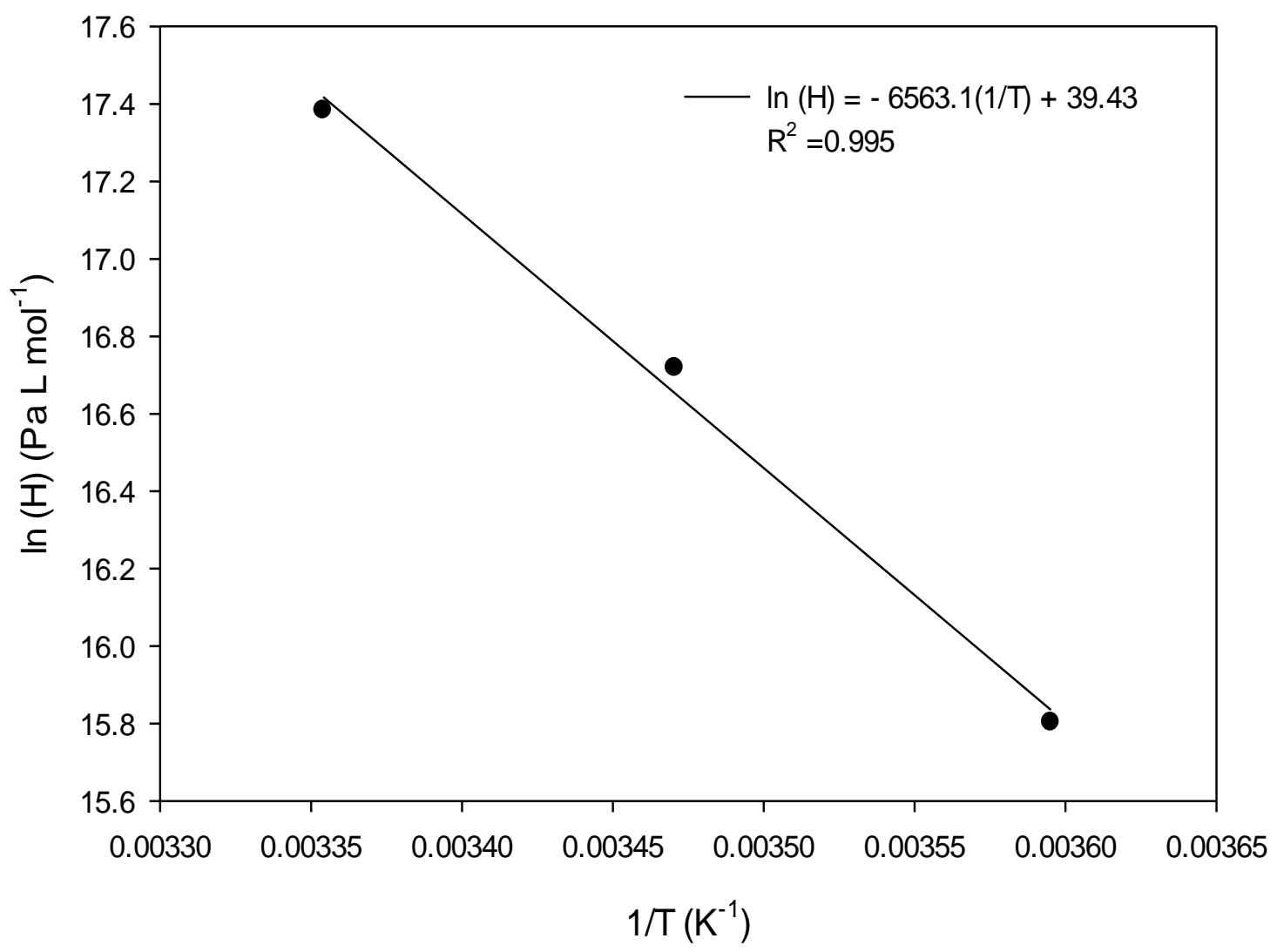

Figure 6.3 Dependence of the Henry's law constant on temperature. 


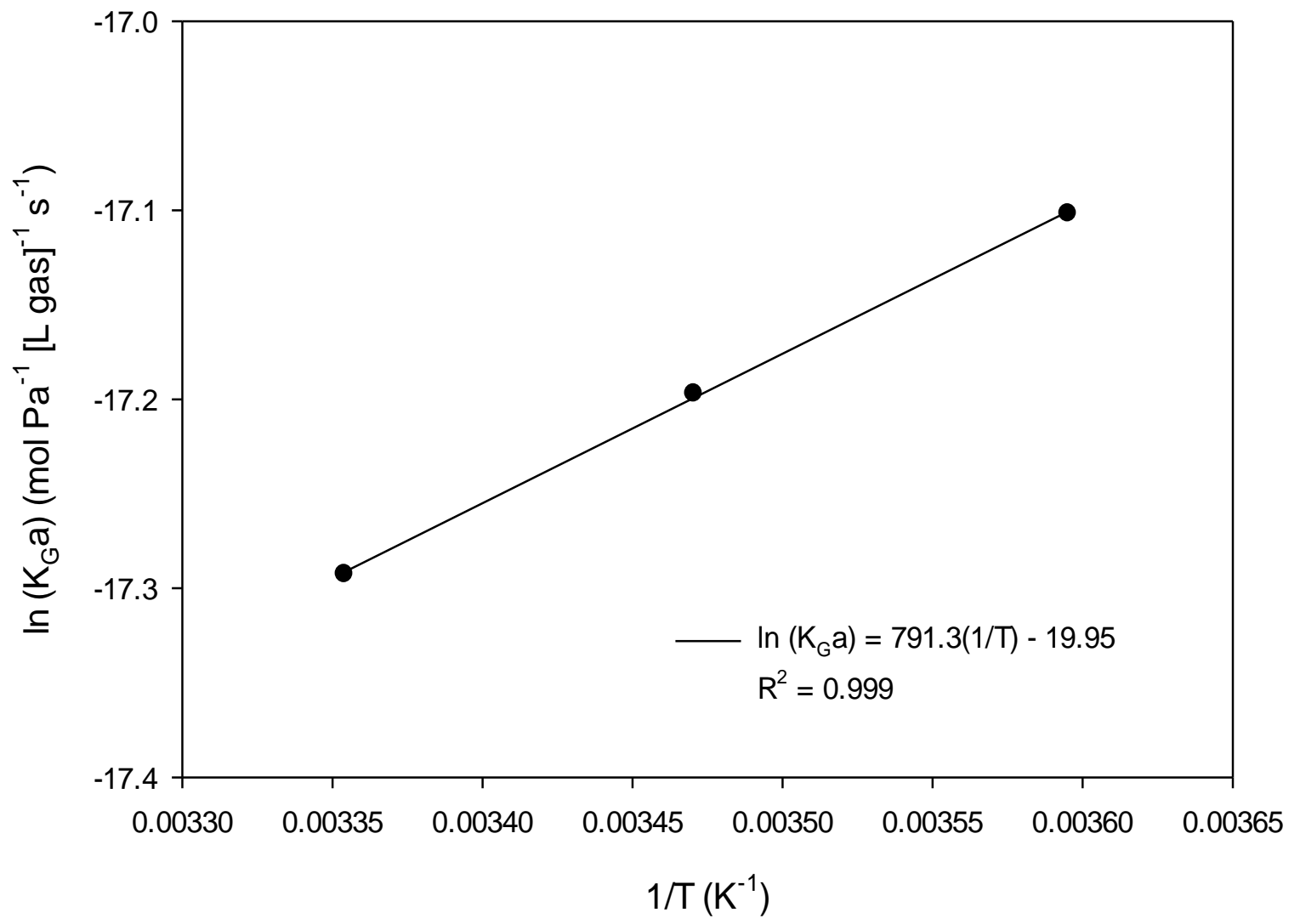

Figure 6.4 Dependence of the overall mass transfer coefficient on temperature.

A C++ program was developed to solve the three mass balance equations (Equations (6.3), (6.4) and (6.9)). The fourth order Runge-Kutta method was applied with an integration step size of $1 \mathrm{~s}$ and the initial conditions as follows:

$$
t=0 \quad C_{\mathrm{NAs}}=C_{\mathrm{NAs} 0} \quad C_{\mathrm{O}_{3}}=0 \text { and } C_{\mathrm{O}_{3} \mathrm{G}}=0
$$

\subsection{EVALUATION OF THE DEVELOPED MODELS}

Data generated from the models were compared with experimental data obtained from different sets of experiments (with different inlet gaseous ozone concentration and different temperatures from the one used in the derivation of the model constants), to find out whether the developed models can predict the concentration profiles of NAs and ozone correctly. Results are shown in Figs. 6.5 and 6.6, respectively. Fig. 6.5 shows the variation of concentrations of NAs and 
ozone with ozonation time at different temperature, while Fig. 6.6 shows the variation of the same concentrations with ozonation time at different inlet gaseous ozone concentration.

It is observed from Figs 6.5(a) and 6.6(a) that the developed models predicted the concentration profiles of NAs in the reactor well. Also, the gaseous concentration of ozone leaving the reactor were well predicted at different reaction temperatures and inlet ozone gas concentrations as shown in Figs. 6.5(c) and 6.6(c), respectively. However, as shown in Figs. 6.5(b) and 6.6(b), although the equilibrium concentration of dissolved ozone was predicted fairly well by the model, the dissolved ozone concentration at the initial stage of the reaction (less than $15 \mathrm{~min}$ ) was not well predicted: the initial actual ozone consumption was higher than that predicted by the model. This deviation was possibly resulted from the inapplicability of the gas-liquid equilibrium conditions at the initial high rate stage of the reaction.

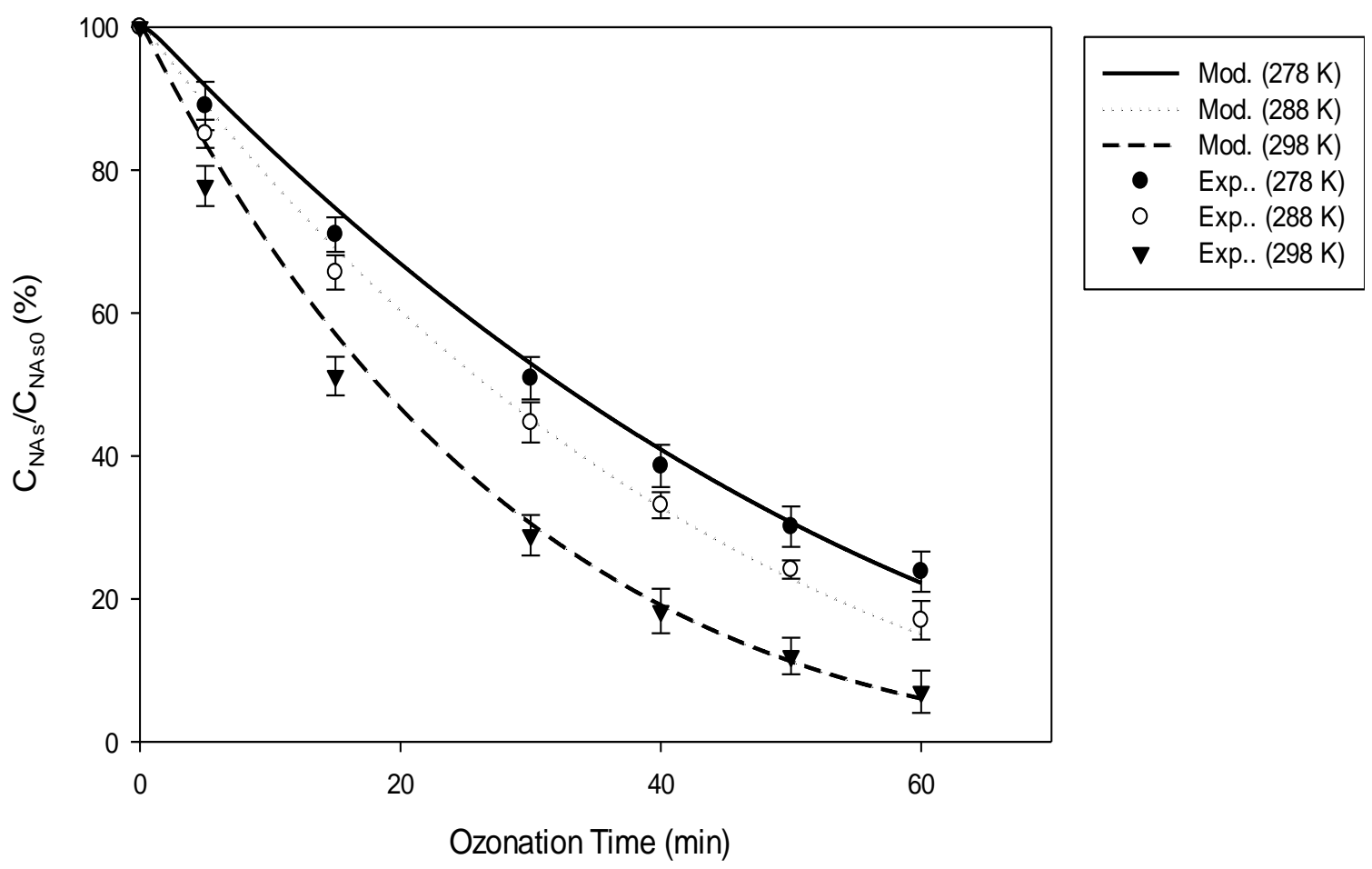

(a) 


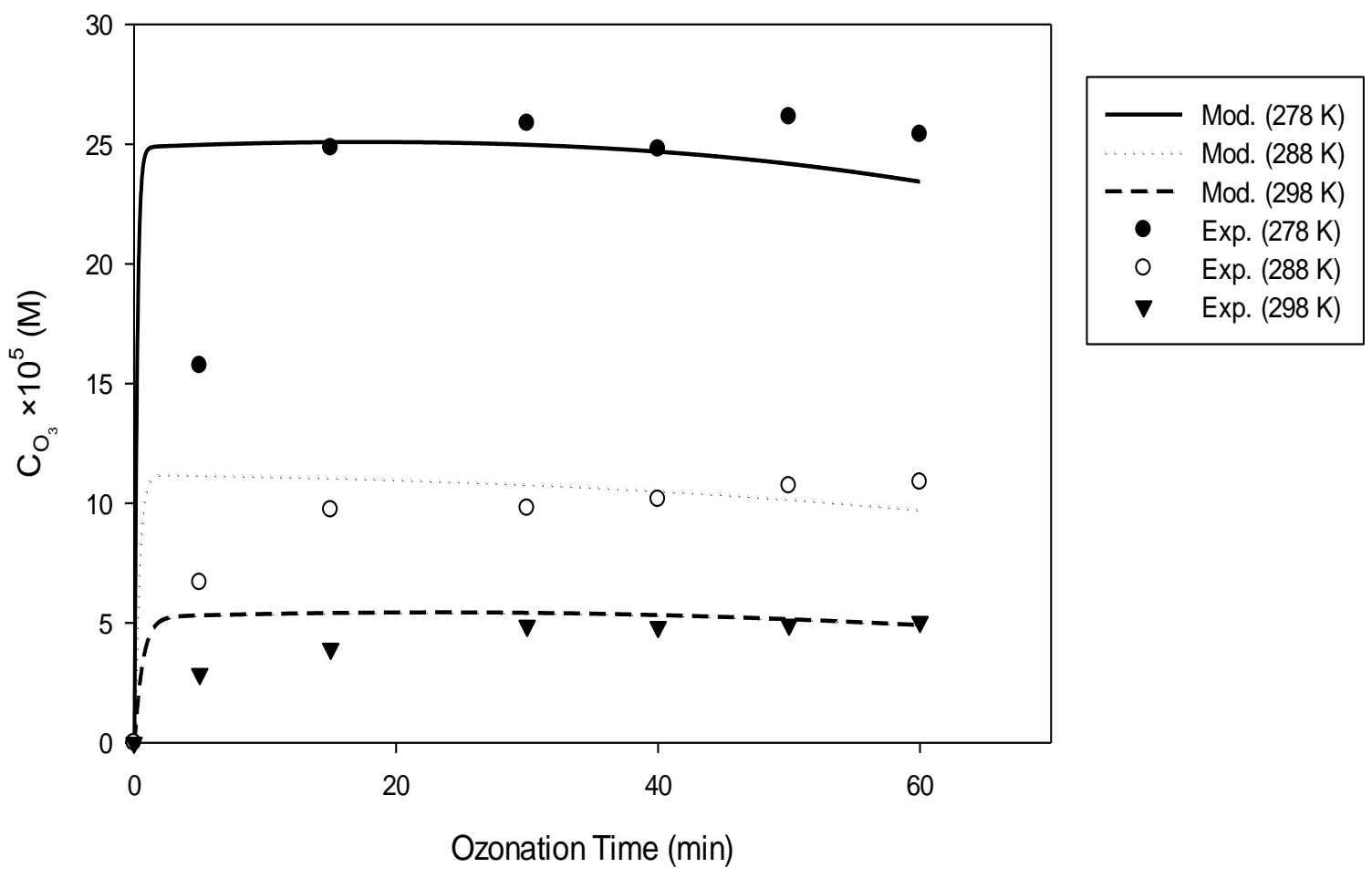

(b) 


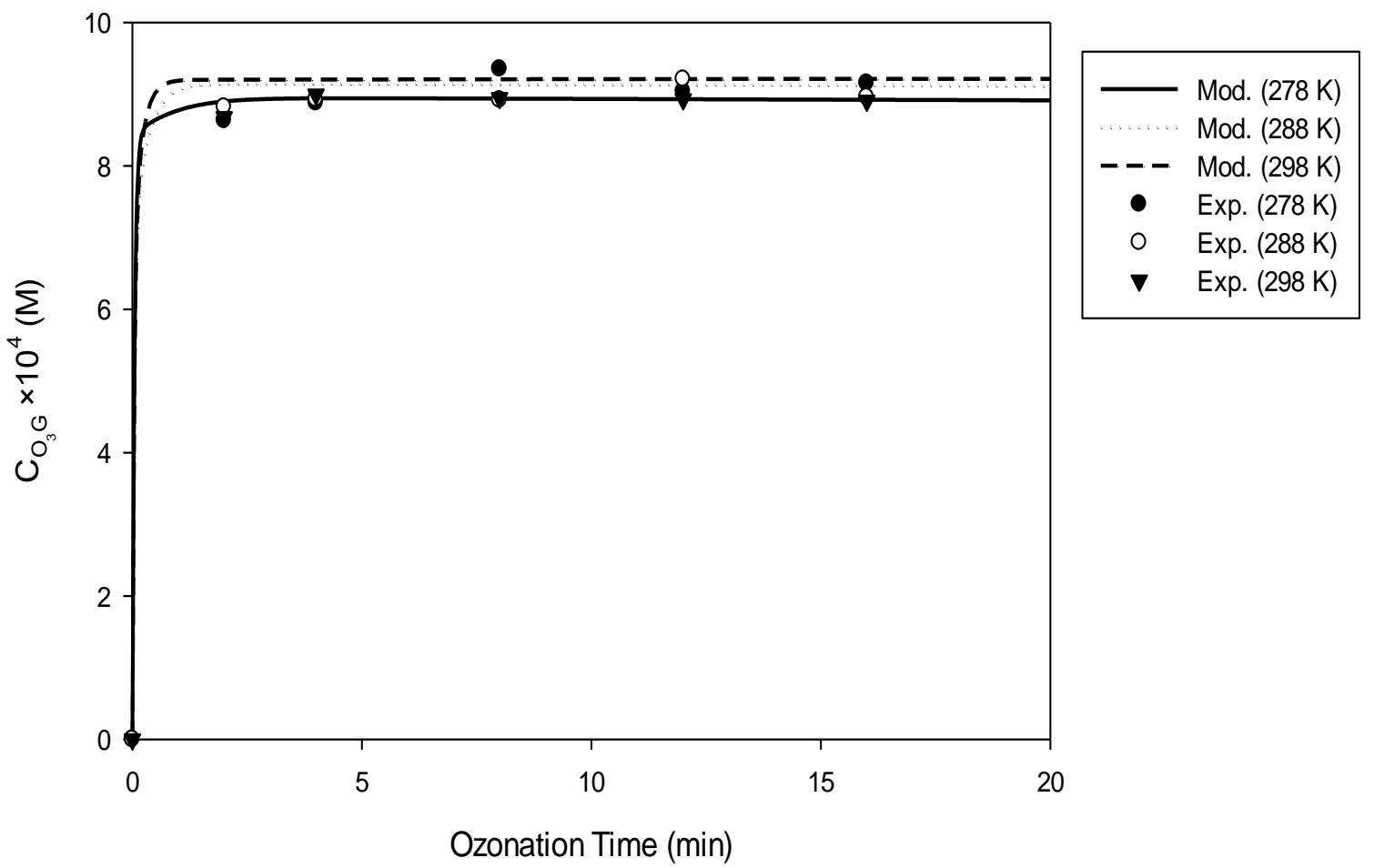

(c)

Figure 6.5 Validation of the mass transfer models developed at different temperature. (a) NAs, (b) dissolved ozone, and (c) ozone in the gas phase at the outlet of the reactor. Mod= values calculated by the model, $=$ values obtained experimentally. $C_{\mathrm{O} 3 \mathrm{Gi}}=9.3 \times 10^{-4} \mathrm{M}, C_{\mathrm{NAs} 0}=4.1 \times 10^{-4} \mathrm{M}, \mathrm{pH}=$ 8.5. 


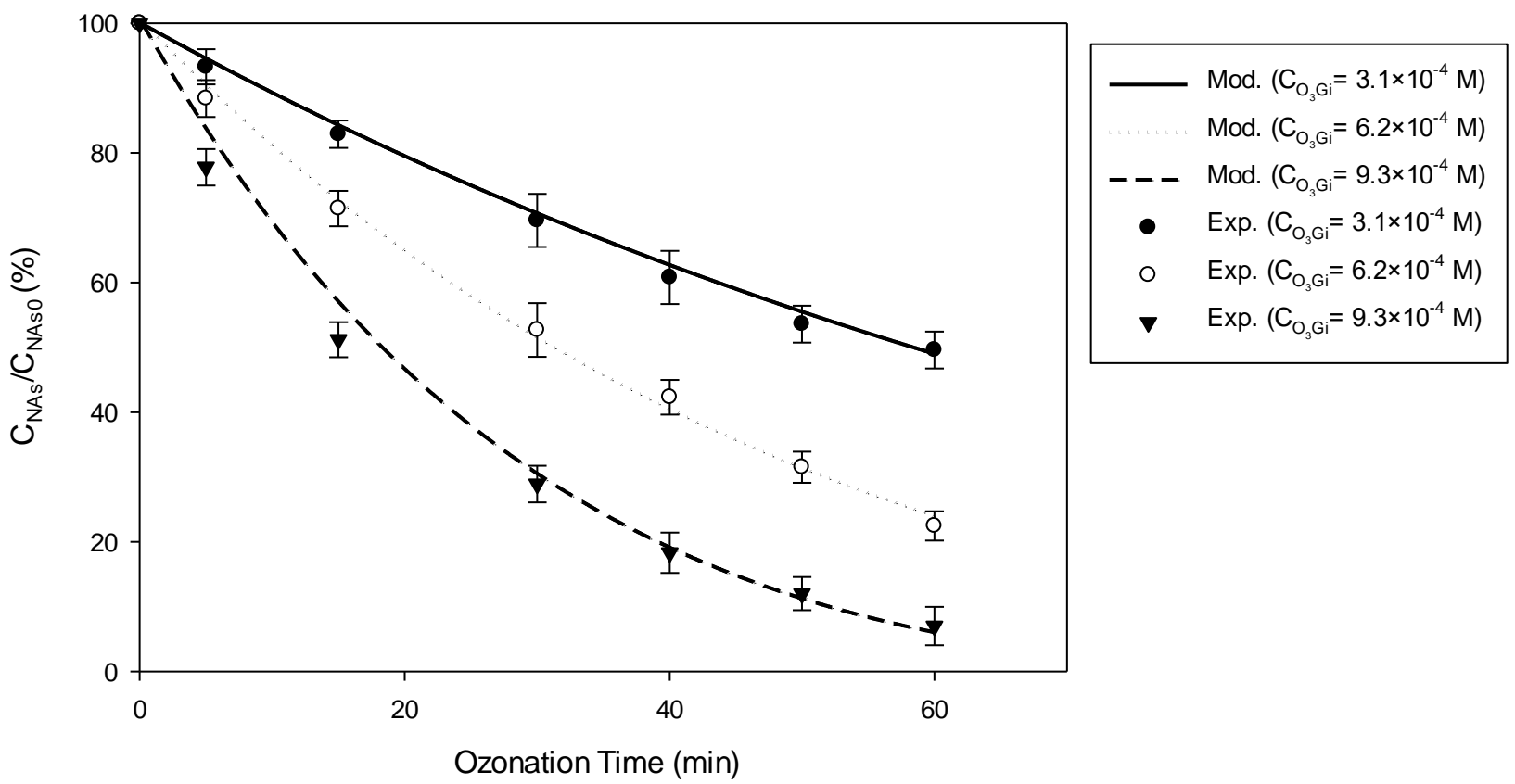

(a)

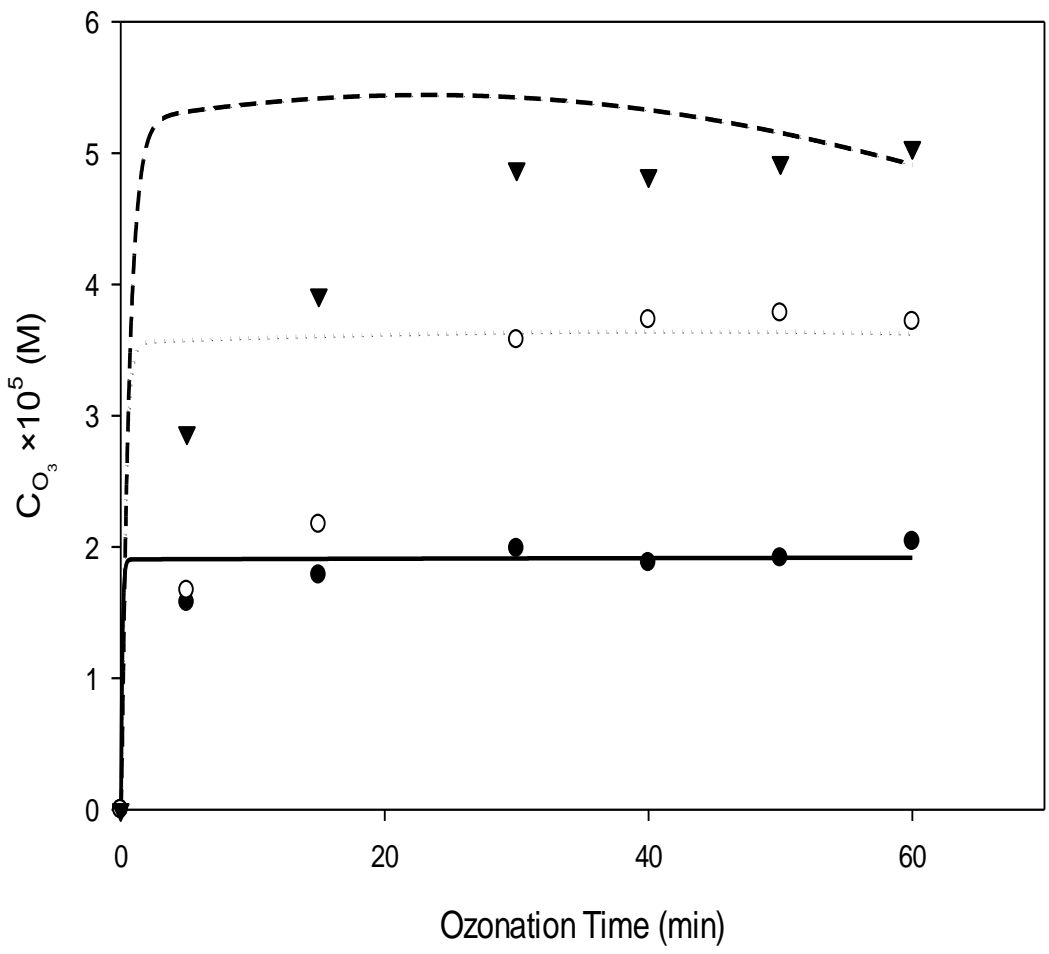

$$
\begin{aligned}
& \text { - Mod. }\left(\mathrm{C}_{\mathrm{O}_{3} \mathrm{Gi}}=3.1 \times 10^{-4} \mathrm{M}\right) \\
& \text { Mod. }\left(\mathrm{C}_{\mathrm{O}_{3} \mathrm{Gi}}=6.2 \times 10^{-4} \mathrm{M}\right) \\
& \text { - - Mod. }\left(\mathrm{C}_{\mathrm{O}_{3} \mathrm{Gi}}=9.3 \times 10^{-4} \mathrm{M}\right) \\
& \text { - Exp. }\left(\mathrm{C}_{\mathrm{O}_{3} \mathrm{Gi}}=3.1 \times 10^{-4} \mathrm{M}\right) \\
& \text { - Exp. }\left(\mathrm{C}_{\mathrm{O}_{3} \mathrm{Gi}}=6.2 \times 10^{-4} \mathrm{M}\right) \\
& \nabla \operatorname{Exp}\left(\mathrm{C}_{\mathrm{O}_{3} \mathrm{Gi}}=9.3 \times 10^{-4} \mathrm{M}\right)
\end{aligned}
$$

(b) 


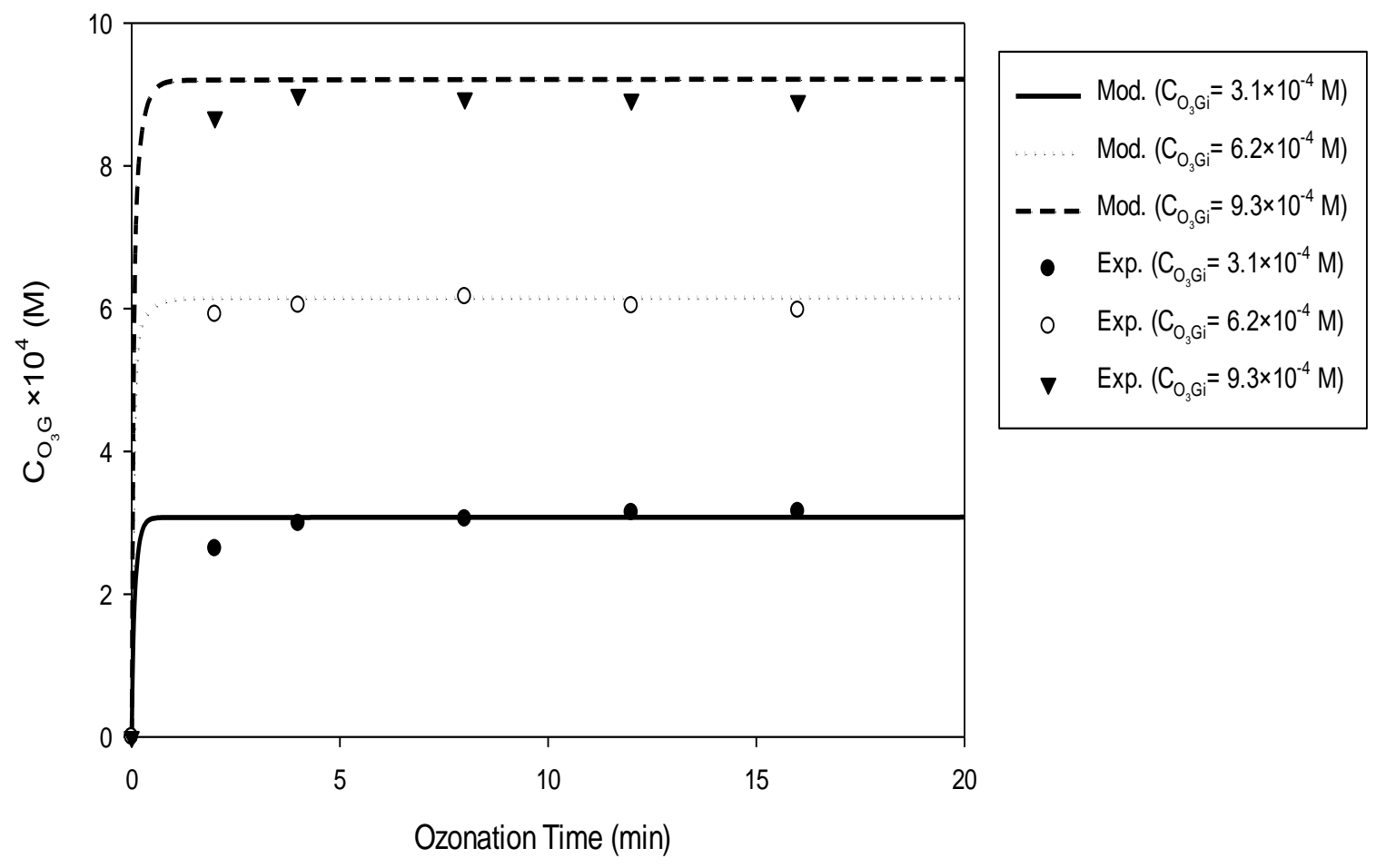

(c)

Figure 6.6 Validation of the mass transfer models developed at different inlet ozone concentrations. (a) NAs, (b) dissolved ozone, and (c) ozone in the gas phase at the outlet of the reactor. Mod. $=$ values calculated by the model, Exp. $=$ values obtained experimentally. $\mathrm{T}=25^{\circ} \mathrm{C}$, $C_{\mathrm{NAs} 0}=4.1 \times 10^{-4} \mathrm{M}, \mathrm{pH}=8.5$. 


\section{CHAPTER 7:}

\section{HETEROGENEOUS CATALYTIC OZONATION OF NAPHTHENIC ACIDS ${ }^{\S}$}

\subsection{EFFECT OF CATALYSTS}

The supported (impregnated) and unsupported catalysts were all tested for their effects on catalyzing the ozone removal of NAs. For impregnated catalysts, each of the metal oxides was studied at different weight percentages in the range of $0-10 \mathrm{wt}$. \%. This range was selected based on the results of previous researchers who used catalytic ozonation to treat organic pollutants other than NAs in wastewater (Yang et al., 2009; Li et al., 2010; Rosal et al., 2010). For example, Rosal et al. (2010) treated wastewater containing fenofibric acid with alumina supported manganese oxides corresponding to 10 wt. $\%$ of $\mathrm{MnO}_{2}$. On the other hand, although the use of lithium as a catalyst in wastewater treatment was not reported, it could promote the catalytic efficiency of some metal oxides such as $\mathrm{MgO}$ for the oxidative coupling of methane (Matsuura et al., 1989). Therefore, lithium oxide together with $\mathrm{MnO}_{2}$ was also tested for NAs removal. To examine and compare the effectiveness of the supported and unsupported catalysts, catalytic ozonation of the NAs solution was conducted in the presence of the same amount of $\left(1 \mathrm{~g} \mathrm{~L}^{-1}\right)$ of each of the catalysts, respectively.

Results of catalyst effect examination are shown in Figure 7.1. It is observed that removal of NAs by the non-catalyzed ozonation was the slowest. All catalysts tested enhanced the ozone removal of NAs. After 5 min ozonation, only $22.2 \%$ of NAs were removed by non-catalyzed ozonation, whereas $38.4 \sim 42.3 \%, 45.4 \%$ and $62.9 \%$ of NAs removal were achieved when the impregnated catalysts, alumina and AC were used, respectively. Also, after 15 min of ozonation, $85.7 \%$ of the NAs were removed by the AC catalyzed ozonation while only $48.8 \%$ were removed by the non-catalyzed one. Obviously, AC was very effective for the NAs removal.

As already reported, the catalytic effect of AC could be due to its capability in promoting the generation of hydroxyl radicals (Jans and Hoigné, 1998) and the hydroxyl radicals generated actually are stronger oxidant than ozone itself (Hoigné and Bader, 1983). That means AC in ozone

$\S$ Al jibouri, A.K.H., Wu J, Upreti S.R. (2016) Heterogeneous Catalytic ozonation of Naphthenic Acids. Sci. Total Environ. Submitted. 
containing aqueous solutions could initiate a radical-type chain reaction that then proceeded in the aqueous phase and accelerated the transformation of $\mathrm{O}_{3}$ into secondary radicals, such as hydroxyl radicals, resulted in an Advanced Oxidation Process (AOP) which was similar to an $\mathrm{O}_{3}$-based AOP involving application of $\mathrm{H}_{2} \mathrm{O}_{2}$ or UV irradiation (Jans and Hoigné, 1998). Based on the results shown in Fig.7.1, AC was investigated further for its performance as a catalyst.

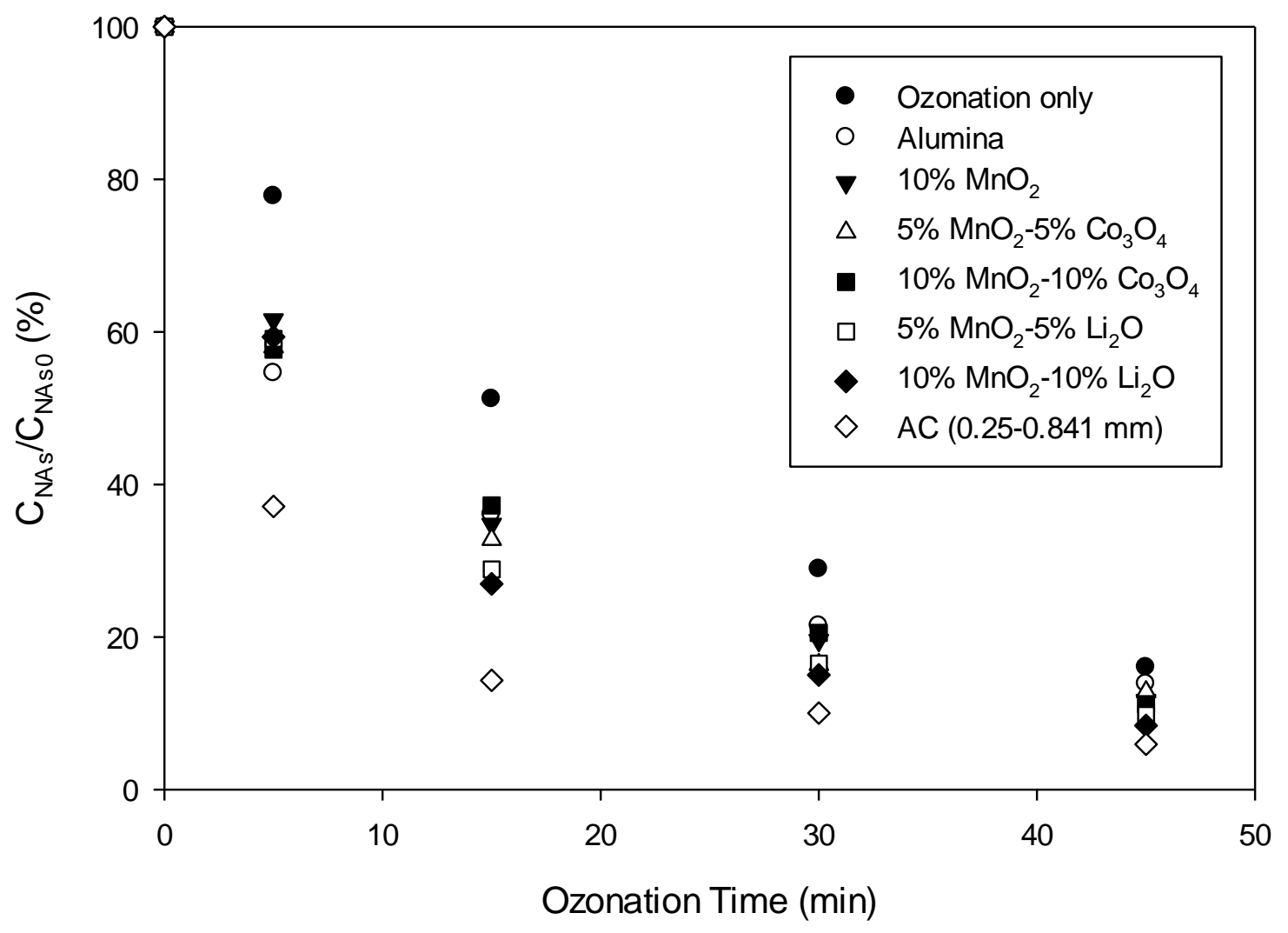

Figure 7.1 Effect of catalysts on the removal of NAs. $\mathrm{T}=25^{\circ} \mathrm{C} ; \mathrm{pH}=8.5 ; \mathrm{C}_{\mathrm{NAs} 0}=4.1 \times 10^{-4} \mathrm{M}$, $\mathrm{C}_{03 \mathrm{Gi}}=9.3 \times 10^{-4} \mathrm{M}$, gas flow rate $=1 \mathrm{~L} \mathrm{~min}^{-1}$, catalyst dosage $=1 \mathrm{~g} \mathrm{~L}^{-1}$.

\subsection{CATALYTIC OZONATION USING ACTIVATED CARBON}

\subsubsection{The adsorbability of AC}

It is known that $\mathrm{AC}$ is also an adsorbent. Therefore, it was also possible that the increased removal of NAs by AC catalyzed ozoantion may result partially from AC's absorption capability. 
Experiments were conducted to examine the extent of AC absorption of NAs. Figure 7.2 shows the adsorption and catalytic ozonation results of $\mathrm{AC}$ in the size range of $0.25-0.841 \mathrm{~mm}$. The results of NAs removal by non-catalyzed ozonation are also shown in this figure for comparison. It is observed that after 5 and $15 \mathrm{~min}$, the removals by adsorption were $7.4 \%$ and $10.1 \%$, respectively, while the removals by AC catalyzed ozonation were $62.9 \%$ and $85.7 \%$. Subtracting from $62.9 \%$ and $85.7 \%$ the removals by non-catalytic ozonation $(22.2 \%$ and $48.8 \%)$ and that by adsorption, the catalytic enhancement for the removals of NAs were $33.3 \%$ and $26.8 \%$ after 5 and 15 min ozonation, respectively. Therefore, in addition to be an adsorbent, AC did act as a catalyst. It is also observed from Figure 7.2 that to remove about $85 \%$ of NAs, the AC catalyzed ozonation only needed $15 \mathrm{~min}$ whereas it took the non-catalyzed ozonation $45 \mathrm{~min}$. It is confirmed that AC particles in the size range of $0.25-2.38 \mathrm{~mm}$ are excellent catalysts and significant savings could be achieved when used in OSPW treatment.

Similar tests on adsorption and catalytic ozonation of NAs were also conducted using AC particles in the size ranges of $0.841-2.38 \mathrm{~mm}$ and $0.037-0.149 \mathrm{~mm}$ (data not shown). Results confirmed that all AC particles tested were both adsorbents and catalysts.

\subsubsection{Effect of AC particle size}

To examine the effect of AC particle size on the removal of NAs, three size ranges of AC were tested: $0.037-0.149 \mathrm{~mm}, 0.25-0.841 \mathrm{~mm}$ and $0.841-2.38 \mathrm{~mm}$. Figure 7.3 shows the results. The results of non-catalyzed ozonation are also shown in Figure 7.3 for comparison. It is observed from Figure 7.3 that in the presence of $1 \mathrm{~g} \mathrm{~L}^{-1}$ of $\mathrm{AC}$, all catalytic ozonation enhanced the removal of NAs, and the smaller the particle size, the better removal efficiency. However, the removal efficiencies of the three size ranges of $\mathrm{AC}$ were not significantly different, especially between the two size ranges of $0.25-0.841 \mathrm{~mm}$ to $0.037-0.149 \mathrm{~mm}$. When the particle sizes decreased from $0.25-0.841 \mathrm{~mm}$ to $0.037-0.149 \mathrm{~mm}$, the maximum increase in removal during the $45 \mathrm{~min}$ ozonation was only $4.3 \%$. The increase in removal efficiency should be due to the increase in surface areas of AC particles when their size were getting smaller. The increase in surface area resulted in more active sites for catalysis and the adsorption area increased accordingly. The fact that the improvement in the removal efficiency of NAs was negligible between AC sizes of 0.25-0.841 $\mathrm{mm}$ and $0.037-0.149 \mathrm{~mm}$ indicates that the surface areas of the former were already enough for 
the given NAs solution. Since the larger particles were easier to be separated for reuse, the AC particles in the size range of $0.25-0.841 \mathrm{~mm}$ should be more practical in use.

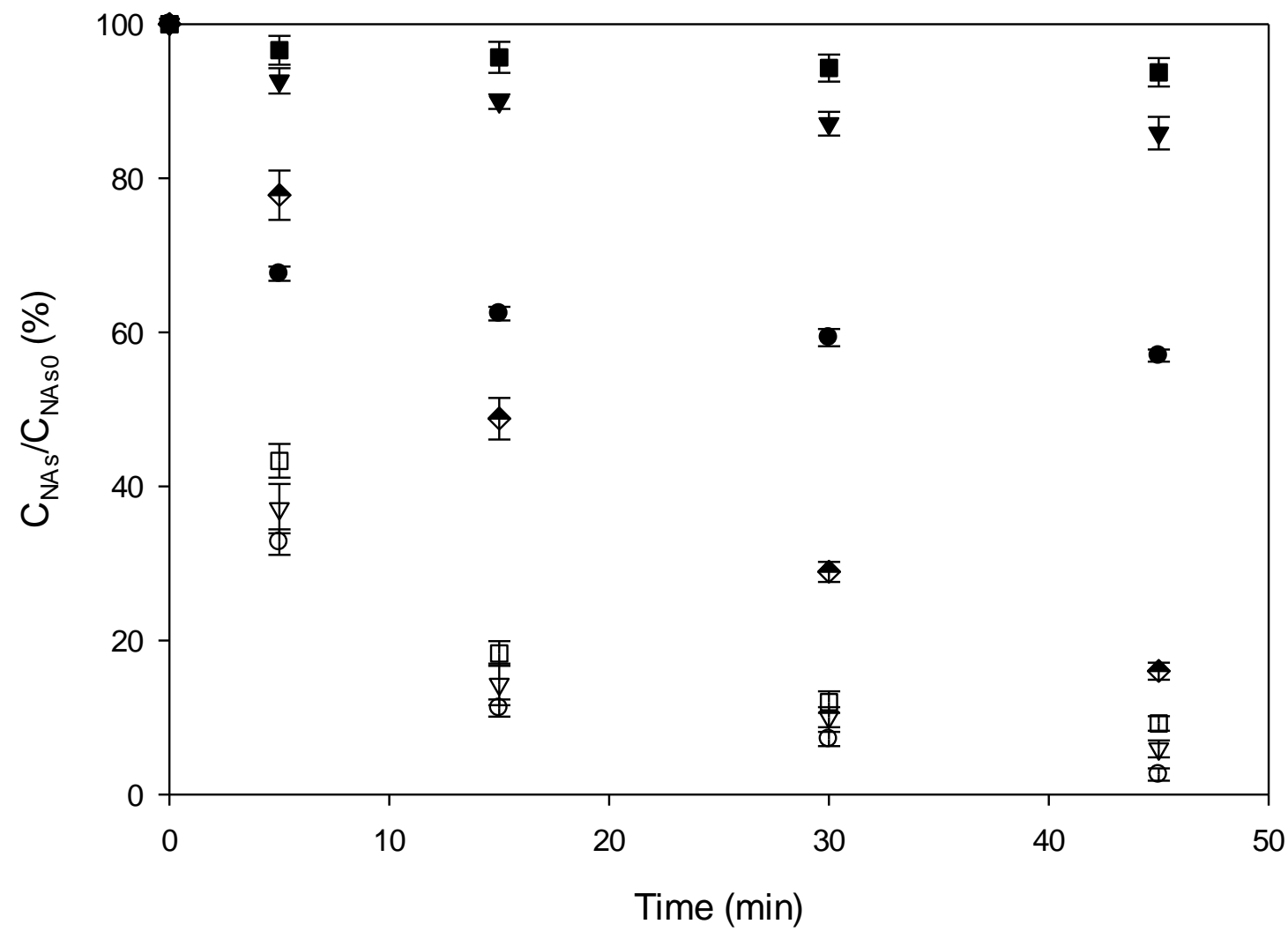

Figure 7.2 Removal of NAs by adsorption (Ads.), ozonation and catalytic ozonation (Cat.) using AC $(0.25-0.841 \mathrm{~mm}) . \mathrm{T}=25^{\circ} \mathrm{C} ; \mathrm{pH}=8.5 ; C_{\mathrm{NAs} 0}=4.1 \times 10^{-4} \mathrm{M}, C_{\mathrm{O} 3 \mathrm{Gi}}=9.3 \times 10^{-4} \mathrm{M}$, gas flow rate $=1 \mathrm{~L} \mathrm{~min}^{-1}, \mathrm{AC}$ dosage $=1 \mathrm{~g} \mathrm{~L}^{-1}$. 


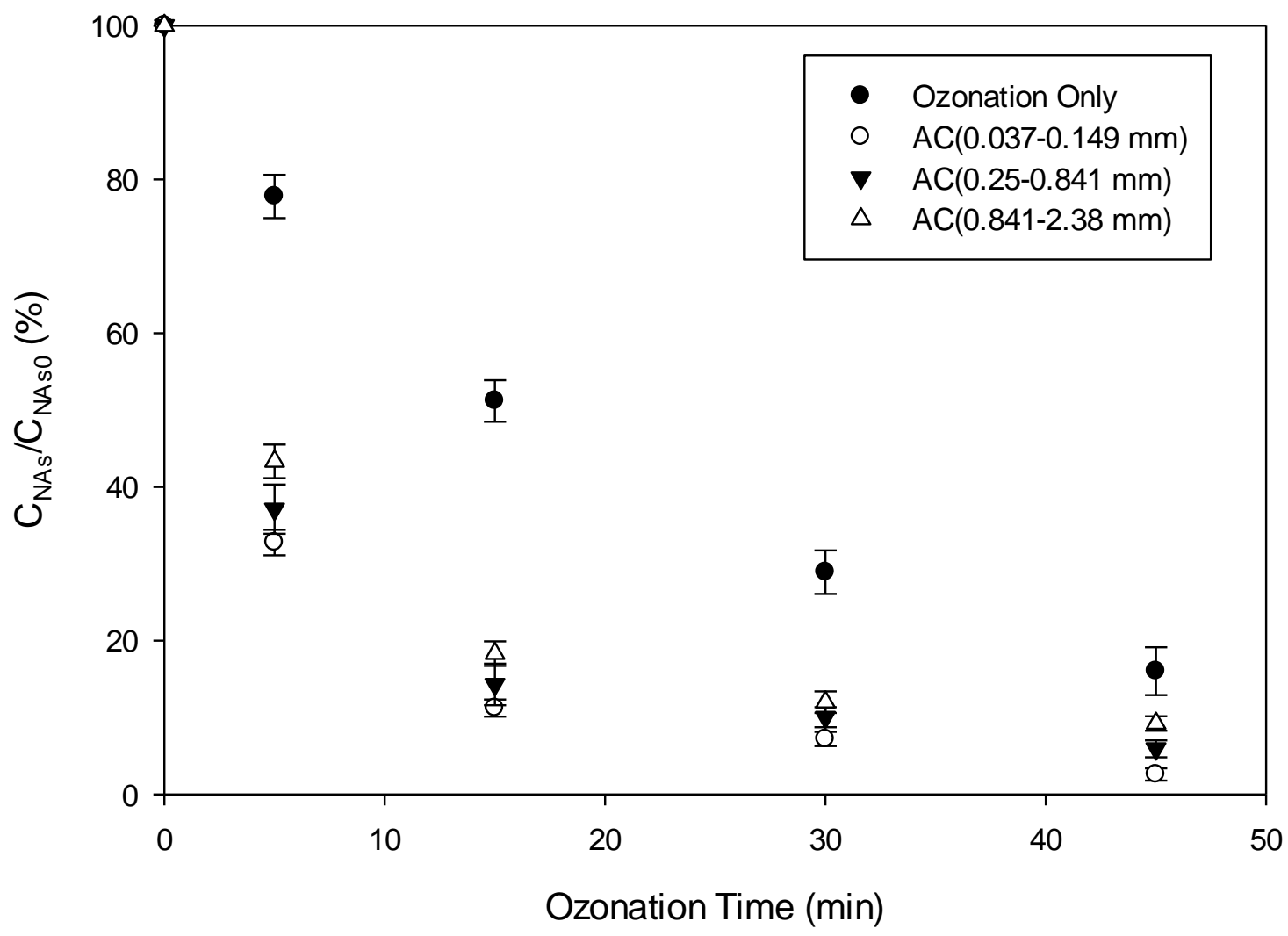

Figure 7.3 Effect of AC particle sizes on the removal of NAs. $\mathrm{T}=25^{\circ} \mathrm{C} ; \mathrm{pH}=8.5 ; C_{\mathrm{NAs} 0}=$ $4.1 \times 10^{-4} \mathrm{M}, C_{\mathrm{O} 3 \mathrm{Gi}}=9.3 \times 10^{-4} \mathrm{M}$, gas flow rate $=1 \mathrm{~L} \mathrm{~min}^{-1}, \mathrm{AC}$ dosage $=1 \mathrm{~g} \mathrm{~L}^{-1}$.

\subsubsection{Effect of AC dosage}

Further experiments were conducted to explore the effect of $\mathrm{AC}$ dosage. Considering that AC sizes of 0.25-0.841 mm provided satisfactory removal efficiency, and further improvements in NAs removal beyond this size range was insignificant, $\mathrm{AC}$ particles of $0.25-0.841 \mathrm{~mm}$ were selected for the experiments. Ozonation was conducted in the presence of different amounts of AC and the results are shown in Figure 7.4. It is observed from Figure 7.4 that the removal of NAs increased significantly with AC dosage until the concentration of $\mathrm{AC}$ reached $1 \mathrm{~g} \mathrm{~L}^{-1}$. Further increase in $\mathrm{AC}$ concentration beyond this point slightly improved the efficiency of catalysis. Therefore, $1 \mathrm{~g} \mathrm{~L}^{-1}$ was considered as the optimum dosage of $\mathrm{AC}$ for the investigated system and was used for the subsequent experiments. 


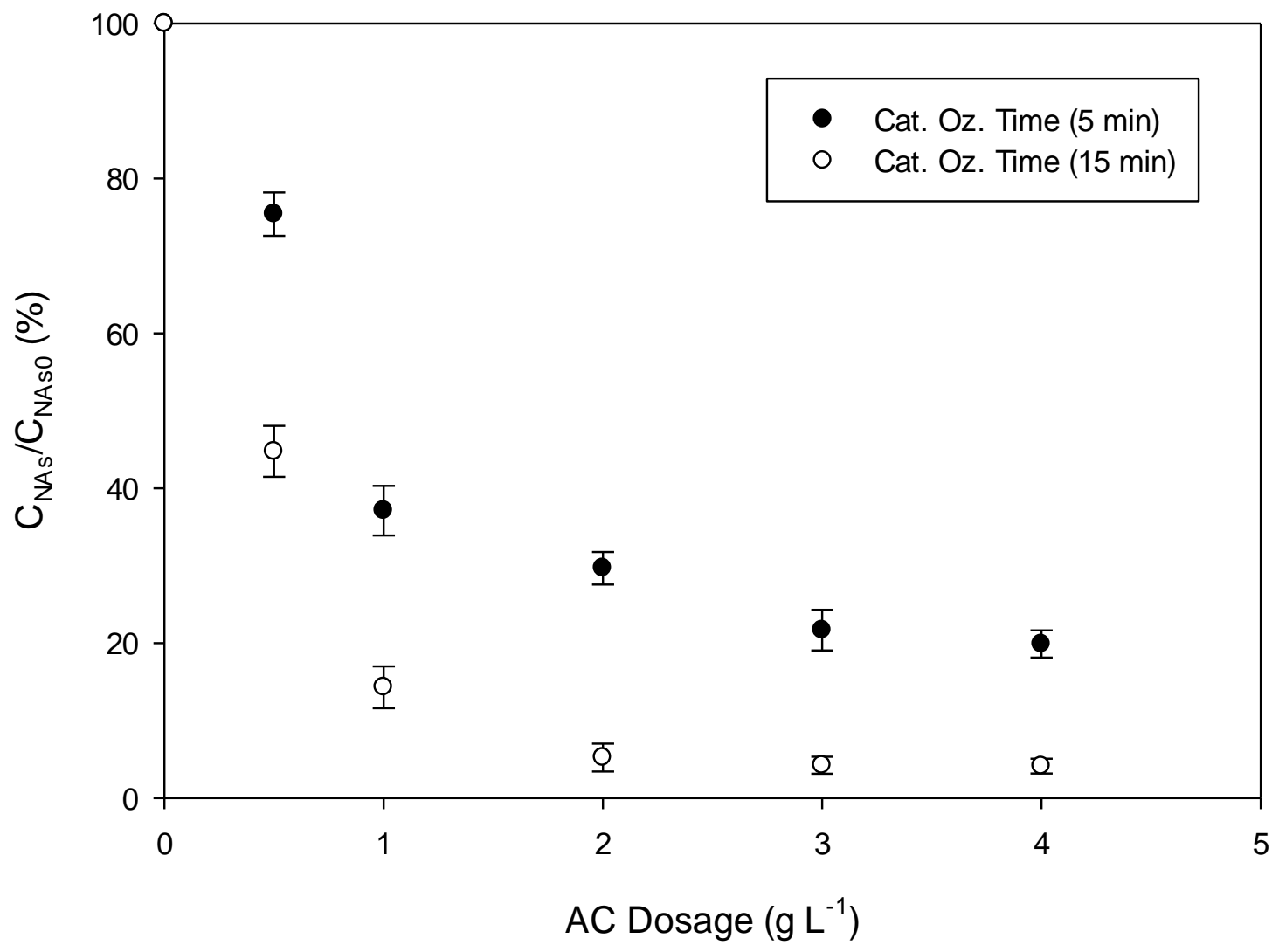

Figure 7.4 Effect of AC dosage on the removal of NAs at 5 and 15 min of catalytic ozonation time. $\mathrm{T}=25{ }^{\circ} \mathrm{C} ; \mathrm{pH}=8.5 ; C_{\mathrm{NAs} 0}=4.1 \times 10^{-4} \mathrm{M} ; C_{\mathrm{O} 3 \mathrm{Gi}}=9.3 \times 10^{-4} \mathrm{M}$; gas flow rate $=1 \mathrm{~L} \mathrm{~min}^{-1} ; \mathrm{AC} \mathrm{P}$. size $=0.25-0.841 \mathrm{~mm}$.

\subsubsection{Detoxification and COD removal}

The toxicity of the NAs solution was also examined before and after ozonation and the results are shown in Figure 7.5. Toxicity reduction by AC catalyzed ozonation was much more efficient than by its non-catalyzed counterpart. As shown in Figure 7.5, after 5 min ozonation, the toxicity reduction of the samples by the non-catalytic ozonation was only13.3\%, however, when $\mathrm{AC}$ particles of $0.037-0.149 \mathrm{~mm}$ were used as catalysts, the toxicity reduction was $57.8 \%$, which was more than four times of that achieved by the non-catalytic ozonation. Also, after $45 \mathrm{~min}$ ozonaton, the toxicity was reduced to $1.2 \%, 3.6 \%$ and $7.2 \%$ by AC catalyzed ozonation with 
particles in the size ranges of $0.037-0.149 \mathrm{~mm}, 0.25-0.841 \mathrm{~mm}$ and $0.841-2.38 \mathrm{~mm}$, respectively, while with the same length of non-catalytic ozonation, the toxicity remaining of the samples was 22.9\%. Obviously, ozone detoxification was enhanced by AC effectively. Moreover, it is observed from Figure 7.5 that the same toxicity removal achieved by 45 min non-catalytic ozonation could be achieved by AC catalyzed ozonation in or less than 15 min. The fact that the use of the AC catalysts reduced the ozonation time to $1 / 3$ of the original indicates that significant savings in operating costs could be obtained by AC catalyzed ozonation.

The chemical oxygen demand (COD) of the samples was also examined before and after ozonation in the presence and absence of AC catalysts, respectively. Figure 7.6 shows the results. Both catalyzed and non-catalyzed ozonation removed sample COD, however, the COD removal was enhanced by the AC catalyzed ozonation. For example, after 5 min ozonation, the COD removal by catalyzed ozonation was over 4 times of that by its non-catalyzed counterpart: 55.4 $61.4 \%$ of COD were removed by the AC-catalyzed ozonation using AC particles in the size ranges of 0.841-2.38 mm and 0.037-0.149 mm, respectively, whereas only 14.4\% COD removal was achieved by the non-catalyzed ozonation. On the other hand, comparing the COD results of Figure 7.6 with the toxicity results of Figure 7.5, it is reasonable to assume that although there were still about 18.5-23.3\% of COD remaining after $45 \mathrm{~min}$ AC catalyzed ozonation, most of the carboxylic acids in NAs had been oxidized to nontoxic compounds. 


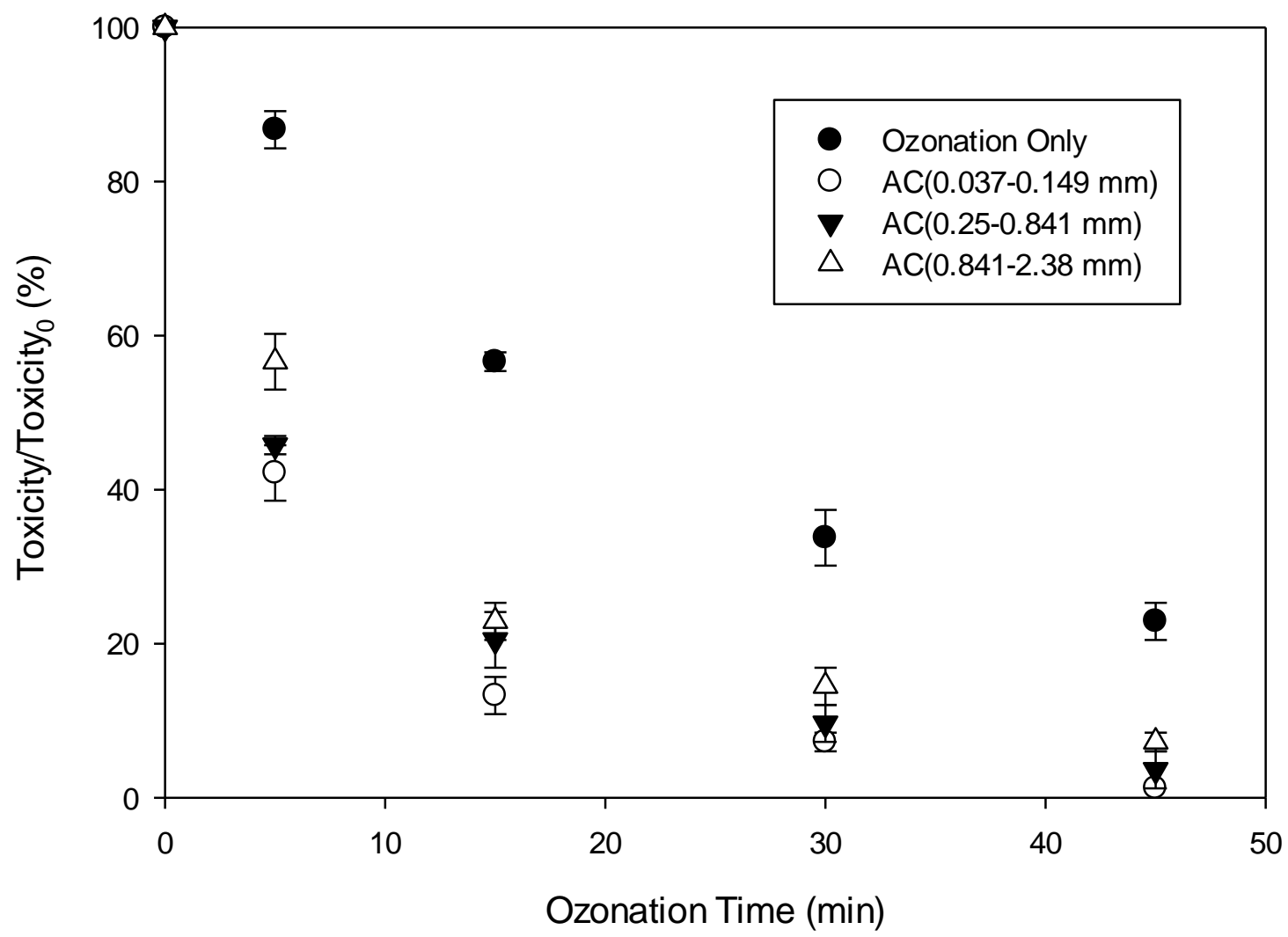

Figure 7.5 Toxicity removal in ozonation and catalytic ozonation of NAs processes. $\mathrm{T}=25^{\circ} \mathrm{C} ; \mathrm{pH}$ $=8.5 ; C_{\mathrm{NAs} 0}=4.1 \times 10^{-4} \mathrm{M} ; C_{\mathrm{O} 3 \mathrm{Gi}}=9.3 \times 10^{-4} \mathrm{M} ;$ gas flow rate $=1 \mathrm{~L} \mathrm{~min}^{-1} ; \mathrm{AC}$ dosage $=1 \mathrm{~g} \mathrm{~L}^{-1}$, Toxicity $_{0}=83 \%$ loss of light. 


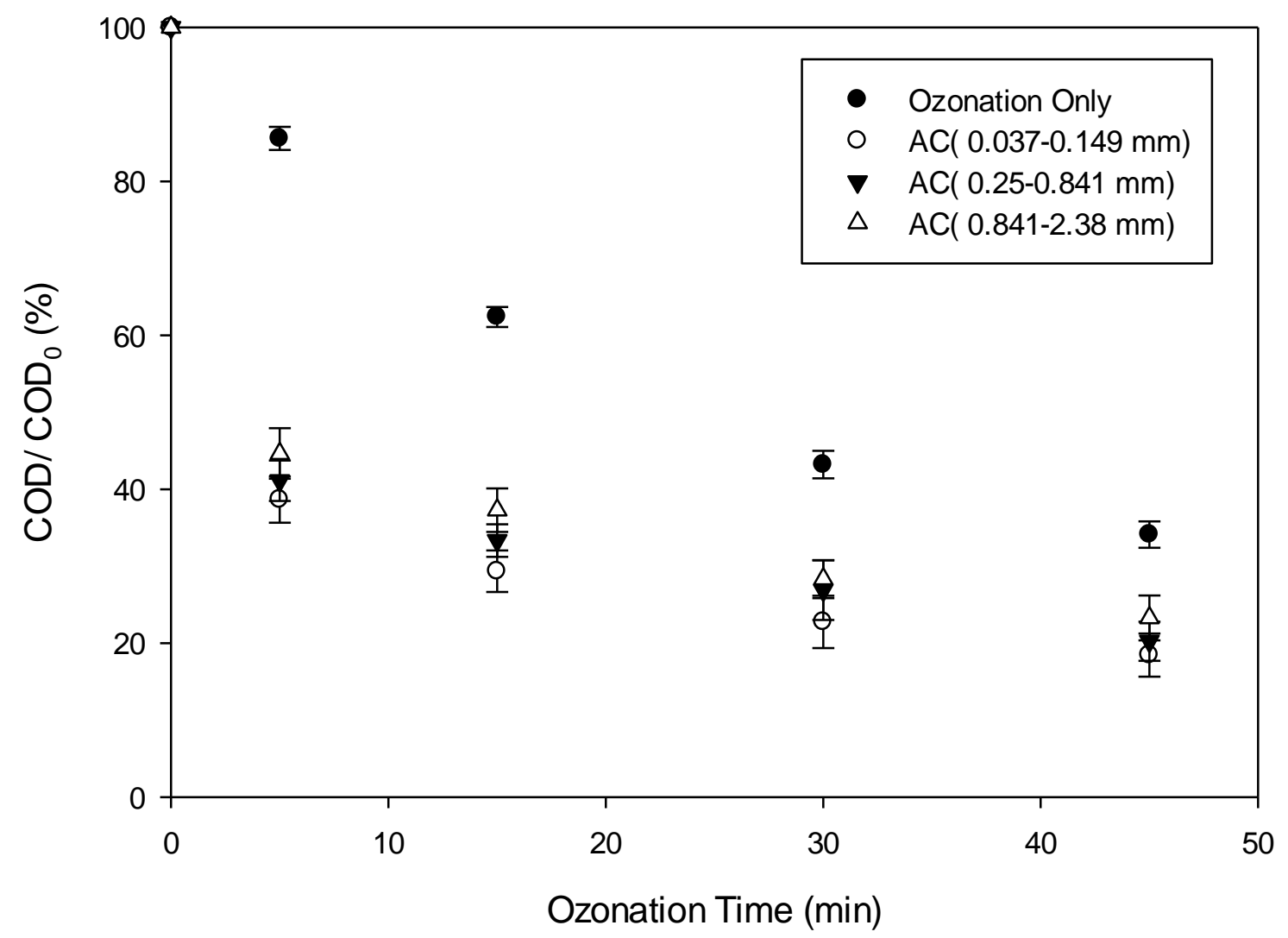

Figure 7.6 COD removal in ozonation and catalytic ozonation of NAs processes. $\mathrm{T}=25^{\circ} \mathrm{C} ; \mathrm{pH}=$ 8.5; $\mathrm{C}_{\mathrm{NAs} 0}=4.1 \times 10^{-4} \mathrm{M} ; \mathrm{C}_{\mathrm{O} 3 \mathrm{Gi}}=9.3 \times 10^{-4} \mathrm{M} ;$ gas flow rate $=1 \mathrm{~L} \mathrm{~min}^{-1} ; \mathrm{AC}$ dosage $=1 \mathrm{~g} \mathrm{~L}^{-1}$.

\subsubsection{The increase in biodegradability}

It is well known that the BOD/COD ratio is a measure of the biodegradability of the samples, the larger this ratio, the more biodegradable of the samples. This ratio was examined for the NAs solution during ozonation in the presence and absence of AC catalysts. The results are shown in Figure 7.7. It is observed from Figure 7.7 that the biodegradability (the dimensionless ratio of $\mathrm{BOD} / \mathrm{COD}$ ) of the samples was significantly enhanced by $\mathrm{AC}$ catalyzed ozonation. For example, after being treated by catalytic ozonation using AC particles of 0.037-0.149 mm, the $\mathrm{BOD} / \mathrm{COD}$ ratio of the samples increased to more than five times of that treated by non-catalytic ozonation. The results indicate that much more bio-recalcitrant NAs has been converted to 
biodegradable compounds by the catalytic ozonation than by its non-catalytic counterpart.

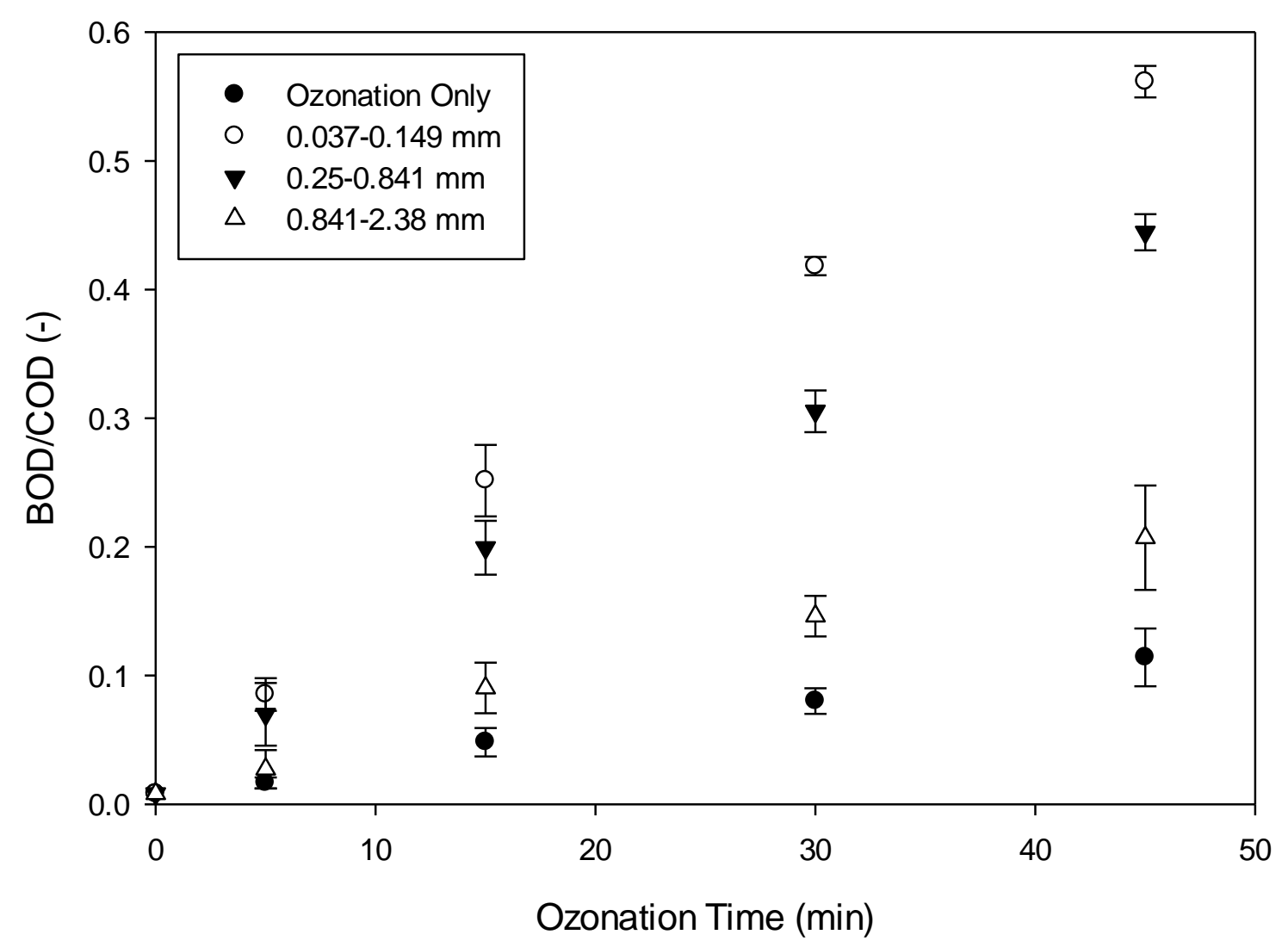

Figure 7.7 Degradability (BOD/COD ratio) in ozonation and catalytic ozonation of NAs processes. $\mathrm{T}=25^{\circ} \mathrm{C} ; \mathrm{pH}=8.5 ; \mathrm{C}_{\mathrm{NAs} 0}=4.1 \times 10^{-4} \mathrm{M} ; \mathrm{C}_{\mathrm{O} 3 \mathrm{Gi}}=9.3 \times 10^{-4} \mathrm{M} ;$ gas flow rate $=1 \mathrm{~L} \mathrm{~min}^{-1} ;$ AC dosage $=1 \mathrm{~g} \mathrm{~L}^{-1}$. 


\section{CHAPTER 8:}

\section{ADVANCED OXIDATION OF NAPHTHENIC ACIDS IN WATER BY OZONE AND HYDROGEN PEROXIDE}

\subsection{INFLUENCE OF OPERATING PARAMETERS ON NAPHTHENIC ACIDS REMOVAL}

\subsubsection{Temperature}

The effect of temperature on the removal of NAs in the presence of $\mathrm{H}_{2} \mathrm{O}_{2}$ is shown in Fig. 8.1. As observed, the effect of this variable was positive from 5 to $25^{\circ} \mathrm{C}$. This anomalous result, however, was affected by $\mathrm{O}_{3}$ solubility which decreases with the increasing temperature. Thus, an increase of temperature should yield an increase in the rate constant of the chemical reaction rate but also a decrease of the $\mathrm{O}_{3}$ solubility. Nevertheless, the negative effect of temperature on the dissolved ozone concentration was not so significant because of the low concentration of dissolved $\mathrm{O}_{3}$, which indicates that the reaction is occurring in the diffusional regime (Charpentier, 1981; Danckwerts, 1970).

\subsubsection{Initial Concentration of Hydrogen Peroxide}

In Fig. 8.2, the influence of initial $\mathrm{H}_{2} \mathrm{O}_{2}$ concentration on the rate of NAs degradation during advanced oxidation process is shown. Increasing $\mathrm{H}_{2} \mathrm{O}_{2}$ concentration to $10^{-3} \mathrm{M}$ led to an increase of the oxidation rate of NAs. It can be seen that above this concentration $\left(10^{-3} \mathrm{M}\right) \mathrm{of}_{2} \mathrm{O}_{2}$, the removal rate of NAs starts to decrease. In order to understand this behavior, it was necessary to determine the kinetic regime of the $\mathrm{O}_{3} / \mathrm{H}_{2} \mathrm{O}_{2}$ process.

Staehelin and Hoigné (1982) found that in homogeneous systems, a second-order kinetic reaction occurs for the $\mathrm{O}_{3}$ decomposition (first order with respect to $\mathrm{O}_{3}$ and $\mathrm{H}_{2} \mathrm{O}_{2}$ ) with the particular characteristic that only the ionic form of $\mathrm{H}_{2} \mathrm{O}_{2}$ reacted with $\mathrm{O}_{3}$. The stoichiometric equation is (Staehelin et al., 1984):

$$
\mathrm{O}_{3}+\mathrm{HO}_{2}^{-} \stackrel{k_{i 1}=2.8 \times 10^{6} M^{-1} \mathrm{~S}^{-1}}{\longrightarrow} \mathrm{O}_{3}^{-\bullet}+\mathrm{HO}_{2}^{\bullet}
$$

This reaction constitutes the initiation step of a radical chain mechanism that eventually leads to the formation of $\mathrm{HO}^{\bullet}$ (Tomiyasu et al., 1985). The kinetic regime of $\mathrm{O}_{3}$ absorption in water containing $\mathrm{H}_{2} \mathrm{O}_{2}$ is defined by its corresponding Hatta number $(\mathrm{Ha})$ which in this case is (Charpentier, 1981): 


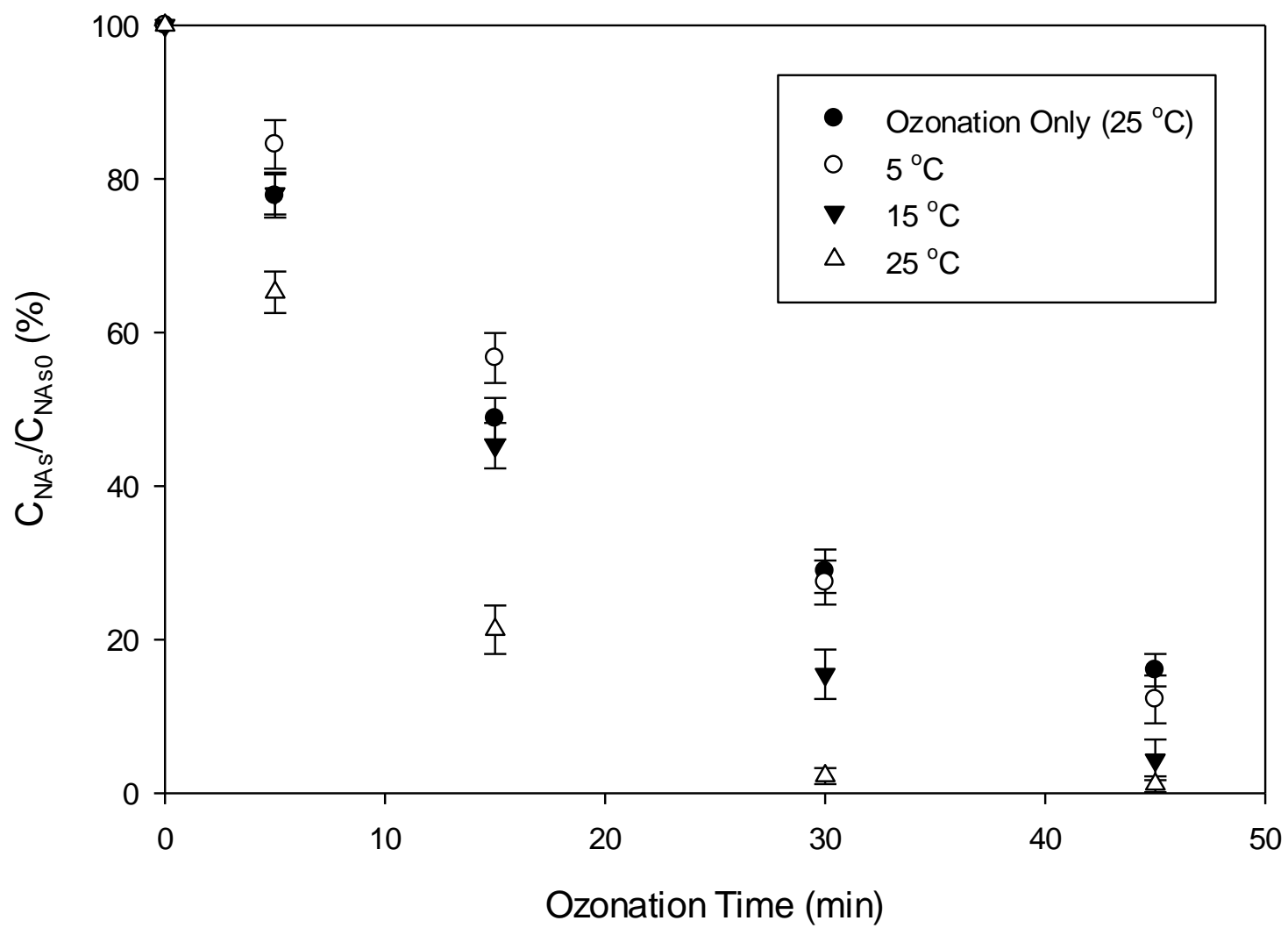

Figure 8.1 Effect of temperature on the removal of NAs. $\mathrm{pH}=8.5 ; C_{\mathrm{O} 3 \mathrm{Gi}}=9.3 \times 10^{-4} \mathrm{M} ; C_{\mathrm{H} 2 \mathrm{O} 2}=$ $10^{-3} \mathrm{M} ; C_{\mathrm{NAs} 0}=10^{-3} \mathrm{M}$.

$H a=\sqrt{\frac{k_{i 1} 10^{(p H-11.8)} D_{\mathrm{O}_{3}} C_{\mathrm{H}_{2} \mathrm{O}_{2}}}{K_{\mathrm{L}}^{2}}}$

where $D_{\mathrm{O}_{3}}$ and $K_{\mathrm{L}}$ are the diffusivity of dissolved ozone and the individual liquid phase mass transfer coefficient, respectively. As observed from Equation (8.2), $\mathrm{Ha}$ depends on both $\mathrm{pH}$ and concentration of hydrogen peroxide. Therefore, at the $\mathrm{pH}$ of 8.5 and for $K_{\mathrm{L}}=2 \times 10^{-}$ ${ }^{4} \mathrm{~m} \mathrm{~s}^{-1}$, an appropriate value for gas-liquid contactors and $D_{\mathrm{O}_{3}}$ to be $1.3 \times 10^{-9} \mathrm{~m}^{2} \mathrm{~s}^{-1}$ (Beltrán, 1997), for total concentrations of $C_{\mathrm{H}_{2} \mathrm{O}_{2}}$ equal to $10^{-4}, 10^{-3}$ and $10^{-2} \mathrm{M}, \mathrm{Ha}$ is $0.067,0.21$ and 0.67, respectively. This means that as the kinetic regime goes from slow to fast, the 


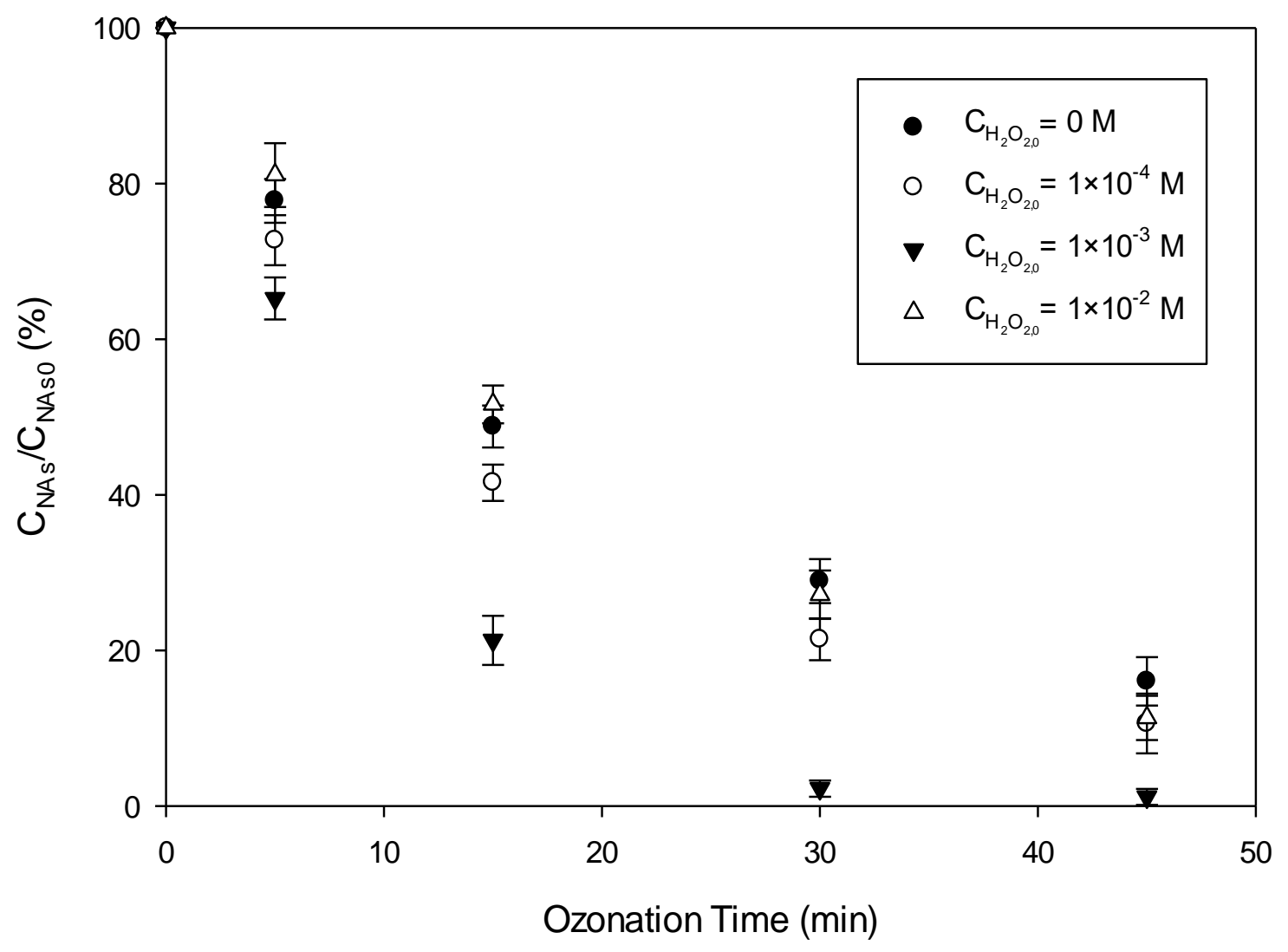

Figure 8.2 Effect of initial hydrogen peroxide concentration on the removal of NAs. $\mathrm{T}=25^{\circ} \mathrm{C} ; \mathrm{pH}=$ $8.5 ; C_{\mathrm{O} 3 \mathrm{Gi}}=9.3 \times 10^{-4} \mathrm{M} ; C_{\mathrm{NAs} 0}=4.1 \times 10^{-4} \mathrm{M}$.

corresponding $\mathrm{O}_{3}$ absorption rate law will be different (Charpentier, 1981; Danckwerts, 1970). In the slow kinetic regime, $\mathrm{H}_{2} \mathrm{O}_{2}$ will act as a promoter for the decomposition of $\mathrm{O}_{3}$ to $\mathrm{HO}^{\circ}$, while in the fast kinetic regime, $\mathrm{H}_{2} \mathrm{O}_{2}$ will act as an inhibitor. It happens mainly due to the increase of the termination reaction rates according to Equations (8.13) and (8.14) listed below. This explains the different effects of $\mathrm{H}_{2} \mathrm{O}_{2}$ concentration in the advanced oxidation process. According to that and the observation of Fig. 8.2, a concentration equal to $10^{-3} \mathrm{M}$ of $\mathrm{H}_{2} \mathrm{O}_{2}$ was chosen to be used in the subsequent experiments. It has to be noted that at this concentration $\left(10^{-3} \mathrm{M}\right)$, the concentration of dissolved $\mathrm{O}_{3}$ was not detectable in the bulk of the liquid during the advanced oxidation process. This indicated that at this concentration of $\mathrm{H}_{2} \mathrm{O}_{2}$ the reaction regime can be considered diffusional 
(Charpentier, 1981). At this regime, $\mathrm{O}_{3}$ is expected to react with other reactants at the gas-liquid interface where the concentration of $\mathrm{O}_{3}$ is equal to the $\mathrm{O}_{3}$ solubility in water $\left(C_{O_{3}^{*}}\right)$.

\subsection{KINETICS OF ADVANCED OXIDATION OF NAPHTHENIC ACIDS}

In previous kinetic studies (Chapter 5) done by our research team (Al jibouri et al., 2015a), it was found that ozone reacts with NAs through direct and indirect (radical) reactions. The radicals $\left(\mathrm{HO}^{\bullet}\right.$ ) are produced from the decomposition of $\mathrm{O}_{3}$. In the present case, when $\mathrm{H}_{2} \mathrm{O}_{2}$ was added in a specific concentration, the removal rate of NAs was significantly promoted. The mechanism of such advanced oxidation of NAs is expected to involve $\mathrm{O}_{3}$ decomposed in the presence of $\mathrm{H}_{2} \mathrm{O}_{2}$ to produce $\mathrm{HO}^{\bullet}$. These radicals $\left(\mathrm{HO}^{\bullet}\right.$ ) react subsequently with NAs in the bulk of liquid (Glaze and Kang, 1989). This mechanism was tested by using $p$-chlorobenzoic acids ( $p C B A$ ) as a $H O^{\bullet}$ probe. The $p$ CBA was added to the NAs solutions, in both the experiments using $\mathrm{O}_{3} / \mathrm{H}_{2} \mathrm{O}_{2}$ and $\mathrm{O}_{3}$ (ozonation only) systems, at a concentration of $6.4 \times 10^{-6} \mathrm{M}$. The idea was to measure the concentration of $\mathrm{HO}^{\bullet}$ in the presence and in the absence of the $\mathrm{H}_{2} \mathrm{O}_{2}$ to see if the $\mathrm{H}_{2} \mathrm{O}_{2}$ is promoting the decomposition of $\mathrm{O}_{3}$ to $\mathrm{HO}^{\circ}$. The same procedure in Section 5.2.1 was used to determine the concentration of $\mathrm{HO}^{\bullet}$. The left hand side of Equation (5.9), $\ln C_{\mathrm{pCBA}} / C_{\mathrm{pCBA}_{0}}$, was plotted against the ozonation time at $25^{\circ} \mathrm{C}$ in Fig. 8.3. It is observed from Fig. 8.3 that a straight line was obtained. The slope of the straight line is the product of $k_{\mathrm{HO}}{ }^{-p c B A}$ and $C_{\mathrm{OH}^{\bullet}}$. With the known value of $k_{\mathrm{HO}} \cdot \mathrm{pCBA}=5 \times 10^{9} \mathrm{M}^{-1} \mathrm{~s}^{-1}$ (Elovitz and von Gunten, 1999; Neta and Dorfman, 1968; Yao and Haag, 1991), the concentrations of $\mathrm{HO}^{\bullet}$ were estimated using the known value of $k_{\mathrm{HO}}{ }^{\text {pсBA }}$ and Equation

(5.9). The corresponding $\mathrm{HO}^{\bullet}$ concentrations were found to be $1.5 \times 10^{-12}$ and $3.0 \times 10^{-11} \mathrm{M}$ in the experiments without and with adding $\mathrm{H}_{2} \mathrm{O}_{2}$, respectively. This means that there is an increase of about $50 \%$ in the concentration of $\mathrm{HO}^{\bullet}$ due to the addition of $\mathrm{H}_{2} \mathrm{O}_{2}$ which supports the assumption that $\mathrm{H}_{2} \mathrm{O}_{2}$ promotes the decomposition of $\mathrm{O}_{3}$ to $\mathrm{HO}^{\bullet}$. 


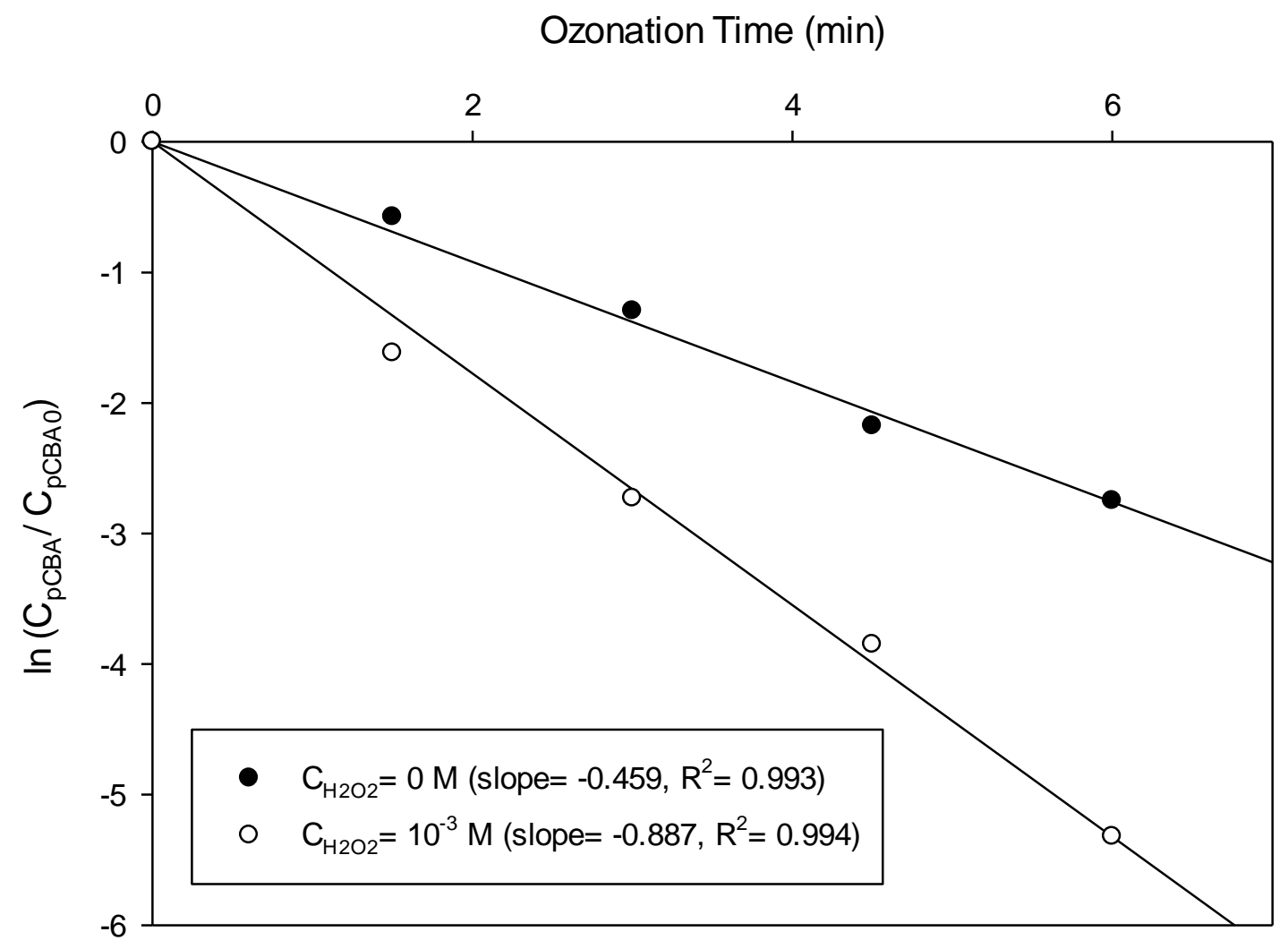

Figure 8.3 Plots of $\ln \left(C_{\mathrm{pCBA}} / C_{\mathrm{pCBA} 0}\right)$ versus ozonation time. $C_{\mathrm{NAs} 0}=4.1 \times 10^{-4} \mathrm{M} ; \mathrm{T}=25^{\circ} \mathrm{C} ; \mathrm{pH}=$ $8.5 ; C_{\mathrm{pCBA} 0}=6.4 \times 10^{-6} \mathrm{M}$.

\subsection{MODELLING THE ADVANCED OXIDATION OF NAPHTHENIC ACIDS}

Previous results showed that ozonation of NAs is carried out through direct reaction with ozone and via radicals (hydroxyl radicals) a priori formed from the decomposition of ozone (Al jibouri et al., 2015a). On the other hand, the presence of important amounts of dissolved ozone suggests undoubtedly that the chemical reactions develop in the bulk water (Charpentier, 1981; Danckwerts, 1970). Under these circumstances and assuming that the ozonation of NAs follows the mechanism of Staehelin and Hoigné (1985), NAs are degraded by the following reactions: Direct reaction with ozone:

$$
O_{3}+N A s \stackrel{k_{d}}{\rightarrow} \text { Intermediates } \quad k_{\mathrm{d}}=3.34 \times 10^{16} \exp \left(-\frac{88.85}{\mathrm{RT}}\right)
$$

Indirect (radical) action of hydroxyl radicals: 


$$
\mathrm{NAs}+\mathrm{HO} \cdot \stackrel{k_{\mathrm{HO}}{ }^{*} \mathrm{NAs}}{\longrightarrow} \text { Intermediates } \quad k_{\mathrm{HO} \cdot \mathrm{NAs}}=6.79 \times 10^{12} \exp \left(-\frac{25.41}{\mathrm{RT}}\right)
$$

The direct and indirect rate constants $\left(k_{\mathrm{d}}\right.$ and $\left.k_{\mathrm{HO}}{ }^{*} \mathrm{NAs}\right)$ were determined previously by our research team (Al jibouri et al., 2015a).

Staehelin and Hoigné (1982) and Forni et al. (1982) showed that the conjugate base of $\mathrm{H}_{2} \mathrm{O}_{2}$ can initiate the decomposition of $\mathrm{O}_{3}$ into $\mathrm{HO}^{*}$. The following shows the sequence of reactions that occur when $\mathrm{O}_{3}$ decomposition is initiated either by peroxide $\left(\mathrm{HO}_{2}^{-}\right)$or hydroxide $\left(\mathrm{OH}^{-}\right)$ions as proposed by (Glaze and Kang, 1989):

\section{$\underline{\text { Reaction }}$}$$
\mathrm{H}_{2}
$$$$
\mathrm{HO}_{2}^{-}+\mathrm{O}_{3} \stackrel{k_{i} 1}{\leftrightarrow} \mathrm{HO}_{2}^{\cdot}+\mathrm{O}_{3}^{-}
$$$$
\mathrm{O}_{3}+\mathrm{OH}^{-} \stackrel{k_{i 2}}{\rightarrow} \mathrm{HO}_{2}^{\cdot}+\mathrm{O}_{2}^{-\bullet}
$$$$
\mathrm{HO}_{2}^{\cdot} \rightleftharpoons \mathrm{O}_{2}^{-\cdot}+\mathrm{H}^{+}
$$$$
\mathrm{O}_{3}+\mathrm{O}_{2}^{-\cdot} \stackrel{k_{1}}{\rightarrow} \mathrm{O}_{3}^{-\bullet}+\mathrm{O}_{2}
$$$$
\mathrm{O}_{3}^{-\cdot}+\mathrm{H}^{+} \stackrel{k_{2}}{\rightarrow} \mathrm{HO}_{3}^{\cdot}
$$$$
\mathrm{HO}_{3}^{\cdot} \stackrel{k_{3}}{\rightarrow} \mathrm{HO}^{\bullet}+\mathrm{O}_{2}
$$$$
H O^{\bullet}+S_{i} \stackrel{k_{s i}}{\rightarrow} \text { product }
$$$$
\mathrm{HO}^{\bullet}+\mathrm{HO}_{2}^{-} \stackrel{k_{4}}{\rightarrow} \mathrm{OH}^{-}+\mathrm{HO}_{2}^{\bullet}
$$$$
\mathrm{HO}^{\bullet}+\mathrm{H}_{2} \mathrm{O}_{2} \stackrel{k_{5}}{\rightarrow} \mathrm{H}_{2} \mathrm{O}+\mathrm{HO}_{2}^{\bullet}
$$$$
\mathrm{HO}^{\bullet}+\mathrm{HPO}_{4}^{2-} \stackrel{k_{5}}{\rightarrow} \mathrm{H}_{2} \mathrm{O}+\mathrm{PO}_{4}^{2-}
$$$$
\mathrm{O}_{3}+\mathrm{HO}^{\bullet} \stackrel{k_{6}}{\rightarrow} \mathrm{HO}_{2}^{\cdot}+\mathrm{O}_{2}
$$

\section{$\underline{\text { Rate constant }}$}

Initiation Reaction

$$
p K=11.8
$$$$
k_{i 1}=2.8 \times 10^{6} M^{-1} s^{-1}
$$$$
k_{i 2}=70 M^{-1} s^{-1}
$$$$
p K=4.8
$$

Propagation Reactions

$$
\begin{aligned}
& k_{1}=1.6 \times 10^{9} M^{-1} s^{-1} \\
& k_{2}=5.2 \times 10^{10} M^{-1} s^{-1} \\
& k_{3}=1.1 \times 10^{5} M^{-1} s^{-1}
\end{aligned}
$$

Termination Reactions 
The rate constants for Equations (8.6) and (8.7) show that initiation by peroxide ion is much more rapid than with the hydroxide ion when peroxide is present in milli-molar concentrations (Staehelin and Hoigné, 1982). Since both processes are proportional to $\mathrm{pH}$, the relative rates of initiation will be pH independent (Glaze and Kang, 1989).

In the termination step of the above mechanism, the scavengers of $\mathrm{HO}^{\bullet}(\mathrm{S})$ in Equation (8.12) could be the NAs, intermediates of NAs oxidation, or any impurities. It is also worth mentioning that intermediates or oxidation byproducts can compete with NAs for the molecular $\mathrm{O}_{3}$ available through their direct reactions (which are not considered). The early analytical studies demonstrated the complexity of NAs mixtures, with about 1500 acids detected by Seifert and Teeter (Seifert and Teeter, 1969). The complexity of NAs mixtures makes the detection of all NAs oxidation intermediates almost an impossible task. Therefore, the intermediates direct and indirect reaction with $\mathrm{O}_{3}$ were not considered in this work due to lack of information about these intermediates.

From the mechanism of the reaction of $\mathrm{O}_{3}$ with NAs and the mass balance equations of $\mathrm{NAs}, \mathrm{O}_{3}$ (applied to the liquid and gas phases) and hydrogen peroxide, the concentration of these species can be predicted for any set of experimental conditions. Thus, the kinetic model equations:

Mass balance of NAs:

$$
-\frac{d C_{\mathrm{NAs}}}{d t}=k_{\mathrm{d}} C_{\mathrm{NAs}} C_{\mathrm{O}_{3}}+k_{\mathrm{HO}}{ }^{\mathrm{NAs}} C_{\mathrm{NAs}} C_{\mathrm{HO}} \cdot
$$

For the oxidation of NAs in the presence of hydrogen peroxide, the concentration of dissolved $\mathrm{O}_{3}$ was non-detectable in the bulk of solution during the reaction. Therefore, the direct reaction (first term in the right side of Equation (8.17) between $\mathrm{O}_{3}$ and NAs in the bulk of liquid was neglected. Moreover, it was assumed that the rate of initiation by peroxide is larger than the rate of initiation by hydroxyl ions.

Mass balance of $\mathrm{O}_{3}$ in water (assuming that gas and liquid phases are well mixed in the reactor):

$$
\frac{d C_{\mathrm{O}_{3}}}{d t}=K_{L} a\left(C_{\mathrm{O}_{3} \mathrm{G}} \mathrm{R} T / H-C_{\mathrm{O}_{3}}\right)-\sum_{i=1}^{4} r_{i}
$$

where $K_{L} a, C_{\mathrm{O}_{3} \mathrm{G}}, R, H$ and $T$ are the overall gas phase mass transfer coefficient referred to the liquid volume, the concentration of $\mathrm{O}_{3}$ in the gas leaving the reactor, universal gas constant, the 
Henry law constant, and temperature, respectively. The term $\sum r_{i}$, represents the decomposition term of $\mathrm{O}_{3}$ due to chemical reactions, defined, neglecting the contribution of its direct reactions with intermediates. Using steady-state approximations for radical intermediates, one may derive the following expression for the rate of change of the aqueous $\mathrm{O}_{3}$ concentration (Beltrán, 1997; Glaze and Kang, 1989):

$$
\begin{aligned}
\sum_{i=1}^{4} r_{i}=3 k_{i 2} 10^{(p H-14)} C_{\mathrm{O}_{3}}+2 k_{i 1} 10^{(p H-11.8)} C_{\mathrm{H}_{2} \mathrm{O}_{2}} C_{\mathrm{O}_{3}} \\
+\left(k_{4} 10^{(p H-11.8)}+k_{5}\right) C_{\mathrm{H}_{2} \mathrm{O}_{2}} C_{\mathrm{HO}}+2 k_{7} C_{\mathrm{HO}} \cdot C_{\mathrm{O}_{3}}
\end{aligned}
$$

Mass balance of $\mathrm{O}_{3}$ in the gas phase:

$$
\frac{d C_{\mathrm{O}_{3 \mathrm{G}}}}{d t}=\frac{v_{\mathrm{G}}}{V_{\mathrm{G}}}\left(C_{\mathrm{O}_{3 \mathrm{Gi}}}-C_{\mathrm{O}_{3 \mathrm{G}}}\right)-\left(\frac{V_{\mathrm{L}}}{V_{\mathrm{G}}}\right) K_{L} a\left(C_{\mathrm{O}_{3 \mathrm{G}}} R T / H-C_{O_{3}}\right)
$$

where $v_{\mathrm{G}}, V_{\mathrm{G}}, V_{\mathrm{L}}$ and $C_{\mathrm{O}_{3 \mathrm{Gi}}}$, the gas volumetric flow rate, gas volume hold up $(0.05 \mathrm{~L})$, liquid volume hold up $(0.5 \mathrm{~L})$, and $\mathrm{O}_{3}$ gas concentration at the reactor inlet, respectively. It has to be noticed that mass balance equations of intermediates should be included in the kinetic model since these compounds also consume $\mathrm{HO}^{\bullet}$ and $\mathrm{O}_{3}$. However, their direct and indirect reactions were neglected because of the lack of information about these intermediates as was explained earlier. As a consequence, mass balance equations for intermediates were not considered.

Mass balance of hydrogen peroxide:

Considering that the peroxide-consuming reactions are Equations (8.6), (8.13), and (8.14), the expression for the rate of change of peroxide concentration can be obtained:

$$
-\frac{d C_{\mathrm{H}_{2} \mathrm{O}_{2}}}{d t}=k_{i 1} 10^{(p H-11.8)} C_{\mathrm{H}_{2} \mathrm{O}_{2}} C_{\mathrm{O}_{3}}+\left(k_{4} 10^{(p H-11.8)}+k_{5}\right) C_{\mathrm{H}_{2} \mathrm{O}_{2}} C_{\mathrm{HO}}
$$

In the semi-batch experiments, $\mathrm{H}_{2} \mathrm{O}_{2}$ was added prior to passing the $\mathrm{O}_{3} / \mathrm{O}_{2}$ gas mixture through the reaction solution. Therefore, it is expected that the $\mathrm{H}_{2} \mathrm{O}_{2} / \mathrm{O}_{3}$ ratio is always high during the reaction. For this reason, the reaction rate is expected to be limited by the $\mathrm{O}_{3}$-transfer rate into the liquid phase. In this region, $\mathrm{O}_{3}$ concentration in the liquid phase is expected to be at steady state (i.e., $d C_{\mathrm{O}_{3}} / d t=0$ ) and at a very low value (i.e. $C_{\mathrm{O}_{3 \mathrm{G}}} \mathrm{R} T / H \gg C_{\mathrm{O}_{3}}$ ). According to that, it can be shown that the steady state concentration of $\mathrm{HO}^{\circ}$ can be expressed as follows (Beltrán, 1997; Glaze and Kang, 1989): 
$C_{\mathrm{HO}_{\mathrm{s}}^{*}}=\frac{K_{L} a C_{\mathrm{O}_{3 \mathrm{G}}} R T / H}{k_{\mathrm{HO} \cdot \mathrm{NAs}} C_{\mathrm{NAs}}+\sum k_{\mathrm{Si}} C_{\mathrm{S}_{\mathrm{i}}}+\left(k_{4} 10^{(p H-11.8)}+k_{5}\right) C_{\mathrm{H}_{2} \mathrm{O}_{2}}}$

where $C_{S_{i}}$ is the concentration of $\mathrm{HO}^{*}$ scavengers. Due to the unknown concentrations of the ozonated NAs (intermediates) at any time, in the denominator of Equation (8.22), the scavenger term of intermediates was neglected. Therefore, the scavenger term in Equation (8.22) was simplified by assuming NAs, $\mathrm{HPO}_{4}^{2-}$ and $\mathrm{H}_{2} \mathrm{O}_{2}$ are the only scavengers in the reaction solution. In the phosphate-buffered system at $\mathrm{pH} 8.5$ in this study, the scavenger should be $\mathrm{HPO}_{4}^{2-}$ (et al., 1973), therefore, the scavenger term in the denominator of Equation (8.22) can be expressed as follows:

$$
\sum k_{\mathrm{Si}} C_{\mathrm{S}_{\mathrm{i}}}=k_{\mathrm{s} 1} C_{\mathrm{HPO}_{4}^{2-}}
$$

where $k_{s 1}$ is the rate constant for the reaction between the hydroxyl radical and the phosphate ions and has the value of $7.9 \times 10^{5} M^{-1} \mathrm{~S}^{-1}$ (Grabner et al., 1973). On the other hand the value of $C_{\mathrm{HPO}_{4}^{2-}}$ should be $0.005 \mathrm{M}$.

The time-dependent $\mathrm{NAs}, \mathrm{O}_{3 \mathrm{G}}$, and peroxide concentrations can be expressed by rearrangement and simplification of Equations $(8.17,8.20$ and 8.21), respectively:

$$
\begin{aligned}
& -\frac{d C_{\mathrm{NAs}}}{d t}=\frac{k_{\mathrm{HO} \cdot{ }_{\mathrm{NAs}}} C_{\mathrm{NAs}} K_{L} a C_{\mathrm{O}_{3 \mathrm{G}}} \mathrm{RT} / H}{k_{\mathrm{HO} \cdot{ }_{\mathrm{NAs}}} C_{\mathrm{NAs}}+k_{6} C_{\mathrm{HPO}_{4}^{2-}}+\left(k_{4} 10^{(p H-11.8)}+k_{5}\right) C_{\mathrm{H}_{2} \mathrm{O}_{2}}} \\
& \frac{d C_{\mathrm{O}_{3 \mathrm{G}}}}{d t}=\frac{v_{\mathrm{G}}}{V_{\mathrm{G}}}\left(C_{\mathrm{O}_{3 \mathrm{Gi}}}-C_{\mathrm{O}_{3 \mathrm{G}}}\right)-\left(\frac{V_{\mathrm{L}}}{V_{\mathrm{G}}}\right) K_{L} a\left(C_{\mathrm{O}_{3 \mathrm{G}}} \mathrm{RT} / H\right) \\
& -\frac{d C_{\mathrm{H}_{2} \mathrm{O}_{2}}}{d t}=0.5 k_{i 1} k_{L} a C_{\mathrm{O}_{3 \mathrm{G}}} R T+0.5 C_{\mathrm{HO}_{\mathrm{s}}^{*}}\left[\left(k_{4} 10^{(p H-11.8)}+k_{5}\right) C_{\mathrm{H}_{2} \mathrm{O}_{2}}+k_{6} C_{\mathrm{HPO}_{4}^{2-}}\right]
\end{aligned}
$$

\subsection{DETERMINATION OF THE OVERALL MASS TRANSFER COEFFICIENTS}

In order to solve Equations (8.24-8.26), it is necessary first to determine the overall mass transfer coefficient $\left(K_{L} a\right)$ and the Henry law constant $(H)$. In an ozonation experiment when the concentrations of ozone in the water and in the gas leaving the reactor have reached their stationary values ( $C_{\mathrm{O}_{3} \mathrm{~S}}$ and $C_{\mathrm{O}_{3} \mathrm{Gs}}$, respectively), $K_{L} a$ and $H$ can be obtained from Equation (8.25). The ozone accumulation term is now zero due to the steady state condition. Therefore:

$$
0=\left(\frac{v_{\mathrm{G}}}{V_{\mathrm{G}}}\right)\left(C_{\mathrm{O}_{3} \mathrm{Gi}}-C_{\mathrm{O}_{3} \mathrm{Gs}}\right)-\left(\frac{V_{\mathrm{L}}}{V_{\mathrm{G}}}\right) K_{L} a\left(C_{\mathrm{O}_{3} \mathrm{Gs}} \mathrm{RT} / H\right)
$$


Two inlet ozone gas concentrations were applied at each temperature in order to get two nonlinear equations, based on Equation (8.27), when the gaseous concentration reaches the stationary concentrations $\left(C_{\mathrm{O}_{3} \mathrm{Gs}}\right)$. The non-linear equations can be expressed in the general form:

$$
\sum_{i=1}^{2} f(i)=\left(\frac{v_{\mathrm{G}}}{V_{\mathrm{G}}}\right)\left[C_{\mathrm{O}_{3} \mathrm{Gi}}(i)-C_{\mathrm{O}_{3} \mathrm{Gs}}(i)\right]-\left(\frac{V_{\mathrm{L}}}{V_{\mathrm{G}}}\right) K_{L} a\left[C_{\mathrm{O}_{3} \mathrm{Gs}}(i) R T / H\right]
$$

The two equations were solved using Newton-Raphson non-linear numerical method to get $K_{L} a$ and $H$ at each temperature (Chapra and Canale, 2009).Table 8.1 shows the results.

Table 8.1 Determination of $K_{G} a$ and $H$.

\begin{tabular}{ccccc}
\hline $\mathrm{T}$ & $C_{\mathrm{O}_{3} \mathrm{Gi}}$ & $C_{\mathrm{O}_{3} \mathrm{Gs}}$ & $H$ & $K_{L} a$ \\
\hline$\left.{ }^{\circ} \mathrm{C}\right)$ & $\left(\mathrm{mol} \mathrm{L} \mathrm{L}^{-1}\right)$ & $\left(\mathrm{mol} \mathrm{L} \mathrm{L}^{-1}\right)$ & $\left(\mathrm{atm} \mathrm{L} \mathrm{mol} \mathrm{mon}^{-1}\right)$ & $\left(\mathrm{s}^{-1}\right)$ \\
\hline \multirow{2}{*}{5} & $6.2 \times 10^{-4}$ & $6.10 \times 10^{-4}$ & 70 & $1.67 \times 10^{-3}$ \\
& $9.3 \times 10^{-4}$ & $9.15 \times 10^{-4}$ & & \\
& $6.2 \times 10^{-4}$ & $6.102 \times 10^{-4}$ & 178 & $4.00 \times 10^{-3}$ \\
15 & $9.3 \times 10^{-4}$ & $9.154 \times 10^{-4}$ & & \\
& $6.2 \times 10^{-4}$ & $6.07 \times 10^{-4}$ & 345 & $1.03 \times 10^{-2}$ \\
25 & $9.3 \times 10^{-4}$ & $9.1 \times 10^{-4}$ & 345 & \\
\hline
\end{tabular}

\subsection{PREDICTION OF NAPHTHENIC ACIDS AND HYDROGEN PEROXIDE CONCENTRATIONS}

A C++ program was developed to solve the differential equations, Equations (8.24-8.26), to obtain the concentration profiles of NAs, $\mathrm{O}_{3 \mathrm{G}}$ and $\mathrm{H}_{2} \mathrm{O}_{2}$. The fourth order Runge-Kutta method was applied, with an integration step size of $1 \mathrm{~s}$, to solve the system of equations with the initial conditions:

$$
t=0 \quad C_{\mathrm{NAs}}=C_{\mathrm{NAs} 0}, \quad C_{\mathrm{H}_{2} \mathrm{O}_{2}}=C_{\mathrm{H}_{2} \mathrm{O}_{20}}, \quad C_{\mathrm{O}_{3 \mathrm{G}}}=0
$$

The model of Equations 8.24- 8.26 was used to predict the concentration profile of NAs at different temperatures and initial hydrogen peroxide concentration. The results of the predicted NAs profiles are shown in Figs. 8.4 and 8.5, respectively. The concentration profile of NAs at different temperatures are well representing the experimental results. The concentration profile of 
NAs at different initial hydrogen peroxide concentrations are a good representation of the experimental results for a concentration of hydrogen peroxide equal or above $10^{-3} \mathrm{M}$. Below this concentration $\left(10^{-3} \mathrm{M}\right)$, it is obvious that the model failed to predict the concentration profile. The most acceptable explanation for this behavior is that the reaction regime is shifting from diffusional to slow regime at this low concentration of hydrogen peroxide. This assumption was supported by the fact that the concentration profile at this low concentration of hydrogen peroxide becomes closer to the profile of ozonation only process; which was proved previously to be a slow kinetic reaction (Al jibouri et al., 2015a). This assumption was also supported by the detection of dissolved ozone in the bulk of liquid after around 5 min of the start of the ozonation process. Plotting hydrogen peroxide concentration profiles at different initial hydrogen peroxide concentrations are also shown in Fig. 8.6. As can be seen from Fig. 8.6, the concentration of hydrogen peroxide depleted after 11 min of the reaction when the initial concentration of hydrogen peroxide is very low $\left(10^{-4} \mathrm{M}\right)$. This again means that, after the depletion of hydrogen peroxide, the reaction became an ozonation process with a slow kinetic regime. Comparing Figs. 8.5 with 8.6 also shows that the rate of NAs removal was much higher than the rate of $\mathrm{H}_{2} \mathrm{O}_{2}$ consumption when the concentration of hydrogen peroxide was equal or above $10^{-3} \mathrm{M}$. This has a great advantage because it means that there is always $\mathrm{H}_{2} \mathrm{O}_{2}$ available during the advanced oxidation of NAs which can promote the decomposition of $\mathrm{O}_{3}$ to $\mathrm{HO}^{\circ}$. The predicted profile of $\mathrm{H}_{2} \mathrm{O}_{2}$ in Fig. 8.6, for initial concentration of hydrogen peroxide of $10^{-3} \mathrm{M}$, also shows that the consumption of $\mathrm{H}_{2} \mathrm{O}_{2}$ was accelerated as the concentration of NAs started to deplete. This behavior is very close to reality because it is well known that $\mathrm{H}_{2} \mathrm{O}_{2}$ forms when $\mathrm{O}_{3}$ is applied in water (Staehelin et al., 1984; Bühler et al., 1984). This reaction is particularly important when unsaturated compounds are present in water, such as the case in NAs, because $\mathrm{O}_{3}$ breaks the aromatic rings or carbon double bonds through the Crieggee mechanism which leads to saturated compounds and the formation of $\mathrm{H}_{2} \mathrm{O}_{2}$ (Criegee, 1957). 


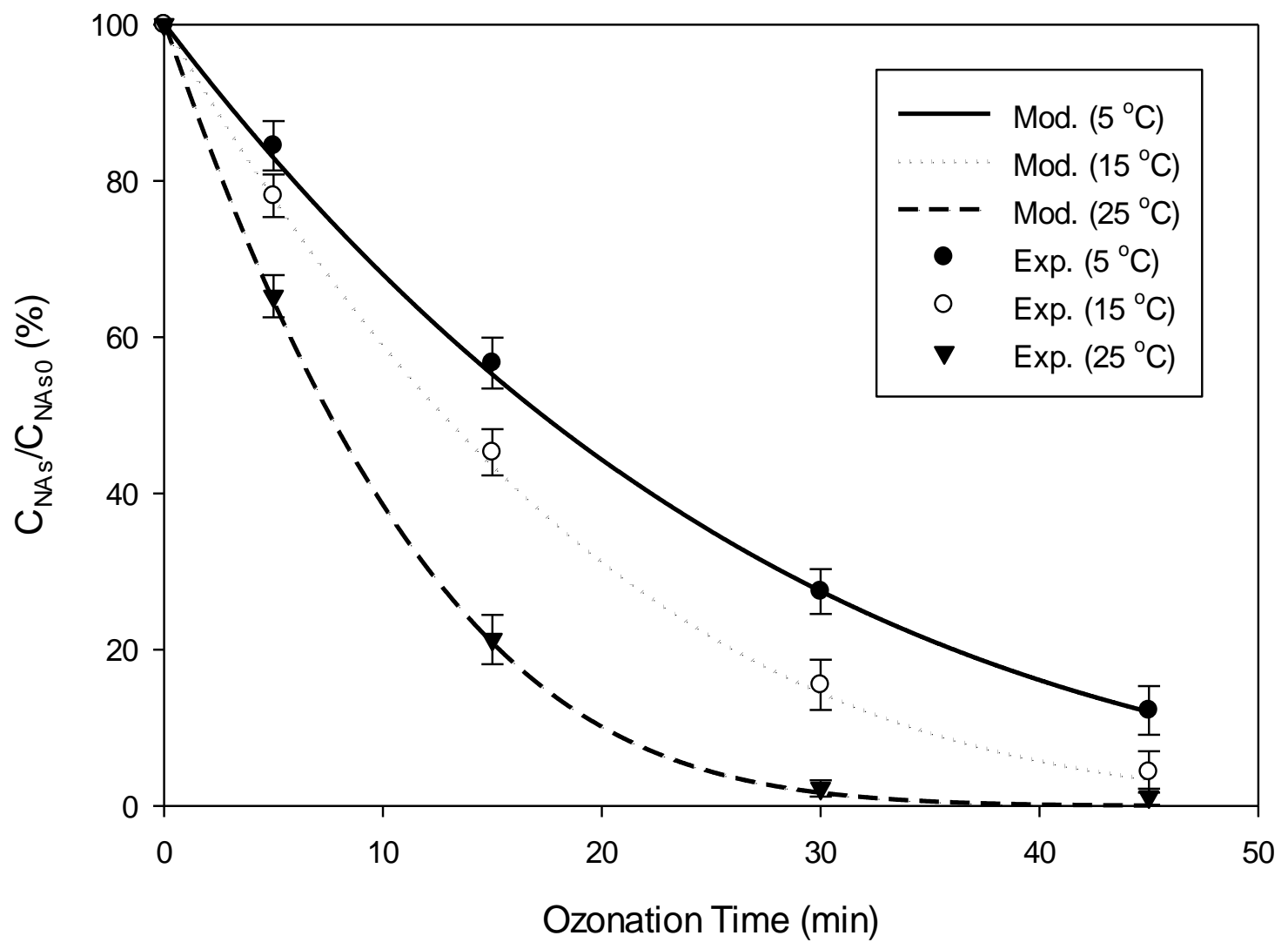

Figure 8.4 Validation of the original advanced oxidation kinetic model. Variation of the predicted (Mod.) and the experimental (Exp.) NAs concentrations with time at different temperatures. $\mathrm{pH}$ 8.5; $C_{\mathrm{H} 2 \mathrm{O} 20}=10^{-3} \mathrm{M} ; C_{\mathrm{NAs} 0}=4.1 \times 10^{-4} \mathrm{M} ; C_{\mathrm{O} 3 \mathrm{Gi}}=9.3 \times 10^{-4} \mathrm{M}$. 


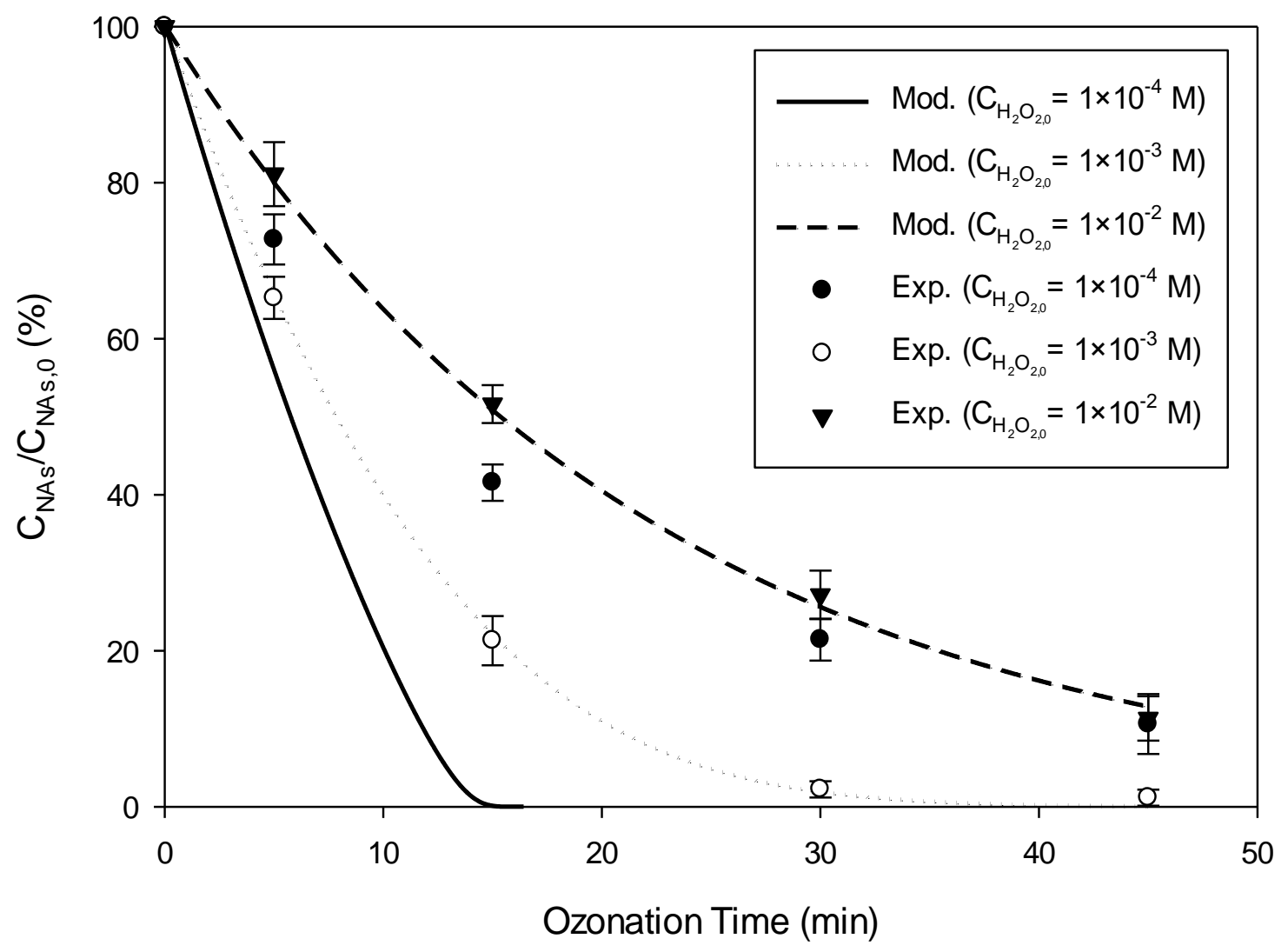

Figure 8.5 Validation of the modified advanced oxidation kinetic model. Variation of the predicted (Mod.) and the experimental (Exp.) NAs concentrations with time at different initial hydrogen peroxide concentrations. $\mathrm{T}=25^{\circ} \mathrm{C} ; \mathrm{pH} 8.5 ; C_{\mathrm{O} 3 \mathrm{Gi}}=9.3 \times 10^{-4} \mathrm{M} ; C_{\mathrm{NAs} 0}=4.1 \times 10^{-4} \mathrm{M}$. 


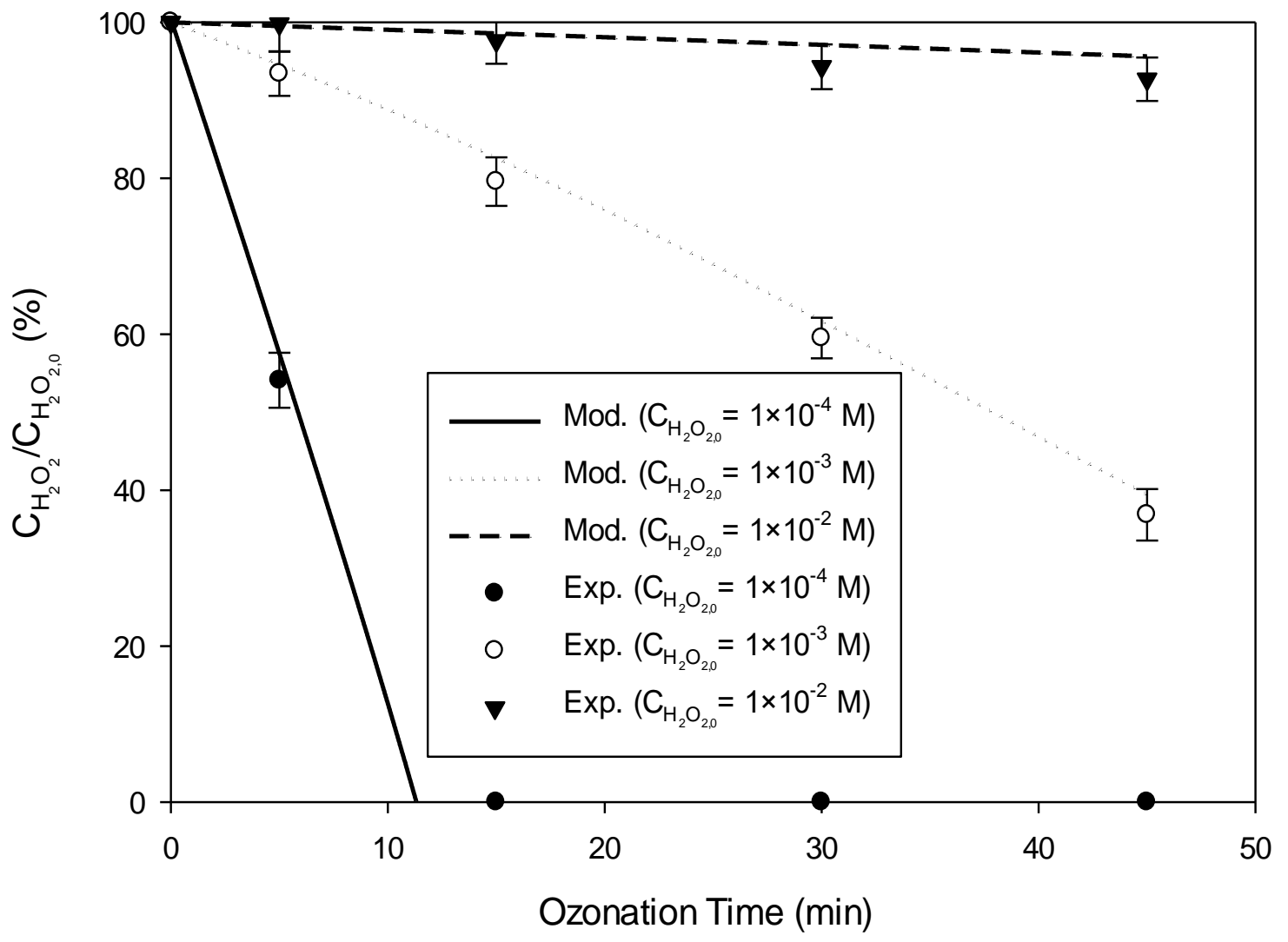

Figure 8.6 Variation of the predicted and experimental $\mathrm{H}_{2} \mathrm{O}_{2}$ concentration with time. $\mathrm{T}=25^{\circ} \mathrm{C}$; $\mathrm{pH}=8.5 ; C_{\mathrm{O} 3 \mathrm{Gi}}=9.3 \times 10^{-4} \mathrm{M} ; C_{\mathrm{NAs} 0}=4.1 \times 10^{-4} \mathrm{M}$. 


\section{CHAPTER 9:}

\section{OPTIMAL CONTROL FOR THE CONTINUOUS OZONATION OF NAPHTHENIC ACIDS IN WATER}

\subsection{CONTINUOUS OZONATION OF NAPHTHENIC ACIDS MATHEMATICAL MODEL}

Ozonation of NAs is carried out through two pathways: direct oxidation of NAs by molecular ozone, and indirect oxidation by hydroxyl radicals formed from the self-decomposition of ozone in water. Also, it was found that the chemical reactions are developed in the bulk water (Al jibouri et al., 2015a). Considering that the ozonation of NAs follows the mechanism of Staehelin and Hoigné (1985), NAs is oxidized as follows (Al jibouri et al., 2015a; Danckwerts, 1970):

The direct reaction with ozone:

$$
O_{3}+N A s \stackrel{\mathrm{k}_{\mathrm{d}}}{\rightarrow} \text { Intermediates } \quad k_{\mathrm{d}}=3.34 \times 10^{16} \exp \left(-\frac{88.85}{\mathrm{RT}}\right)
$$

The indirect reaction with hydroxyl radicals:

$$
N A s+H O \cdot \stackrel{k_{\mathrm{HO}}{ }^{*} \mathrm{NAs}}{\longrightarrow} \text { Intermediates } \quad k_{\mathrm{HO} \cdot \mathrm{NAs}}=6.79 \times 10^{12} \exp \left(-\frac{25.41}{\mathrm{RT}}\right)
$$

The equations of calculating direct and indirect rate constants $\left(k_{\mathrm{d}}\right.$ and $\left.k_{\mathrm{HO}} \cdot \mathrm{NAs}\right)$ were derived in our previous study as shown in Chapter 6 (Al jibouri et al., 2015a).

Combining the above information with mass balances of NAs and ozone, the models to predict the concentration profiles of NAs and ozone are (Charpentier, 1981; Danckwerts, 1970):

Mass balance of NAs

The disappearance of NAs is due to the direct and indirect ozonation:

$$
\frac{d C_{\mathrm{NAs}}}{d t}=\frac{v_{\mathrm{L}}}{V_{\mathrm{L}}}\left(C_{\mathrm{NAs} i}-C_{\mathrm{NAs}}\right)-k_{\mathrm{d}} C_{\mathrm{NAs}} C_{\mathrm{O}_{3}}-k_{\mathrm{HO} \cdot{ }_{\mathrm{NAs}}} C_{\mathrm{NAs}} C_{\mathrm{HO}} \cdot
$$

where $V_{\mathrm{L}}, v_{\mathrm{L}}$, and $C_{\mathrm{NAsi}}$ are the liquid hold-up volume within the reactor $(2.7 \mathrm{~L})$, the volumetric liquid flow rate through the system and inlet NAs concentration, respectively.

\section{Mass balance of dissolved ozone}

Based on the fact that the overall reaction between ozone and NAs is a slow reaction and assuming that gas and liquid phases are well mixed in the reactor, the mass balance of dissolved ozone is as follows: 


$$
\frac{d C_{\mathrm{O}_{3}}}{d t}=\left(\frac{V_{\mathrm{G}}}{V_{\mathrm{L}}}\right) K_{G} a\left(C_{\mathrm{O}_{3} \mathrm{G}} \mathrm{RT} / H-C_{\mathrm{O}_{3}}\right)-\left(\frac{\nu_{\mathrm{L}}}{V_{\mathrm{L}}}\right) C_{\mathrm{O}_{3}}-\sum_{i=1}^{4} r_{i}
$$

where $V_{\mathrm{G}}, K_{G} a, C_{\mathrm{O}_{3} \mathrm{G}}, \mathrm{R}, H$ and $T$ are the gas hold-up volume within the reactor $(2.29 \mathrm{~L})$, the overall mass transfer coefficient referred to the gas phase, the concentration of ozone in the gas leaving the reactor, universal gas constant, the Henry's law constant and temperature, respectively. Optimum liquid circulation flow rare $\left(2 \mathrm{~L} \mathrm{~min}^{-1}\right)$ and the liquid and gas hold-up volumes $\left(V_{\mathrm{L}}, V_{\mathrm{G}}\right)$ were determined experimentally in a previous work, by our research team, through pulse injection of methylene blue in a steady flow of pure water. More details can be found in our previous work (Al jibouri et al., 2015b).

The rate of disappearance of dissolved ozone can be written as (Beltrán et al., 1994):

$$
\sum_{i=1}^{4} r_{i}=\left(k_{\mathrm{d}} C_{\mathrm{NAs}}+k_{i} 10^{(p H-14)}+k_{1} C_{\mathrm{O}_{2}^{-}}+k_{2} C_{\mathrm{HO}}\right) C_{\mathrm{O}_{3}}
$$

The expressions for the radical concentrations in Equation (9.5) are (Staehelin and Hoigné, 1985; Beltrán et al., 1994):

$$
\begin{aligned}
& C_{\mathrm{HO}} \cdot= \frac{2 k_{i} 10^{(p H-14)} C_{\mathrm{O}_{3}}}{k_{\mathrm{HO} \cdot \mathrm{NAs}} C_{\mathrm{NAs}}+\sum k_{\mathrm{Si}} C_{\mathrm{S}_{\mathrm{i}}}} \\
& C_{\mathrm{O}_{2}^{-\bullet}}=\frac{2 k_{i} 10^{(p H-14)}+k_{2} C_{\mathrm{HO}^{\bullet}}}{k_{1}}
\end{aligned}
$$

According to Staehelin and Hoigné, the rate constants in Equations (9.6) and (9.7) are: $k_{i}=$ $70 M^{-1} S^{-1}, k_{1}=1.9 \times 10^{9} M^{-1} S^{-1}$, and $k_{2}=2.0 \times 10^{9} M^{-1} S^{-1}$ (Staehelin and Hoigné, 1985). On the other hand, $C_{S_{\mathrm{i}}}$ in Equation (9.6) is the concentration of the scavengers. In the phosphatebuffered system at pH 8.5 in this study, the scavenger should be $\mathrm{HPO}_{4}^{2-}$ (Grabner et al., 1973). Therefore, the scavenger term in the denominator of Equation (9.6) can be expressed as follows:

$$
\sum k_{\mathrm{Si}} C_{\mathrm{S}_{\mathrm{i}}}=k_{\mathrm{s} 1} C_{\mathrm{HPO}_{4}^{2-}}
$$

where $k_{\mathrm{s} 1}$ is the rate constant for the reaction between the hydroxyl radical and the phosphate ions and has the value of $7.9 \times 10^{5} M^{-1} S^{-1}$ (Grabner et al., 1973).

Mass balance of ozone in the gas phase 


$$
\frac{d C_{\mathrm{O}_{3} \mathrm{G}}}{d t}=\left(\frac{v_{\mathrm{G}}}{V_{\mathrm{G}}}\right)\left(C_{\mathrm{O}_{3} \mathrm{Gi}}-C_{\mathrm{O}_{3} \mathrm{G}}\right)-K_{G} a\left(C_{\mathrm{O}_{3} \mathrm{G}} \mathrm{RT} / H-C_{\mathrm{O}_{3}}\right)
$$

where $v_{\mathrm{G}}$ and $C_{\mathrm{O}_{3} \mathrm{Gi}}$ are the gas volumetric flow rate and ozone gas concentration at the reactor inlet, respectively. The first term in the right side of Equation (9.9) represents the driving force of ozone mass transfer in the gas phase while the second term represents the driving force for the absorption of ozone from the gas to the liquid phases.

The Henry law constant was determined experimentally in a previous work by our research team and it was found to be equal to $35.5 \times 10^{6} \mathrm{~Pa} \mathrm{M}^{-1}$ at $25^{\circ} \mathrm{C}$ (Al jibouri et al., 2016). The overall mass transfer coefficient was determined when the concentrations of both gaseous and dissolved ozone reaches the stationary or equilibrium conditions. According to Equation (9.9), when gaseous and dissolved ozone reach their stationary concentrations, i.e., equilibrium state, the ozone accumulation term is zero and the concentrations of dissolved ozone and ozone in the gas phase leaving the reactor are $C_{O_{3} S}$ and $C_{O_{3} G s}$, respectively. Thus, Equation (9.9) becomes:

$$
K_{G} a=\left(\frac{v_{\mathrm{G}}}{V_{\mathrm{G}}}\right)\left(C_{\mathrm{O}_{3} \mathrm{Gi}}-C_{\mathrm{O}_{3} \mathrm{Gs}}\right) /\left(C_{\mathrm{O}_{3} \mathrm{Gs}} \mathrm{RT} / \mathrm{H}-C_{\mathrm{O}_{3} \mathrm{~s}}\right)
$$

Table 9.1 shows the values of $K_{G} a$ which were determined at different gas flow rates.

Table 9.1 Determination of $K_{G} a$

\begin{tabular}{cccc}
\hline$v_{\mathrm{G}}$ & $C_{\mathrm{O}_{3} \mathrm{~s}}$ & $C_{\mathrm{O}_{3} \mathrm{Gs}}$ & $K_{G} a$ \\
\hline$\left(\mathrm{L} \mathrm{min}^{-1}\right)$ & $(M) \times 10^{5}$ & $(M) \times 10^{4}$ & $\begin{array}{c}(\text { mol atm } \\
{[\text { L of gas }]^{-1}} \\
\left.S^{-1}\right) \times 10^{3}\end{array}$ \\
\hline 0.25 & 2.5 & 8.49 & 4.29 \\
0.5 & 3.6 & 8.89 & 5.71 \\
1 & 4.6 & 9.13 & 6.96 \\
2 & 5.0 & $9 . .22$ & 8.08 \\
3.5 & 5.3 & 9.26 & 8.71 \\
\hline
\end{tabular}

\subsection{OPTIMAL CONTROL PROBLEM}

Optimal control can be defined as the function that optimizes the performance of system changing with time, space or any other independent variables. Control, on the other hand, is the 
use of a function to control the state of the system and obtain some desired performance (Upreti, 2013).

Subject to Equations (9.3-9.9), the optimal control problem is to find the undetermined ozone/ oxygen gas mixture flow rate versus time or the control function $(u)$ to minimize the concentration of NAs in the outlet liquid stream of continuous ozonation process at a fixed final time $\left(t_{\mathrm{f}}=60 \mathrm{~min}\right)$, i.e., minimize the objective functional:

$$
\begin{aligned}
I=\frac{y_{0}\left(\mathrm{t}_{\mathrm{f}}\right)}{\overline{y_{0}}}=\frac{1}{\overline{y_{0}}} \int_{0}^{t_{\mathrm{f}}} d y_{0}=\frac{1}{\overline{y_{0}}} \int_{0}^{t_{\mathrm{f}}} \frac{d y_{0}}{d t} d t \\
=\frac{1}{\overline{y_{0}}} \int_{0}^{t_{\mathrm{f}}}\left\{\frac{\nu_{\mathrm{L}}}{V_{\mathrm{L}}}\left(\overline{y_{0}}-y_{0}\right)-k_{\mathrm{d}} y_{0} y_{1}-k_{\mathrm{HO} \cdot{ }_{\mathrm{NAs}}} y_{0} C_{\mathrm{HO}} \cdot\right\} d t
\end{aligned}
$$

Or in the general form:

$$
I=\int_{0}^{t_{\mathrm{f}}} F\left(y_{0}, y_{1}\right) d t
$$

Subject to:

$$
\begin{aligned}
& \dot{y}_{0}=\frac{d y_{0}}{d t}=\frac{v_{\mathrm{L}}}{V_{\mathrm{L}}}\left(\overline{y_{0}}-y_{0}\right)-k_{\mathrm{d}} y_{0} y_{1}-k_{\mathrm{HO}} \cdot \mathrm{NAs} y_{0} C_{\mathrm{HO}} \cdot \\
& \dot{y}_{1}=\frac{d y_{1}}{d t}=\left(\frac{V_{\mathrm{G}}}{V_{\mathrm{L}}}\right) K_{G} a\left(y_{2} \mathrm{RT} / H-y_{1}\right)-\frac{v_{\mathrm{L}}}{V_{\mathrm{L}}} y_{1}-R_{i} \\
& \dot{y}_{2}=\frac{d y_{2}}{d t}=\left(\frac{u}{V_{\mathrm{G}}}\right)\left(\overline{y_{2}}-y_{2}\right)-K_{G} a\left(y_{2} \mathrm{RT} / H-y_{1}\right)
\end{aligned}
$$

with the initial conditions:

$$
y_{0}(0)=\overline{y_{0}}, \quad y_{1}(0)=0, \quad y_{2}(0)=0
$$

where:

$$
\begin{aligned}
& y_{0}=C_{\mathrm{NAs}}, \overline{y_{0}}=C_{\mathrm{NAsi}}, y_{1}=C_{\mathrm{O}_{3}}, \quad y_{2}=C_{\mathrm{O}_{3} \mathrm{G}}, \quad \overline{y_{2}}=C_{\mathrm{O}_{3} \mathrm{Gi}} \\
& C_{\mathrm{HO}} \cdot=\frac{2 k_{i} 10^{(p H-14)} y_{1}}{k_{\mathrm{HO} \cdot \mathrm{NAs}} y_{0}+\sum k_{\mathrm{Si}} C_{\mathrm{S}_{\mathrm{i}}}}
\end{aligned}
$$




$$
\begin{aligned}
& C_{\mathrm{O}_{2}^{-}}=\frac{2 k_{i} 10^{(p H-14)}+k_{2} C_{\mathrm{HO}}}{k_{1}} \\
& R_{i}=\left(k_{d} y_{0}+k_{i} 10^{(p H-14)}+k_{1} C_{O_{2}^{-\cdot}}+k_{2} C_{H O} \cdot\right) y_{1}
\end{aligned}
$$

and the algebraic inequality constraint that the undetermined ozone/ oxygen gas mixture flow rate versus time or the control function $(u)$ will be less or equal to a specific value $\left(D_{1}\right)$ :

$$
u \leq D_{1} \text { or } u-D_{1} \leq 0
$$

This constraint is essential to obtain a practical solution and to prevent the flooding in the packed column of the reaction system. Our unconstrained optimal control preliminary results showed that $u(t)$ could jump to impractical value $\left(4000 \mathrm{~L} \mathrm{~min}^{-1}\right)$.

If $I$, in Equation (9.11), is minimum at $\hat{y}$, then the values of $I$ for all other admissible functions in the vicinity of $\hat{y}$ cannot be lower than the value of $I$ at $\hat{y}$. Precisely:

$$
I(y)-I(\hat{y}) \geq 0
$$

is the necessary condition for the minimum of $I$ where $y$ is any admissible function in the vicinity and the norm of the function change $(y-\hat{y})$ is less than some positive number. Denoting $(y-\hat{y})$ by $\delta y$ in the above inequality, we have:

$$
I(\hat{y}+\alpha \delta y)-I(\hat{y}) \geq 0
$$

where $\alpha$ is a non-zero scalar variable with absolute value less than or equal to unity. In other words, $-1 \leq \alpha<0$ and $0<\alpha \leq 1$ are the two intervals of $\alpha$. Now if $I$ has a variation at $\hat{y}$, then from the definition of variation and its homogeneity property (Upreti, 2013):

$$
I(\hat{y}+\alpha \delta y)-I(\hat{y})=\delta I(\hat{y} ; \alpha \delta y)=\alpha \delta I(\hat{y} ; \delta y) \equiv \alpha \delta I
$$

for sufficiently small $\alpha$ in its prescribed intervals. Hence, from Inequality of Equation (9.22) and Equation (9.23):

$$
\alpha \delta I \geq 0
$$

According to the above inequality, $\delta I$ should be either

1. greater than or equal to zero when $\alpha$ is greater than zero, or

2. less than or equal to zero when $\alpha$ is less than zero

Thus, $\delta I=0$ is the only non-contradicting condition that is applicable for the minimum of $I$. As a consequence,

$$
\delta I=0
$$


is the necessary condition for the minimum of the functional $I$. Not guaranteeing an optimum of $I$, Equation (9.25) is just a logical consequence of $I$ being an optimum.

Equations (9.13-9.15) are called the state equation since it describes the state of the system through the state variables $\boldsymbol{y}$ as a function of the independent variable $t$. It is assumed that $F$ and $\dot{\boldsymbol{y}}$ have continuous partial derivatives with respect to $y$ and $u$. Note that this problem is autonomous in the sense that the independent variable does not appear explicitly in $F$ or $\boldsymbol{y}$. When it does, the problem is easily convertible to the autonomous form.

Observe that the objective functional $I$ in Equation (9.11) is influenced by the control $u$ indirectly. The indirect influence stems from $y$ being affected by $u$ through the state equation constraint, i.e., Equation (9.15). Hence, to solve the problem, we need to first obtain an explicit solution $\boldsymbol{y}=\boldsymbol{y}(u)$ and then substitute it in the expression of $F$. However, such solutions do not exist for such complex optimal control problems, which is constrained by highly non-linear state equations. The recourse is to adjoin the constraints of an optimal control problem to the objective functional using new variables called Lagrange multipliers. Their introduction obviates the need to obtain explicit solutions of state variables in terms of controls. The optimization of the resulting augmented functional is then equivalent to the constrained optimization of the original functional. This outcome - which is called the Lagrange Multiplier Rule (Upreti, 2013).

In the present problem defined by Equations (9.11-9.16), we adjoin the state equation constraint to $I$ using a Lagrange multiplier $\lambda$ and obtain the augmented functional:

$$
\begin{aligned}
& M=\int_{0}^{t_{\mathrm{f}}}\left\{\frac{1}{\overline{y_{0}}}\left[\frac{v_{\mathrm{L}}}{V_{\mathrm{L}}}\left(\overline{y_{0}}-y_{0}\right)-k_{\mathrm{d}} y_{0} y_{1}-k_{\mathrm{HO}} \cdot \mathrm{NAs}_{0} y_{0} C_{\mathrm{HO}} \cdot\right]\right. \\
& +\lambda_{0}\left[-\dot{y}_{0}+\frac{v_{\mathrm{L}}}{V_{\mathrm{L}}}\left(\overline{y_{0}}-y_{0}\right)-k_{\mathrm{d}} y_{0} y_{1}-k_{\mathrm{HO}}{ }_{\mathrm{NAs}} y_{0} C_{\mathrm{HO}} \cdot\right] \\
& +\lambda_{1}\left[-\dot{y}_{1}+\left(\frac{V_{\mathrm{G}}}{V_{\mathrm{L}}}\right) K_{G} a\left(y_{2} \mathrm{R} T / H-y_{1}\right)-\frac{v_{\mathrm{L}}}{V_{\mathrm{L}}} y_{1}-R_{i}\right] \\
& +\lambda_{2}\left[-\dot{y}_{2}+\left(\frac{v_{\mathrm{G}}}{V_{\mathrm{G}}}\right)\left(\overline{y_{2}}-y_{2}\right)-K_{G} a\left(y_{2} \mathrm{R} T / H-y_{1}\right)\right] \\
& \left.+\mu\left[u-D_{1}\right]\right\} d t
\end{aligned}
$$

where $\lambda$ are the undetermined costate variables and $\mu$ are the time dependent Lagrange multipliers corresponding to the algebraic inequality constraints. 


\subsubsection{Necessary Conditions for the Minimum}

The above augmented functional can be rewritten as follow:

$$
M=\int_{\mathbf{0}}^{t_{\mathrm{f}}}\left\{F\left(y_{0}, y_{1}\right)+\boldsymbol{\lambda} \boldsymbol{G}(\boldsymbol{y}, \dot{\boldsymbol{y}}, \boldsymbol{u})+\mu f\right\} d t
$$

For the given initial condition, i.e., Equation (9.16), the minimization of $M$ is then equivalent to the minimization of $I$ constrained by the state and inequality equations. Observe how the integrand in Equation (9.27) is formed by multiplying $\lambda$ by $\boldsymbol{G}$, which consists of all terms of the state equations constraint moved to the right-hand side. We will follow this approach, which will later on enable us to introduce a useful mnemonic function called the Lagrangian The Lagrange multipliers $\lambda$ is also known as the adjoint or costate variable. It is an undetermined function of an independent variable, which is $t$ in the present problem. Both $\lambda$ and the optimal $u$ are determined by the necessary condition for the minimum of $M$. The subsequent analysis expands the necessary condition, which is terse as such, into a set of workable equations or necessary conditions to be satisfied at the minimum.

Now we introduce the Lagrangian by rewriting the augmented functional $(M)$ :

$$
M=\int_{\mathbf{0}}^{t_{\mathrm{f}}}\left[F+\lambda^{\top}(-\dot{\boldsymbol{y}}+\boldsymbol{g})+\mu f\right] d t=\int_{\mathbf{0}}^{t_{\mathrm{f}}}\left(L-\lambda^{\top} \dot{\boldsymbol{y}}\right) d t
$$

where $L$ is the Lagrangian defined as:

$$
L=F+\lambda^{\top} \boldsymbol{g}+\mu f
$$

By substitution, we get:

$$
\begin{aligned}
L=\left[\frac{\nu_{\mathrm{L}}}{V_{\mathrm{L}}}\left(\overline{y_{0}}-y_{0}\right)-k_{\mathrm{d}} y_{0} y_{1}-k_{\mathrm{HO} \cdot \mathrm{NAs}} y_{0} C_{\mathrm{HO}} \cdot\right]\left(\frac{1}{\overline{y_{0}}}+\lambda_{0}\right) \\
+\left[\left(\frac{V_{\mathrm{G}}}{V_{\mathrm{L}}}\right) K_{G} a\left(y_{2} \mathrm{RT} / H-y_{1}\right)-\frac{v_{\mathrm{L}}}{V_{\mathrm{L}}} y_{1}-R_{i}\right] \lambda_{1} \\
+\left[\left(\frac{u}{V_{\mathrm{G}}}\right)\left(\overline{y_{2}}-y_{2}\right)-K_{G} a\left(y_{2} \mathrm{RT} / H-y_{1}\right)\right] \lambda_{2}+\mu\left[u-\mathrm{D}_{1}\right]
\end{aligned}
$$

The necessary condition for the minimum of $M$ is that its variation $\delta M$ be zero, that is, 


$$
\begin{gathered}
\delta M=\int_{\mathbf{0}}^{t_{\mathrm{f}}}\left[\left(L_{\boldsymbol{y}}+\dot{\boldsymbol{\lambda}}\right)^{\top} \boldsymbol{\delta} \boldsymbol{y}+\left(L_{\lambda}+\dot{\boldsymbol{y}}\right)^{\top} \boldsymbol{\delta} \boldsymbol{\lambda}+L_{\mu} \delta \mu+L_{u} \delta u\right] d t \\
-\boldsymbol{\lambda}^{\top}\left(t_{\mathrm{f}}\right) \boldsymbol{\delta} \boldsymbol{y}\left(t_{\mathrm{f}}\right)=0
\end{gathered}
$$

The coefficients of $\boldsymbol{\delta} \boldsymbol{\lambda}$ in the above equation are equal to zero because of the differential equations constraints. Since $\delta M$ should be zero at the minimum, the following equations are necessary at the minimum of $M$ :

$$
\begin{gathered}
\dot{\boldsymbol{\lambda}}=-L_{\boldsymbol{y}}, \dot{\boldsymbol{y}}=L_{\lambda}=\boldsymbol{g}, L_{\mu}=f \leq 0, L_{u}=0, \quad \lambda\left(t_{\mathrm{f}}\right)=0, \quad \mu \geq 0, \\
, \mu L_{\mu}=0
\end{gathered}
$$

The necessary conditions for the minimum:

- The state equations: [Equations (9.13-9.15)]

with the initial conditions:

$y_{0}(0)=\overline{y_{0}}, \quad y_{1}(0)=0, \quad y_{2}(0)=0$

- The costate equations:

$$
\begin{aligned}
\frac{d \lambda_{0}}{d t}=-L_{y_{0}}= & {\left[\left(\frac{\nu_{\mathrm{L}}}{V_{\mathrm{L}}}\right)+k_{\mathrm{d}} y_{1}+k_{\mathrm{HO} \cdot \mathrm{NAs}} C_{\mathrm{HO}} \cdot+k_{\mathrm{HO} \cdot \mathrm{NAs}} y_{0} \frac{d C_{\mathrm{HO}}}{d y_{0}}\right]\left(\frac{1}{\overline{y_{0}}}\right.} \\
& \left.+\lambda_{0}\right)+\lambda_{1} \frac{d R_{i}}{d y_{0}} \\
\frac{d \lambda_{1}}{d t}=-L_{y_{1}}= & {\left[k_{\mathrm{d}} y_{0}+k_{\mathrm{HO} \cdot \mathrm{NAs}} y_{0} \frac{d C_{\mathrm{HO}}}{d y_{1}}\right]\left(\frac{1}{\overline{y_{0}}}+\lambda_{0}\right) } \\
& +\left[\left(\frac{V_{G}}{V_{\mathrm{L}}}\right) K_{G} a+\left(\frac{\nu_{\mathrm{L}}}{V_{\mathrm{L}}}\right)+\frac{d R_{i}}{d y_{1}}\right] \lambda_{1}-K_{G} a \lambda_{2} \\
\frac{d \lambda_{2}}{d t}=-L_{y_{2}}= & -\left(\frac{V_{\mathrm{G}}}{V_{\mathrm{L}}}\right) K_{G} a(\mathrm{RT} / H) \lambda_{1}+\left[\left(\frac{u}{V_{\mathrm{G}}}\right)+K_{G} a \mathrm{RT} / H\right] \lambda_{2}
\end{aligned}
$$

with the final conditions:

$\lambda_{0}\left(t_{\mathrm{f}}\right)=0, \lambda_{1}\left(t_{\mathrm{f}}\right)=0, \lambda_{2}\left(t_{\mathrm{f}}\right)=0$

where:

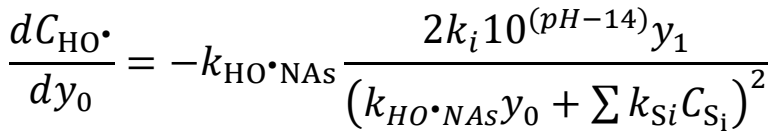

$$
\begin{aligned}
& \frac{d C_{\mathrm{HO}}}{d y_{1}}=\frac{2 k_{i} 10^{(p H-14)}}{k_{\mathrm{HO}}{ }^{N A s} y_{0}+\sum k_{\mathrm{Si}} C_{\mathrm{S}_{\mathrm{i}}}}
\end{aligned}
$$




$$
\begin{aligned}
& \frac{d C_{\mathrm{O}_{2}^{-}}}{d y_{0}}=\left(\frac{k_{2}}{k_{1}}\right) \frac{d C_{\mathrm{HO}^{\bullet}}}{d y_{0}} \\
& \frac{d C_{\mathrm{O}_{2}^{-}}}{d y_{1}}=\left(\frac{k_{2}}{k_{1}}\right) \frac{d C_{\mathrm{HO}^{\bullet}}}{d y_{1}} \\
& \frac{d R_{i}}{d y_{0}}=\left(k_{\mathrm{d}}+k_{1} \frac{d C_{\mathrm{C}_{2}^{-}}}{d y_{0}}+k_{2} \frac{d C_{\mathrm{HO}^{*}}}{d y_{0}}\right) y_{1} \\
& \frac{d R_{i}}{d y_{1}}=\left(k_{\mathrm{d}} y_{0}+k_{i} 10^{(p H-14)}+k_{1} C_{\mathrm{O}_{2}^{-}}+k_{2} C_{\mathrm{HO}^{*}}+k_{1} \frac{d C_{\mathrm{O}_{2}^{-}}}{d y_{1}}+k_{2} \frac{d C_{\mathrm{HO}^{*}}}{d y_{1}}\right)
\end{aligned}
$$

- Stationarity conditions w.r.t. controls, $u(t)$ :

$$
L_{u}=\left(\frac{\lambda_{2}}{V_{G}}\right)\left(\overline{y_{2}}-y_{2}\right)+\mu=0
$$

- The stationary condition with respect to the Lagrange multipliers $(\mu)$ :

$$
L_{\mu}=u-D_{1} \leq 0
$$

- $\mu \geq 0$, and the complimentary slackness condition:

$$
\mu\left[u-D_{1}\right]=0
$$

The last two necessary conditions were driven from the John Multiplier Theorem where the following preconditions must be satisfied (Upreti, 2013):

1. The Gateaux differentials of both $M$ and $f$ are weakly continuous near $\hat{u}(t)$.

2. The constraint qualification - There exists a $\delta u$ for which $f(\hat{u} ; \delta u) \neq 0$ whenever the constraint is active.

Observe that the complementary slackness condition, $\mu\left[u-D_{1}\right]=0$, requires $\mu$ to be zero when the constraint is inactive. Otherwise, $\mu$ could be zero or greater.

\subsubsection{Computational Algorithm to Determine Optimal $(\widehat{u})$}

The necessary conditions derived in the previous section contain nonlinear differential equations with split boundaries whose analytical solution is not possible. Therefore, the optimal control problem has to be solved numerically. The following is the computational algorithm, which was utilized to determine the optimal $u(t)$ : 
1. Transform the optimal control problem from the variable time interval $\left[0, t_{\mathrm{f}}\right]$ to the fixed $\sigma$-interval, $[0,1]$

2. Assume a value for the number of grids $(N)$ and the control function $u(t)$ at each grid point.

3. Integrate state equations forward using the initial conditions and the control function values.

4. Evaluate the objective functional.

5. Integrate costate equations backward using the final conditions.

6. Improve $u(t)$ using the gradient of the objective functional and the Penalty function method (Upreti, 2013).

7. Repeat computations Step 3 onward until there is no further reduction in the objective functional.

To handle the inequality, the penalty function method was used (Upreti, 2013). At any time, the Lagrange multipliers corresponding to the inequality are prescribed as:

$$
\mu=\left\{\begin{array}{l}
0 \text { if } f(t) \leq 0 \\
1 \text { if } f(t)>0
\end{array}\right\}
$$

Thus, the augmented objective functional has the penalty function $\mu$, which is positive and enlarges $M$ whenever any inequality is violated.

The computational algorithm was programmed in $\mathrm{C}++$ and executed on Itanium quad processor (64 bit, 3.4GHz, 8.0GB of RAM) with Intel compiler. The initial step size of integration and tolerances on integration accuracy and gradient improvement were reduced until the change in the objective functional $\left[\hat{y}_{0}\left(t_{\mathrm{f}}\right) / \bar{y}_{0}\right]$ value became negligible. At this point, the optimal policy $\left[\hat{u}_{i}(t)\right]$ was obtained.

\subsubsection{Solving the optimal control problem}

First, it has to be mentioned that the optimal control problem was solved by using variable final time instead of fixed final time. The preliminary results from solving the optimal control problem with variable final time showed that the final time could reach $150 \mathrm{~min}$. On the other hand, the experimental results, as will be shown later in Section 9.3, showed that the change in NAs concentration becomes negligible after $60 \mathrm{~min}$ of the ozonation process $\left(10^{-7} \mathrm{M}\right)$. Therefore, fixed final time was chosen to solve the optimal control problem. 
It also has to be emphasis that the outcome from solving the above optimal control problem is based on the necessary conditions for the minimum. The necessary conditions are the consequence of a minimum, whether local or global. The satisfaction of these conditions does not guarantee the global optimum but merely provides a candidate for it. It is the satisfaction of the sufficient conditions that guarantees the global optimum, which is almost an impossible task (Upreti, 2013; Mangasarian, 1966). Hence, to increase the confidence on the final optimal solution, the optimal control problem needs to be solved with different initial guesses to the numerical algorithm. If several optima are obtained, then the most optimal among them is adopted. There is no golden rule to ensure that the optimum is global.

The optimal control problem was solved using the previously mentioned algorithm. The number of grids were chosen to be 3600. The initial guess of the control function (gas flow rate) was assumed at each grid point. In each run, the initial guesses of the control function was fixed in the range $0.25-3.5 \mathrm{~L} \mathrm{~min}^{-1}$. For example, the initial guess of the control function was fixed at $0.25 \mathrm{~L} \mathrm{~min}^{-1}$ at all the grid points. The concentration profiles of NAs, which were obtained from solving the optimal control problem, are shown in Fig. 9.1. As can be seen from Fig. 9.1, the concentration profiles are very close to each other. This indicates, as expected, that there is a limitation for the removal of NAs in such continuous ozonation processes. The objective functionals $\left[\hat{y}_{0}\left(t_{\mathrm{f}}\right) / \bar{y}_{0}\right]$ were in the range of $15.55-16.58 \%$ for using control policies with initial guesses in the range of 0.25-3.5 $\mathrm{L} \mathrm{min}^{-1}$, respectively (Table 9.2). The differences in the objective functionals are insignificant. Therefore, it can be considered that the major factor in choosing the best optimal solution is the solution that provide the minimum consumption of ozone gas during the ozonation process. In this case, the operating cost is also expected to be very small and very close to the minimum.

Fig. 9.2 shows the control policies obtained from solving the optimal control problem using different initial guesses of the control function $\left[u_{i}\right]$. It is obvious that different initial guesses of the control functions produce different profiles for the control polices $\left(\hat{u}_{i}\right)$. The consumption of gaseous ozone were calculated, using Fig. 9.2, by determining the area under the curve for each control policy during the ozonation process (60 min). The results for the consumption of gaseous ozone are shown in Table 9.2. It is also obvious that the minimum consumption of gaseous ozone is achieved by using the optimal control policy $\left[\hat{u}_{3}(t)\right]$. For this control policy, the consumption of gaseous ozone was only $91.61 \mathrm{~L}$ during the ozonation process. By comparing Fig. 9.1 and Fig. 
9.2, it can be concluded that increasing gas flow rate above a certain level has no effect on the removal of NAs. In order to explain this behavior, it is necessary to study the concentration profiles of dissolved ozone.

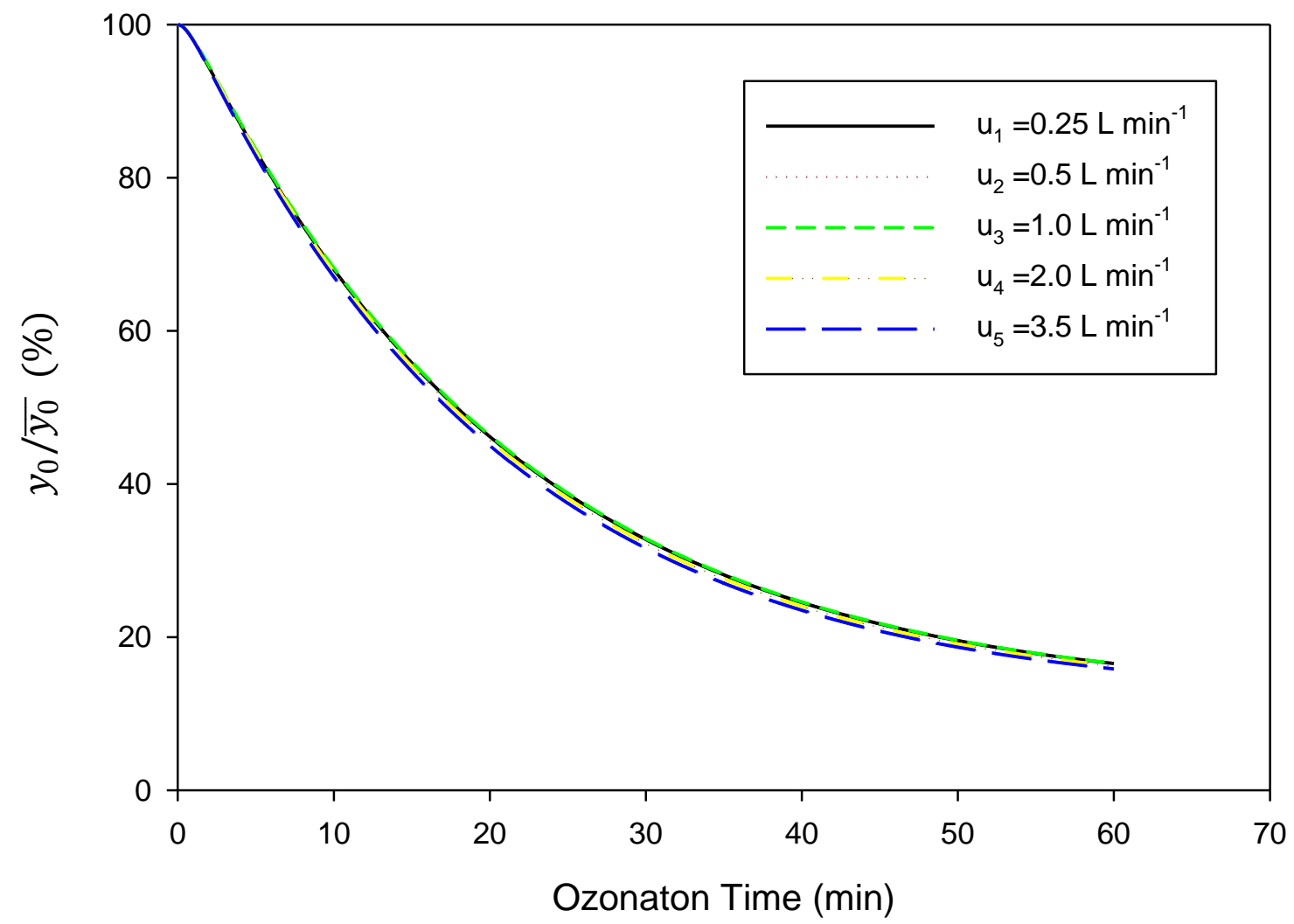

Figure 9.1 Concentration profiles of NAs using different optimal policies (gas flow rate) starting with different initial guesses for the control policies $\left(\mathrm{u}_{\mathrm{i}}\right)$.

Fig. 9.3 shows the concentration profiles of dissolved ozone generated from solving the optimal control problem using different initial guesses of the control policies (gas flow rate). Concentrations of dissolved ozone reached stationary concentration (around $7.0 \times 10^{-5} \mathrm{M}$ ). The effect of using different optimal control policies $\left[\hat{u}_{i}(t)\right]$ has little effect on the dissolved ozone concentration profiles, similar to the case of NAs concentration profiles (Fig. 9.1). It is known that ozone solubility in water is limited and it is depending on temperature (Roth and Sullivan, 1981). Therefore, increasing gas flowrate will increase the rate of ozone absorption from gas to liquid 
phase and the concertation of dissolved ozone will increase subsequently. Dissolved ozone concentration will increase to reach its maximum solubility at each specific temperature. Therefore, increasing gas flow rate above that level will have no effect on the ozonation process and it will only lead to increase the operating cost as a result of excess ozone gas generation.

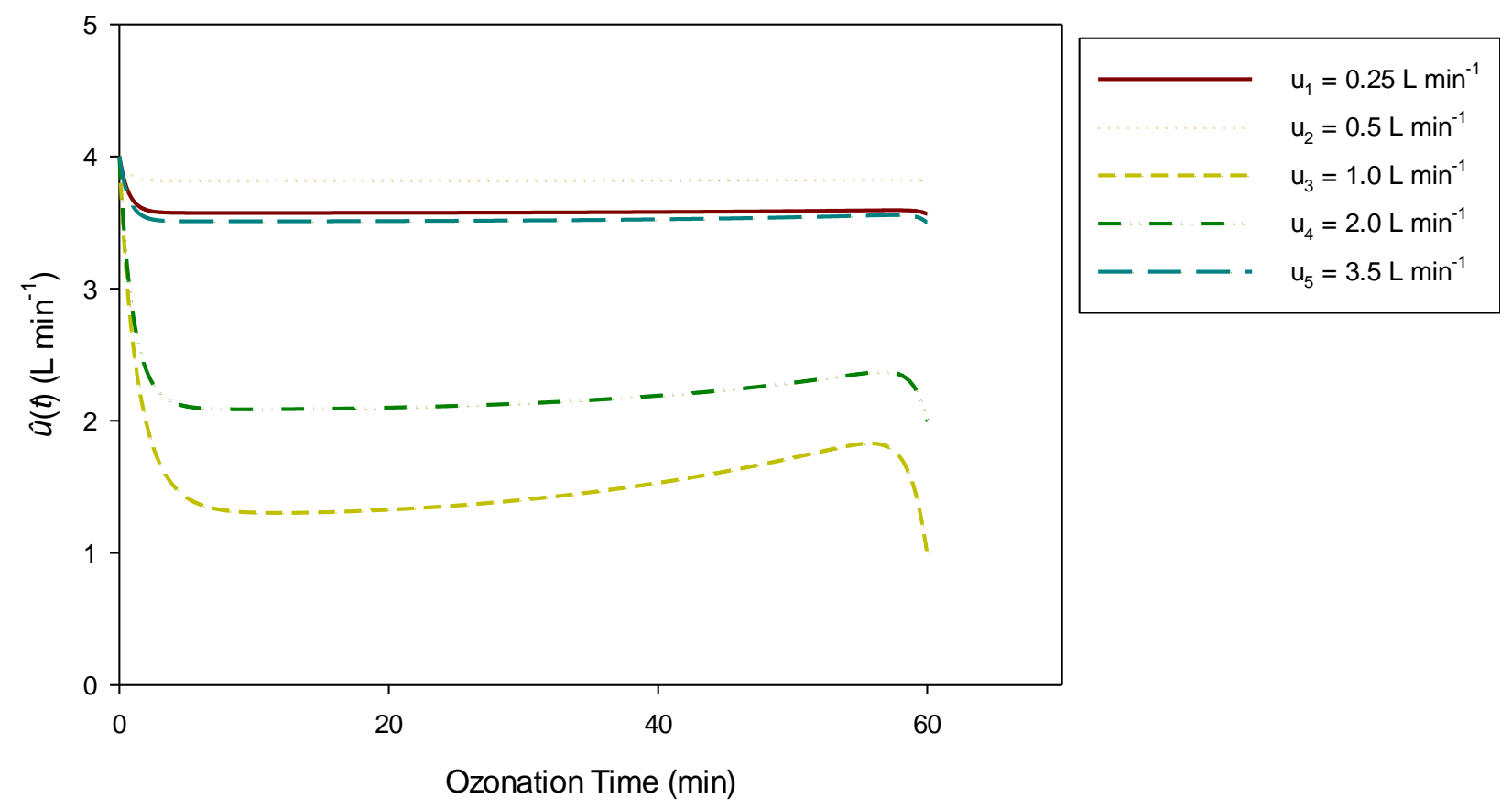

Figure 9.2 Optimal control policies (gas flow rates) starting with different initial guesses for these policies $\left(\mathrm{u}_{\mathrm{i}}\right)$. 
Table 9.2 Objective functional $\left[I=\hat{y}_{0}\left(t_{\mathrm{f}}\right) / \bar{y}_{0}\right]$ and gas consumption as functions of initial guesses of optimal policies $u_{i}$.

\begin{tabular}{ccc}
\hline & & \\
$\mathrm{u}_{\mathrm{i}}$ & $\hat{y}_{0}\left(t_{\mathrm{f}}\right) / \bar{y}_{0}$ & $\int_{0}^{\mathrm{t}_{\mathrm{f}}} \hat{u}(t) d t$ \\
& & $(\mathrm{~L})$ \\
\hline$\left(\mathrm{L} \mathrm{min}^{-1}\right)$ & $(\%)$ & 214.94 \\
0.25 & 15.57 & 229.30 \\
0.5 & 15.55 & $\mathbf{9 1 . 6 1}$ \\
$\mathbf{1}$ & $\mathbf{1 6 . 5 8}$ & 131.96 \\
2 & 16.2 & 211.60 \\
\hline 3.5 & 15.84 & \\
\hline
\end{tabular}

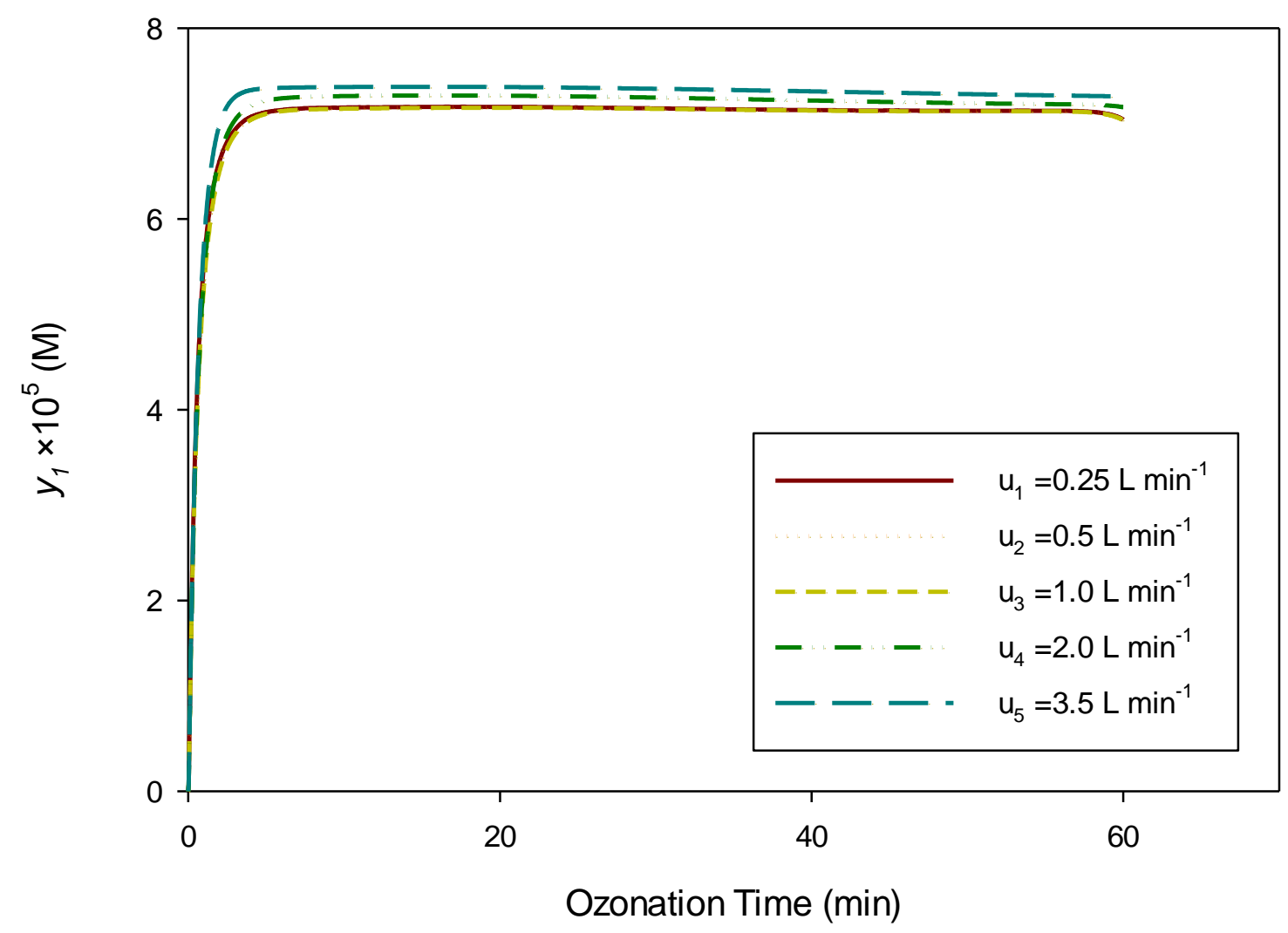

Figure 9.3 Concentration profiles of dissolved ozone using different optimal policies (gas flow rate) starting with different initial guesses for the control policies $\left(\mathrm{u}_{\mathrm{i}}\right)$. 


\subsection{VALIDATION OF CONCENTRATION PROFILES USING OPTIMAL POLICY}

Fig. 9.4 shows the predicted control policy, which was generated from solving the control problem, and the experimental control policy, which was generated by Labview software after implementing the predicted control policy in the continuous ozonation process. The periodic valleys in the experimental control policy were caused by the automatic periodic purging of the gas to reset the ozone gas monitor in the inlet stream to the reaction system. As can be seen from Fig 9.4, the experimental control policy is well matching the predicted one with a maximum absolute difference of $0.15 \mathrm{~L} \mathrm{~min}^{-1}$. This well matching was caused by choosing an optimum PID values to control the proportional control valve.

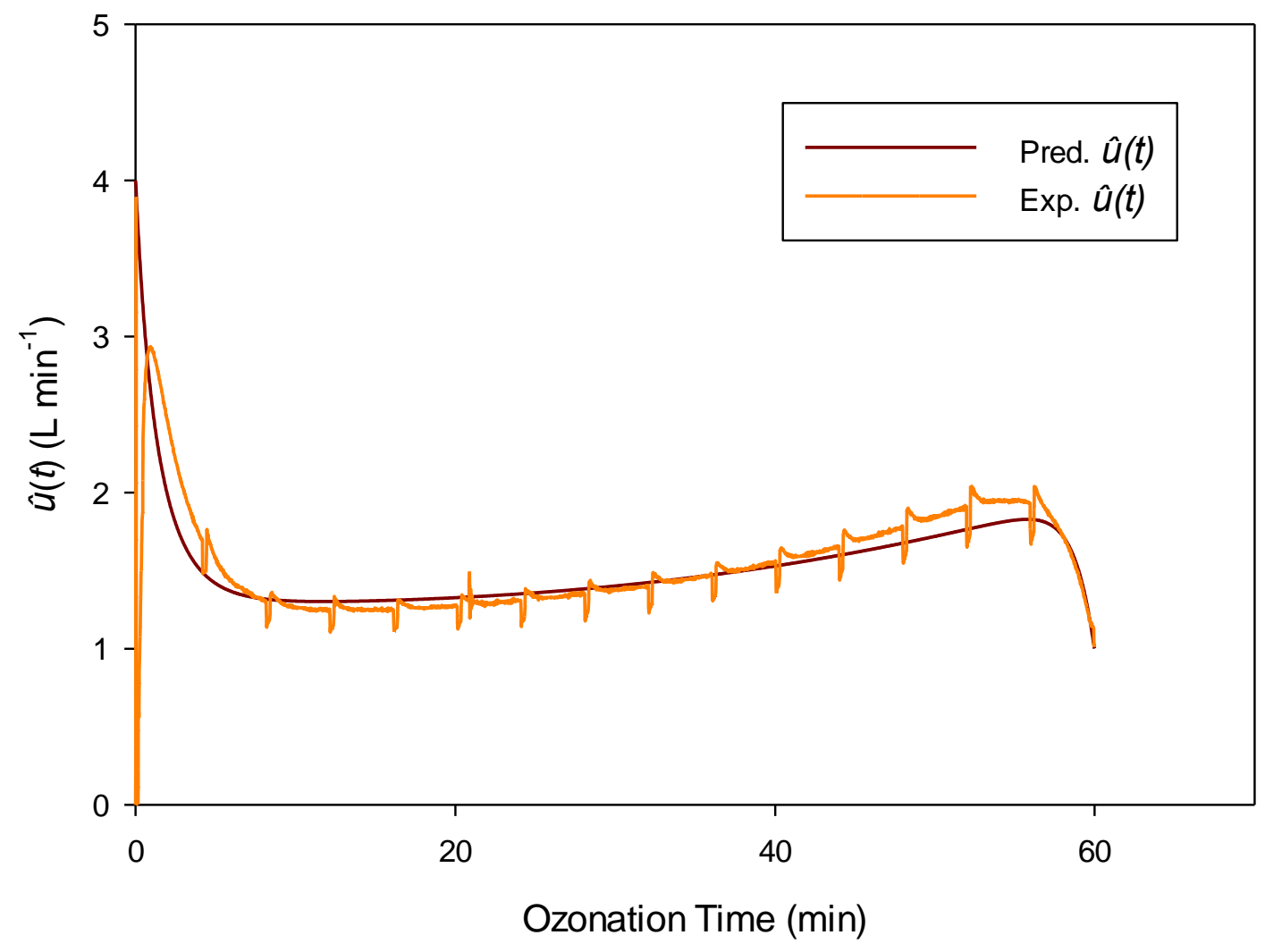

Figure 9.4 Predicted (Pred.) and experimental (Exp.) control policies $\widehat{u}_{3}(t)$. 
Fig. 9.5 shows a comparison between predicted concentration profiles, obtained from solving the optimal control problem, against the experimental concentration profiles obtained by implementing the optimal control policy $\left[\hat{u}_{3}(t)\right]$. As can be seen, predicted concertation profiles are well representing the experimental profiles. Experimental objective functional $\left[\hat{y}_{0}\left(t_{\mathrm{f}}\right) / \bar{y}_{0}\right]$ was 13.5\%. The absolute difference between the experimental and predicted objective functionals, obtained from solving the optimal control problem (16.58\%), was $2.18 \%$. Predicted concentration profiles for NAs, dissolved ozone and gaseous ozone were also validated for the whole ozonation time (60 $\mathrm{min}$ ) as can be seen in Fig. 9.5. The maximum absolute difference between predicted and experimental NAs, dissolved ozone, and gaseous ozone concentration profiles were $2.18 \%$, $4.56 \times 10^{-6} \mathrm{M}$, and $5.48 \times 10^{-5} \mathrm{M}$, respectively.

In another experiment, gas flow rate was fed at steady state flow of $1.5 \mathrm{~L} \mathrm{~min}^{-1}$. This value was determined by dividing the minimum consumption of gas $(91.61 \mathrm{~L}$ in Table 9.2) by the total ozonation time $(60 \mathrm{~min})$. The goal was to have a steady flow of the gas, which is expected to be easier to control than the gas flow which is changing with time (control policy) and at the same time considering gas consumption that is needed to reach minimum concentration of NAs in the outlet stream. Experimental objective functional $\left[y_{0}\left(t_{\mathrm{f}}\right) / \overline{y_{0}}\right]$ in this case was $18.42 \%$ and the absolute difference between experimental and predicted objective functionals was $1.3 \%$. By comparing the results obtained from using control policy and steady flow of the gas, it can be seen that the objective functional obtained from using the optimal control policy gives better results than the steady flow of the gas. This indicates that the demands for gas flow rate is changing with time. Therefore, operation with optimal policy gives better results. Nevertheless, using steady flow based on the results obtained from solving the optimal control problem could be a better choice in order to simplify the operation of the process.

It was mentioned earlier that the main purpose of using optimal control for a continuous ozonation process is to degrade NAs to the limit that the effluent from the process are considered rapid biodegradable substance with low toxicity level. Therefore, it is necessary to determine the COD, BOD/COD, and toxicity for ozonated NAs. 


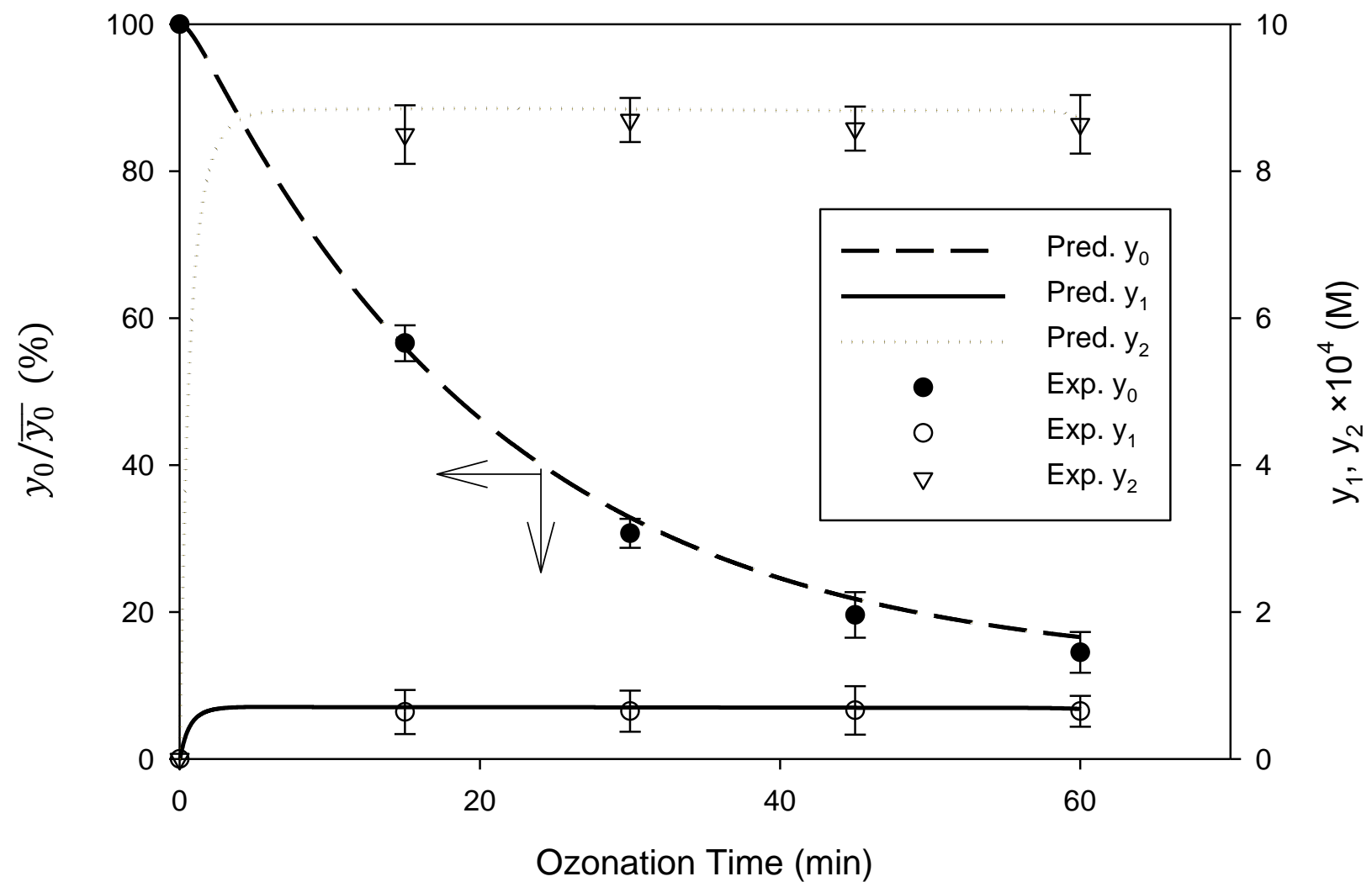

Figure 9.5 Predicted (Pred.) and experimental (Exp.) concentration profiles of NAs, dissolved ozone, and gaseous ozone obtained by using the optimal policy $\hat{u}_{3}(t)$.

\subsection{BIODEGRADABILITY AND DETOXIFICATION}

According to the United Nation standards, organic substances are considered as rapid biodegradable substances if BOD/COD ratio equal or exceed 0.5 (United Nations, 2009). The results for the $\mathrm{BOD} / \mathrm{COD}$ ratio of the liquid outlet stream from the continuous ozonation process obtained by implementing the optimal control policy $\left[\hat{u}_{3}(t)\right]$ are shown in Fig. 9.6. BOD/COD ratio increased to reach 0.52 at the final time. This means that the outlet stream from this continuous ozonation process contains only rapid biodegradable substances as a result of implementing the optimal control policy. Using steady flow of the gas at $1.5 \mathrm{~L} \mathrm{~min}^{-1}$, the BOD/COD ratio increased to reach 0.48 at the final time. 


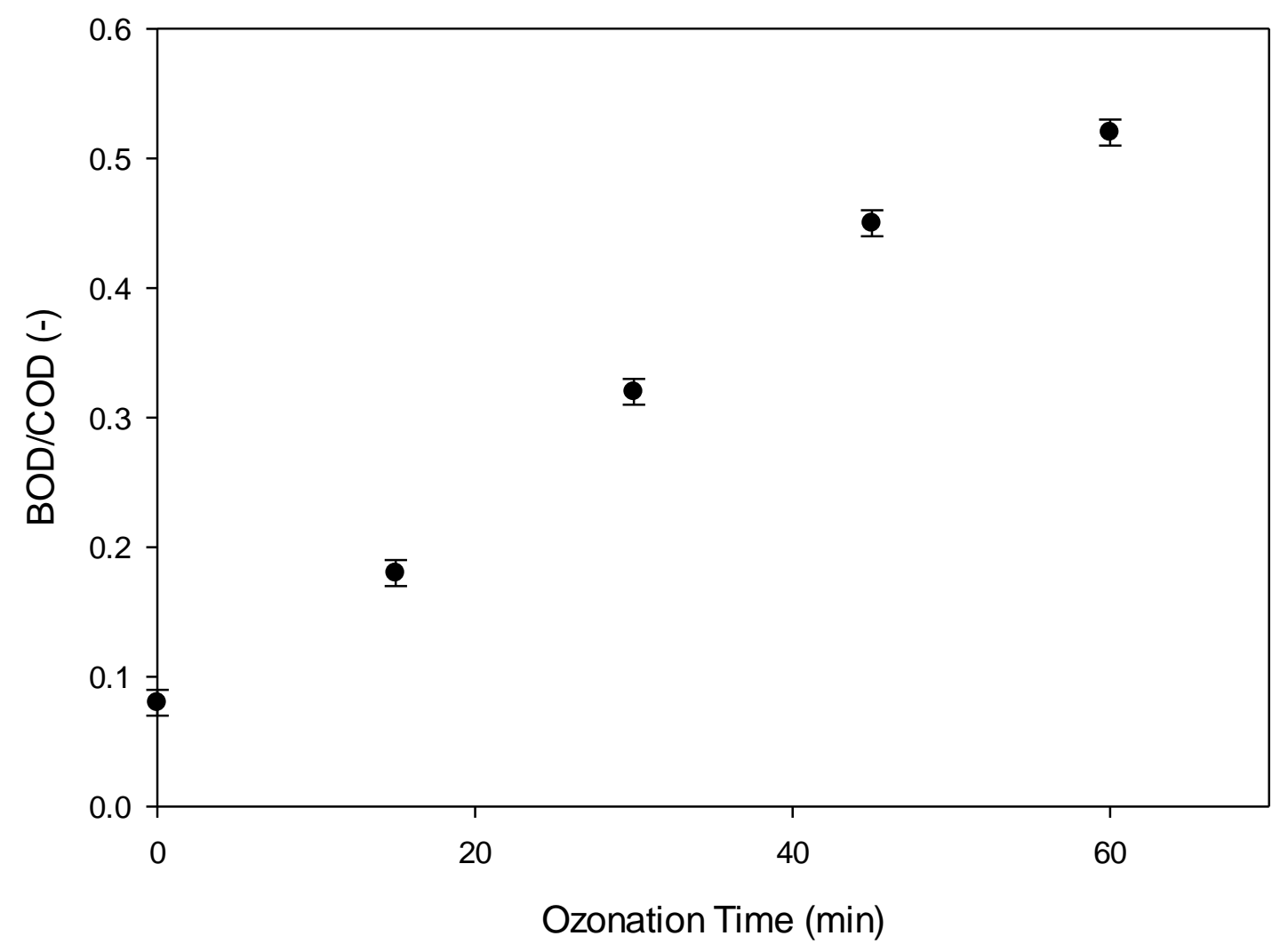

Figure 9.6 Biodegradability, as BOD/COD ratio, of ozonated NAs.

The results for the toxicity of the liquid outlet stream from the continuous ozonation process obtained by implementing the optimal control policy $\left[\hat{u}_{3}(t)\right]$ are shown in Fig. 9.7. At the final ozonation time (60 min), 92.77\% of the toxicity, compared to the inlet stream, was removed due to implementing the optimal policy on the gas flow rate. By comparing Fig. 9.6 and Fig 9.7, it can be concluded that the best practice is to use the optimally controlled continuous ozonation process to remove non-biodegradable organic substances, including NAs, and most of the toxicity followed by natural biodegradation process to degrade the remaining organic substances and remove the remaining toxicity. Using steady flow of the gas at $1.5 \mathrm{~L} \mathrm{~min}^{-1}$, the toxicity reduced by $91.2 \%$ at the final time. 


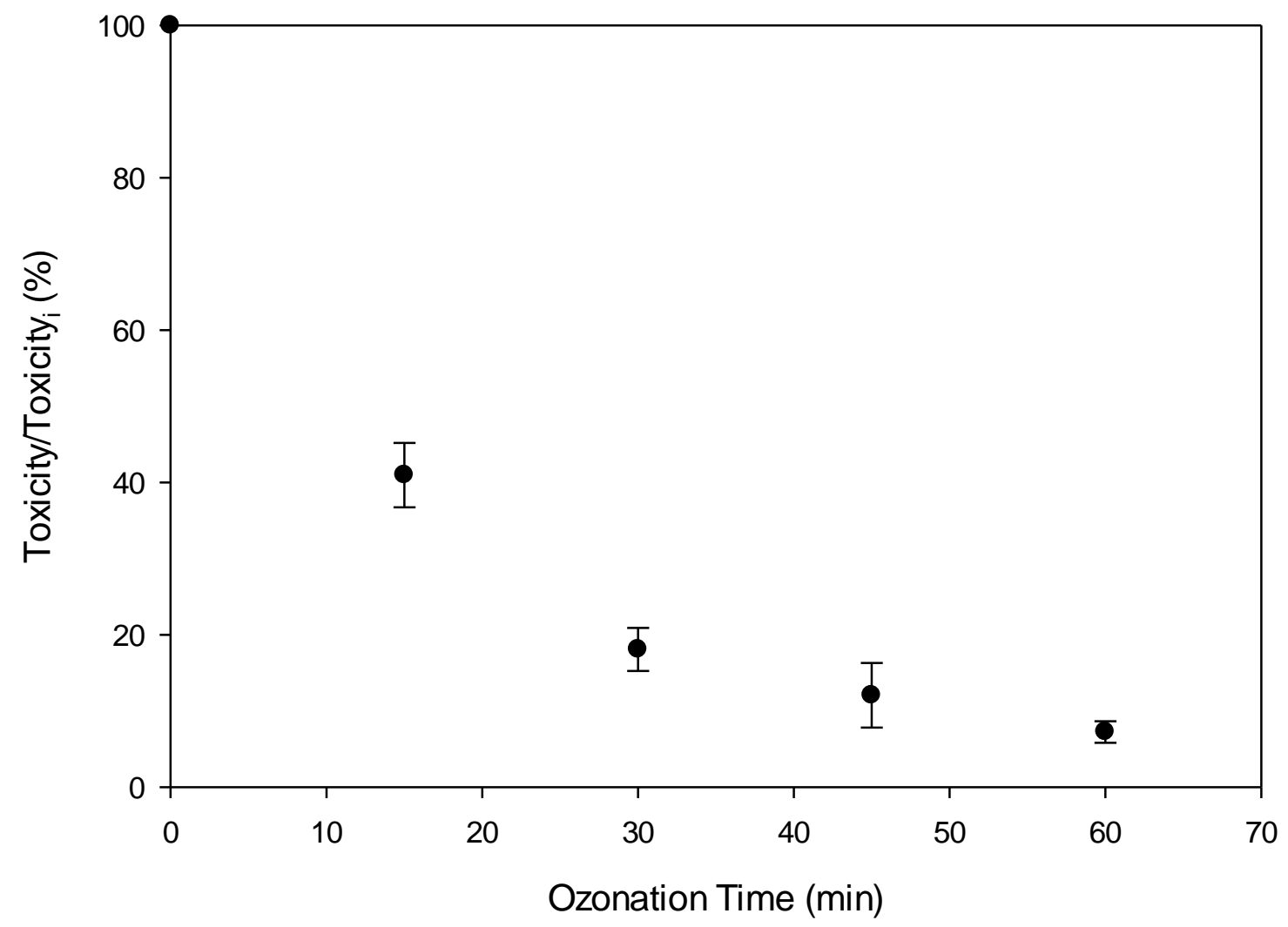

Figure 9.7 Toxicity of ozonated NAs. Toxicity $=83 \%$ loss of light. 


\section{CHAPTER 10: \\ OPTIMAL CONTROL FOR CONTINUOUS ADVANCED OXIDATION OF NAPHTHENIC AIDS IN WATER}

Results for the degradation of NAs from the catalytic ozonation process using AC (Chapter 7) were compared with the results from that of advanced oxidation using ozone/ hydrogen peroxide process (Chapter 8 ). The goal was to choose the process that provide the best results in order to optimally control its continuous process. Several factors were considered in the selection of the process, including the costs of both the chemicals and the separation of the catalyst. It was decided to conduct an optimal control for a continuous advanced oxidation process using ozone/ hydrogen peroxide and leave the optimal control of continuous catalytic ozonation process for future works.

\subsection{CONTINUOUS ADVANCED OXIDATION OF NAPHTHENIC ACIDS MATHEMATICAL MODEL}

Ozonation of NAs is carried out through two pathways: direct oxidation of NAs by molecular ozone, and indirect oxidation by hydroxyl radicals formed from the self-decomposition of ozone in water. Also, it was found that the chemical reactions are developed in the bulk water (Al jibouri et al., 2015a). Considering that the ozonation of NAs follows the mechanism of Staehelin and Hoigné (1985), NAs is oxidized as follows (Al jibouri et al., 2015a; Danckwerts, 1970):

The direct reaction with ozone:

$$
O_{3}+N A s \stackrel{k_{\mathrm{d}}}{\rightarrow} \text { Intermediates } \quad k_{\mathrm{d}}=3.34 \times 10^{16} \exp \left(-\frac{88.85}{\mathrm{R} T}\right)
$$

The indirect reaction with hydroxyl radicals:

$$
N A s+H O^{\circ} \stackrel{k_{\mathrm{HO}}{ }^{\mathrm{NAs}}}{\longrightarrow} \text { Intermediates } \quad k_{\mathrm{HO}}{ }^{\cdot \mathrm{NAs}}=6.79 \times 10^{12} \exp \left(-\frac{25.41}{\mathrm{RT}}\right)
$$

The equations of calculating direct and indirect rate constants $\left(k_{d}\right.$ and $\left.k_{H O^{*}}{ }_{N A S}\right)$ were derived in Chapter 6. (Al jibouri et al., 2015a). Combining the above information with mass balances of NAs and ozone, the models to predict the concentration profiles of NAs and ozone are: Mass balance of NAs; the disappearance of NAs is due to the direct and indirect ozonation: 


$$
\frac{d C_{\mathrm{NAs}}}{d t}=\left(\frac{v_{\mathrm{L}}}{V_{\mathrm{L}}}\right)\left(C_{\mathrm{NAsi}}-C_{\mathrm{NAs}}\right)-k_{\mathrm{d}} C_{\mathrm{NAs}} C_{\mathrm{O}_{3}}-k_{\mathrm{HO} \cdot{ }_{\mathrm{NAs}}} C_{\mathrm{NAs}} C_{\mathrm{HO}} \cdot
$$

where $V_{\mathrm{L}}, v_{\mathrm{L}}$, and $C_{\mathrm{NAs} i}$ are the liquid hold-up volume within the reactor $(2.7 \mathrm{~L})$, the volumetric liquid flow rate through the system and inlet NAs concentration, respectively.

Mass balance of dissolved ozone: based on the fact that the overall reaction between ozone and NAs is a slow reaction and assuming that gas and liquid phases are well mixed in the reactor, the mass balance of dissolved ozone is as follows:

$$
\frac{d C_{\mathrm{O}_{3}}}{d t}=K_{L} a\left(C_{\mathrm{O}_{3} \mathrm{G}} \mathrm{RT} / H-C_{\mathrm{O}_{3}}\right)-\left(\frac{\nu_{\mathrm{L}}}{V_{\mathrm{L}}}\right) C_{\mathrm{O}_{3}}-\sum_{i=1}^{5} r_{i}
$$

where $K_{L} a, C_{\mathrm{O}_{3} \mathrm{G}}, \mathrm{R}, H$, and $T$ are the overall mass transfer coefficient referred to the liquid phase, the concentration of ozone in the gas leaving the reactor, the universal gas constant, the Henry's law constant and temperature, respectively.

The term $\sum r_{i}$, represents the decomposition term of $\mathrm{O}_{3}$ due to chemical reactions, defined with neglecting the contribution of its direct reactions with intermediates. Using steady-state approximations for radical intermediates, one may derive the following expression for the rate of change of the aqueous $\mathrm{O}_{3}$ concentration (Beltrán, 1997; Glaze and Kangt, 1989):

$$
\begin{gathered}
\sum_{i=1}^{5} r_{i}=k_{d} C_{N A s} C_{O_{3}}+3 k_{i 2} 10^{(p H-14)} C_{O_{3}}+2 k_{i 1} 10^{(p H-11.8)} C_{H_{2} O_{2}} C_{O_{3}} \\
+\left(k_{4} 10^{(p H-11.8)}+k_{5}\right) C_{H_{2} O_{2}} C_{H O} \cdot+2 k_{7} C_{H O} C_{O_{3}}
\end{gathered}
$$

Mass balance of $\mathrm{O}_{3}$ in the gas phase:

$$
\frac{d C_{\mathrm{O}_{3 \mathrm{G}}}}{d t}=\left(\frac{v_{\mathrm{G}}}{V_{\mathrm{G}}}\right)\left(C_{\mathrm{O}_{3 \mathrm{Gi}}}-C_{\mathrm{O}_{3 \mathrm{G}}}\right)-\left(\frac{V_{\mathrm{L}}}{V_{\mathrm{G}}}\right) K_{L} a\left(C_{\mathrm{O}_{3 \mathrm{G}}} \mathrm{RT} / H-C_{\mathrm{O}_{3}}\right)
$$

where $v_{\mathrm{G}}, V_{\mathrm{G}}$, and $C_{\mathrm{O}_{3 \mathrm{Gi}}}$, are the gas volumetric flow rate, the gas hold-up volume within the reactor $(2.29 \mathrm{~L})$, and $\mathrm{O}_{3}$ gas concentration at the reactor inlet, respectively. Optimum liquid circulation flow rare $\left(2 \mathrm{~L} \mathrm{~min}^{-1}\right)$ and the liquid and gas hold-up volumes $\left(V_{\mathrm{L}}, V_{\mathrm{G}}\right)$ were determined experimentally in a previous work, by our research team, through pulse injection of methylene blue in a steady flow of pure water. More details can be found in our previous work (Al jibouri et al., 2015b).

It is important to notice that mass balance equations of intermediates should be included in the kinetic model since these compounds also consume $\mathrm{HO}^{\bullet}$ and $\mathrm{O}_{3}$. However, their direct and 
indirect reactions were neglected because of the lack of information about these intermediates as was explained earlier. The early analytical studies demonstrated the complexity of NAs mixtures, with about 1500 acids detected by Seifert and Teeter (1969). The complexity of NAs mixtures makes the detection of all NAs oxidation intermediates almost an impossible task. Therefore, the intermediates direct and indirect reactions of intermediates with $\mathrm{O}_{3}$ were not considered in this work due to lack of information about these intermediates. As a consequence, mass balance equations for intermediates were not considered.

Mass balance of hydrogen peroxide: considering the peroxide-consuming reactions, the expression for the rate of change of peroxide concentration can be obtained (Glaze and Kangt, 1989):

$$
\begin{gathered}
\frac{d C_{\mathrm{H}_{2} \mathrm{O}_{2}}}{d t}=\left(\frac{v_{\mathrm{L}}}{V_{\mathrm{L}}}\right)\left(C_{\mathrm{H}_{2} \mathrm{O}_{2 \mathrm{i}}}-C_{\mathrm{H}_{2} \mathrm{O}_{2}}\right)-k_{i 1} 10^{(p H-11.8)} C_{\mathrm{H}_{2} \mathrm{O}_{2}} C_{\mathrm{O}_{3}} \\
-\left(k_{4} 10^{(p H-11.8)}+k_{5}\right) C_{\mathrm{H}_{2} \mathrm{O}_{2}} C_{\mathrm{HO}}
\end{gathered}
$$

where $C_{\mathrm{H}_{2} \mathrm{O}_{2 \mathrm{i}}}$ is the inlet hydrogen peroxide concentration. In the continuous $\mathrm{AOP}, \mathrm{H}_{2} \mathrm{O}_{2}$ was injected prior to passing the $\mathrm{O}_{3} / \mathrm{O}_{2}$ gas mixture through the reaction solution. Therefore, it is expected that the $\mathrm{H}_{2} \mathrm{O}_{2} / \mathrm{O}_{3}$ ratio will always be high during the reaction. For this reason, the reaction rate is expected to be limited by the $\mathrm{O}_{3}$-transfer rate into the liquid phase. In this region, $\mathrm{O}_{3}$ concentration in the liquid phase is expected to be at steady state (i.e., $d C_{O_{3}} / d t=0$ ) and at a very low value (i.e. $C_{O_{3 G}} R T / H \gg C_{O_{3}}$ ). According to that, it can be shown that the steady state concentration of $\mathrm{HO}^{\bullet}$ can be expressed as follow (Beltrán, 1997; Glaze and Kangt, 1989):

$C_{\mathrm{HO}_{\mathrm{s}}}=\frac{K_{L} a C_{\mathrm{O}_{3 \mathrm{G}}} \mathrm{RT} / H}{k_{\mathrm{HO} \cdot \mathrm{NAs}} C_{\mathrm{NAs}}+\sum k_{\mathrm{Si}} C_{\mathrm{S}_{\mathrm{i}}}+\left(k_{4} 10^{(p H-11.8)}+k_{5}\right) C_{\mathrm{H}_{2} \mathrm{O}_{2}}}$

where $C_{\mathrm{S}_{\mathrm{i}}}$ is the concentration of $\mathrm{HO}^{\bullet}$ scavengers. Due to the unknown concentrations of the ozonated NAs (intermediates) at any time, in the denominator of Equation (10.8), the scavenger term of intermediates was simplified by assuming NAs, $\mathrm{HPO}_{4}^{2-}$ and $\mathrm{H}_{2} \mathrm{O}_{2}$ are the only scavengers in the reaction solution. In the phosphate-buffered system at $\mathrm{pH} 8.5$ in this study, the scavenger should be $\mathrm{HPO}_{4}^{2-}$ (Grabner et al., 1973). Therefore, the scavenger term in the denominator of Equation (10.8) can be expressed as follows:

$$
\sum k_{\mathrm{Si}} C_{\mathrm{S}_{\mathrm{i}}}=k_{\mathrm{S} 1} C_{\mathrm{HPO}_{4}^{2-}}
$$


where $k_{\mathrm{s} 1}$ is the rate constant for the reaction between the hydroxyl radical and the phosphate ions and has the value of $7.9 \times 10^{5} M^{-1} S^{-1}$ (Grabner et al., 1973).

The time-dependent NAs and peroxide concentrations can be expressed by rearrangement and simplification of Equations (10.3 and 10.7), respectively:

$$
\begin{aligned}
& \frac{d C_{\mathrm{NAs}}}{d t}=\left(\frac{v_{\mathrm{L}}}{V_{\mathrm{L}}}\right)\left(C_{\mathrm{NAsi}}-C_{\mathrm{NAs}}\right)-k_{\mathrm{HO} \cdot \mathrm{NAs}} C_{\mathrm{NAs}} C_{\mathrm{HO}} \cdot \\
& \frac{d C_{\mathrm{H}_{2} \mathrm{O}_{2}}}{d t}=\left(\frac{\nu_{\mathrm{L}}}{V_{\mathrm{L}}}\right)\left(C_{\mathrm{H}_{2} \mathrm{O}_{2 \mathrm{i}}}-C_{\mathrm{H}_{2} \mathrm{O}_{2}}\right)-\frac{0.5 k_{i 1} K_{L} a C_{\mathrm{O}_{3 \mathrm{G}}} \mathrm{RT}}{H} \\
& -0.5 C_{\mathrm{HO}_{\mathrm{s}}}\left[\left(k_{4} 10^{(p H-11.8)}+k_{5}\right) C_{\mathrm{H}_{2} \mathrm{O}_{2}}+k_{6} C_{\mathrm{HPO}_{4}^{2-}}\right]
\end{aligned}
$$

The Henry's law constant was determined experimentally in my previous work and it was found to be equal to $35.0 \times 10^{6} \mathrm{~Pa} \mathrm{M}^{-1}$ at $25^{\circ} \mathrm{C}$ (Chapter 8). The overall mass transfer coefficient was determined when the concentrations of both gaseous and dissolved ozone reached the stationary or equilibrium conditions. According to Equation (10.6), when gaseous and dissolved ozone reach their stationary concentrations (equilibrium state), the ozone accumulation term is zero and the concentrations of dissolved ozone and ozone in the gas phase leaving the reactor are $C_{\mathrm{O}_{3} \mathrm{~s}}$ and $C_{\mathrm{O}_{3} \mathrm{Gs}}$, respectively. Thus, Equation (10.6) becomes:

$$
K_{L} a=\left(\frac{v_{\mathrm{G}}}{V_{\mathrm{G}}}\right)\left(C_{\mathrm{O}_{3} \mathrm{Gi}}-C_{\mathrm{O}_{3} \mathrm{Gs}}\right) /\left(\left(\frac{V_{\mathrm{L}}}{V_{\mathrm{G}}}\right)\left(C_{\mathrm{O}_{3} \mathrm{Gs}} \mathrm{RT} / H-C_{\mathrm{O}_{3} \mathrm{~s}}\right)\right)
$$

Equation (10.12) was used to determine $K_{L} a$ at different gas flowrates. Table 10.1 shows the values of $K_{L} a$ which were determined at different gas flow rates.

Table 10.1 Determination of $K_{L} a$.

\begin{tabular}{cccc}
\hline $\begin{array}{c}v_{\mathrm{G}} \\
\left.(\mathrm{L} \mathrm{min})^{-1}\right)\end{array}$ & $\begin{array}{c}C_{\mathrm{O}_{3} \mathrm{Gi}} \\
(M) \times 10^{4}\end{array}$ & $\begin{array}{c}C_{\mathrm{O}_{3} \mathrm{Gs}} \\
(M) \times 10^{6}\end{array}$ & $\left.\begin{array}{c}K_{L} a \\
\left(\mathrm{~mol} \mathrm{~Pa}^{-1}\right.\end{array} L^{-1} \mathrm{~s}^{-1}\right) \times 10^{2}$ \\
\hline 0.5 & 8.21 & 0.0 & 0.29 \\
1.0 & 8.74 & 1.3 & 0.59 \\
3.5 & 8.91 & 3.2 & 1.40 \\
\hline
\end{tabular}




\subsection{OPTIMAL CONTROL PROBLEM}

Optimal control can be defined as the function that optimizes the performance of a system changing with time, space or any other independent variables. Control, on the other hand, is the use of a function to control the state of the system and obtain some desired performance (Upreti, 2013).

Subject to Equations (10.6), (10.10) and (10.11), the optimal control problem is to find the undetermined ozone/ oxygen gas mixture flow rate versus time or the control function $(u)$ to minimize the concentration of NAs in the outlet gas stream at the final time $\left(t_{\mathrm{f}}=60 \mathrm{~min}\right)$, i.e., minimize the objective functional:

$$
\begin{aligned}
I=\frac{y_{0}\left(t_{\mathrm{f}}\right)}{\overline{y_{0}}}=\frac{1}{\overline{y_{0}}} \int_{0}^{t_{\mathrm{f}}} d y_{0}=\int_{0}^{t_{\mathrm{f}}} \frac{d y_{0}}{d t} d t \\
=\frac{1}{\overline{y_{0}}} \int_{0}^{t_{\mathrm{f}}}\left\{\frac{v_{\mathrm{L}}}{V_{\mathrm{L}}}\left(\overline{y_{0}}-y_{0}\right)-k_{\mathrm{d}} y_{0} y_{1}-k_{\mathrm{HO} \cdot{ }_{\mathrm{NAs}}} y_{0} C_{\mathrm{HO}_{s}}\right\} d t
\end{aligned}
$$

where $y_{0}=C_{\mathrm{NAs}}, \overline{y_{0}}=C_{\mathrm{NAsi}}, \quad y_{1}=C_{\mathrm{O}_{3}}, \quad y_{2}=C_{\mathrm{O}_{3} \mathrm{G}}, \overline{y_{2}}=C_{O_{3} G i}, y_{3}=C_{H_{2} O_{2}}, \overline{y_{3}}=C_{H_{2} O_{2 i}}$ subject to the process models:

$$
\begin{aligned}
& \frac{d y_{0}}{d t}=\left(\frac{\nu_{\mathrm{L}}}{V_{\mathrm{L}}}\right)\left(\overline{y_{0}}-y_{0}\right)-k_{\mathrm{d}} y_{0} y_{1}-k_{\mathrm{HO} \cdot \mathrm{NAs}} y_{0} C_{\mathrm{HO}_{\mathrm{s}}} \\
& \frac{d y_{1}}{d t}=K_{L} a\left(y_{2} \mathrm{R} T / H-y_{1}\right)-\left(\frac{\nu_{\mathrm{L}}}{V_{\mathrm{L}}}\right) y_{1}-R_{i} \\
& R_{i}=\left(k_{\mathrm{d}} y_{0}+3 k_{i 2} 10^{(p H-14)}+2 k_{i 1} 10^{(p H-11.8)} y_{3}+2 k_{7} C_{\mathrm{HO}_{\mathrm{s}}}\right) y_{1} \\
& +\left(k_{4} 10^{(p H-11.8)}+k_{5}\right) y_{3} C_{\mathrm{HO}_{\mathrm{s}}} \\
& \frac{d y_{2}}{d t}=\left(\frac{u}{V_{\mathrm{G}}}\right)\left(\overline{y_{2}}-y_{2}\right)-\left(\frac{V_{\mathrm{L}}}{V_{\mathrm{G}}}\right) K_{L} a\left(y_{2} \mathrm{RT} / H-y_{1}\right) \\
& \frac{d y_{3}}{d t}=\frac{v_{\mathrm{L}}}{V_{\mathrm{L}}}\left(\overline{y_{3}}-y_{3}\right)-\frac{0.5 k_{i 1} K_{L} a y_{2} \mathrm{RT}}{H}-0.5 C_{\mathrm{HO}_{\mathrm{s}}}\left[\left(k_{4} 10^{(p H-11.8)}+k_{5}\right) y_{3}+k_{6} C_{H P O_{4}^{2-}}\right.
\end{aligned}
$$

with the conditions

$y_{0}(0)=\overline{y_{0}}, \quad y_{1}(0)=0, \quad y_{2}(0)=0, \quad y_{3}(0)=\overline{y_{3}}$

where 


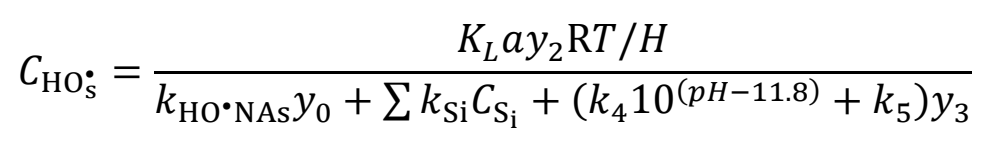

and the algebraic inequality constraint that the undetermined ozone/ oxygen gas mixture flow rate versus time or the control function $(u)$ will be less or equal to a specific value $\left(D_{1}\right)$ :

$$
u \leq D_{1} \text { or } u-D_{1} \leq 0
$$

This constraint is essential because unconstrained optimal control preliminary results showed that $u$ could jump to an impractical value (4000 $\mathrm{L} \mathrm{min}^{-1}$ ).

It has to be mentioned that the optimal control problem was solved first by using variable final time instead of fixed final time. The preliminary results from solving the optimal control problem with variable final time showed that the final time could reach $150 \mathrm{~min}$. On the other hand, the experimental results, as will be shown later in Section 10.3, showed that the change in NAs concentration becomes negligible after $45 \mathrm{~min}$ of the ozonation process $\left(10^{-7} \mathrm{M}\right)$. Therefore, fixed final time was chosen to solve the optimal control problem.

Equations (10.14-10.20) are the constraints of the optimal control problem for which the minimization of $I$ is equivalent to the minimization of the following augmented objective functional:

$$
\begin{aligned}
& M=\int_{0}^{t_{\mathrm{f}}}\left\{\frac{1}{\overline{y_{0}}}\left[\left(\frac{v_{L}}{V_{L}}\right)\left(\overline{y_{0}}-y_{0}\right)-k_{d} y_{0} y_{1}-k_{\mathrm{HO}} \cdot{ }_{\mathrm{NAs}} y_{0} C_{\mathrm{HO} \circ_{s}}\right]\right. \\
& +\lambda_{0}\left[-\dot{y}_{0}+\left(\frac{v_{\mathrm{L}}}{V_{\mathrm{L}}}\right)\left(\overline{y_{0}}-y_{0}\right)-k_{\mathrm{d}} y_{0} y_{1}-k_{\mathrm{HO}}{ }^{\mathrm{NAs} s} y_{0} C_{\mathrm{HO}_{\mathrm{s}}}\right] \\
& +\lambda_{1}\left[-\dot{y}_{1}+K_{L} a\left(y_{2} \mathrm{R} T / H-y_{1}\right)-\frac{v_{L}}{V_{L}} y_{1}-R_{i}\right] \\
& +\lambda_{2}\left[-\dot{y}_{2}+\left(\frac{u}{V_{\mathrm{G}}}\right)\left(\overline{y_{2}}-y_{2}\right)-\left(\frac{V_{\mathrm{L}}}{V_{\mathrm{G}}}\right) K_{L} a\left(y_{2} \mathrm{RT} / H-y_{1}\right)\right] \\
& +\lambda_{3}\left[-\dot{y}_{3}+\left(\frac{v_{\mathrm{L}}}{V_{\mathrm{L}}}\right)\left(\overline{y_{3}}-y_{3}\right)-0.5 k_{i 1} k_{L} a y_{2} R T\right. \\
& \left.-0.5 C_{H O_{s}^{*}}\left[\left(k_{4} 10^{(p H-11.8)}+k_{5}\right) y_{3}+k_{6} C_{\mathrm{HPO}_{4}^{2-}}\right]\right] \\
& \left.+\mu\left[u-\mathrm{D}_{1}\right]\right\} d t
\end{aligned}
$$


where $\lambda_{i}$ are the undetermined costate variables and $\mu$ are the time dependent Lagrange multipliers corresponding to the equality constraints.

\subsubsection{Necessary Conditions for the Minimum}

The above augmented functional can be rewritten as follow:

$$
\begin{gathered}
M=\int_{0}^{t_{\mathrm{f}}} F\left(y_{0}, y_{1}, y_{2}\right)+\lambda_{0} G_{0}\left(y_{0}, y_{1}, y_{2}\right)+\lambda_{1} G_{1}\left(y_{0}, y_{1}, y_{2}, y_{3}\right)+\lambda_{2} G_{2}\left(y_{1}, y_{2}, u\right) \\
\quad+\lambda_{3} G_{3}\left(y_{2}, y_{3}\right)+\mu f d t
\end{gathered}
$$

or in the general form:

$$
M=\int_{0}^{t_{\mathrm{f}}}\left[F+\lambda^{\top}(-\dot{\boldsymbol{y}}+\boldsymbol{g})+\mu f\right] d t=\int_{0}^{t_{f}}\left(L-\lambda^{\top} \dot{\boldsymbol{y}}\right) d t
$$

where $L$ is the Lagrangian defined as:

$$
\begin{aligned}
L=F+\lambda^{\top} \boldsymbol{g} & +\mu f \\
L=\left[( \frac { v _ { \mathrm { L } } } { V _ { \mathrm { L } } } ) \left(\overline{y_{0}}\right.\right. & \left.\left.-y_{0}\right)-k_{\mathrm{d}} y_{0} y_{1}-k_{\mathrm{HO} \cdot{ }^{\circ} \mathrm{s}} y_{0} C_{\mathrm{HO}_{\mathrm{s}}}\right]\left(\frac{1}{\overline{y_{0}}}+\lambda_{0}\right) \\
+ & {\left[K_{L} a\left(y_{2} \mathrm{RT} / H-y_{1}\right)-\left(\frac{\nu_{\mathrm{L}}}{V_{\mathrm{L}}}\right) y_{1}-R_{i}\right] \lambda_{1} } \\
+ & {\left[\left(\frac{u}{V_{\mathrm{G}}}\right)\left(\overline{y_{2}}-y_{2}\right)-\left(\frac{V_{\mathrm{L}}}{V_{\mathrm{G}}}\right) K_{L} a\left(y_{2} \mathrm{RT} / H-y_{1}\right)\right] \lambda_{2} } \\
+ & {\left[\left(\frac{v_{\mathrm{L}}}{V_{\mathrm{L}}}\right)\left(\overline{y_{3}}-y_{3}\right)-0.5 k_{i 1} k_{L} a y_{2} \mathrm{RT}\right.} \\
& \left.-0.5 C_{\mathrm{HO}_{\mathrm{s}}}\left[\left(k_{4} 10^{(p H-11.8)}+k_{5}\right) y_{3}+k_{6} C_{\mathrm{HPO}_{4}^{2-}}\right]\right] \lambda_{3}+\mu\left[u-\mathrm{D}_{1}\right]
\end{aligned}
$$

The necessary condition for the minimum of $M$ is that its variation $\delta M$ be zero, that is,

$$
\delta M=\int_{0}^{t_{\mathrm{f}}}\left[\left(L_{y}+\dot{\boldsymbol{\lambda}}\right)^{\top} \delta \boldsymbol{y}+\left(L_{\lambda}+\dot{\boldsymbol{y}}\right)^{\top} \delta \boldsymbol{\lambda}+L_{\mu} \delta \mu+L_{u} \delta u\right] d t-\lambda^{\top}\left(t_{\mathrm{f}}\right) \delta y\left(t_{\mathrm{f}}\right)=0
$$

The coefficients of $\delta \lambda$ in the above equation are equal to zero because of the differential equations

constraints. Since $\delta M$ should be zero at the minimum, the following equations are necessary at the minimum of $M$ : 


$$
\begin{gathered}
\dot{\boldsymbol{\lambda}}=-L_{\boldsymbol{y}}, \quad \boldsymbol{y}=L_{\lambda}=\boldsymbol{g}, \quad L_{\mu}=f \leq 0, \quad L_{u}=0, \quad \lambda\left(t_{f}\right)=0, \quad \mu \geq 0, \\
, \mu L_{\mu}=0
\end{gathered}
$$

The necessary conditions for the minimum

- The state equations: [Equations (10.14-10.18)] with the conditions:

$y_{0}(0)=\overline{y_{0}}, \quad y_{1}(0)=0, \quad y_{2}(0)=0, \quad y_{3}(0)=\overline{y_{3}}$

- The costate equations:

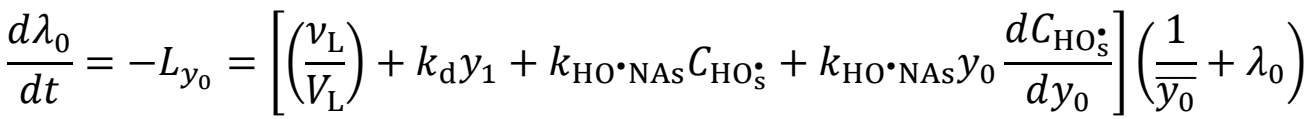

$$
\begin{aligned}
& +\lambda_{1} \frac{d R_{i}}{d y_{0}}+0.5\left[\left(k_{4} 10^{(p H-11.8)}+k_{5}\right) y_{3}+k_{6} C_{\mathrm{HPO}_{4}^{2-}}\right] \frac{d C_{\mathrm{HO}_{s}}}{d y_{1}} \lambda_{3} \\
& \frac{d \lambda_{1}}{d t}=-L_{y_{1}}=\left[k_{\mathrm{d}} y_{0}+k_{\mathrm{HO} \cdot \mathrm{NAs}} y_{0} \frac{d C_{\mathrm{HO}_{s}^{*}}}{d y_{1}}\right]\left(1+\lambda_{0}\right)+\left[K_{L} a+\left(\frac{v_{\mathrm{L}}}{V_{\mathrm{L}}}\right)+\frac{d R_{i}}{d y_{1}}\right] \lambda_{1} \\
& -\left(\frac{V_{\mathrm{L}}}{V_{\mathrm{G}}}\right) K_{L} a \lambda_{2} \\
& \frac{d \lambda_{2}}{d t}=-L_{y_{2}}=-K_{L} a \mathrm{R} T / H \lambda_{1}+\left[\left(\frac{u}{V_{\mathrm{L}}}\right)+\frac{\left(\frac{V_{\mathrm{L}}}{V_{\mathrm{G}}}\right) K_{L} a R T}{H}\right] \lambda_{2}+0.5 k_{i 1}\left(k_{L} a \mathrm{R} T / H\right) \lambda_{3} \\
& \frac{d \lambda_{3}}{d t}=-L_{y_{3}}=\left[\left(\frac{u}{V_{L}}\right)+\frac{\left(\frac{V_{\mathrm{L}}}{V_{\mathrm{G}}}\right) K_{L} a \mathrm{R} T}{H}\right] \lambda_{2}+\frac{d R_{i}}{d y_{3}} \lambda_{1} \\
& +\left[\left(\frac{u}{V_{\mathrm{L}}}\right)+0.5\left[\left(k_{4} 10^{(p H-11.8)}+k_{5}\right) y_{3}+k_{6} C_{\mathrm{HPO}_{4}^{2-}}\right] \frac{d C_{\mathrm{HO}_{s}^{*}}}{d y_{1}}\right. \\
& \left.+0.5 C_{\mathrm{HO}_{\mathrm{s}}}\left[\left(k_{4} 10^{(p H-11.8)}+k_{5}\right)\right]\right]
\end{aligned}
$$

with the conditions:

$\lambda_{0}\left(\mathrm{t}_{\mathrm{f}}\right)=0, \lambda_{1}\left(\mathrm{t}_{\mathrm{f}}\right)=0, \lambda_{2}\left(\mathrm{t}_{\mathrm{f}}\right)=0, \lambda_{3}\left(\mathrm{t}_{\mathrm{f}}\right)=0$

where: 


$$
\begin{aligned}
& \frac{d C_{\mathrm{HO}}}{d y_{0}}=-\frac{k_{\mathrm{HO} \cdot{ }^{*} A s} K_{L} a y_{2} \mathrm{RT} / H}{\left(k_{\mathrm{HO} \cdot \mathrm{NAs}} y_{0}+\sum k_{\mathrm{Si}} C_{\mathrm{S}_{\mathrm{i}}}+\left(k_{4} 10^{(p H-11.8)}+k_{5}\right) y_{3}\right)^{2}} \\
& \frac{d C_{\mathrm{HO}^{*}}}{d y_{2}}=\frac{K_{L} a \mathrm{RT} / H}{\mathrm{k}_{\mathrm{HO}} \cdot \mathrm{NAs}_{0}+\sum k_{\mathrm{Si}} C_{\mathrm{S}_{\mathrm{i}}}+\left(k_{4} 10^{(p H-11.8)}+k_{5}\right) y_{3}} \\
& \frac{d C_{\mathrm{HO}^{\bullet}}}{d y_{3}}=-\frac{\left(k_{4} 10^{(p H-11.8)}+k_{5}\right) K_{L} a y_{2} \mathrm{RT} / H}{\left(k_{\mathrm{HO} \cdot \mathrm{NAs}} y_{0}+\sum k_{\mathrm{Si}} C_{\mathrm{S}_{\mathrm{i}}}+\left(k_{4} 10^{(p H-11.8)}+k_{5}\right) y_{3}\right)^{2}} \\
& \frac{d R_{i}}{d y_{0}}=k_{\mathrm{d}} y_{1} \\
& \frac{d R_{i}}{d y_{1}}=k_{\mathrm{d}} y_{0}+3 k_{i 2} 10^{(p H-14)}+2 k_{i 1} 10^{(p H-11.8)} y_{3}+2 k_{7} C_{\mathrm{HO}_{\mathrm{s}}} \\
& \frac{d R_{i}}{d y_{2}}=\left(k_{4} 10^{(p H-11.8)}+k_{5}\right) y_{3} \frac{d C_{\mathrm{HO}_{s}}}{d y_{2}} \\
& \frac{d R_{i}}{d y_{3}}=2 k_{i 1} 10^{(p H-11.8)} y_{1}+\left(k_{4} 10^{(p H-11.8)}+k_{5}\right) C_{\mathrm{HO}_{\mathrm{s}}} \\
& +\left[\left(k_{4} 10^{(p H-11.8)}+k_{5}\right) y_{3}+2 k_{7} y_{1}\right] \frac{d C_{\mathrm{HO}_{\mathrm{s}}}}{d y_{2}}
\end{aligned}
$$

- Stationarity conditions w.r.t. controls, $u(t)$

$$
L_{u}=\left(\frac{\lambda_{2}}{V_{\mathrm{G}}}\right)\left(\overline{y_{2}}-y_{2}\right)+\mu=0
$$

- The stationary condition with respect to the Lagrange multipliers $(\mu)$

$$
L_{\mu}=u-D_{1} \leq 0
$$

- $\mu \geq 0$, and the complimentary slackness condition:

$$
\mu\left[u-D_{1}\right]=0
$$

\subsubsection{Computational Algorithm to Determine Optimal $(\widehat{u})$}

The computational algorithm, which was used to solve the optimal control problem, was similar to the algorithm described in Section 9.2.2.

\subsubsection{Solving the Optimal Control Problem}

It has to be mentioned that the outcome from solving the above optimal control problem is based on the necessary conditions for the optimum. The necessary conditions are the consequence of an optimum, whether local or global. The satisfaction of these conditions does not guarantee 
the global optimum but merely provides a candidate for it. It is the satisfaction of the sufficient conditions that guarantees the global optimum, which is almost an impossible task (Mangasarian, 1966; Upreti, 2013). Hence, to increase the confidence on the final optimal solution, the optimal control problem needs to be solved with different initial guesses to the numerical algorithm. If several optima are obtained, then the most optimal among them is adopted. There is no golden rule to ensure that the optimum is global.

The optimal control problem was solved using the previously mentioned algorithm. The number of grids was chosen to be 3600 . The initial guess of the control function (gas flow rate) was assumed at each grid point. In each run, the initial guesses of the control function was fixed in the range $0.25-3.5 \mathrm{~L} \mathrm{~min}^{-1}$. For example, the initial guess of the control function was fixed at $0.25 \mathrm{~L} \mathrm{~min}^{-1}$ at all the grid points. The concentration profiles of NAs, which were obtained from solving the optimal control problem, are shown in Fig. 10.1. As can be seen from Fig. 10.1, the concentration profiles are very close to each other. This indicates that the minimum concentration of NAs at the final time (the objective functional) has been reached even with using different initial guesses of the control functions. The objective functionals $\left[\hat{y}_{0}\left(t_{\mathrm{f}}\right) / \bar{y}_{0}\right]$ were in the range of 4.20$4.05 \%$ for using control policies with initial guesses in the range of $0.25-3.5 \mathrm{~L} \mathrm{~min}^{-1}$, respectively (Table 10.2). In this case, the differences in the objective functionals are insignificant. Therefore, it can be considered that the major factor in choosing the best optimal solution is the solution that provides the minimum consumption of ozone gas during the AOP (45 min). In this case, the operating cost is also expected to be the smallest and very close to the minimum.

Fig. 10.2 shows the control policies obtained from solving the optimal control problem using different initial guesses of the control function $\left[\mathrm{u}_{\mathrm{i}}\right]$. It is obvious that different initial guesses of the control functions produce different profiles for the control polices $\left(\hat{u}_{i}\right)$. The consumption of gaseous ozone was calculated, using Fig. 10.2, by determining the area under the curve for each control policy during the ozonation process ( $45 \mathrm{~min})$. The results for the consumption of gaseous ozone are shown in Table 10.2. It is also obvious that the minimum consumption of gaseous ozone is achieved when the the control policies are $\hat{u}_{1}=\hat{u}_{2}=\hat{u}_{3}$. For these control policies, the consumption of gaseous ozone was only $110.20 \mathrm{~L}$ of the gas during the ozonation process (45 min). By comparing Fig. 10.1 and Fig. 10.2, it can be concluded that increasing gas flow rate above a certain level has no effect on the removal of NAs and it will only increase the operating cost as a result of generating an excess amount of ozone gas. 


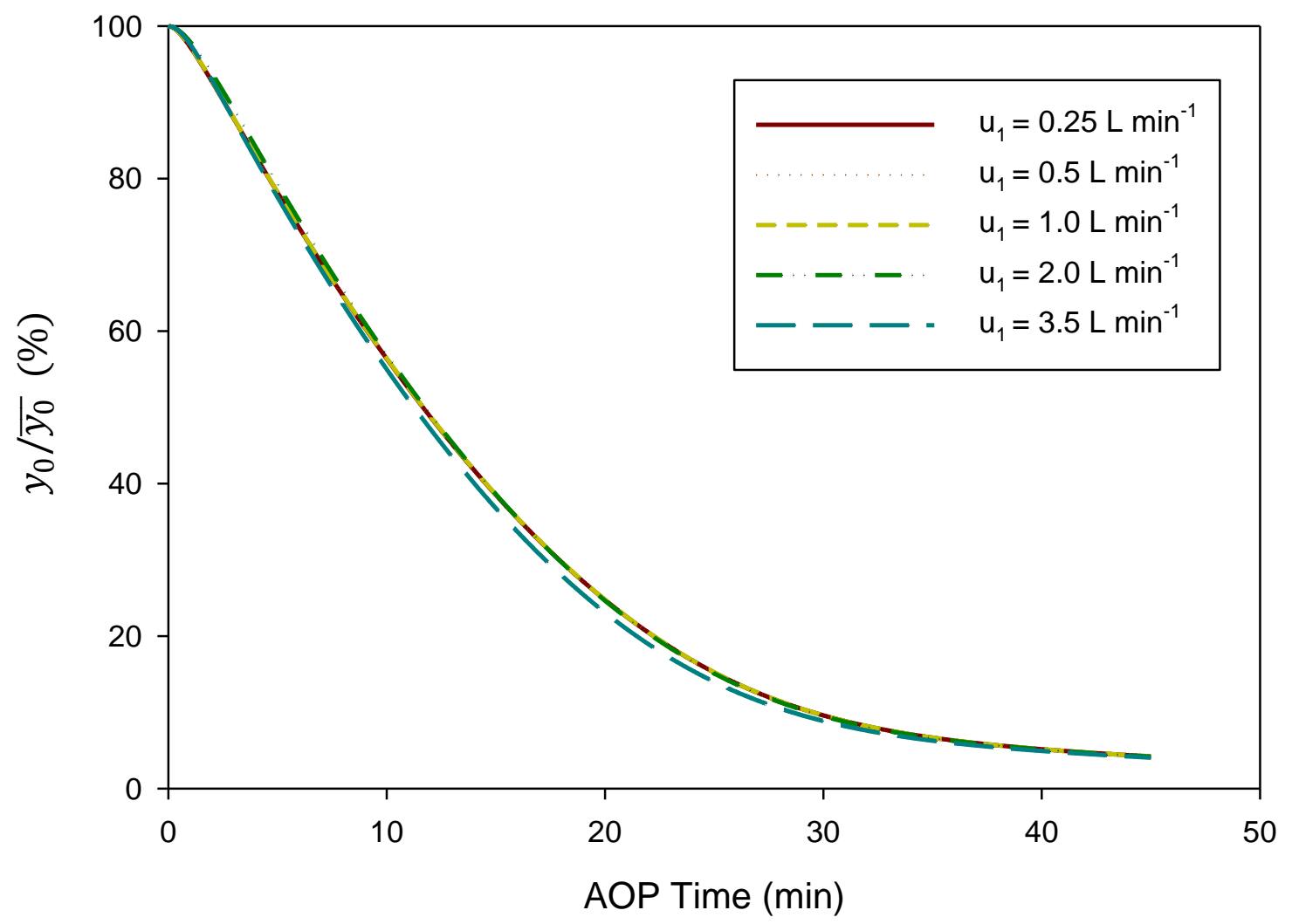

Figure 10.1 Concentration profiles of NAs using different optimal policies (gas flow rate) starting with different initial guesses for the control policies $\left(u_{i}\right)$.

Fig. 10.3 shows the concentration profiles of hydrogen peroxide generated from solving the optimal control problem using different control policies (gas flow rate). Around 71.41-74.74\% of the inlet hydrogen peroxide has been consumed in the continuous AOP using control policies $\left(\hat{u}_{1} \sim \hat{u}_{5}\right) \mathrm{L} \mathrm{min}^{-1}$, respectively. Increasing gas flow rate will increase the absorption rate of ozone at the gas-liquid interface. The rate of reaction between dissolved ozone and hydrogen peroxide will increase subsequently. It is known that ozone solubility in water is limited and it is depending on temperature (Roth and Sullivan, 1981). Therefore, increasing gas flowrate will increase the rate of ozone absorption from gas to liquid phase and the concentration of dissolved ozone at the gasliquid interface will increase subsequently. Solving the optimal control problem showed that the concentration profiles of dissolved ozone in the bulk of liquid was very close to zero during the 
AOP. This results was supported by the experimental results were no dissolved ozone was detected during the AOP. Therefore, it was fair to assume that most of the reaction between ozone and hydrogen peroxide occurs at the liquid interface. By considering; reaction between hydrogen peroxide and dissolved ozone is the major reaction for hydrogen peroxide consumption; perfect mixing so dissolved ozone concentration at the interface is linked to gaseous ozone through Henry law, and gaseous ozone reaches stationary concentration shortly after the starting of AOP (Fig. 10. 4), can explain the first order consumption rate of hydrogen peroxide as shown in Fig. (10.3).

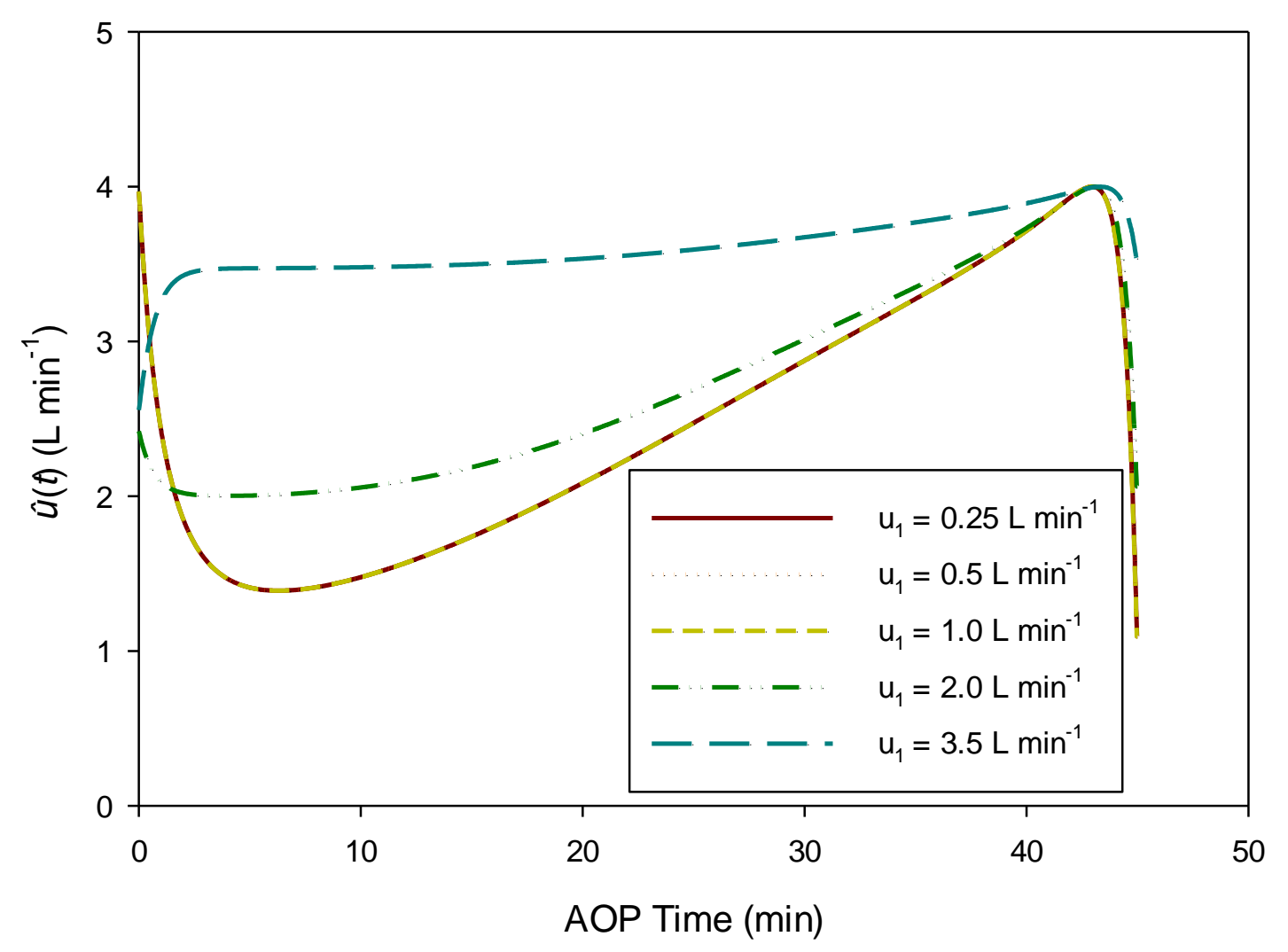

Figure 10.2 Optimal control policies (gas flow rates) starting with different initial guesses for these policies $\left(u_{i}\right)$. 
Table 10.2 Objective functional $\left[I=\hat{y}_{0}\left(t_{\mathrm{f}}\right) / \bar{y}_{0}\right]$ and gas consumption as functions of initial guesses of optimal policies $u_{i}$.

\begin{tabular}{ccc}
\hline & & \\
$\mathrm{u}_{\mathrm{i}}$ & $\hat{y}_{0}\left(t_{\mathrm{f}}\right) / \bar{y}_{0}$ & $\int_{0}^{\mathrm{t}_{\mathrm{f}}} \hat{u}(t) d t$ \\
\hline$\left(\mathrm{L} \mathrm{min}^{-1}\right)$ & $(\%)$ & $(\mathrm{L})$ \\
\hline 0.25 & 4.20 & 110.20 \\
0.5 & 4.20 & 110.20 \\
1 & 4.20 & 110.20 \\
2 & 4.19 & 121.64 \\
3.5 & 4.05 & 162.36 \\
\hline
\end{tabular}

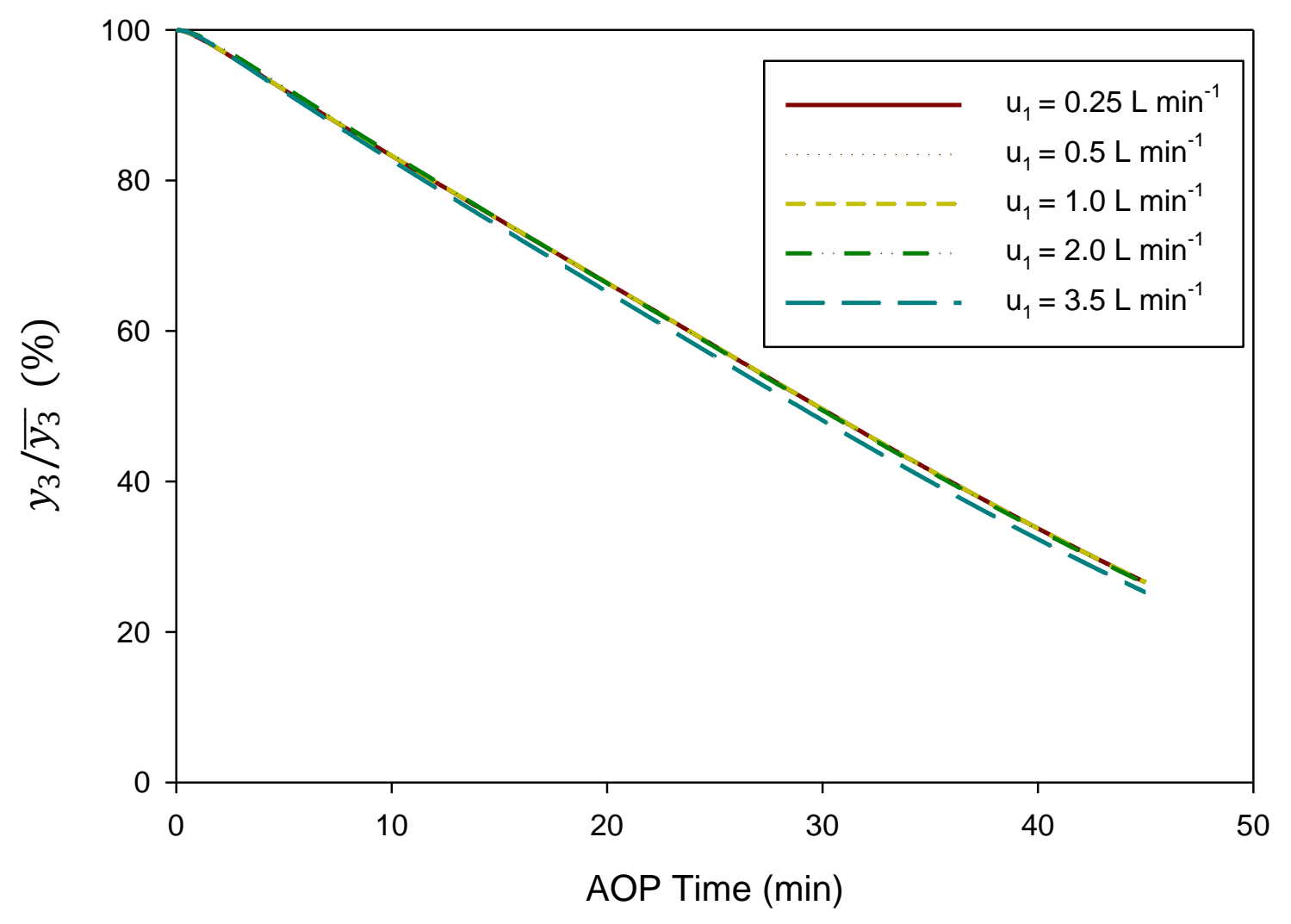

Figure 10.3 Concentration profiles of hydrogen peroxide using different optimal policies (gas flow rate) starting with different initial guesses for the control policies $\left(\mathrm{u}_{\mathrm{i}}\right)$. 


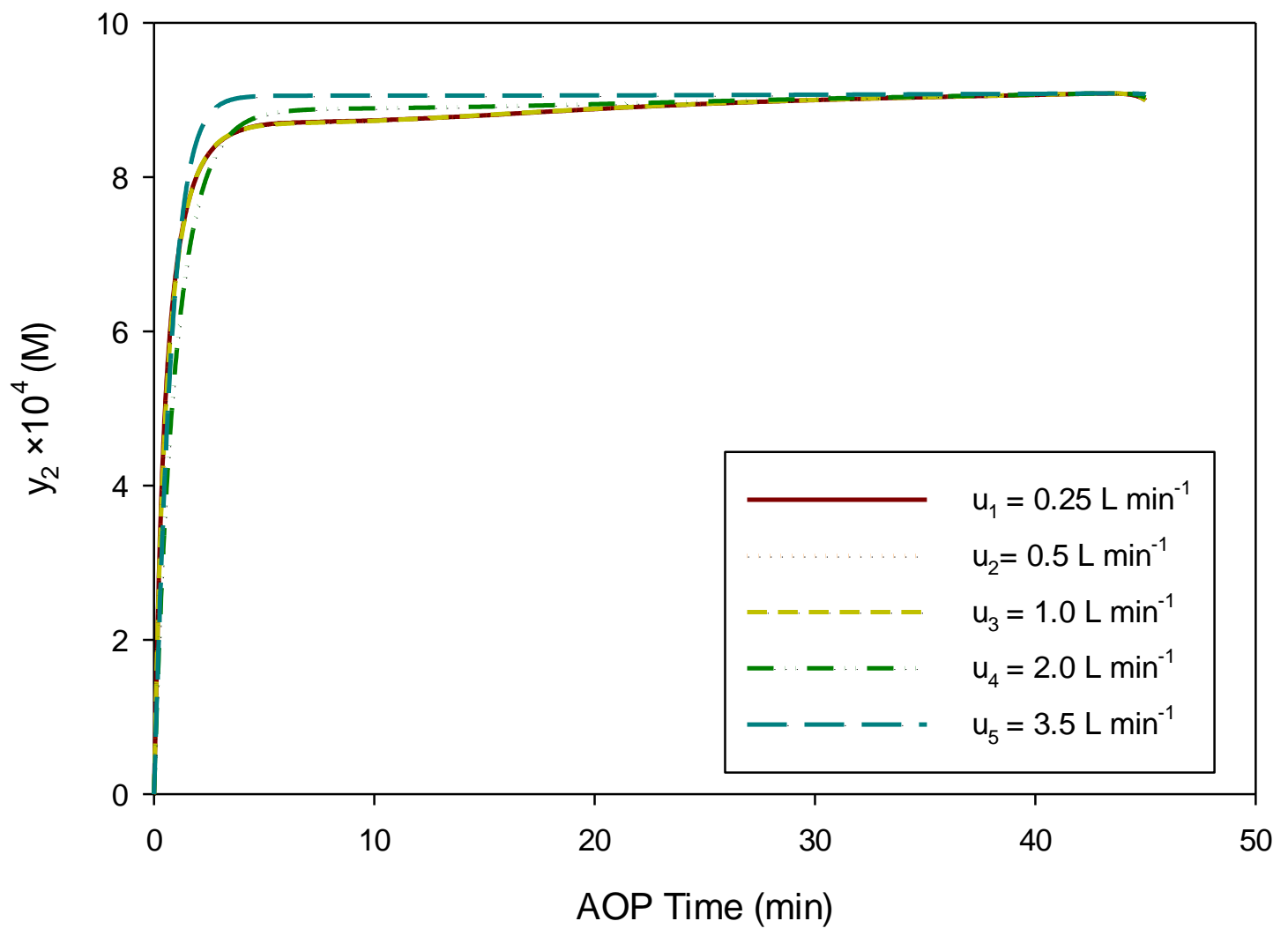

Figure 10.4 Concentration profiles of gaseous ozone using different optimal policies (gas flow rate) starting with different initial guesses for the control policies $\left(\mathrm{u}_{\mathrm{i}}\right)$.

\subsection{VALIDATION OF CONCENTRATION PROFILES USING OPTIMAL POLICY}

Fig. 10.5 shows the predicted control policy, which was generated from solving the control problem, and the experimental control policy, which was generated by Labview software after implementing the predicted control policy in the continuous ozonation process. The periodic valleys in the experimental control policy were caused by the automatic periodic purging of the gas to reset the ozone gas monitor in the inlet stream to the reaction system. As can be seen from Fig 10.5, the experimental control policy is well matching the predicted one with maximum 
absolute difference of $0.14 \mathrm{~L} \mathrm{~min}^{-1}$. This well matching was caused by choosing an optimum PID values to control the proportional control valve.

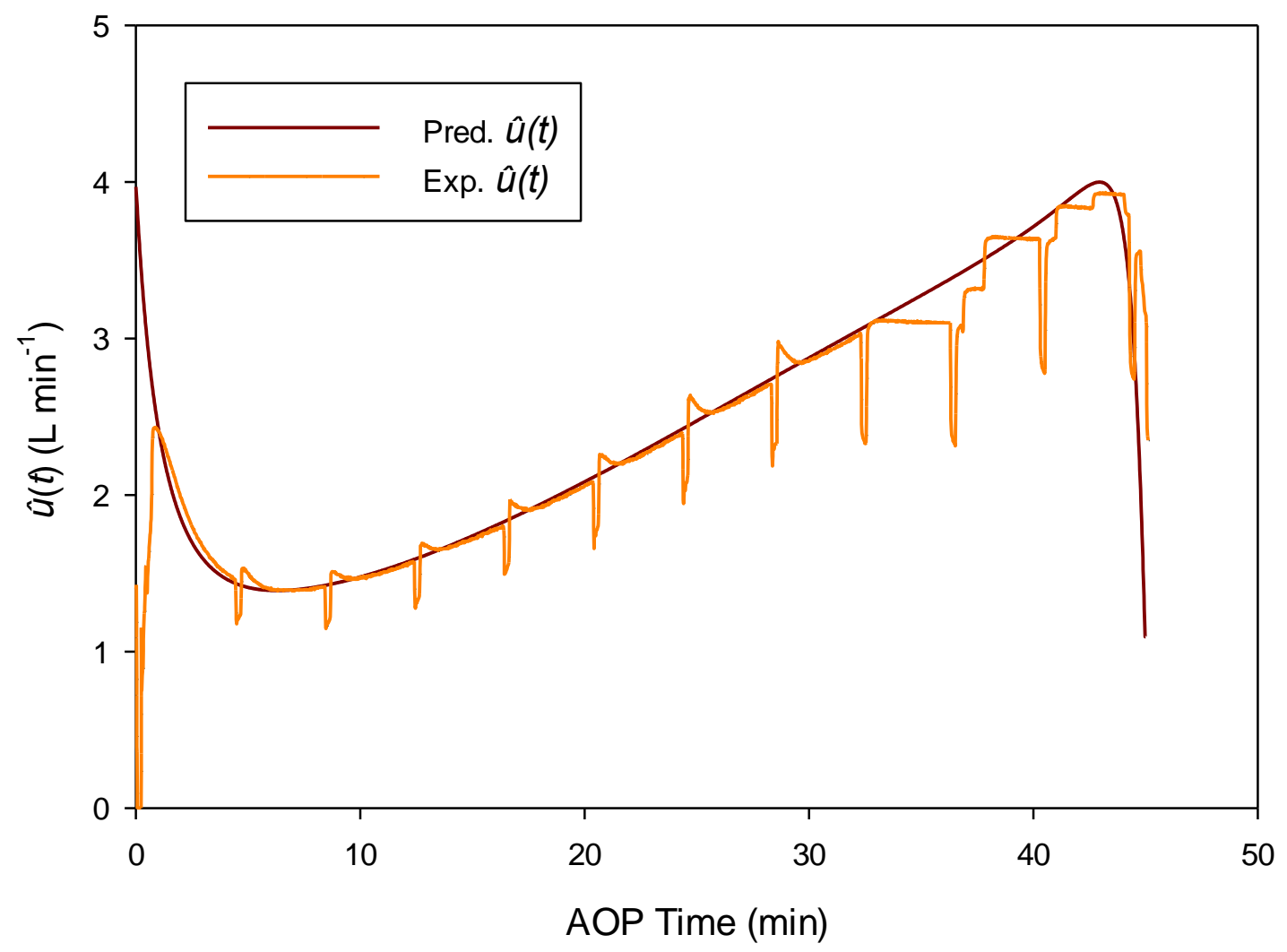

Figure 10.5 Predicted (Pred.) and experimental (Exp.) control policies $\widehat{u}_{3}(t)$.

Fig. 10.6 shows a comparison between predicted concentration profiles, obtained from solving the optimal control problem, against the experimental concentration profiles obtained by implementing the optimal control policy $\left[\hat{u}_{3}(t)\right]$. As can be seen, calculated concentration profiles are well representing of the experimental profiles. Experimental objective functional $\left[\hat{y}_{0}\left(t_{\mathrm{f}}\right) / \bar{y}_{0}\right]$ was 3.8\%. The absolute difference between the experimental and the predicted objective functionals, obtained from solving the optimal control problem (3.2\%), was $0.46 \%$. Predicted concentration profiles for NAs, dissolved ozone and gaseous ozone were also validated for the whole ozonation time (45 min) as shown in Fig. 10.6. The maximum absolute difference between 
predicted and experimental NAs, hydrogen peroxide and gaseous ozone concentration profiles were $1.45 \%, 1.54 \%$, and $1.84 \times 10^{-5} \mathrm{M}$, respectively.

In another experiment, gas flow rate was fed at steady state flow of $2.5 \mathrm{~L} \mathrm{~min}^{-1}$. This value was determined by approximately dividing the minimum consumption of gas $(110.20 \mathrm{~L}$ in Table 10.2) by the total ozonation time ( $45 \mathrm{~min}$ ). The goal was to have a steady flow of the gas, which is expected to be easier to control than the gas flow which is changing with time (control policy) and at the same time considering gas consumption that is needed to reach minimum concentration of NAs in the outlet stream. Experimental objective functional $\left[y_{0}\left(t_{\mathrm{f}}\right) / \overline{y_{0}}\right]$ in this case was $4.4 \%$ and the absolute difference between experimental and predicted objective functionals, obtained from solving the optimal control problem (3.2\%), was $0.85 \%$. By comparing the results obtained from using control policy and steady flow of the gas, it can be seen that the objective functional obtained from using the optimal control policy gives a slightly better results than the steady flow of the gas (absolute difference of $0.42 \%$ ). Nevertheless, using steady flow, based on the results obtained from solving the optimal control problem, could be a better choice in order to simplify the operation of the process.

It was mentioned earlier that the main purpose of using optimal control for a continuous AOP is to degrade NAs to the limit that the effluent from the process are considered rapidly biodegradable substance with low toxicity level. Therefore, it is necessary to determine the COD, BOD/COD, and toxicity for oxidized NAs. 


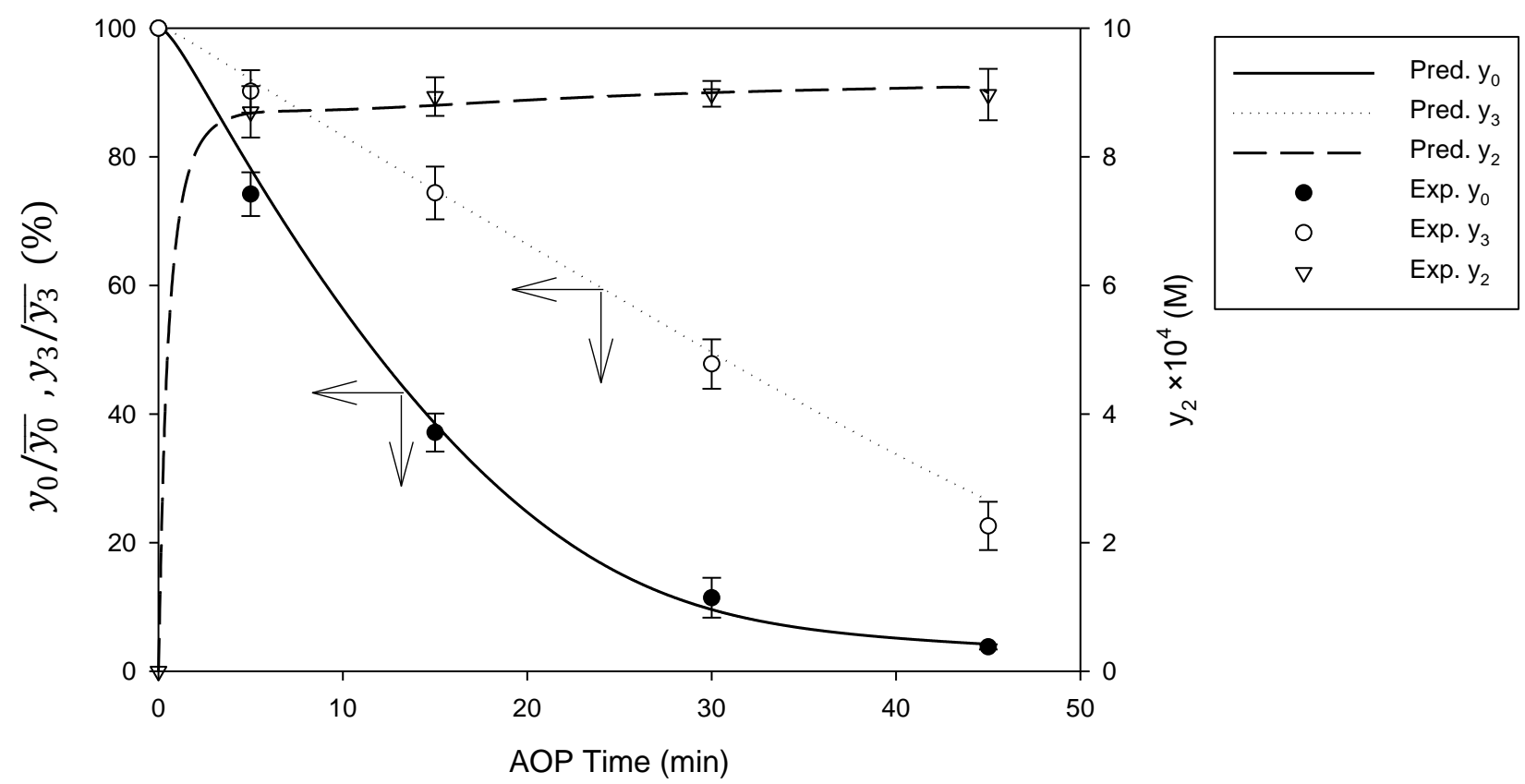

Figure 10.6 Predicted (Pred.) and experimental (Exp.) concentration profiles of NAs, hydrogen peroxide, and gaseous ozone obtained by using the optimal policy $\widehat{u}_{3}(t)$.

\subsection{BIODEGRADABILITY AND DETOXIFICATION}

According to the United Nation standards, organic substances are considered as rapid biodegradable substances if BOD/COD ratio equal or exceed 0.5 (United Nations, 2009). The results for the $\mathrm{BOD} / \mathrm{COD}$ ratio of the liquid outlet stream from the continuous ozonation process obtained by implementing the optimal control policy $\left[\hat{u}_{3}(t)\right]$ are shown in Fig 10.7. The $\mathrm{BOD} / \mathrm{COD}$ ratio increased to reach 0.71 at the final ozonation time (45 $\mathrm{min}$ ). This means that the outlet stream from this continuous ozonation process contains only rapid biodegradable substances as a result of implementing the optimal control policy. This shows the importance of using hydrogen peroxide in the AOP for the degradation of such bio-recalcitrant organic substances, such as NAs. Using steady flow of the gas at $2.5 \mathrm{~L} \mathrm{~min}^{-1}$, the BOD/COD ratio increased to reach 0.69 at the final time. 


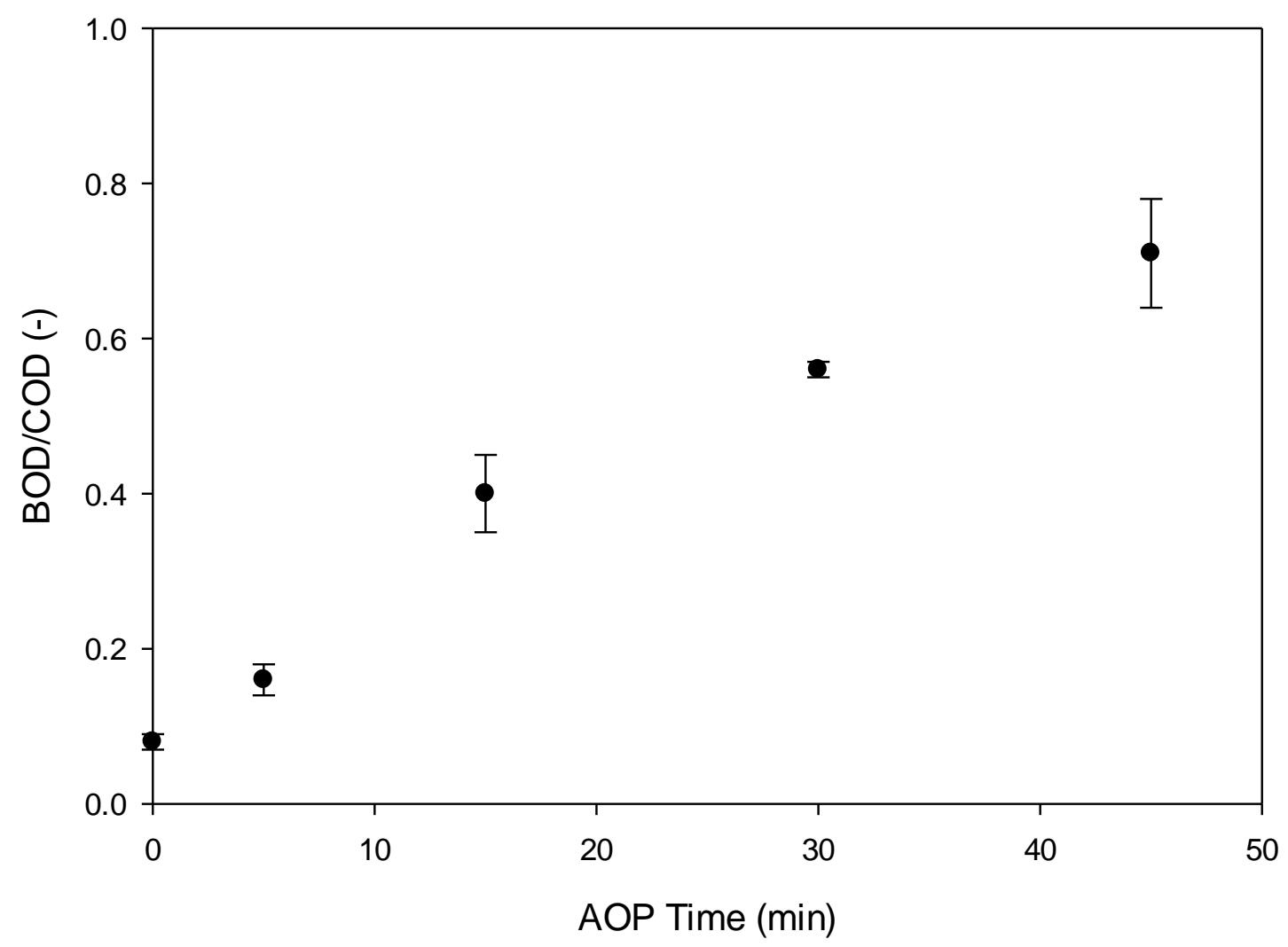

Figure 10.7 Biodegradability, as BOD/COD ratio, of oxidized NAs with AOP time

The results for the toxicity of the liquid outlet stream from the continuous AOP obtained by implementing the optimal control policy $\left[\hat{u}_{3}(t)\right]$ are shown in Fig. 10.8. At the final AOP time (45 $\mathrm{min}$ ), $95.2 \% \%$ of the toxicity, compared to the inlet stream, was removed due to implementing the optimal policy on the gas flow rate. By comparing Fig. 10.7 and Fig 10.8, it can be concluded that the best practice is to use the optimally controlled continuous AOP to remove nonbiodegradable organic substances, including NAs, and most of the toxicity followed by natural biodegradation process to degrade the remaining organic substances and remove the remaining toxicity. By using steady flow of the gas at $2.5 \mathrm{~L} \mathrm{~min}^{-1}$, the toxicity reduced by $93.9 \%$ at the final time. 


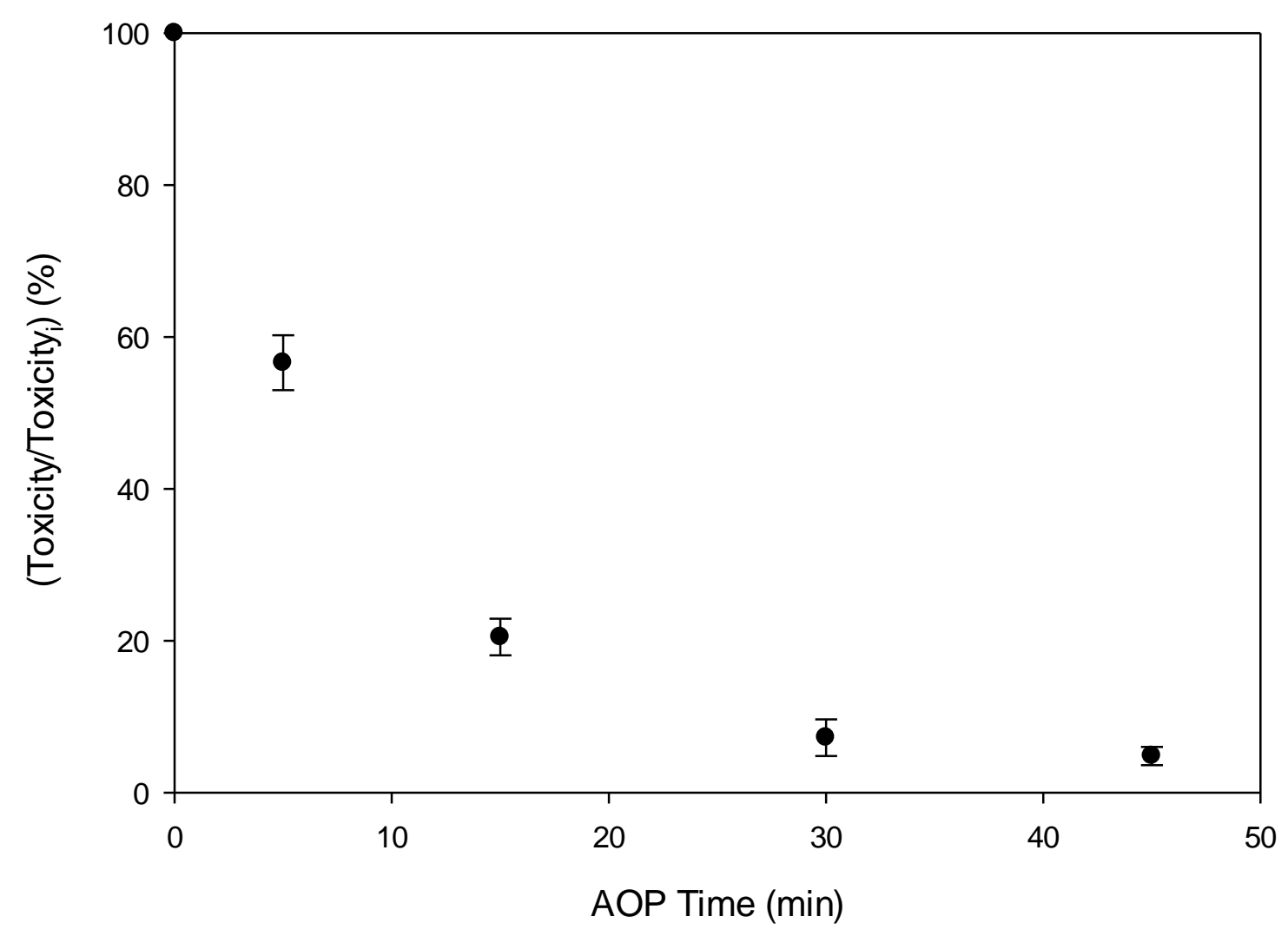

Figure 10.8 Toxicity of advanced oxidized NAs. Toxicity $=83 \%$ loss of light.

By comparing the results of Chapter 9 with Chapter 10, it is obvious that the removal of NAs was much higher by using ozone/ hydrogen peroxide process compared to the ozonation process. The absolute difference for NAs removal was $9.7 \%$. Toxicity removal was also higher by using ozone/ hydrogen peroxide process with absolute difference of $2.43 \%$. For the biodegradability, as $\mathrm{BOD} / \mathrm{COD}$ ratio, both processes have produced rapid biodegradable substances as final products from their liquid outlet streams. BOD/COD was 0.52 and 0.71 for the ozonation and ozone/ hydrogen peroxide processes, respectively. We have to keep in our mind that this was only possible to be achieved when the liquid flow rate was reduce to $0.025 \mathrm{~L} \mathrm{mn}^{-1}$ in the case of ozonation process, which is half of the liquid flow rate in the case of ozone/ hydrogen peroxide process. This means the capital cost for the ozonation process will be higher than the one of ozone/ hydrogen peroxide process. On the other hand, this improvement in NAs degradation and toxicity removal was only possible, in the case of ozone/ hydrogen peroxide process, by using 
hydrogen peroxide and an increase of gas consumption. The average gas flow rates were $1.5 \mathrm{~L}$ $\min ^{-1}$ and $2.5 \mathrm{~L} \mathrm{~min}^{-1}$ for the ozonation and ozone/ hydrogen peroxide processes, respectively. This will add an extra operating cost to the ozone/ hydrogen peroxide process compared to the ozonation process. Therefore, the factors that affecting which treatment process to choose are: the desired removal rate of the pollutant and the acceptable capital and operating costs. 


\section{CHAPTER 11: CONCLUSIONS}

This study was conducted to develop innovative continuous ozonation and ozone based advanced oxidation processes that can effectively degrade industrial non-biodegradable pollutants. Naphthenic acids was used as the model pollutant in this study due to its importance as a major pollutant in oil and oil sands industries. The achieved target was to convert bio-recalcitrant NAs into biodegradable substances with minimum consumption of ozone gas (operating cost).

Effects of different operating parameter on the ozone removal of NAs were explored. Parameters examined included ozone concentration, ozone/oxygen flow rate, $\mathrm{pH}$ and mixing. It was found that among all parameters examined, ozone concentration had the most significant effect on the removal of NAs. An empirical model was developed to correlate the NAs concentration with the following parameters: ozone concentration, ozone/oxygen flow rate and $\mathrm{pH}$. In addition, a theoretical analysis was conducted to gain the insight into the relationship between the removal of NAs and the operating parameters.

The kinetic study of the direct ozonation between molecular ozone and the model naphthenic acids (NAs) in water was conducted in the presence of sufficient amount of a radical scavenger, sodium bicarbonate. It was found that the removal rate of NAs increased with the increase in temperature. By using a differential method, the rate constants of the direct ozonation were determined from experimental data to be $0.67,2.71$ and $8.85 \mathrm{M}^{-1} \mathrm{~s}^{-1}$ at 5,15 and $25^{\circ} \mathrm{C}$, respectively. Also, the activation energy of the direct ozonation was found to be $88.85 \mathrm{~kJ} / \mathrm{mol}$. Furthermore, the kinetic regime of the direct ozonation of NAs was examined. The Hatta numbers calculated at the three temperature levels were all less than 0.02. Therefore, it is concluded that the direct ozonation of NAs is a slow reaction occurred in the bulk liquid. The kinetics of the indirect ozonation (free radical oxidation) of the model NAs was also investigated in this study. By using $p \mathrm{CBA}$ as a hydroxyl radical probe compound to determine the hydroxyl radical concentration, and applying the concept of $R_{c t}$, the rate constants of the indirect ozonation of NAs were determined to be $1.12 \times 10^{8}, 1.78 \times 10^{8}$ and $2.33 \times 10^{8} \mathrm{M}^{-1} \mathrm{~s}^{-1}$ at 5,15 and $25^{\circ} \mathrm{C}$, respectively. Furthermore, the activation energy of the indirect ozonation was determined from the Arrhenius plot of the rate constants to be $25.41 \mathrm{~kJ} \mathrm{~mole}^{-1}$. For the overall ozonation of NAs by both direct and radical 
reactions, the presence of important amount of dissolved ozone in the reaction systems indicated that overall, ozonation of NAs was a slow reaction.

Models based on mass balance were developed to predict concentration profiles of commercial NAs, dissolved ozone and gaseous ozone for the process of ozone removal of NAs from water in a semi-batch reactor. The models were validated at different reaction temperatures and different inlet ozone concentrations. The models successfully predicted, within the range of operating parameters investigated, the concentration profiles of NAs and the gaseous ozone leaving the reactor. The equilibrium concentration of dissolved ozone can also be well predicted by the developed model. However, the actual ozone consumption was higher than that predicted by the model at the initial period of the ozonation process. This deviation was possibly resulted from the inapplicability of the gas-liquid equilibrium conditions at the initial high rate stage of the reaction. The Henry's law constant and the overall mass transfer coefficient for the given system were determined experimentally.

Heterogeneous catalysts were applied to ozone treatment of NAs solution for the first time. Catalysts tested in this study included alumina, $\mathrm{AC}$, and alumina supported metal oxides: $\mathrm{MnO}_{2}$, $\mathrm{MnO}_{2} / \mathrm{Co}_{3} \mathrm{O}_{4}$, and $\mathrm{MnO}_{2} / \mathrm{Li}_{2} \mathrm{O}$. All the tested catalysts enhanced the removal of NAs. After 5 min ozonation, the removal of NAs was $38.4 \sim 42.3 \%, 45.4 \%$ and $62.9 \%$ when $1 \mathrm{~g} \mathrm{~L}^{-1}$ of the supported catalysts, alumina and $\mathrm{AC}$ were used, respectively, while only $22.2 \%$ removal were achieved by their non-catalyzed counterpart. Among all catalysts tested, AC was found to be very effective. Results of adsorption tests of AC also indicated that in addition to being an adsorbent, AC particles were excellent catalysts for the ozonation of NAs. AC significantly enhanced the removal of NAs and COD, the detoxification of the NAs and the increase of sample biodegradability. To achieve $85 \%$ removal of NAs, the AC catalyzed ozonation only needed 15 min whereas 45 min were needed by its non-catalyzed counterpart. Also, the efficiency of detoxification and COD removal by the catalyzed ozonation was over four times of that by the non-catalyzed ozonation. After the AC catalyzed ozonation, the biodegradability of the ozonated NAs could be more than five times of that treated by non-catalyzed ozonation. Experimental results also indicated that for the NAs solution tested, the AC particles in the size range of $0.25-0.841 \mathrm{~mm}$ at the dosage of $1 \mathrm{~g} \mathrm{~L}^{-1}$ were the optimum values.

The kinetic study of the advanced oxidation of NAs using $\mathrm{O}_{3} / \mathrm{H}_{2} \mathrm{O}_{2}$ in water was carried out at different operating conditions. It was found that the rate of NAs removal increases with both 
inlet $\mathrm{O}_{3}$ gas concentration and reaction temperature. The decomposition of $\mathrm{O}_{3}$ is accelerates in the presence of $\mathrm{H}_{2} \mathrm{O}_{2}$ to generates $\mathrm{HO}^{\bullet}$ in the water, which then reacts with NAs in the bulk of liquid. This was confirmed from the experimental results obtained in the presence of $p$ CBA which was used as a $\mathrm{HO}^{\circ}$ probe to determine $\mathrm{HO}^{\circ}$ concnetration. The concentration of $\mathrm{HO}^{\circ}$ increased by $50 \%$ due to the decomposition of $\mathrm{O}_{3}$ in the presence of hydrogen peroxide. The rate of NAs removal was observed to be directly proportional to $\mathrm{H}_{2} \mathrm{O}_{2}$ concentration up to $10^{-3} \mathrm{M}$. Above this concentration, the removal rate of NAs started to decrease due to the shifting of the reaction kinetic regime from slow to fast. At this stage $\mathrm{H}_{2} \mathrm{O}_{2}$ started to act as an inhibitor to the formation of $\mathrm{HO}^{*}$ instead of promoter. Kinetic models were proposed based on the mass balance of $\mathrm{NAs}_{2} \mathrm{H}_{2} \mathrm{O}_{2}$, dissolved and gaseous ozone. The proposed models were used to predict the concentration profiles of NAs at different temperatures and initial hydrogen peroxide concentrations. The model was well representing the experimental results of NAs except for initial concentration of hydrogen peroxide equal or below $10^{-4} \mathrm{M}$. The proposed model also shows that predicted rate of $\mathrm{H}_{2} \mathrm{O}_{2}$ consumption is less than the rate of NAs removal. This means that $\mathrm{H}_{2} \mathrm{O}_{2}$ will always be available to react with $\mathrm{O}_{3}$ to produce $\mathrm{HO}^{*}$ during the reaction time. Moreover, the decomposition of $\mathrm{H}_{2} \mathrm{O}_{2}$ increases as the pollutant (NAs) concentrations diminishes.

An optimal control framework was developed to enhance the continuous ozonation of NAs process using ozone/oxygen gas flow rate versus time as a control function. The necessary conditions for minimum NAs concentration in the outlet stream were derived. A computational algorithm was developed and programmed to determine the optimal control function. Using an experimentally determined relation, the optimal control function was then converted into optimal gas flow rate versus time policy and implemented in a continuous ozonation process. Implementing the control policy has minimized the experimental objective functional $\left[\hat{y}_{0}\left(t_{\mathrm{f}}\right) / \bar{y}_{0}\right]$ to $13.5 \%$. The absolute difference between the experimental objective functional and to the predicted objective functional obtained from solving the optimal control problem (16.58\%) was 2.18\%. Predicted concentration profiles for NAs, dissolved ozone and gaseous ozone were also validated for the whole ozonation $(60 \mathrm{~min})$. The maximum absolute difference between predicted and experimental NAs, dissolved ozone, and gaseous ozone concentration profiles are $2.18 \%$, $4.56 \times 10^{-6} \mathrm{M}$, and $5.48 \times 10^{-5} \mathrm{M}$, respectively. Using steady gas flow of $1.5 \mathrm{~L} \mathrm{~min}^{-1}$, which was determined from solving the optimal control problem, the experimental objective functional $\left[y_{0}\left(t_{\mathrm{f}}\right) / \overline{y_{0}}\right]$ was $18.42 \%$ with absolute difference between the experimental objective functional 
and the predicted objective functional obtained from solving the optimal control problem (16.58\%) of $1.3 \%$. By comparing the results obtained from using control policy and steady flow of the gas, it can be seen that the objective functional obtained from using the optimal control policy gives better results than the steady flow of the gas. Using steady flow based on the results obtained from solving the optimal control problem could be a better choice rather than the optimal policy in order to simplify the operating of the process. Biodegradability (BOD/COD) for ozonated NAs were determined at the final ozonation time for using the optimal control policy and the steady flow of the gas at $1.5 \mathrm{~L} \mathrm{~min}^{-1}$ and it was found that BOD/COD ratios reached 0.52 and 0.49 respectively. While toxicity was reduced by $92.77 \%$ and $91.20 \%$, respectively. At this level, liquid outlet stream is considered to contain only rapid biodegradable organic substances.

An optimal control framework was also developed to enhance the continuous AOP of NAs using ozone/oxygen gas flow rate versus time as a control function. The necessary conditions for minimum NAs concentration in the outlet stream were derived. A computational algorithm was developed and programmed to determine the optimal control function. Using an experimentally determined relation, the optimal control function was then converted into optimal gas flow rate versus time policy and implemented in continuous AOP. Predicted concertation profiles were well representing of the experimental profiles. Experimental objective functional $\left[\hat{y}_{0}\left(t_{\mathrm{f}}\right) / \bar{y}_{0}\right]$ was $3.8 \%$. The absolute difference between the experimental objective functional and the predicted objective functional obtained from solving the optimal control problem $(3.2 \%)$ was $0.46 \%$. Predicted concentration profiles for NAs, hydrogen peroxide and gaseous ozone, which were obtained from implementing the optimal policy, were also validated The maximum absolute difference between predicted and experimental NAs, hydrogen peroxide and gaseous ozone concentration profiles were $1.45 \%, 1.54 \%$, and $1.84 \times 10^{-5} \mathrm{M}$, respectively. Using steady gas flow of $2.5 \mathrm{~L} \mathrm{~min}^{-1}$, which was determined from solving the optimal control problem, the experimental objective functional $\left[y_{0}\left(t_{\mathrm{f}}\right) / \overline{y_{0}}\right]$ was $4.4 \%$ and the absolute difference between the experimental objective functional and the predicted objective functional obtained from solving the optimal control problem $(3.2 \%)$ was $0.85 \%$. Using steady flow based on the results obtained from solving the optimal control problem could be a better choice in order to simplify the operating of the process. Biodegradability (BOD/COD) ratios for the outlet stream were determined at the final time for implementing the optimal control policy and the steady flow of the gas at $2.5 \mathrm{~L} \mathrm{~min}^{-1}$ and 
it was found that $\mathrm{BOD} / \mathrm{COD}$ ratios reached 0.71 and 0.69 , respectively. While toxicity was reduced by $95.2 \%$ and $93.9 \%$, respectively.

The above results show that using optimally controlled continuous ozonation and ozone/ hydrogen peroxide processes has removed non-biodegradable organic pollutants, such as NAs, and most of the toxicity. Liquid outlet streams from these processes contain only rapid biodegradable organic substances. These results provide a promising solution for the removal of industrial biorecalcitrant organic pollutants and their toxicities using the above processes. The factors that affecting which treatment process to choose are: the desired removal rate of the pollutant and the acceptable capital and operating costs. These processes can be followed by natural biodegradation process to degrade the remaining organic substances and remove the remaining toxicity. 


\section{APPENDIX A:}

\section{EXPERIMENTAL DATA}

\section{A.1 EXPERIMENTAL DATA FOR CHAPTER 4}

Table A.1 Experimental data for Fig.4.1.

\begin{tabular}{|c|c|c|c|c|}
\hline Time & $\begin{array}{c}\mathrm{C}_{\mathrm{NAs}} \\
\text { Trial 1 }\end{array}$ & $\begin{array}{c}\mathrm{C}_{\mathrm{NAs}} \\
\text { Trial 2 }\end{array}$ & $\begin{array}{c}\mathrm{C}_{\mathrm{NAs}} \\
\text { Average }\end{array}$ & $\begin{array}{c}\mathrm{C}_{\mathrm{NAs}} \\
\mathrm{SD}\end{array}$ \\
\hline $\mathrm{min}$ & $\mathrm{mg} \mathrm{L}^{-1}$ & $\mathrm{mg} \mathrm{L}^{-1}$ & $\mathrm{mg} \mathrm{L}^{-1}$ & $\mathrm{mg} \mathrm{L}^{-1}$ \\
\hline 0 & 100 & 100 & 1 & 0 \\
\hline 5 & 88.80 & 89.00 & 0.89 & 0.00 \\
\hline 15 & 69.90 & 70.65 & 0.70 & 0.01 \\
\hline 30 & 53.12 & 51.69 & 0.52 & 0.01 \\
\hline 60 & 28.65 & 29.13 & 0.29 & 0.00 \\
\hline 120 & 3.31 & 5.11 & 0.04 & 0.01 \\
\hline
\end{tabular}


Table A.2 Experimental data for Fig. 4.4.

\begin{tabular}{|c|c|c|c|c|c|c|c|c|c|c|}
\hline \multirow[t]{2}{*}{ Run \# } & $\begin{array}{l}\text { Ozone } \\
\text { conc. }\end{array}$ & flow rate & $\mathrm{pH}$ & \multirow{2}{*}{$\begin{array}{c}\text { Mixing } \\
(200 \mathrm{rpm})\end{array}$} & $\begin{array}{l}\mathrm{C}_{\mathrm{NAs}} \\
\text { (Exp.) }\end{array}$ & $\begin{array}{l}\mathrm{C}_{\mathrm{NAs}} \\
\text { (Calc.) }\end{array}$ & $\mathrm{C}_{\mathrm{NAs}} \mathrm{SD}$ & $\mathrm{CI}$ & $\mathrm{C}_{\mathrm{NAs}}+\mathrm{CI}$ & $\mathrm{C}_{\mathrm{NAs}}-\mathrm{CI}$ \\
\hline & wt. $\%$ & $\mathrm{~L} \min ^{-1}$ & - & & $\mathrm{mg} \mathrm{L}^{-1}$ & $m g L^{-1}$ & $m g L^{-1}$ & $\mathrm{mg} \mathrm{L}^{-1}$ & $\mathrm{mg} \mathrm{L}^{-1}$ & $\mathrm{mg} \mathrm{L}^{-1}$ \\
\hline 1 & 0.5 & 3 & 12 & $\mathrm{~N}$ & 59.83 & 62.44 & 1.85 & 2.93 & 65.37 & 59.51 \\
\hline 2 & 0.5 & 1 & 12 & $\mathrm{~N}$ & 62.25 & 83.50 & 15.02 & 23.81 & 107.30 & 59.69 \\
\hline 3 & 2.25 & 2 & 10 & $\mathrm{Y}$ & 47.53 & 56.79 & 6.54 & 10.37 & 67.16 & 46.41 \\
\hline 4 & 4 & 3 & 8 & $\mathrm{Y}$ & 45.33 & 48.61 & 2.32 & 3.67 & 52.28 & 44.93 \\
\hline 5 & 4 & 3 & 12 & $\mathrm{~N}$ & 16.32 & 16.33 & 0.01 & 0.02 & 16.35 & 16.32 \\
\hline 6 & 2.25 & 2 & 10 & $\mathrm{~N}$ & 49.5 & 56.79 & 5.15 & 8.16 & 64.95 & 48.62 \\
\hline 7 & 0.5 & 1 & 8 & $\mathrm{Y}$ & 87.52 & 76.69 & 7.66 & 12.14 & 88.83 & 64.55 \\
\hline 8 & 4 & 1 & 8 & $\mathrm{Y}$ & 53.24 & 49.07 & 2.95 & 4.67 & 53.74 & 44.40 \\
\hline 9 & 4 & 3 & 12 & $\mathrm{Y}$ & 5.63 & 16.33 & 7.57 & 12.00 & 28.33 & 4.34 \\
\hline 10 & 0.5 & 1 & 8 & $\mathrm{~N}$ & 80.71 & 76.69 & 2.84 & 4.51 & 81.20 & 72.18 \\
\hline 11 & 4 & 1 & 8 & $\mathrm{~N}$ & 34.18 & 49.07 & 10.53 & 16.69 & 65.76 & 32.38 \\
\hline 12 & 0.5 & 3 & 8 & $\mathrm{Y}$ & 54.94 & 78.24 & 16.48 & 26.11 & 104.35 & 52.13 \\
\hline 13 & 4 & 1 & 12 & $\mathrm{Y}$ & 28.2 & 39.40 & 7.92 & 12.55 & 51.96 & 26.85 \\
\hline 14 & 0.5 & 1 & 12 & $\mathrm{Y}$ & 94.02 & 83.50 & 7.44 & 11.80 & 95.29 & 71.70 \\
\hline 15 & 4 & 1 & 12 & $\mathrm{~N}$ & 65.46 & 39.40 & 18.43 & 29.20 & 68.61 & 10.20 \\
\hline 16 & 4 & 3 & 8 & $\mathrm{~N}$ & 66.74 & 48.61 & 12.82 & 20.32 & 68.93 & 28.29 \\
\hline 17 & 0.5 & 3 & 12 & $\mathrm{Y}$ & 79.91 & 62.44 & 12.35 & 19.57 & 82.02 & 42.87 \\
\hline 18 & 0.5 & 3 & 8 & $\mathrm{~N}$ & 90.82 & 78.24 & 8.90 & 14.10 & 92.34 & 64.14 \\
\hline
\end{tabular}

$\mathrm{SD}=$ Standard deviation $; \mathrm{CI}=$ Confidence interval at $97.5 \%$ probability .

\section{A.2 EXPERIMENTAL DATA FOR CHAPTER 5}

Table A.3 Experimental data for Fig. 5.1.

\begin{tabular}{|c|c|c|c|c|c|}
\hline \multirow{2}{*}{ Time } & \multicolumn{5}{|c|}{$\mathrm{C}_{\text {NAs }} / \mathrm{C}_{\mathrm{NAs} 0}(\%)$} \\
\cline { 2 - 6 } & $\mathrm{C}_{\mathrm{HCO} 3 \mathrm{t}}=0 \mathrm{mM}$ & $\mathrm{C}_{\mathrm{HCO} 3 \mathrm{t}}=5 \mathrm{mM}$ & $\mathrm{C}_{\mathrm{HCO} \mathrm{t}}=10 \mathrm{mM}$ & $\mathrm{C}_{\mathrm{HCO3t}}=20 \mathrm{mM}$ & $\mathrm{C}_{\mathrm{HCO} 3 \mathrm{t}}=75 \mathrm{mM}$ \\
\hline 0 & 100 & 100 & 100 & 100 & 100 \\
\hline 5 & 77.8 & 82.1 & 85.2 & 91.7 & 71.1 \\
\hline 15 & 48.8 & 53.4 & 58.59 & 73.93 & 55 \\
\hline 30 & 28.9 & 34.3 & 41 & 54.32 & 45.8 \\
\hline 40 & 18.3 & 23 & 34.4 & 45.1 & 35.2 \\
\hline 50 & 12 & 18.5 & 26.85 & 36.7 & 29.6 \\
\hline 60 & 7 & 14.4 & 22.35 & 28.71 & \\
\hline
\end{tabular}


Table A.4 Experimental data for Figs. 5.2, 5.3 and 6.5(b).

\begin{tabular}{|c|c|c|c|c|c|c|}
\hline \multirow{2}{*}{$\begin{array}{l}\text { Time } \\
(\mathrm{min})\end{array}$} & \multicolumn{3}{|c|}{$\mathrm{C}_{\mathrm{NAs}} / \mathrm{C}_{\mathrm{NAs} 0}(\%)$} & \multicolumn{3}{|c|}{$\mathrm{C}_{\mathrm{O} 3} \times 10^{5}(\mathrm{M})$} \\
\hline & $\mathrm{T}=5{ }^{\circ} \mathrm{C}$ & $\mathrm{T}=15{ }^{\circ} \mathrm{C}$ & $\mathrm{T}=25^{\circ} \mathrm{C}$ & $\mathrm{T}=5^{\circ} \mathrm{C}$ & $\mathrm{T}=15^{\circ} \mathrm{C}$ & $\mathrm{T}=25^{\circ} \mathrm{C}$ \\
\hline \multicolumn{7}{|c|}{ Without scavenger } \\
\hline 0 & 100.00 & 100.00 & 100.00 & 0.00 & 0.00 & 0.00 \\
\hline 5 & 89.00 & 85.10 & 77.80 & 15.76 & 6.69 & 2.87 \\
\hline 15 & 71.00 & 65.70 & 51.20 & 24.85 & 9.72 & 3.92 \\
\hline 30 & 50.90 & 44.70 & 28.90 & 25.87 & 9.79 & 4.38 \\
\hline 40 & 38.60 & 33.10 & 18.30 & 24.80 & 10.16 & 4.28 \\
\hline 50 & 30.10 & 24.10 & 12.00 & 26.15 & 10.73 & 4.28 \\
\hline 60 & 23.80 & 17.00 & 7.00 & 25.41 & 10.88 & 4.42 \\
\hline \multicolumn{7}{|c|}{ With scavenger } \\
\hline 0 & 100 & 100 & 100 & 0 & 0 & 0 \\
\hline 5 & 95.10 & 92.20 & 91.1 & 15.76 & 6.69 & 2.87 \\
\hline 15 & 86.20 & 78.50 & 74.50 & 24.85 & 9.72 & 3.92 \\
\hline 30 & 74.00 & 62.20 & 55.00 & 25.87 & 9.79 & 4.38 \\
\hline 40 & 66.9 & 52.90 & 45.80 & 24.80 & 10.16 & 4.28 \\
\hline 50 & 61.10 & 45.40 & 35.20 & 26.15 & 10.73 & 4.28 \\
\hline 60 & 55.50 & 39.60 & 29.60 & 25.41 & 10.88 & 4.42 \\
\hline
\end{tabular}

Table A.5 Experimental data for Fig. 5.4.

\begin{tabular}{|c|c|c|c|c|c|c|c|c|c|c|c|c|}
\hline \multirow[b]{2}{*}{ Time } & \multicolumn{4}{|c|}{$\mathrm{T}=5^{\circ} \mathrm{C}$} & \multicolumn{4}{|c|}{$\mathrm{T}=15^{\circ} \mathrm{C}$} & \multicolumn{4}{|c|}{$\mathrm{T}=25^{\circ} \mathrm{C}$} \\
\hline & $\begin{array}{l}\mathrm{C}_{\mathrm{NAs}} \\
\times 10^{4}\end{array}$ & $\begin{array}{l}\mathrm{C}_{03} \\
\times 10^{5}\end{array}$ & $\begin{array}{c}\mathrm{dC}_{\mathrm{NAs}} / \mathrm{dt} \\
\times 10^{7}\end{array}$ & $\begin{array}{l}\left(\mathrm{C}_{\mathrm{NAs}}\right. \\
\left.\mathrm{C}_{\mathrm{O} 3}\right) \\
\times 10^{7}\end{array}$ & $\begin{array}{l}\mathrm{C}_{\mathrm{NAs}} \\
\times 10^{4}\end{array}$ & $\begin{array}{l}\mathrm{C}_{\mathrm{O} 3} \\
\times 10^{5}\end{array}$ & $\begin{array}{c}\mathrm{dC}_{\mathrm{NAs}} / \mathrm{dt} \\
\times 10^{7}\end{array}$ & $\begin{array}{l}\left(\mathrm{C}_{\mathrm{NAs}}\right. \\
\left.\mathrm{C}_{\mathrm{O} 3}\right) \\
\times 10^{7}\end{array}$ & $\begin{array}{l}\mathrm{C}_{\mathrm{NAs}} \\
\times 10^{4}\end{array}$ & $\begin{array}{l}\mathrm{C}_{03} \\
\times 10^{5}\end{array}$ & $\begin{array}{c}\mathrm{dC}_{\mathrm{NAs}} / \mathrm{dt} \\
\times 10^{7}\end{array}$ & $\begin{array}{l}\left(\mathrm{C}_{\mathrm{NAs}}\right. \\
\left.\mathrm{C}_{\mathrm{O} 3}\right) \\
\times 10^{7}\end{array}$ \\
\hline$(\min )$ & $(\mathrm{M})$ & (M) & $\left(\mathrm{M} \mathrm{s}^{-1}\right)$ & $\left(\mathrm{M}^{2}\right)$ & (M) & (M) & $\left(\mathrm{M} \cdot \mathrm{s}^{-1}\right)$ & $\left(\mathrm{M}^{2}\right)$ & (M) & (M) & $\left(\mathrm{M} \cdot \mathrm{s}^{-1}\right)$ & $\left(\mathrm{M}^{2}\right)$ \\
\hline 0 & 4.08 & 0.00 & 0.00 & 0.00 & 4.08 & 0.00 & 0.00 & 0.00 & 4.08 & 0.00 & 0.00 & 0.00 \\
\hline 5 & 3.88 & 25.48 & -0.67 & 0.99 & 3.76 & 10.43 & -1.06 & 0.39 & 3.72 & 3.89 & -1.21 & 0.14 \\
\hline 15 & 3.52 & 25.88 & -0.61 & 0.91 & 3.20 & 10.84 & -0.93 & 0.35 & 3.04 & 4.12 & -1.13 & 0.13 \\
\hline 30 & 3.02 & 25.98 & -0.55 & 0.78 & 2.54 & 9.97 & -0.74 & 0.25 & 2.24 & 4.22 & -0.88 & 0.09 \\
\hline 40 & 2.73 & 25.63 & -0.48 & 0.70 & 2.16 & 10.46 & -0.63 & 0.23 & 1.87 & 4.06 & -0.63 & 0.08 \\
\hline 50 & 2.49 & 25.19 & -0.39 & 0.63 & 1.85 & 10.78 & -0.51 & 0.20 & 1.44 & 4.22 & -0.72 & 0.06 \\
\hline 60 & 2.27 & 25.26 & -0.38 & 0.57 & 1.62 & 10.14 & -0.39 & 0.16 & 1.21 & 4.41 & -0.38 & 0.05 \\
\hline
\end{tabular}


Table A.6 Experimental data for Fig. 5.5.

\begin{tabular}{|c|c|c|c|}
\hline $\mathrm{T}$ & $1 / \mathrm{T}$ & $\mathrm{k}_{\mathrm{d}}$ & $\ln \left(\mathrm{k}_{\mathrm{d}}\right)$ \\
\hline$\left({ }^{\circ} \mathrm{C}\right)$ & $(1 / \mathrm{K})$ & $\left(\mathrm{M}^{-1} \cdot \mathrm{s}^{-1}\right)$ & $\left(\mathrm{M}^{-1} \cdot \mathrm{s}^{-1}\right)$ \\
\hline 5 & 0.0036 & 0.6737 & -0.3950 \\
\hline 15 & 0.0035 & 2.7091 & 0.9966 \\
\hline 25 & 0.0034 & 8.8464 & 2.1800 \\
\hline
\end{tabular}

Table A.7 Experimental data for Fig. 5.6.

\begin{tabular}{|c|c|c|c|c|c|}
\hline \multirow{2}{*}{ Time } & \multicolumn{3}{|c|}{$C_{p \mathrm{CBA}} / \mathrm{C}_{p \mathrm{CBA} 0}$} & \multirow{2}{*}{$\ln \left(\mathrm{C}_{p \mathrm{CBA}} / \mathrm{C}_{p \mathrm{CBA} 0}\right)$} & $\mathrm{SD}$ \\
\cline { 2 - 6 } & 1st Trial & 2nd Trial & Avg. & & \\
\hline$(\mathrm{min})$ & $(-)$ & $(-)$ & $(-)$ & $(-)$ & $(-)$ \\
\hline 0 & 1.000 & 1.000 & 1.000 & 0 & 0 \\
\hline 1.5 & 0.616 & 0.510 & 0.563 & -0.5745 & 0.0750 \\
\hline 3 & 0.340 & 0.208 & 0.274 & -1.2946 & 0.0933 \\
\hline 4.5 & 0.1192 & 0.108 & 0.114 & -2.1760 & 0.0081 \\
\hline 6 & 0.120 & 0.008 & 0.064 & -2.7489 & 0.0792 \\
\hline
\end{tabular}

Table A.8 Experimental data for Fig. 5.7.

\begin{tabular}{|c|c|c|c|c|c|c|c|c|c|c|c|c|}
\hline \multirow[b]{2}{*}{ Time } & \multicolumn{4}{|c|}{$\mathrm{T}=5^{\circ} \mathrm{C}$} & \multicolumn{4}{|c|}{$\mathrm{T}=15^{\circ} \mathrm{C}$} & \multicolumn{4}{|c|}{$\mathrm{T}=25^{\circ} \mathrm{C}$} \\
\hline & $\begin{array}{l}\mathrm{C}_{\mathrm{NAs}} \\
\times 10^{4}\end{array}$ & $\begin{array}{l}\mathrm{C}_{\mathrm{O} 3 \mathrm{~s}} \\
\times 10^{5}\end{array}$ & $\begin{array}{c}\left(\mathrm{dC}_{\mathrm{NAs}} /\right. \\
\mathrm{dt}) \\
\times 10^{8}\end{array}$ & $\begin{array}{l}\left(\mathrm{C}_{\mathrm{NAs}}\right. \\
\left.\mathrm{C}_{\mathrm{O} 3 \mathrm{~s}}\right) \\
\times 10^{8}\end{array}$ & $\begin{array}{l}\mathrm{C}_{\mathrm{NAs}} \\
\times 10^{4}\end{array}$ & $\begin{array}{l}\mathrm{C}_{\mathrm{O} 3 \mathrm{~s}} \\
\times 10^{5}\end{array}$ & $\begin{array}{c}\left(\mathrm{dC}_{\mathrm{NAs}} /\right. \\
\mathrm{dt}) \\
\times 10^{8}\end{array}$ & $\begin{array}{l}\left(\mathrm{C}_{\mathrm{NAs}}\right. \\
\left.\mathrm{C}_{\mathrm{O} 3 \mathrm{~s}}\right) \\
\times 10^{8}\end{array}$ & $\begin{array}{l}\mathrm{C}_{\mathrm{NAs}} \\
\times 10^{4}\end{array}$ & $\begin{array}{l}\mathrm{C}_{\mathrm{O} 3 \mathrm{~s}} \\
\times 10^{5}\end{array}$ & $\begin{array}{c}\left(\mathrm{dC}_{\mathrm{NAs}} /\right. \\
\mathrm{dt}) \\
\times 10^{8}\end{array}$ & $\begin{array}{l}\left(\mathrm{C}_{\mathrm{NAs}}\right. \\
\left.\mathrm{C}_{\mathrm{O} 3 \mathrm{~s}}\right) \\
\times 10^{8}\end{array}$ \\
\hline$(\min )$ & (M) & (M) & $\left(\mathrm{M}^{-1} \mathrm{~s}^{-1}\right)$ & $\left(\mathrm{M}^{2}\right)$ & (M) & (M) & $\left(\mathrm{M} \cdot \mathrm{s}^{-1}\right)$ & $\left(\mathrm{M}^{2}\right)$ & (M) & (M) & $\left(\mathrm{M} \cdot \mathrm{s}^{-1}\right)$ & $\left(\mathrm{M}^{2}\right)$ \\
\hline 0 & 4.08 & 0 & 0 & 0 & 4.08 & 0 & 0 & 0 & 4.08 & 0 & 0 & 0 \\
\hline 30 & 2.04 & 25.9 & -9.52 & 5.28 & 1.82 & 9.79 & -9.52 & 1.79 & 1.18 & 4.38 & -10.1 & 0.52 \\
\hline 40 & 1.59 & 24.1 & -7.55 & 3.83 & 1.35 & 10.2 & -7.89 & 1.37 & 0.75 & 4.28 & -7.21 & 0.32 \\
\hline 50 & 1.23 & 26.8 & -5.99 & 3.29 & 0.98 & 10.7 & -6.12 & 1.06 & 0.49 & 4.28 & -4.29 & 0.21 \\
\hline 60 & 0.97 & 25.4 & -4.29 & 2.47 & 0.69 & 10.9 & -4.83 & 0.76 & 0.29 & 4.42 & -3.4 & 0.13 \\
\hline
\end{tabular}


Table A.9 Experimental data for Fig. 5.8.

\begin{tabular}{|c|c|c|c|c|c|}
\hline $\mathrm{T}$ & $1 / \mathrm{T}$ & $\mathrm{k}_{\mathrm{d}}$ & $\operatorname{Rct} \times 10^{8}$ & $\mathrm{k}_{\text {HONAs }}$ & $\ln \left(\mathrm{k}_{\text {HONAs }}\right)$ \\
\hline$\left({ }^{\circ} \mathrm{C}\right)$ & $\left(\mathrm{K}^{-1}\right)$ & $\left(\mathrm{M}^{-1} \cdot \mathrm{s}^{-1}\right)$ & $(-)$ & $\left(\mathrm{M}^{-1} \cdot \mathrm{s}^{-1}\right)$ & $\left(\mathrm{M}^{-1} \cdot \mathrm{s}^{-1}\right)$ \\
\hline 5 & 0.0036 & 0.67 & 0.6 .0 & $1.12 \mathrm{E}+08$ & 18.53 \\
\hline 15 & 0.0035 & 2.71 & 1.52 & $1.78 \mathrm{E}+08$ & 19.00 \\
\hline 25 & 0.0034 & 8.85 & 3.80 & $2.33 \mathrm{E}+08$ & 19.27 \\
\hline
\end{tabular}

\section{A.3 EXPERIMENTAL DATA FOR CHAPTER 6}

Table A.10 Experimental data for Figs. 6.1 and 6.6(a).

\begin{tabular}{|c|c|c|c|c|c|c|c|c|c|c|c|c|}
\hline \multirow{3}{*}{$\begin{array}{l}\text { Time } \\
(\mathrm{min})\end{array}$} & \multicolumn{12}{|c|}{$\mathrm{C}_{\mathrm{NAs}} / \mathrm{C}_{\mathrm{NAs} 0}(\%)$} \\
\hline & \multicolumn{4}{|c|}{$\mathrm{C}_{\mathrm{O} 3 \mathrm{Gi}}=3.1 \times 10^{-4}(\mathrm{M} 0$} & \multicolumn{4}{|c|}{$\mathrm{C}_{\mathrm{O} 3 \mathrm{Gi}}=6.2 \times 10^{-4}(\mathrm{M})$} & \multicolumn{4}{|c|}{$\mathrm{C}_{\mathrm{O} 3 \mathrm{Gi}}=9.3 \times 10^{-4}(\mathrm{M})$} \\
\hline & Trial 1 & Trial 2 & Avg. & $\mathrm{SD}$ & Trial 1 & Trial 2 & Avg. & SD & Trial 1 & Trial 2 & Avg. & SD \\
\hline 0 & 100.0 & 100.0 & 100 & 0 & 100 & 100 & 100 & 0 & 100 & 100 & 100 & 0 \\
\hline 5 & 91.4 & 95.2 & 93.3 & 2.70 & 86.4 & 90.4 & 88.4 & 2.83 & 79.8 & 75.8 & 77.8 & 2.83 \\
\hline 15 & 84.4 & 81.4 & 82.9 & 2.12 & 73.4 & 69.5 & 71.44 & 2.73 & 49.3 & 53.1 & 51.2 & 2.69 \\
\hline 30 & 72.5 & 66.7 & 69.6 & 4.10 & 55.6 & 49.8 & 52.7 & 4.14 & 30.9 & 26.9 & 28.9 & 2.83 \\
\hline 40 & 57.9 & 63.7 & 60.8 & 4.10 & 40.4 & 44.2 & 42.3 & 2.69 & 20.5 & 16.1 & 18.3 & 3.11 \\
\hline 50 & 55.6 & 51.6 & 53.6 & 2.83 & 29.8 & 33.2 & 31.5 & 2.4 & 10.2 & 13.8 & 12 & 2.55 \\
\hline 60 & 47.6 & 51.6 & 49.6 & 2.83 & 24.0 & 20.9 & 22.45 & 2.26 & 4.9 & 9.1 & 7.0 & 2.97 \\
\hline
\end{tabular}

Table A.11 Experimental data for Figs. 6.2 and 6.6(b).

\begin{tabular}{|c|c|c|c|}
\hline \multirow{2}{*}{$\begin{array}{c}\text { Time } \\
(\mathrm{min})\end{array}$} & $\mathrm{C}_{\mathrm{O} 3 \mathrm{Gi}}=3.1 \times 10^{-4}(\mathrm{M})$ & $\mathrm{C}_{\mathrm{O} 3 \mathrm{Gi}}=6.2 \times 10^{-4}(\mathrm{M})$ & $\mathrm{C}_{\mathrm{O} 3 \mathrm{Gi}}=9.3 \times 10^{-4}(\mathrm{M})$ \\
\hline 0 & 0 & 0 & 0 \\
\hline 5 & 1.58 & 1.67 & 2.87 \\
\hline 15 & 1.79 & 2.17 & 3.92 \\
\hline 30 & 1.99 & 3.58 & 4.88 \\
\hline 40 & 1.88 & 3.73 & 4.83 \\
\hline 50 & 1.92 & 3.78 & 4.93 \\
\hline 60 & 2.04 & 3.72 & 5.04 \\
\hline
\end{tabular}


Table A.12 Experimental data for Figs. 6.3 and 6.4.

\begin{tabular}{|c|c|c|c|c|c|}
\hline $\mathrm{T}$ & $1 / \mathrm{T}$ & $\mathrm{H} \times 10^{6}$ & $\ln (\mathrm{H})$ & $\mathrm{K}_{\mathrm{G}} \mathrm{a} \times 10^{-8}$ & $\ln \left(\mathrm{K}_{\mathrm{G}} \mathrm{a}\right)$ \\
\hline${ }^{\circ} \mathrm{C}$ & $\left(\mathrm{K}^{-1}\right)$ & $\left(\mathrm{Pa} \mathrm{M}^{-1}\right)$ & $\left(\mathrm{Pa} \mathrm{M}^{-1}\right)$ & $\left(\mathrm{mol} \mathrm{Pa} \mathrm{P}^{-1}\left[\mathrm{~L}\right.\right.$ of gas $\left.\left.^{-1}\right] \mathrm{s}^{-1}\right)$ & $\left(\mathrm{mol} \mathrm{Pa}{ }^{-1}\left[\mathrm{~L}\right.\right.$ of $\left.\left.\operatorname{gas}^{-1}\right] \mathrm{s}^{-1}\right)$ \\
\hline 5 & $3.60 \mathrm{E}-03$ & 7.3 & 15.80 & 3.74 & -17.1016 \\
\hline 15 & $3.47 \mathrm{E}-03$ & 1824 & 16.72 & 3.40 & -17.1969 \\
\hline 25 & $3.35 \mathrm{E}-03$ & 3546 & 17.38 & 3.09 & -17.2925 \\
\hline
\end{tabular}

Table A.13 Experimental data for Fig. 6.5(a).

\begin{tabular}{|c|c|c|c|c|c|c|c|c|c|c|c|c|}
\hline \multirow{3}{*}{$\begin{array}{l}\text { Time } \\
\text { (min) }\end{array}$} & \multicolumn{12}{|c|}{$\mathrm{C}_{\mathrm{NAs}} / \mathrm{C}_{\mathrm{NAs} 0}(\%)$} \\
\hline & \multicolumn{4}{|c|}{$\mathrm{T}=5{ }^{\circ} \mathrm{C}$} & \multicolumn{4}{|c|}{$\mathrm{T}=15^{\circ} \mathrm{C}$} & \multicolumn{4}{|c|}{$\mathrm{T}=25^{\circ} \mathrm{C}$} \\
\hline & Trial 1 & Trial 2 & Avg. & SD & Trial 1 & Trial 2 & Avg. & SD & Trial 1 & Trial 2 & Avg. & SD \\
\hline 0 & 100 & 100 & 100 & 0 & 100 & 100 & 100 & 0 & 100 & 100 & 100 & 0 \\
\hline 5 & 86.60 & 91.40 & 89.00 & 3.39 & 83.70 & 86.50 & 85.10 & 1.98 & 75.80 & 79.80 & 77.80 & 2.83 \\
\hline 15 & 69.30 & 72.70 & 71.00 & 2.40 & 67.40 & 64.00 & 65.70 & 2.40 & 49.30 & 53.10 & 51.20 & 2.69 \\
\hline 30 & 53.00 & 48.80 & 50.90 & 2.97 & 46.70 & 42.70 & 44.70 & 2.83 & 26.90 & 30.90 & 28.90 & 2.83 \\
\hline 40 & 36.50 & 40.70 & 38.60 & 2.97 & 31.80 & 34.40 & 33.10 & 1.84 & 20.50 & 16.10 & 18.30 & 3.11 \\
\hline 50 & 28.10 & 32.10 & 30.10 & 2.83 & 25.00 & 23.20 & 24.10 & 1.27 & 13.80 & 10.20 & 12.00 & 2.55 \\
\hline 60 & 25.80 & 21.80 & 23.80 & 2.83 & 15.10 & 18.90 & 17.00 & 2.69 & 4.90 & 9.10 & 7.00 & 2.97 \\
\hline
\end{tabular}

Table A. 14 Experimental data for Figs. 6.5(c) and 6.6(c).

\begin{tabular}{|c|c|c|c|c|c|c|}
\hline \multirow{2}{*}{$\begin{array}{c}\text { Time } \\
(\mathrm{min})\end{array}$} & \multicolumn{5}{|c|}{ Effect of Temp. } & \multicolumn{3}{c|}{$\mathrm{C}_{\mathrm{O} 3 \mathrm{G}} \times 10^{4}(\mathrm{M})$} \\
\cline { 2 - 7 } & $\mathrm{T}=5{ }^{\circ} \mathrm{C}$ & $\mathrm{T}=15^{\circ} \mathrm{C}$ & $\mathrm{T}=25^{\circ} \mathrm{C}$ & $\mathrm{C}_{\mathrm{O} 3 \mathrm{Gi}}=3.1 \times 10^{-4}(\mathrm{M})$ & $\mathrm{C}_{\mathrm{O} 3 \mathrm{Gi}}=3.1 \times 10^{-4}(\mathrm{M})$ & $\mathrm{C}_{\mathrm{O} 3 \mathrm{Gi}}=3.1 \times 10^{-4}(\mathrm{M})$ \\
\hline 0 & 0 & 0 & 0 & 0 & 0 & 0 \\
\hline 2 & 8.63 & 8.82 & 8.68 & 2.63 & 5.92 & 8.68 \\
\hline 4 & 8.88 & 8.93 & 9.00 & 2.99 & 6.05 & 9.00 \\
\hline 8 & 9.35 & 8.92 & 8.95 & 3.05 & 6.17 & 8.95 \\
\hline 12 & 9.04 & 9.21 & 8.93 & 3.14 & 6.04 & 8.93 \\
\hline 16 & 9.16 & 8.96 & 8.91 & 3.16 & 5.98 & 8.91 \\
\hline
\end{tabular}




\section{A.4 EXPERIMENTAL DATA FOR CHAPTER 7}

Table A.15 Experimental data for Fig. 7.1.

\begin{tabular}{|c|c|c|c|c|c|c|c|c|c|c|c|c|}
\hline \multirow{4}{*}{$\begin{array}{l}\text { Time } \\
\text { (min) }\end{array}$} & \multicolumn{12}{|c|}{$\mathrm{C}_{\mathrm{NAs}} / \mathrm{C}_{\mathrm{NAs} 0}(\%)$} \\
\hline & \multirow{2}{*}{\multicolumn{4}{|c|}{ Ozonation only }} & \multicolumn{8}{|c|}{ Catalytic ozonation } \\
\hline & & & & & \multicolumn{4}{|c|}{ Alumina } & \multicolumn{4}{|c|}{$10 \% \mathrm{MnO}_{2}$} \\
\hline & Trial 1 & Trial 2 & Avg. & SD & Trial 1 & Trial 2 & Avg. & SD & Trial 1 & Trial 2 & Avg. & SD \\
\hline 0 & 100 & 100 & 100 & 0 & 100 & 100 & 100 & 0 & 100 & 100 & 100 & 0 \\
\hline 5 & 75.80 & 79.80 & 77.80 & 2.83 & 56.42 & 52.83 & 54.63 & 2.54 & 60.23 & 63.02 & 61.63 & 1.97 \\
\hline 15 & 53.10 & 49.30 & 51.20 & 2.69 & 33.86 & 38.27 & 36.07 & 3.12 & 32.78 & 36.80 & 34.79 & 2.84 \\
\hline 30 & 30.90 & 26.90 & 28.90 & 2.83 & 23.28 & 19.63 & 21.46 & 2.58 & 21.36 & 17.75 & 19.55 & 2.55 \\
\hline 45 & 13.81 & 18.21 & 16.01 & 3.11 & 15.92 & 11.76 & 13.84 & 2.94 & 13.63 & 9.78 & 11.71 & 2.72 \\
\hline \multirow{3}{*}{$\begin{array}{l}\text { Time } \\
(\mathrm{min})\end{array}$} & \multicolumn{12}{|c|}{ Catalytic ozonation } \\
\hline & \multicolumn{4}{|c|}{5 wt. $\% \mathrm{MnO}_{2} / 5$ wt. $\% \mathrm{Co}_{3} \mathrm{O}_{4}$} & \multicolumn{4}{|c|}{10 wt. $\% \mathrm{MnO}_{2} / 10$ wt. $\% \mathrm{Co}_{3} \mathrm{O}_{4}$} & \multicolumn{4}{|c|}{5 wt. $\% \mathrm{MnO}_{2} / 5$ wt. $\% \mathrm{Li}_{2} \mathrm{O}$} \\
\hline & Trial 1 & Trial 2 & Avg. & SD & Trial 1 & Trial 2 & Avg. & SD & Trial 1 & Trial 2 & Avg. & SD \\
\hline 0 & 100 & 100 & 100 & 0 & 100 & 100 & 100 & 0 & 100 & 100 & 100 & 0 \\
\hline 5 & 60.36 & 55.69 & 58.02 & 3.30 & 56.26 & 59.16 & 57.71 & 2.05 & 57.15 & 61.04 & 59.09 & 2.75 \\
\hline 15 & 34.76 & 30.74 & 32.75 & 2.84 & 39.29 & 35.22 & 37.25 & 2.88 & 26.55 & 31.12 & 28.84 & 3.23 \\
\hline 30 & 18.19 & 14.53 & 16.36 & 2.59 & 18.36 & 22.69 & 20.52 & 3.06 & 18.69 & 14.31 & 16.50 & 3.10 \\
\hline 45 & 10.90 & 14.66 & 12.78 & 2.66 & 13.26 & 9.09 & 11.18 & 2.95 & 8.44 & 11.08 & 9.76 & 1.87 \\
\hline \multirow{3}{*}{$\begin{array}{l}\text { Time } \\
\text { (min) }\end{array}$} & \multicolumn{12}{|c|}{ Catalytic ozonation } \\
\hline & \multicolumn{4}{|c|}{10 wt. $\% \mathrm{MnO}_{2} / 10$ wt. $\% \mathrm{Li}_{2} \mathrm{O}$} & \multicolumn{4}{|c|}{$\mathrm{AC}(0.25-0.841 \mathrm{~mm})$} & & & & \\
\hline & Trial 1 & Trial 2 & Avg. & SD & Trial 1 & Trial 2 & Avg. & SD & & & & \\
\hline 0 & 100 & 100 & 100 & 0 & 100 & 100 & 100 & 0 & & & & \\
\hline 5 & 61.10 & 57.62 & 59.36 & 2.46 & 39.37 & 34.84 & 37.1 & 3.2 & & & & \\
\hline 15 & 25.63 & 28.30 & 26.96 & 1.89 & 12.38 & 16.20 & 14.29 & 2.7 & & & & \\
\hline 30 & 12.95 & 17.09 & 15.03 & 2.93 & 10.94 & 9.10 & 10.02 & 1.3 & & & & \\
\hline 45 & 9.73 & 7.07 & 8.40 & 1.88 & 5.14 & 6.70 & 5.92 & 1.1 & & & & \\
\hline
\end{tabular}


Table A.16 Experimental data for Fig. 7.2.

\begin{tabular}{|c|c|c|c|c|c|c|c|c|c|c|c|c|}
\hline \multirow{3}{*}{$\begin{array}{l}\text { Ads. } \\
\text { Time } \\
\text { (min) }\end{array}$} & \multicolumn{12}{|c|}{$\mathrm{C}_{\mathrm{NAs}} / \mathrm{C}_{\mathrm{NAs} 0}(\%)$} \\
\hline & \multicolumn{4}{|c|}{ P. size $=0.037-0.149 \mathrm{~mm}$} & \multicolumn{4}{|c|}{ P. size $=0.25-0.841 \mathrm{~mm}$} & \multicolumn{4}{|c|}{ P. size $=0 . .841-2.38 \mathrm{~mm}$} \\
\hline & Trial 1 & Trial 2 & Avg. & SD & Trial 1 & Trial 2 & Avg. & SD & Trial 1 & Trial 2 & Avg. & SD \\
\hline 0 & 100 & 100 & 100 & 0 & 100 & 100 & 100 & 0 & 100 & 100 & 100 & 0 \\
\hline 5 & 66.96 & 68.28 & 67.62 & 0.93 & 91.48 & 93.81 & 92.65 & 1.65 & 95.30 & 97.96 & 96.63 & 1.88 \\
\hline 15 & 61.81 & 63.06 & 62.44 & 0.88 & 89.29 & 90.62 & 89.95 & 0.94 & 94.29 & 97.13 & 95.71 & 2.01 \\
\hline 30 & 58.53 & 60.11 & 59.32 & 1.12 & 86.02 & 88.20 & 87.11 & 1.54 & 93.08 & 95.55 & 94.32 & 1.75 \\
\hline 45 & 56.44 & 57.56 & 57.00 & 0.79 & 84.37 & 87.37 & 85.87 & 2.12 & 92.48 & 95.07 & 93.77 & 1.83 \\
\hline
\end{tabular}

Table A.17 Experimental data for Fig. 7.2 and 7.3.

\begin{tabular}{|c|c|c|c|c|c|c|c|c|c|c|c|c|}
\hline \multirow{3}{*}{$\begin{array}{l}\text { Time } \\
(\min )\end{array}$} & \multicolumn{12}{|c|}{$\mathrm{C}_{\mathrm{NAs}} / \mathrm{C}_{\mathrm{NAs} 0}(\%)$} \\
\hline & \multicolumn{4}{|c|}{ P. size $=0.037-0.149 \mathrm{~mm}$} & \multicolumn{4}{|c|}{ P. size $=0.25-0.841 \mathrm{~mm}$} & \multicolumn{4}{|c|}{ P. size $=0 . .841-2.38 \mathrm{~mm}$} \\
\hline & $\begin{array}{c}\text { Trial } \\
1\end{array}$ & $\begin{array}{c}\text { Trial } \\
2\end{array}$ & Avg. & SD & $\begin{array}{c}\text { Trial } \\
1\end{array}$ & $\begin{array}{c}\text { Trial } \\
2\end{array}$ & Avg. & SD & $\begin{array}{c}\text { Trial } \\
1\end{array}$ & $\begin{array}{c}\text { Trial } \\
2\end{array}$ & Avg. & SD \\
\hline 0 & 100 & 100 & 100 & 0 & 100 & 100 & 100 & 0 & 100 & 100 & 100 & 0 \\
\hline 5 & 33.92 & 31.59 & 32.76 & 1.65 & 39.37 & 34.84 & 37.10 & 3.20 & 44.87 & 41.76 & 43.32 & 2.20 \\
\hline 15 & 12.00 & 10.42 & 11.21 & 1.12 & 16.20 & 12.38 & 14.29 & 2.70 & 17.16 & 19.42 & 18.29 & 1.60 \\
\hline 30 & 6.54 & 7.87 & 7.20 & 0.94 & 10.94 & 9.10 & 10.02 & 1.30 & 12.99 & 11.01 & 12.00 & 1.40 \\
\hline 45 & 3.14 & 2.01 & 2.58 & 0.80 & 6.70 & 5.14 & 5.92 & 1.10 & 9.88 & 8.54 & 9.21 & 0.95 \\
\hline
\end{tabular}

Table A.18 Experimental data for Fig. 7.4.

\begin{tabular}{|c|c|c|c|c|}
\hline \multirow{2}{*}{$\begin{array}{c}\text { AC Dosage } \\
\left(\mathrm{mg} \mathrm{L}^{-1}\right)\end{array}$} & \multicolumn{3}{|c|}{$\mathrm{C}_{\mathrm{NAs}} / \mathrm{C}_{\mathrm{NAs} 0}(\%)$} \\
\cline { 2 - 4 } & Avg & SD & \multicolumn{2}{c|}{$(15 \mathrm{~min})$} \\
\hline 0 & 100 & 0 & Avg. & SD \\
\hline 0.5 & 75.42 & 2.8 & 44.76 & 0 \\
\hline 1 & 37.1 & 3.2 & 14.29 & 2.7 \\
\hline 2 & 29.67 & 2.1 & 5.22 & 1.8 \\
\hline 3 & 21.67 & 2.64 & 4.22 & 1.1 \\
\hline 4 & 19.88 & 1.75 & 4.11 & 0.96 \\
\hline
\end{tabular}


Table A.19 Experimental data for Fig. 7.5.

\begin{tabular}{|c|c|c|c|c|c|c|c|c|c|c|c|c|}
\hline \multirow{3}{*}{$\begin{array}{l}\text { Time } \\
\text { (min) }\end{array}$} & \multicolumn{12}{|c|}{ Toxicity/Toxicity $_{0}(\%)$} \\
\hline & \multicolumn{4}{|c|}{ Ozonation only } & \multicolumn{4}{|c|}{ P. size $=0.037-0.149 \mathrm{~mm}$} & \multicolumn{4}{|c|}{ P. size $=0.25-0.841 \mathrm{~mm}$} \\
\hline & Trial 1 & Trial 2 & Avg. & SD & Trial 1 & Trial 2 & Avg. & SD & Trial 1 & Trial 2 & Avg. & SD \\
\hline 0 & 100 & 100 & 100 & 0 & 100 & 100 & 100 & 0 & 100 & 100 & 100 & 0 \\
\hline 5 & 88.45 & 85.04 & 86.747 & 2.41 & 39.61 & 44.72 & 42.17 & 3.61 & 44.93 & 46.63 & 45.78 & 1.20 \\
\hline 15 & 57.47 & 55.77 & 56.6265 & 1.20 & 14.96 & 11.55 & 13.25 & 2.41 & 23.04 & 17.93 & 20.48 & 3.61 \\
\hline 30 & 31.18 & 36.29 & 33.7349 & 3.61 & 6.38 & 8.08 & 7.23 & 1.20 & 11.34 & 7.93 & 9.64 & 2.41 \\
\hline 45 & 21.19 & 24.60 & 22.90 & 2.41 & 1.55 & 0.86 & 1.20 & 0.49 & 1.91 & 5.32 & 3.61 & 2.41 \\
\hline \multirow{2}{*}{$\begin{array}{l}\text { Time } \\
(\mathrm{min})\end{array}$} & \multicolumn{4}{|c|}{ P. size $=0 . .841-2.38 \mathrm{~mm}$} & & & & & & & & \\
\hline & Trial 1 & Trial 2 & Avg. & SD & & & & & & & & \\
\hline 0 & 100 & 100 & 100 & 0 & & & & & & & & \\
\hline 5 & 54.07 & 59.18 & 56.63 & 3.61 & & & & & & & & \\
\hline 15 & 24.60 & 21.19 & 22.89 & 2.41 & & & & & & & & \\
\hline 30 & 12.75 & 16.16 & 14.46 & 2.41 & & & & & & & & \\
\hline 45 & 8.08 & 6.38 & 7.23 & 1.20 & & & & & & & & \\
\hline
\end{tabular}

Table A.20 Experimental data for Fig. 7.6.

\begin{tabular}{|c|c|c|c|c|c|c|c|c|c|c|c|c|}
\hline \multirow{3}{*}{$\begin{array}{l}\text { Time } \\
\text { (min) }\end{array}$} & \multicolumn{12}{|c|}{$\mathrm{COD} / \mathrm{COD}_{0}(\%)$} \\
\hline & \multicolumn{4}{|c|}{ Ozonation Only } & \multicolumn{4}{|c|}{ P. size $=0.037-0.149 \mathrm{~mm}$} & \multicolumn{4}{|c|}{ P. size $=0.25-0.841 \mathrm{~mm}$} \\
\hline & Trial 1 & Trial 2 & Avg. & SD & Trial 1 & Trial 2 & Avg. & SD & Trial 1 & Trial 2 & Avg. & SD \\
\hline 0 & 100 & 100 & 100 & 0 & 100 & 100 & 100 & 0 & 100 & 100 & 100 & 0 \\
\hline 5 & 84.53 & 86.65 & 85.59 & 1.50 & 40.77 & 36.53 & 38.65 & 3.00 & 39.24 & 42.99 & 41.11 & 2.65 \\
\hline 15 & 63.32 & 61.48 & 62.40 & 1.30 & 31.24 & 27.42 & 29.33 & 2.70 & 31.84 & 34.82 & 33.33 & 2.11 \\
\hline 30 & 41.93 & 44.48 & 43.20 & 1.80 & 20.35 & 25.16 & 22.75 & 3.40 & 29.61 & 24.14 & 26.88 & 3.87 \\
\hline 45 & 35.30 & 32.90 & 34.10 & 1.70 & 20.43 & 16.47 & 18.45 & 2.80 & 22.05 & 18.44 & 20.24 & 2.55 \\
\hline \multirow{2}{*}{$\begin{array}{l}\text { Time } \\
(\mathrm{min})\end{array}$} & \multicolumn{4}{|c|}{ P. size $=0 . .841-2.38 \mathrm{~mm}$} & & & & & & & & \\
\hline & Trial 1 & Trial 2 & Avg. & $\mathrm{SD}$ & & & & & & & & \\
\hline 0 & 100 & 100 & 100 & 0 & & & & & & & & \\
\hline 5 & 42.32 & 46.99 & 44.65 & 3.30 & & & & & & & & \\
\hline 15 & 35.26 & 39.28 & 37.27 & 2.84 & & & & & & & & \\
\hline 30 & 30.08 & 26.57 & 28.32 & 2.48 & & & & & & & & \\
\hline 45 & 21.22 & 25.34 & 23.27 & 2.91 & & & & & & & & \\
\hline
\end{tabular}


Table A.21 Experimental data for Fig. 7.7.

\begin{tabular}{|c|c|c|c|c|c|c|c|c|}
\hline \multirow{2}{*}{$\begin{array}{c}\text { Time } \\
(\mathrm{min})\end{array}$} & \multicolumn{9}{|c|}{ Ozon/COD } \\
\cline { 2 - 9 } & Ozonation only & P. size $=0.037-0.149 \mathrm{~mm}$ & \multicolumn{2}{|c|}{ P. size $=0.25-0.841 \mathrm{~mm}$} & \multicolumn{2}{c|}{ P. size $=0.841-2.38 \mathrm{~mm}$} \\
\hline & Avg. & SD & Avg. & SD & Avg. & SD & Avg. & SD \\
\hline 0 & 0.01 & 0.00 & 0.01 & 0.00 & 0.01 & 0.00 & 0.01 & 0.00 \\
\hline 5 & 0.02 & 0.00 & 0.15 & 0.01 & 0.12 & 0.02 & 0.05 & 0.01 \\
\hline 15 & 0.05 & 0.01 & 0.29 & 0.03 & 0.23 & 0.02 & 0.10 & 0.02 \\
\hline 30 & 0.08 & 0.01 & 0.42 & 0.01 & 0.31 & 0.02 & 0.15 & 0.02 \\
\hline 45 & 0.11 & 0.02 & 0.56 & 0.01 & 0.44 & 0.01 & 0.21 & 0.04 \\
\hline
\end{tabular}

\section{A.5 EXPERIMENTAL DATA FOR CHAPTER 8}

Table A.22 Experimental data for Figs. 8.1 and 8.4.

\begin{tabular}{|c|c|c|c|c|c|c|c|c|c|c|c|c|}
\hline \multirow{3}{*}{$\begin{array}{l}\text { Time } \\
(\mathrm{min})\end{array}$} & \multicolumn{12}{|c|}{$\mathrm{C}_{\mathrm{NAs}} / \mathrm{C}_{\mathrm{NAs} 0}(\%)$} \\
\hline & \multicolumn{4}{|c|}{ Ozonation only } & \multicolumn{4}{|c|}{$\mathrm{T}=5^{\circ} \mathrm{C}$} & \multicolumn{4}{|c|}{$\mathrm{T}=15^{\circ} \mathrm{C}$} \\
\hline & Trial 1 & Trial 2 & Avg. & SD & Trial 1 & Trial 2 & Avg. & SD & Trial 1 & Trial 2 & Avg. & SD \\
\hline 0 & 100 & 100 & 100 & 0 & 100 & 100 & 100 & 0 & 100 & 100 & 100 & 0 \\
\hline 5 & 75.80 & 79.80 & 77.80 & 2.83 & 82.28 & 86.73 & 84.51 & 3.15 & 76.19 & 80.04 & 78.11 & 2.72 \\
\hline 15 & 53.10 & 49.30 & 51.20 & 2.69 & 54.39 & 59.00 & 56.70 & 3.26 & 43.16 & 47.36 & 45.26 & 2.97 \\
\hline 30 & 30.90 & 26.90 & 28.90 & 2.83 & 25.40 & 29.46 & 27.43 & 2.87 & 13.21 & 17.75 & 15.48 & 3.21 \\
\hline 45 & 13.81 & 18.21 & 16.01 & 3.11 & 10.01 & 14.41 & 12.21 & 3.11 & 2.47 & 6.22 & 4.34 & 2.65 \\
\hline \multirow{2}{*}{$\begin{array}{l}\text { Time } \\
(\mathrm{min})\end{array}$} & \multicolumn{4}{|c|}{$\mathrm{T}=25^{\circ} \mathrm{C}$} & & & & & & & & \\
\hline & Trial 1 & Trial 2 & Avg. & SD & & & & & & & & \\
\hline 0 & 100 & 100 & 100 & 0 & & & & & & & & \\
\hline 5 & 63.34 & 67.16 & 65.25 & 2.70 & & & & & & & & \\
\hline 15 & 19.06 & 23.51 & 21.29 & 3.15 & & & & & & & & \\
\hline 30 & 1.49 & 2.97 & 2.23 & 1.05 & & & & & & & & \\
\hline 45 & 0.42 & 1.89 & 1.16 & 1.04 & & & & & & & & \\
\hline
\end{tabular}


Table A.23 Experimental data for Figs. 8.2 and 8.5.

\begin{tabular}{|c|c|c|c|c|c|c|c|c|c|c|c|c|}
\hline \multirow{3}{*}{$\begin{array}{l}\text { Time } \\
(\mathrm{min})\end{array}$} & \multicolumn{12}{|c|}{$\mathrm{C}_{\mathrm{NAs}} / \mathrm{C}_{\mathrm{NAs} 0}(\%)$} \\
\hline & \multicolumn{4}{|c|}{ Ozonation only } & \multicolumn{4}{|c|}{$\mathrm{C}_{\mathrm{H} 2 \mathrm{O} 2}=1 \times 10^{-4} \mathrm{M}$} & \multicolumn{4}{|c|}{$\mathrm{C}_{\mathrm{H} 2 \mathrm{O} 2}=1 \times 10^{-3} \mathrm{M}$} \\
\hline & Trial 1 & Trial 2 & Avg. & $\mathrm{SD}$ & Trial 1 & Trial 2 & Avg. & SD & Trial 1 & Trial 2 & Avg. & SD \\
\hline 0 & 100 & 100 & 100 & 0 & 100 & 100.00 & 100 & 0 & 100 & 100.00 & 100 & 0 \\
\hline 5 & 75.80 & 79.80 & 77.80 & 2.83 & 70.46 & 75.01 & 72.74 & 3.22 & 63.34 & 67.16 & 65.25 & 2.7 \\
\hline 15 & 53.10 & 49.30 & 51.20 & 2.69 & 39.9 & 43.21 & 41.55 & 2.34 & 19.06 & 23.51 & 21.29 & 3.15 \\
\hline 30 & 30.90 & 26.90 & 28.90 & 2.83 & 19.52 & 23.31 & 21.42 & 2.68 & 1.49 & 2.97 & 2.23 & 1.05 \\
\hline 45 & 13.81 & 18.21 & 16.01 & 3.11 & 7.88 & 13.31 & 10.60 & 3.84 & 0.42 & 1.89 & 1.16 & 1.04 \\
\hline \multirow{2}{*}{$\begin{array}{l}\text { Time } \\
(\mathrm{min})\end{array}$} & \multicolumn{4}{|c|}{$\mathrm{C}_{\mathrm{H} 2 \mathrm{O} 2}=1 \times 10^{-2} \mathrm{M}$} & & & & & & & & \\
\hline & Trial 1 & Trial 2 & Avg. & SD & & & & & & & & \\
\hline 0 & 100 & 100.00 & 100 & 0 & & & & & & & & \\
\hline 5 & 78.22 & 84.02 & 81.12 & 4.1 & & & & & & & & \\
\hline 15 & 49.91 & 53.35 & 51.63 & 2.43 & & & & & & & & \\
\hline 30 & 24.96 & 29.36 & 27.16 & 3.11 & & & & & & & & \\
\hline 45 & 9.31 & 13.33 & 11.32 & 2.84 & & & & & & & & \\
\hline
\end{tabular}

Table A.24 Experimental data for Fig. 8.3.

\begin{tabular}{|c|c|c|c|c|c|c|c|c|c|c|}
\hline \multirow{3}{*}{$\begin{array}{l}\text { Time } \\
\text { (min) }\end{array}$} & \multicolumn{5}{|c|}{$\mathrm{C}_{\mathrm{H} 2 \mathrm{O} 2,0}=0 \mathrm{M}$} & \multicolumn{5}{|c|}{$\mathrm{C}_{\mathrm{H} 2 \mathrm{O} 2,0}=1 \times 10^{-3} \mathrm{M}$} \\
\hline & \multicolumn{4}{|c|}{$\mathrm{C}_{p \mathrm{CBA}} / \mathrm{C}_{p \mathrm{CBA} 0}$} & \multirow{2}{*}{$\begin{array}{c}\ln \left(\mathrm{C}_{p \mathrm{CBA}} /\right. \\
\left.\mathrm{C}_{p \mathrm{CBA} 0}\right)\end{array}$} & \multicolumn{4}{|c|}{$\mathrm{C}_{p \mathrm{CBA}} / \mathrm{C}_{p \mathrm{CBA} 0}$} & \multirow{2}{*}{$\begin{array}{c}\ln \left(\mathrm{C}_{p \mathrm{CBA}} /\right. \\
\left.\mathrm{C}_{p \mathrm{CBA}}\right)\end{array}$} \\
\hline & Trial 1 & Trial 1 & Avg. & SD & & Trial 1 & Trial 2 & Avg. & SD & \\
\hline 0 & 1.000 & 1.000 & 1.000 & 0.000 & 0.000 & 1.000 & 1.000 & 1.000 & 0.000 & 0.000 \\
\hline 2 & 0.806 & 0.866 & 0.836 & 0.042 & -0.179 & 0.778 & 0.700 & 0.739 & 0.055 & -0.303 \\
\hline 4 & 0.663 & 0.717 & 0.690 & 0.038 & -0.371 & 0.496 & 0.540 & 0.518 & 0.031 & -0.658 \\
\hline 6 & 0.594 & 0.550 & 0.572 & 0.031 & -0.559 & 0.402 & 0.368 & 0.385 & 0.024 & -0.955 \\
\hline 8 & 0.446 & 0.432 & 0.439 & 0.010 & -0.823 & 0.328 & 0.292 & 0.310 & 0.025 & -1.171 \\
\hline
\end{tabular}


Table A.25 Experimental data for Fig. 8.6.

\begin{tabular}{|c|c|c|c|c|c|c|c|c|c|c|c|c|}
\hline \multirow{3}{*}{$\begin{array}{l}\text { Time } \\
\text { (min) }\end{array}$} & \multicolumn{12}{|c|}{$\mathrm{C}_{\mathrm{H} 2 \mathrm{O} 2}(\mathrm{M})$} \\
\hline & \multicolumn{4}{|c|}{$\mathrm{C}_{\mathrm{H} 2 \mathrm{O} 2,0}=1 \times 10^{-4} \mathrm{M}$} & \multicolumn{4}{|c|}{$\mathrm{C}_{\mathrm{H} 2 \mathrm{O} 2,0}=1 \times 10^{-3} \mathrm{M}$} & \multicolumn{4}{|c|}{$\mathrm{C}_{\mathrm{H} 2 \mathrm{O} 2,0}=1 \times 10^{-2} \mathrm{M}$} \\
\hline & Trial 1 & Trial 2 & Avg. & $\mathrm{SD}$ & Trial 1 & Trial 2 & Avg. & $\mathrm{SD}$ & Trial 1 & Trial 2 & Avg. & SD \\
\hline 0 & 100 & 100.00 & 100 & 0 & 100 & 100 & 100 & 0 & 100 & 100 & 100 & 0 \\
\hline 5 & 51.62 & 56.60 & 54.11 & 3.52 & 91.43 & 95.47 & 93.45 & 2.86 & 97.29 & 102.34 & 99.81 & 3.57 \\
\hline 15 & 0 & 0.00 & 0 & 0 & 77.37 & 81.78 & 79.58 & 3.12 & 95.56 & 99.75 & 97.65 & 2.96 \\
\hline 30 & 0 & 0.00 & 0 & 0 & 57.69 & 61.37 & 59.53 & 2.6 & 92.28 & 96.35 & 94.32 & 2.88 \\
\hline 45 & 0 & 0.00 & 0 & 0 & 34.51 & 39.18 & 36.84 & 3.3 & 90.75 & 94.70 & 92.72 & 2.79 \\
\hline
\end{tabular}

\section{A.6 EXPERIMENTAL DATA FOR CHAPTER 9}

Table A.26 Experimental data for Fig. 9.5.

\begin{tabular}{|c|c|c|c|c|c|c|c|c|c|c|c|c|}
\hline $\begin{array}{c}\text { Time } \\
(\mathrm{min})\end{array}$ & \multicolumn{4}{|c|}{$\mathrm{C}_{\mathrm{NAs}} / \mathrm{C}_{\mathrm{NAsi}}(\%)$} & \multicolumn{4}{c|}{$\mathrm{C}_{\mathrm{O} 3} \times 10^{-5}(\mathrm{M})$} & \multicolumn{4}{c|}{$\mathrm{C}_{\mathrm{O} 3 \mathrm{G}} \times 10^{-4}(\mathrm{M})$} \\
\hline 0 & Trial 1 & Trial 2 & Avg. & SD & Trial 1 & Trial 2 & Avg. & SD & Trial 1 & Trial 2 & Avg. & SD \\
\hline 15 & 100 & 100 & 100 & 0 & 0 & 0 & 0 & 0 & 0 & 0 & 0 & 0 \\
\hline 30 & 29.33 & 54.87 & 56.60 & 2.45 & 4.28 & 8.52 & 6.40 & 3.00 & 8.79 & 8.22 & 8.50 & 0.40 \\
\hline 45 & 21.79 & 17.41 & 19.60 & 3.10 & 4.28 & 8.95 & 6.61 & 3.30 & 8.71 & 8.29 & 8.50 & 0.30 \\
\hline 60 & 15.46 & 11.53 & 13.50 & 2.78 & 5.02 & 7.99 & 6.50 & 2.10 & 8.32 & 8.89 & 8.60 & 0.40 \\
\hline
\end{tabular}

Table A.27 Experimental data for Fig. 9.6.

\begin{tabular}{|c|c|c|c|c|c|c|c|c|c|c|c|c|}
\hline $\begin{array}{c}\text { Time } \\
(\mathrm{min})\end{array}$ & \multicolumn{4}{|c|}{ BOD } & \multicolumn{4}{c|}{ COD } & \multicolumn{4}{c|}{ BOD/COD } \\
\hline 0 & 23.79 & 27.10 & 25.44 & 2.34 & 330.00 & 330.00 & 330.00 & 0.00 & 0.07 & 0.08 & 0.08 & 0.01 \\
\hline 15 & 32.24 & 36.65 & 34.44 & 3.12 & 195.00 & 197.00 & 196.00 & 1.41 & 0.17 & 0.19 & 0.18 & 0.01 \\
\hline 30 & 38.14 & 40.94 & 39.54 & 1.98 & 122.00 & 126.00 & 124.00 & 2.83 & 0.31 & 0.32 & 0.32 & 0.01 \\
\hline 45 & 42.80 & 45.88 & 44.34 & 1.76 & 98.00 & 101.00 & 110.00 & 2.12 & 0.44 & 0.45 & 0.45 & 0.01 \\
\hline 60 & 44.67 & 47.81 & 46.24 & 2.22 & 87.00 & 91.00 & 89.00 & 2.83 & 0.51 & 0.53 & 0.52 & 0.01 \\
\hline
\end{tabular}


Table A.28 Experimental data for Fig. 9.7.

\begin{tabular}{|c|c|c|c|c|c|}
\hline \multirow{2}{*}{$\begin{array}{c}\text { Time } \\
(\mathrm{min})\end{array}$} & \multicolumn{3}{|c|}{ Toxicity $(\%$ Loss of Light) } & \multirow{2}{*}{ Tox./Tox.o } \\
\cline { 2 - 5 } & Trial 1 & Trial 2 & Avg. & SD & $(\%)$ \\
\hline 0 & 83.00 & 83.00 & 83.00 & 0.00 & 100.00 \\
\hline 15 & 41.00 & 35.00 & 38.00 & 4.24 & 45.78 \\
\hline 30 & 13.00 & 17.00 & 15.00 & 2.83 & 18.07 \\
\hline 45 & 7.00 & 13.00 & 10.00 & 4.24 & 12.05 \\
\hline 60 & 5.00 & 7.00 & 6.00 & 1.41 & 7.23 \\
\hline
\end{tabular}

\section{A.7 EXPERIMENTAL DATA FOR CHAPTER 10}

Table A.29 Experimental data for Fig. 10.6.

\begin{tabular}{|c|c|c|c|c|c|c|c|c|c|c|c|c|}
\hline \multirow{2}{*}{$\begin{array}{c}\text { Time } \\
(\mathrm{min})\end{array}$} & \multicolumn{4}{|c|}{$\mathrm{C}_{\mathrm{NAs}} / \mathrm{C}_{\mathrm{NAsi}}(\%)$} & \multicolumn{3}{c|}{$\mathrm{C}_{\mathrm{H} 2 \mathrm{O} / \mathrm{C}_{\mathrm{H} 2 \mathrm{O} 2}(\%)}$} & \multicolumn{3}{c|}{$\mathrm{C}_{\mathrm{O} 3 \mathrm{G}} \times 10^{-4}(\mathrm{M})$} \\
\hline 0 & Trial 1 & Trial 2 & Avg. & $\mathrm{SD}$ & Trial 1 & Trial 2 & Avg. & SD & Trial 1 & Trial 2 & Avg. & SD \\
\hline 5 & 100 & 100 & 100 & 0 & 100 & 100 & 100 & 0 & 0 & 0 & 0 & 0 \\
\hline 15 & 76.61 & 71.80 & 74.20 & 3.40 & 92.54 & 87.87 & 90.20 & 3.30 & 8.42 & 8.99 & 8.70 & 0.40 \\
\hline 30 & 9.23 & 35.03 & 37.12 & 2.95 & 71.50 & 77.30 & 74.40 & 4.10 & 9.11 & 8.69 & 8.90 & 0.30 \\
\hline 45 & 4.09 & 3.52 & 3.80 & 0.40 & 19.93 & 25.26 & 22.60 & 3.77 & 8.69 & 9.26 & 8.97 & 0.4 \\
\hline
\end{tabular}

Table A.30 Experimental data for Fig. 10.7.

\begin{tabular}{|c|c|c|c|c|c|c|c|c|c|c|c|c|}
\hline \multirow{2}{*}{$\begin{array}{c}\text { Time } \\
(\mathrm{min})\end{array}$} & \multicolumn{4}{|c|}{ BOD } & \multicolumn{4}{c|}{ COD } & \multicolumn{4}{c|}{ BOD/COD } \\
\hline 0 & Trial 1 & Trial 2 & Avg. & SD & Trial 1 & Trial 2 & Avg. & SD & Trial 1 & Trial 2 & Avg. & SD \\
\hline 5 & 23.79 & 27.10 & 25.44 & 2.34 & 330 & 330 & 330 & 0.00 & 0.07 & 0.08 & 0.08 & 0.01 \\
\hline 15 & 40.99 & 31.02 & 29.23 & 2.54 & 183.00 & 179.00 & 181.00 & 2.83 & 0.15 & 0.17 & 0.16 & 0.02 \\
\hline 30 & 50.69 & 43.34 & 3.32 & 112.00 & 106.00 & 109.00 & 4.24 & 0.37 & 0.43 & 0.40 & 0.05 \\
\hline 45 & 58.02 & 54.38 & 52.65 & 2.45 & 92.00 & 96.00 & 94.00 & 2.83 & 0.55 & 0.57 & 0.56 & 0.01 \\
\hline
\end{tabular}


Table A.31 Experimental data for Fig. 10.8.

\begin{tabular}{|c|c|c|c|c|c|}
\hline \multirow{2}{*}{$\begin{array}{c}\text { Time } \\
(\text { min) }\end{array}$} & \multicolumn{4}{|c|}{ Toxicity (\% Loss of Light) } & \multirow{2}{*}{ Tox./Tox.o } \\
\cline { 2 - 5 } & Trial 1 & Trial 2 & Avg. & SD & $(\%)$ \\
\hline 0 & 83 & 83 & 83 & 0 & 100 \\
\hline 5 & 45.00 & 49.00 & 47 & 2.83 & 56.63 \\
\hline 15 & 16.00 & 18.00 & 17 & 1.41 & 20.48 \\
\hline 30 & 7.00 & 5.00 & 6 & 1.41 & 7.23 \\
\hline 45 & 6.00 & 2.00 & 4 & 2.83 & 4.82 \\
\hline
\end{tabular}




\section{APPENDIX B: \\ STANDARD CURVES}

\section{B.1 NAPHTHENIC ACIDS STANDARD CURVE}

The standard method for the quantification of NAs (FTIR procedure), proposed by Jivraj et al. (1995), was used. Fig. B.1 shows the absorbance peaks for the carboxylic acids at different NAs concentrations. Two peaks are shown; the highest one is at $1698 \mathrm{~cm}^{-1}$ (for hydrogen-bonded dimmers) and the smallest one is at $1737 \mathrm{~cm}^{-1}$ (for monomers). These two peaks deviate a little bit from the reported values (1743 and $1705 \mathrm{~cm}^{-1}$ ) by Jivraj et al. (1995) which might happen due to using different commercial NAs or because of using different software to analyze the data. Triplicate trials showed the same results. The peak heights at $1736 \mathrm{~cm}^{-1}$ and $1698 \mathrm{~cm}^{-1}$ were summed for each standard and graphed versus the NAs concentration (Table B.1). The standard curve was established based on Table B.1 as shown in Fig. B.2. This standard curve was used to quantify NAs concentration in all subsequent experiments.

Table B.1 Experimental data for NAs standard curve.

\begin{tabular}{|c|c|c|c|c|}
\hline C $_{\text {NAs. }}$ & \multicolumn{4}{|c|}{ Total Corrected Height (\%T) } \\
\hline (mg/ ml DCM $)$ & Trial 1 & Trial 2 & Avg. & SD \\
\hline 0 & 0.230 & 0.100 & 0.165 & 0.092 \\
\hline 5 & -0.340 & -0.210 & -0.275 & 0.092 \\
\hline 10 & -0.470 & -0.350 & -0.410 & 0.085 \\
\hline 20 & -0.980 & -0.850 & -0.915 & 0.092 \\
\hline 40 & -1.850 & -1.980 & -1.915 & 0.092 \\
\hline 60 & -2.720 & -2.890 & -2.805 & 0.120 \\
\hline 80 & -3.630 & -3.500 & -3.565 & 0.092 \\
\hline 100 & -4.720 & -4.600 & -4.660 & 0.085 \\
\hline 120 & -5.460 & -5.330 & -5.395 & 0.092 \\
\hline
\end{tabular}

$\mathrm{DCM}=$ dichloromethane 


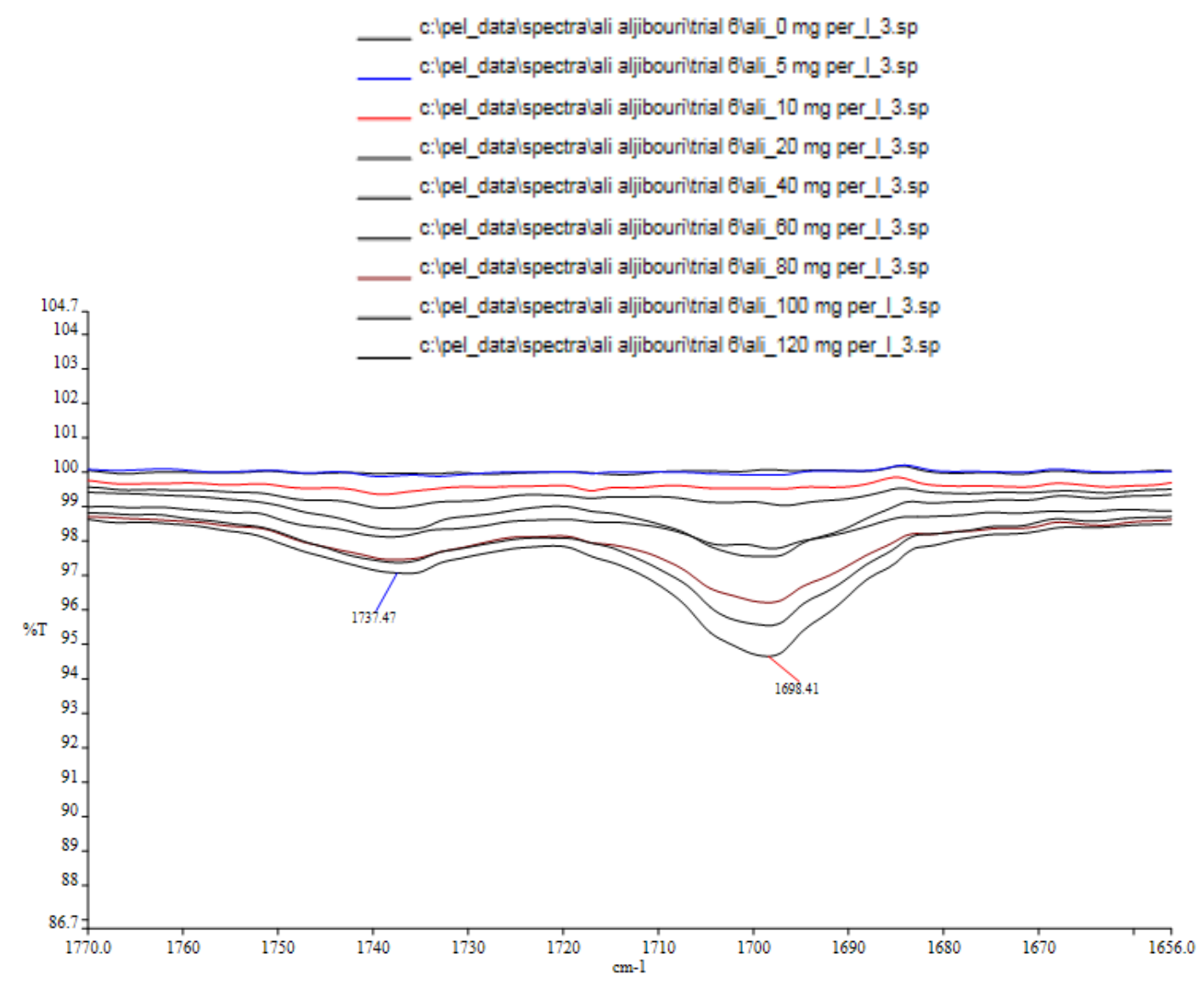

Figure B.1 Spectra for different concentrations of NA dissolved in DCM. 


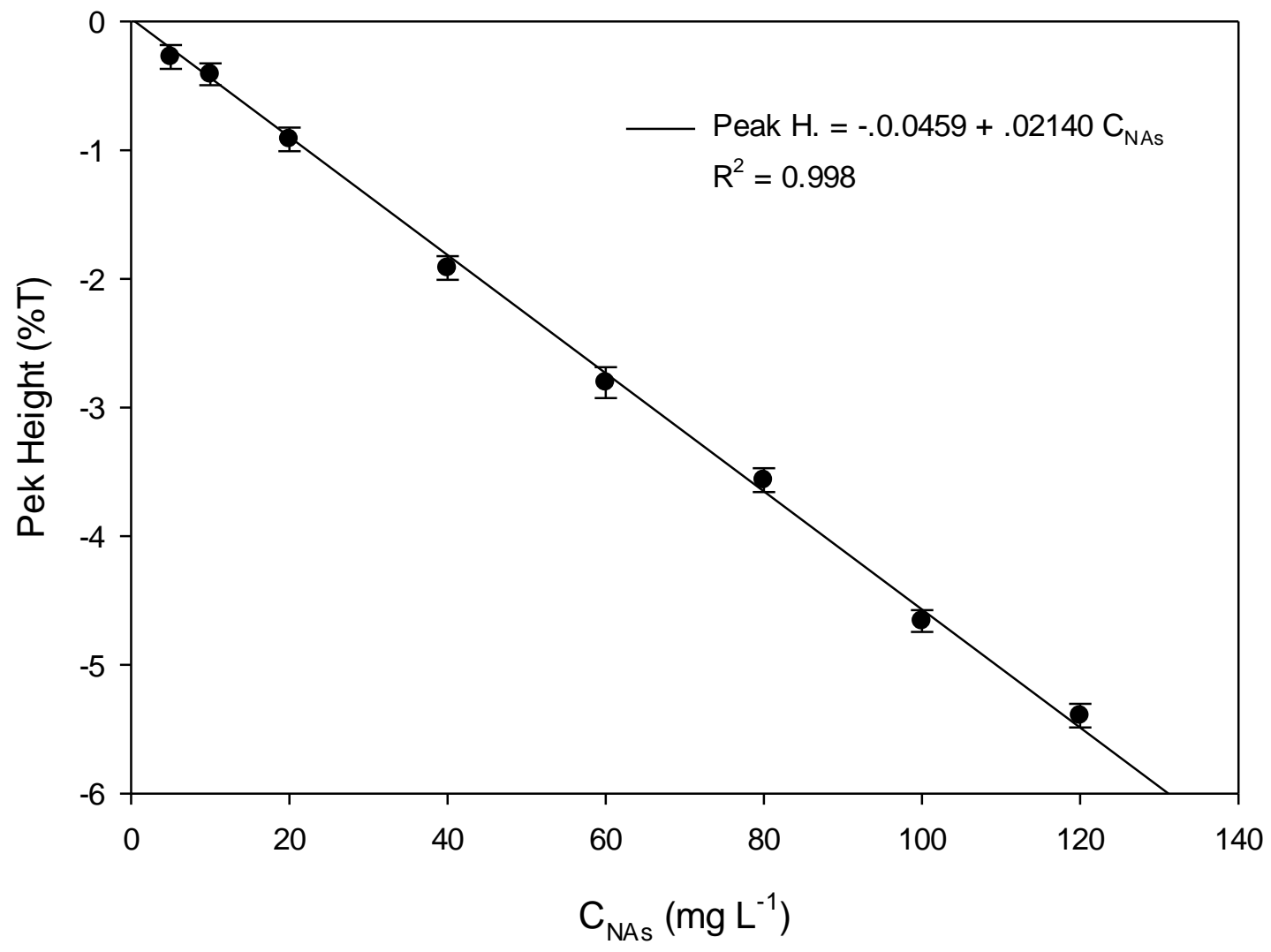

Figure B.2 Standard curve for NAs concentration measurement.

\section{B.2 HYDROGEN PEROXIDE STANDARD CURVE}

Hydrogen peroxide standard curve was prepared according to the Water Resource Foundation (WRF, 2009). Table B.2 shows the experimental data which were used to establish the hydrogen peroxide standard curve (Fig. B.3) 
Table B.2 Experimental data for hydrogen peroxide standard curve.

\begin{tabular}{|c|c|c|c|c|c|c|}
\hline \multirow{2}{*}{ sample } & \multicolumn{4}{|c|}{ Abs. (-) } & $\mathrm{C}_{\mathrm{H} 2 \mathrm{O} 2}$ & $\mathrm{C}_{\mathrm{H} 2 \mathrm{O} 2} \times 10^{5}$ \\
\cline { 2 - 7 } & Trial 1 & Trial 2 & Avg. & $\mathrm{SD}$ & $\mathrm{mg} \mathrm{L}^{-1}$ & $(\mathrm{M})$ \\
\hline 0 & 0 & 0 & 0 & 0 & 0 & 0 \\
\hline 1 & 0.016 & 0.02 & 0.018 & 0.003 & 0.8 & 2.352 \\
\hline 2 & 0.042 & 0.045 & 0.043 & 0.002 & 1.6 & 4.704 \\
\hline 3 & 0.077 & 0.07 & 0.073 & 0.005 & 2.4 & 7.056 \\
\hline 4 & 0.105 & 0.1 & 0.102 & 0.004 & 3.2 & 9.408 \\
\hline
\end{tabular}

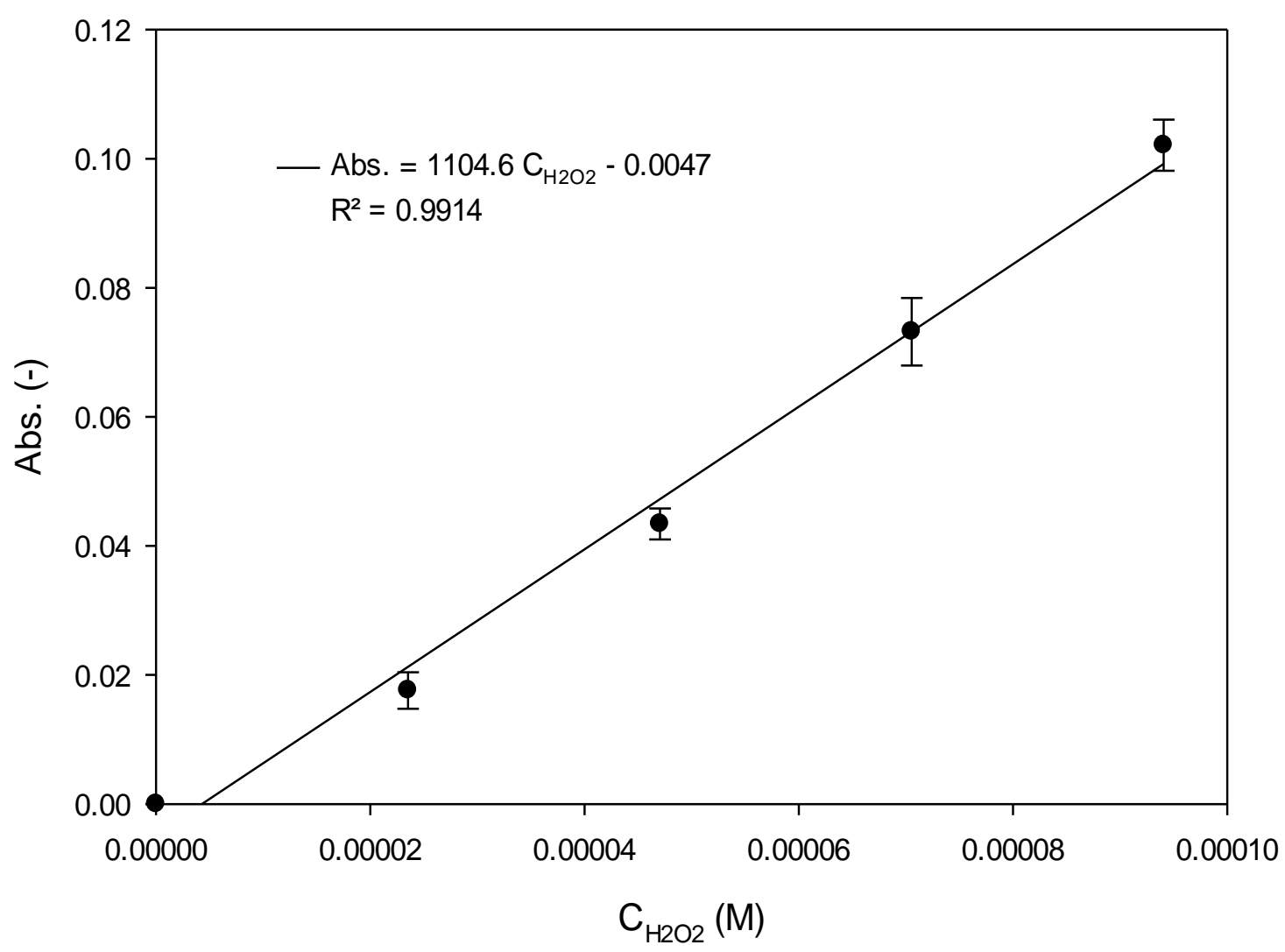

Figure B.3 Standard curve for hydrogen peroxide concentration measurement. 


\section{REFERENCES}

Adhoum N., Monser L. (2004). Removal of phthalate on modified activated carbon: application to the treatment of industrial wastewater. Separ. Purif. Tech. 38: 233-239.

Agenson K. O., Oh J.-H., Urase T. (2003). Retention of a wide variety of organic pollutants by different nanofiltration/reverse osmosis membranes: controlling parameters to the process. J. Membr. Sci. 225: 91-103.

Ahad J., Pakdel H., Savard M., Calderhead A., Gammon P., Rivera A., Peru K., John V. Headley J. (2013). Characterization and quantification of mining-related "naphthenic acids" in groundwater near a major oil sands tailings pond. Environ. Sci. Technol. 47: 5023-5030.

Alberta Chamber of Resources. (2004, 01 30). Oil Sands Technology Roadmap, Unlock the Potential. From Alberta Chamber of Resources:

http://www.strategywest.com/downloads/ACR200401.pdf. . Accessed May 03, 2013,

Al jibouri A. K. H., Wu J. (2015). Model development for naphthenic acids ozonation process. Environ. Sci. Poll. Res. 22: 2558-2565.

Al jibouri A. K. H., Wu J., Upreti S. R. (2015a). Ozonation of Naphthenic Acids in Water: Kinetic Study. Water Air Soil Pollut. 226(10): 338.

Al jibouri A. K. H., Wu J., Upreti S. R. (2015b). Continuous ozonation of methylene blue in water. J. Water Proess. Eng. 8: 142-150.

Al jibouri A. K. H., Wu J., Upreti S. R. (2016). Application of mass balance models in the process of ozone removal of naphthenic acids from water. Can. J. Chem. Eng. Accepted.

Alberta Government (2014). Alberta's oil sands: the facts. http://www.energy.gov.ab.ca/OilSands/pdfs/AlbertasOilSandsFactsJan14.pdf. Accessed May 13, 2015.

Allen E. W. 2008a. Process water treatment in Canada's oil sands industry: I. Target pollutants and treatment objectives. J. Environ. Eng. Sci. 7(2):123-138.

Allen E. W. (2008b). Process water treatment in Canada's oil sands industry: II. A review of emerging technologies. J. Environ. Eng. Sci. 7(5):499-524.

Alvares A. B. C., Diaper C., Parsons A. (2001). Partial oxidation by ozone to remove recalcitrance from wastewaters-A review. Environ. Technol. 22: 409-427. 
Anderson J. C. , Wiseman S. B., Wang N., Moustafa A., Perez-Estrada L., Gamal El-Din M., Martin J. W., Liber K., \& Giesy J. P. (2012). Effectiveness of Ozonation Treatment in Eliminating Toxicity of Oil Sands Process-Affected Water to Chironomus dilutus. Environ. Sci. Technol. 46(1):486-493.

Antonopoulou M., Evgenidou E., Lambropoulou D., \& Konstantinou I. (2014). A review on advanced oxidation processes for the removal of taste and odor compounds from aqueous media. Water Res. 53:215-234.

APHA (2005). APHA Method 4500-03, Ozone (residual). Indigo colorimetric method. In A.E. Greenberg, L.S. Clesceri, A.D. Eaton (Eds.), Standard methods for the examination of water and wastewater, 21st edition. (pp. 4-106). Washington, D.C.: American Public Health Association.

Armstrong S. A., Headley J. V., Peru K. M., \& Germida J. J. (2009). Differences in phytotoxicity and dissipation between ionized and nonionized oil sands naphthenic acids in wetland plants." Environ. Toxicol. Chem. 28(10): 2167-2174.

Banerjee D. K. (2012). Oil sands, heavy oil, and bitumen: from recovery to refinery. Tulsa, Oklahoma: PennWell Corporation.

Bartholomew, C.H., Farrauto, R.J. (2006). Fundamentals of Industrial Catalytic Processes. (2nd Ed.) New Jersey: John Wily \& Sons Inc.

Beltrán F. J. (1997). Theoretical Aspects of the Kinetics of Competitive First Reactions of Ozone in the $\mathrm{O}_{3} / \mathrm{H}_{2} \mathrm{O}_{2}$ and $\mathrm{O}_{3} / \mathrm{UV}$ Oxidation Processes. Ozone Sic. Eng. 19(1): 13-38.

Beltrán F. J., García-Araya J. F., Acedo B. (1994). Advanced oxidation of atrazine in water. I. Ozonation. Water Res. 28: 2153-2164.

Beltrán F. J., Ovejero G., Encinar J. M., Rivas J. (1995). Oxidation of polynuclear aromatic hydrocarbons in water. 1. Ozonation. Ind. Eng. Chem. Res. 34: 1596-1606.

Beltrán F. J., Rivas F. J., Ferna’ndez L. A., Älvarez P. M., \& Montero-de-Espinosa R. (2002). Kinetics of catalytic ozonation of oxalic acid in water with activated carbon. Ind. Eng. Chem. Res. 41(25): 6510-6517.

Bettle G., Tittlebaum M. E. (1995). Demonstration of an ozoneinitiated, oxygen-based autoxidation waste-water treatment technology. J. Environ. Sci. Health A 30: 1791-1805.

Bilstad T., Espedal E. (1996). Membrane separation of produced water. Water Sci. Technol. 34: 239-246. 
Bird RB, Stewart W. E., Lightfoot E. N. (2007) Transport Phenomena. John Wiley \& Sons Inc., New York, pp. 555-557

Boerger, H.; MacKinnon, M.; van Meer, T.; and Verbeek, A. (1992). Wet Landscape Option for Reclamation of Oil Sands Fine Tails. Second International Conference on Environmental Issues and Management of Waste in Energy and Minerals Production, (pp. 1249-1261). Rotterdam, Netherlands.

Brient, J. A.; Wessner, P. J.; and Doly, M. N. (1995). Naphthenic Acids. In J. Kroschwitz, Encyclopedia of Chemical Technology (Vol. 16, pp. 1017-1029). New York: John Wiley.

Brown L. D., Pérez-Estrada L., Wang N., El-Din M. G., Martin J. W., Fedora, P. M., Ulrich A. C. (2013). Indigenous microbes survive in situ ozonation improving biodegradation of dissolved organic matter in aged oil sands process-affected waters. Chemosphere 93: 27482755.

Bühler R. E., Staehelin J., Hoigne J. (1984). The ozone decomposition in water by use radiolysis I. $\mathrm{HO}_{2} / \mathrm{O}_{2}{ }^{-}$and $\mathrm{HO}_{3} / \mathrm{O}^{-}$as intermediates. J. Phys. Chem. 88: 2560-2564.

Buxton G. V., Greenstock C. L., Helman W. P., Ross A. B. (1988). Critical review of data constants for reactions of hydrated electrons, hydrogen atoms, and hydroxyl radicals $\left(\mathrm{HO}^{\bullet} / \mathrm{O}^{-\bullet}\right)$ in aqueous solution. J. Phys. Chem. Ref. Data 17: 513-886.

Campos J. C., Borges R. M. H., Oliveira Filho A. M., Nobrega R., Sant'Anna J. (2002). Oilfield wastewater treatment by combined microfiltration and biological processes. Water Res. 36: 95-104.

Canadian Association of Petroleum Producers. (2012). Crude Oil: Forcast, Markets \& Pipelines. From Canadian Association of Petroleum Producers: http://www.capp.ca/getdoc.aspx?DocId=209546\&DT=NTV. Accessed May 03, 2013.

Chapra S. C. and Canale R. P. (2009). Numerical Methods for Engineers (6 Ed.). New York: McGraw-Hill.

Charpentier J. C. (1981). Mass transfer rates in gas liquid absorbers and reactors. In J.C.

Charpentier (Ed.), Advances in Chemical Engineering (pp. 3-133). New York: Academic Press.

Chen J. W.; Hui C., Keller T.; Smith G. (1967). Catalytic ozonation in aqueous system. AIChE symposium series 166: 206-212. 
Chiron S., Fernandez-Alba A., Rodriguez A., Garcia-Calvo E. (2000). Pesticide chemical oxidation: state-of-the-art. Water Res. 34(2): 366-377.

Clemente, J.S.; Prasad, N.G.N.; MacKinnon, M.D.; and Fedorak, P.M. (2003). A Statistical Comparison of Naphthenic Acids Characterized by Gas Chromatography Mass Spectrometry. Chemosphere 50: 1265-1274

Clemente J. S., Fedorak P. M. (2005) A review of the occurrence, analyses, toxicity, and biodegradation of naphthenic acids. Chemosphere 60: 585-600.

Clemente J., MacKinnon M., Fedoran P. (2004). Aerobic biodegradation of two commercial naphthenic acids preparations. Environ. Sci. Technol. 38: 1009-1016.

Criegee R. (1957). The course of ozonation of unsaturated compounds. Rec. Chem. Prog. 18: 110-120.

Croué J.P., Beltrán F. J. Legube B. Doré M. (1989). Effect of preozonation on the organic halide formation potential of an aquatic fulvic acid. Ind. Eng. Chem. Res. 28: 1082-1089.

Danckwerts P. V. (1970). Gas-liquid reactions. New York: McGraw Hill.

Del Rio L. F., Hadwin A. K. M., Pinto L. J., MacKinnon M. D., Moore M. M. (2006)

Degradation of naphthenic acids by sediment micro-organisms. J. Appl. Microbiol. 101: 1049-1061.

Dhandapan B., \& Oyama S. T. (1997). Gas-Phase ozone decomposition catalysts. Appl. Catal. B 11(2):129-166.

Doran G. F., Williams K. L., Drago J. A., Huang S. S., Leong L.Y. C. (1998). Pilot-study results to convert oilfield produced water to drinking-water or reuse quality. In Proceedings of the SPE Annual Technical Conference, New Orleans, LA. Production Operations and Engineering/General, New Orleans, La. pp. 403-417.

Dyke C. A., Bartels C. R. (1990). Removal of organics from offshore produced waters using nanofiltration membrane technology. Environ. Prog. 9: 183-186.

Dzidic, I.; Somerville, A.C.; Raia, J. C.; and Hart, H. V. (1988). Determination of Naphthenic Acids in California Crudes and Refinery Wastewaters by Fluoride Ion Chemical Ionization Mass Spectrometry. Anal. Chem. 60, 1318-1323.

Elovitz M. S. and von Gunten U. (1999). Hydroxyl Radical/Ozone Ratios during Ozonation Processes. I. The Rct Concept. Ozone Sci. Eng. 21(3): 239-260. 
Elovitz M.S., von Gunten U., Kaiser H. (2000). Hydroxyl radical/ozone ratios during ozonation processes. II. The effect of temperature, $\mathrm{pH}$, alkalinity, and DOM properties. Ozone Sci. Eng. 22: 123-150.

Energy Resources Conservation Board (ERCB) (2013). ST98-2013: Alberta's energy reserve 2012 and supply/demand outlook 2013-2022. (pp. 3-2). Calgary, AB, Canada: Government of Alberta. http://www.aer.ca/documents/sts/ST98/ST98-2013.pdf. Accessed May 13, 2015.

Energy Resources Conservation Board (ERCB) (2009). ST98-2009: Alberta's Energy Reserves 2008 and Supply/Demand Outlook 2009-2018. From http://www.aer.ca/documents/sts/ST98/st98-2009.pdf. Accessed April 20, 2014.

Fan, T.-P. (1991). Characterization of Naphthenic Acids in Petroleum by Fast Atom Bombardment Mass Spectrometry of Large Biomolecules. Science 246: 64-71.

Fogler H. S. (2006). Elements of Chemical Reaction Engineering (4 Ed.). Upper Saddle River. NJ: Pearson Education, Inc.

Forni L., Bahnemann D., Hart E. J. (1982). Mechanism of the hydroxide ion-initiated decomposition of ozone in aqueous solution. J. Phys. Chem. 86(2): 255-259.

Frank, R. A.; Kavanagh, R.; Burnison, B. K.; Arsenault, G.; Headley, J. V.; Peru, K. M.; Van Der Kraak, G. ; and Solomon, K. R. (2008). Toxicity Assessment of Collected Fractions from an Extracted Naphthenic Acid Mixture. Chemosphere 72: 1309-1314.

Fu H., Gamal El-Din M., Smith D. W., MacKinnon M. D., Zubot W. (2008) Degradation of naphthenic acids in Athabasca oil sands process affected water using ozone. International Oil Sands Tailing Conference. Dec. 7-10, Edmonton, Alberta, Canada

Gamal El-Din M., Fu H., Wang N., Chelme-Ayala P., Pérez-Estrada L., Drzewicz P., Martin J. W., Zubot W., Smith D. W. (2011) Naphthenic acids speciation and removal during petroleum-coke adsorption and ozonation of oil sands process-affected water. Sci. Total. Environ. 409: 5119-5125.

Garcia-Garcia E., Ge J. Q., Oladiran A., Montgomery B., Gamal El-Din M., Perez-Estrada L. C., Stafford J. L., Martin J. W., \& Belosevic M. (2011). Ozone treatment ameliorates oil sands process water toxicity to the mammalian immune system. Water Res. 45(18):5849-5857.

Glaze W. H., Kang J. W., Chapin D. H. (1987). The chemistry of water treatment processes involving ozone, hydrogen peroxide and ultraviolet radiation, Ozone Sci. Eng. 9: 335-342. 
Glaze W. H., Kang J. W. (1989). Advanced Oxidation Processes. Description of a Kinetic Model for the Oxidation of Hazardous Materials in Aqueous Media with Ozone and Hydrogen Peroxide in a Semibatch Reactor. Ind. Eng. Chem. Res. 28: 1573-1580.

Government of Alberta (2010). Facts about water in Alberta. http://environment.gov.ab.ca/info/library/6364.pdf. Accessed May, 03. 2015.

Grabner G., Getoff N, Schwörer F. (1973). Pulsradiolyse von $\mathrm{H}_{3} \mathrm{PO}_{4}, \mathrm{H}_{2} \mathrm{PO}^{-}, \mathrm{HPO}_{4}{ }^{2-}$ und $\mathrm{P}_{2} \mathrm{O}_{7}{ }^{4-}$ in Wässriger Lösung-I. Geschwindigkeitskonstanten der reaktionen mit den primärprodukten der wasserradiolyse. Int. J. Radiat. Phys. Ch. 5(5): 393-403.

Grewer, D. M.; Young, R. F.; Whittal, R. M.; and Fedorak, P. M. (2010). Naphthenic Acids and Other Acid-Extractables in Water Samples from Alberta: What is Being Measured?. Sci. Total Environ. 408: 5997-6010.

Hagen M. O., Katzenback B. A., Islam M. D. S., Gamal El-Din M., Belosevic M. (2014). The analysis of goldfish (Carassius auratus L.) innate immune responses after acute and subchronic exposures to oil sands process-affected water. Toxicol. Sci. 138: 59-68.

Han X., MacKinnon M., Martin J. (2009). Estimating the in situ biodegradation of naphthenic acids in oil sands process waters by HPLC/HRMS. Chemosphere 76: 63-70.

Hansen B. R., Davies, S. R. H. (1994). Review of potential technologies for the removal of dissolved components from produced water. Chem. Eng. Res. Des. 72: 176-188.

He Y., Wiseman S. B., Zhang X., Hecker M., Jones P. D., Gamal El-Din M., Martin J. W., \& Giesy J. P. (2010). Ozonation attenuates the steroidogenic disruptive effects of sediment free oil sands process water in the H295R cell line. Chemosphere 80(5):578-584.

He Y., Patterson S., Wang N., Hecker M., Martin J. W., Gamal El-Din M., Giesy J. P., Wiseman S. ( 2012) Toxicity of untreated and ozone-treated oil sands process-affected water (OSPW) to early life stages of the fathead minnow (Pimephales promelas). Water Res. 46: 6359-6368.

Headley J. V., McMartin D. W. (2004) A review of the occurrence and fate of naphthenic acids in aquatic environments. J Environ. Sci. Health A39: 1989-2010.

Herman, D. C.; Fedorak, P. M.; MacKinnon, M. D.; and Costerton, J. W. (1994). Biodegradation of Naphthenic Acids by Microbial Populations in Indigenous to Oil Sands Tailings. Can. J. Microbiol. 40: 467-477. 
Hermosilla D., Merayo N., Gascó A., Blanco. Á. (2015). The application of advanced oxidation technologies to the treatment of effluents from the pulp and paper industry: a review. Environ. Sci. Pollut. Res. 22(1): 168-191.

Hoigné J. (1998). Chemistry of aqueous ozone and transformation of pollutants by ozonation and advanced oxidation processes. In The Handbook of Environmental Chemistry Vol. 5, Part C, Quality and Treatment of Drinking Water II, in J. Hrubec, Ed. (pp. 83-141). SpringerVerlag: Heidelberg.

Hoigné J., Bader H. (1967). The role of hydroxyl radical reactions in ozonation processes in aqueous solutions. Water Res. 10: 377-386.

Hoigné J., Bader H. (1983a). Rate constants of direct reactions of ozone with organic and inorganic compounds in water. I. Non-dissociating organic compounds. Water Res. 17: 173-183.

Hoigné J., Bader H. (1983b) Rate constants of reactions of ozone with organic and inorganic compounds in water-II Dissociating organic compounds. Water Res. 17: 185-194.

Holowenko F. M., MacKinnon M. D., Fedorak P. M. (2001) Naphthenic acids and surrogate naphthenic acids in methanogenic microcosms. Water Res. 35: 2595-2606.

Hwang G., Dong T., Islam M. S., Sheng Z., Pérez-Estrada L. A., Liu Y., Gamal El-Din M. (2013) The impacts of ozonation on oil sands process-affected water biodegradability and biofilm formation characteristics in bioreactors. Bioresource Technol. 130: 269-277.

Ioannoua L. A., Li Puma G., Fatta-Kassinos D. (2015). Treatment of winery wastewater by physicochemical, biological and advanced processes: A review. J. Hazard. Mater. 286: 343-368.

Jans U., Hoigné J. (1998). Activated carbon and carbon black catalyzed transformation of aqueous ozone into OH-Radicals. Ozone Sci. Eng. 20(1):67-90.

Ji G., Sun T., Zhou Q., Sui X., Chang S., Li P. (2002). Constructed subsurface flow wetland for treating heavy oil-produced water of the Liaohe Oilfield in China. Ecol. Eng. 18: 459-465.

Jivraj M. N., MacKinnon M., Fung B. (1995) Naphthenic Acids Extraction and Quantitative Analyses with FT-IR Spectroscopy. In: Syncrude Canada Research Department (Ed) Syncrude Analytical Methods Manual. Edmonton, Alberta 
Kannel P. R., Gan T. Y. (2012) Naphthenic acids degradation and toxicity mitigation in tailings wastewater systems and aquatic environments: A review. J. Environ. Sci. Health Part A 47: $1-21$.

Kasprzyk-Horderna B., Ziółek M., Nawrocki J. (2003). Catalytic ozonation and methods of enhancing molecular ozone reactions in water treatment. Appl. Catal. B 46(15): 639-669.

Legube B., Karpel Vel Leitner N. (1999). Catalytic ozonation: a promising advanced oxidation technology for water treatment. Catal. Today 53: 61-72.

Lester Y., Avisar D., \& Mamane H. (2010). Photodegradation of the antibiotic sulphamethoxazole in water with $\mathrm{UV} / \mathrm{H}_{2} \mathrm{O}_{2}$ advanced oxidation process. Environ. Technol. 31(2): 175-183.

Levenspiel O. 1999. Chemical Reaction Engineering (3 Ed.). New York, NY: John Wiley \& Sons.

Li G., An T., Chen J., Sheng G., Fu J., Chen F., Zhang S., Zhao H. (2006). Photoelectrocatalytic decontamination of oilfield produced wastewater containing refractory organic pollutants in the presence of high concentration of chloride ions. J. Hazard. Mater. 138: 392-400.

Li, B., Xu, X., Zhu, L., Ding, W., Mahmood, Q. (2010). Catalytic ozonation of industrial wastewater containing chloro and nitro aromatics using modified diatomaceous porous filling. Desalination 254(1-3): 90-98.

Lin S. H., Yeh, K. L., (1993). Looking to treat wastewater? Try ozone. Chem. Eng. May: 112116.

Lin S. H., Lan W. J. (1998). Waste oil/water emulsion treatment by membrane processes. J. Hazard. Mater. 59: 189-199.

List, B.R.; and Lord, E.R.F. (1997). Syncrude's Tailings Management Practices from Research to Implementation. Syncrude Energy.

Liu J., Xu Z., Masliyah J. (2005) Processability of oil sand ores in Alberta. Energy Fuels 19: 2056-2063

Lo C. C., Brownlee B. G., Bunce N. J. (2006) Mass spectrometric and toxicological assays of Athabasca oil sands naphthenic acids. Water Res. 40: 655-664.

Luo Y., Guoa W., Ngo H. H., Nghiemb L. D., Hai F. I., Zhang J., Liang S., \& Wang X. C. (2014). A review on the occurrence of micropollutants in the aquatic environment and their fate and removal during wastewater treatment. Sci. Total Environ. 473-474: 619-641. 
MacKinnon M. D., \& Boerger, H. (1986). Description of two treatment methods for detoxifying oil sands tailings pond water. Water Qual. Res. J. Can. 21: 496-513.

MacKinnon, M. (2004), Oil Sands Water Quality Issues: Properties, Treatment, and Discharge Options. Oil Sands Water Usage Workshop (February 24-25).

Mangasarian O. L. (1966). Sufficient conditions for the optimal control of nonlinear. SIAM J. Control 4: 139-152.

Marr J. B., Mohammed M., MacKinnon M., Rogers M. (1996). Removal of naphthenic acid from water via $\mathrm{pH}$ adjustment, coagulation and sand filtration. In Proceedings of the International Water Conference, Engineer's Society of Western Pennsylvania, Pittsburgh, Pa. pp. 738-754.

Martin J. W., Barri T., Han X., Fedorak P. M., Gamal El-Din M., Perez L., Scott A. C., \& Jiang J. T. (2010). Ozonation of oil sands process water accelerates microbial bioremediation. Environ. Sci. Technol. 44(21): 8350-8356.

Matsuura, I., Utsumi, Y., Doi, T. (1989). Oxidative coupling of methane over lithium-doped ultrafine crystalline magnesium oxide. Appl. Catal. 47: 299-306.

McNaught, A. D., Wilkinson, A. (1997). IUPAC Compendium of Chemical Terminology (2nd Ed.). Oxford: Wiley-Blackwell, Chichester.

Mezohegyi G., van der Zee F. P., Font J., Fortuny A., Fabregat A. (2012). Towards advanced aqueous dye removal processes: A short review on the versatile role of activated carbon." $J$. Environ. Manage. 102: 148-164.

Modren Water Inc. 2013. Delta Tox II User Manual. New Castle, USA: Modren Water Inc.

Morrison R. T., Boyd R. N. (1987). Organic Chemistry. (4 Ed.) Newton, MA: Allyn \& Bacon. National Energy Board (2004). Canada's Oil Sands: Opportunities and Challengess to 2015.From National Energy Board: http://www.neb.gc.ca/clfnsi/rnrgynfmtn/nrgyrprt/lsnd/pprtntsndchllngs20152004/pprtntsndchllngs20152004-eng.pdf Accessed May 03, 2013.

National Energy Board (2013). Canada's Oil Sands: Opportunities and Challenges to 2015. Retrieved from National Energy Board: http://www.neb-one.gc.ca/clfnsi/rnrgynfmtn/nrgyrprt/lsnd/pprtntsndchllngs20152006/pprtntsndchllngs20152006-eng.pdf Accessed May 03, 2013. 
Natural Resources Canada, (2011). Canadian Crude Oil, Natural Gas and Petroleum Products: Review of 2009 \& Outlook to 2030. From http://www.nrcan.gc.ca/sites/www.nrcan.gc.ca/files/energy/pdf/eneene/sources/crubru/revr ev/pdf/revrev-09-eng.pdf . Accessed April 01, 2014

Nero V., Farwell A., Lister A., Van der Kraak G., Lee L. E. J., Van Meer T., MacKinnon M. D., \& Dixon D. G. (2006). Gill and liver histopathological changes in yellow perch (Perca flavescens) and goldfish (Carassius auratus) exposed to oil sands process affected water. Ecotoxicol. Environ. Saf. 63(3): 365-377.

Neta P., \& Dorfman L. M. (1968). Pulse radiolysis studies. XIII: Rate constants for the reaction of hydroxyl radicals with aromatic compounds in aqueous solutions. Adv. Chem. Ser. 81: 222-230.

Peng H., Volchek K., MacKinnon M., Wong W. P., Brown C. E. (2004). Application on to nanofiltration to water management options for oil sands operation. Desalination 170: 137150.

Pereira A. S., Islam M. S., El-Din M. G., Martin J. W. (2013). Ozonation degrades all detectable organic compound classes in oil sands process-affected water; an application of highperformance liquid chromatography/obitrap mass spectrometry. Rapid Commun. Mass Spectrom. 27: 2317-2326.

Perez-Estrada L. A., Han X., Drzewicz P., Gamal El-Din M., Fedorak P. M., Martin J. W. (2011) Structure-reactivity of naphthenic acids in the ozonation process. Environ. Sci. Technol. 45: $7431-7437$.

Qi L., You H., Zhang R., Zhao X., Wu D. (2011). Degradation of 4-Chlorophenol Simulated Bio-Chemical Effluent from Coal Gasification Industry by Catalytic Ozonation. 5th International Conference on Bioinformatics and Biomedical Engineering.

Quagraine, E. K.; Peterson, H. G.; and Headley, J. V. (2005). In Situ Bioremediation of Naphthenic Acids Contaminated Tailing Pond Waters in the Athabasca Oil Sands Region. Demonstrated Field Studies and Plausible Options. A Review. J. of Environ. Sci. Health A 40: $685-722$.

Rice R. G., Browning M. E. (1981) Ozone treatment of industrial wastewater. Noyes Cata Corp, Park Ridge, NJ. 
Riebel A. H., Erickson R. E., Abshire C. J., Bailey P. S. (1960). Ozonation of carbon-nitrogen bonds. I. Nucleophilic attack of ozone. J. Am. Chem. Soc. 82: 1801-1807.

Rivera-Utrillaa J., Sánchez-Polo M., Gómez-Serrano V., Álvarez P. M., Alvim-Ferraz M. C. M., \& Dias J. M. (2011). Activated carbon modifications to enhance its water treatment applications. An overview. J. Hazard. Mater. 187(1-3):1-23.

Rogers V. V., Wickstrom M., Liber K., \& MacKinnon M. D. (2002). Acute and subchronic mammalian toxicity of naphthenic acids from oil sands tailings. Toxicol. Sci. 66(2): 347355.

Rosal, R, Gonzalo, M.S., Rodríguez, A., García-Calvo, E. (2010). Catalytic ozonation of fenofibric acid over alumina-supported manganese oxide. J. Hazard. Mater. 183: 271-278.

Roth J. A., Sullivan D. E. (1981) Solubility of ozone in water. Ind. Eng. Chem. Fundam. 20: 137-140.

Rudzinski, W. E.; Oehlers, L.; and Zhang, Y. (2002). Tandem Mass Spectrometric Characterization of Commercial Naphthenic Acids and a Maya Crude Oil. Energy Fuels 16: $1178-1185$.

Schramm L. L., Stasiuk E. N., MacKinnon M. (2000) Surfactants in Athabasca oil sands slurry conditioning, flotation recovery, and tailings processes. In: Schramm L (Ed.) Surfactants, fundamentals and applications in the petroleum industry. Cambridge University Press, Cambridge, UK, pp. 365-430

Scott, A. C.; MacKinnon, M. D.; and Fedorak, P. M. (2005). Naphthenic Acids in Athabasca Oil Sands Tailings Water are Less Biodegradable than Commercial Naphthenic Acids. Environ. Sci. Technol. 39: 8388-8394.

Scott A. C., Zubot W., MacKinnon M. D., Smith D. W., Fedorak P. M. (2008) Ozonation of oil sands process water removes naphthenic acids and toxicity. Chemosphere 71: 156-160.

Seifert W. K., Teeter R. M. (1969). Preparative thin-layer chromatography and high resolution mass spectrometry of crude oil carboxylic acids. Anal. Chem. 41: 786-795.

Singh, R. P. and Eckert, R. C. (1975). Ozone reactions in relation to the aromatic. International symposium on delignification with oxygen, ozone and peroxides. Raleigh, New York.

Sotelo J., Beltrán F. J., Benitez J., Beltran-Heredia J. (1989). Henry's law constant for the ozonewater system. Water Res. 23: 1239-1246. 
Staehelin J., Hoigné J. (1985). Decomposition of ozone in water in the presence of organic solutes acting as promoters and inhibitors of radical chain reactions. Environ. Sci. Technol. 19: 1206-1213.

Staehelin J.; Bühler R. E.; Hoigné J. (1984). The ozone decomposition in water by use radiolysis II.OH and $\mathrm{HO}_{4}$ as chain intermediates. J. Phys. Chem. 88: 5999-6004.

Staehelin S., Hoigné J. (1982). Decomposition of ozone in water: rate of initiation by hydroxide ions and hydrogen peroxide. Environ. Sci. Technol. 16: 666-681.

StatPoint Technologies Inc. (2010) STATGRAPHICS® Centurion XVI. http://www.Statgraphics.com. Accessed May 012013

Sui M., Xing S., Sheng L.; Huang S., Guo H. (2012). Heterogeneous catalytic ozonation of ciprofloxacin in water with carbon nanotube supported manganese oxides as catalyst. $J$. Hazard. Mater. (227-228): 227-236.

Suncor Energy (2010). Report on sustainability. From: http://sustainability.suncor.com/2010/pdf/T3150_ROS_EN_WEB_July21.pdf. . Accessed Nov. 01, 2012

Suncor Energy (2010). Summary report on sustainability. http://sustainability.suncor.com/2010/default.aspx. Accessed May 13, 2015.

Teare M., Burrowes A., Baturin-Pollock C., Rokosh D., Evans C., and Marsh R. (2013). ST982013 Alberta's Energy Reserves 2012 and Supply/Demand Outlook 2013-2022. Calgary, Alberta: Energy Resources Conservation Board. http://www.aer.ca/documents/sts/ST98/ST98-2013.pdf. Accessed September 28, 2014.

Tellez G. T., Nirmalakhandan N., Gardea-Torresdey J. L. (2002). Performance evaluation of an activated sludge system for removing petroleum hydrocarbons from oilfield produced water. Adv. Environ. Res. 6: 455-470.

Tomiyasu H., Fukutomi H., Gordon G. (1985). Kinetics and mechanism of ozone decomposition in basic aqueous solution. Inorg. Chem. 24: 2962-2966.

United Nations, Committee of Experts on the Transport of Dangerous Goods. (2009).

Recommendations on the Transport of Dangerous Goods: Model Regulations. New York: United Nations and Geneva. pp. 165.

Upreti, S. R. (2013). Optimal Control for Chemical Engineers. New York: CRC Press. 
Vilhunen S., Sillanpää M. (2010). Recent developments in photochemical and chemical AOPs in water treatment: a mini-review. Rev. Environ. Sci. Biotechnol. 9(4): 323-330.

Visser S. A. (1983). Comparative study of the elementary composition of fulvic acid and humic acid of aquatic origin and from soils and microbial substrates. Water Res. 17: 1393-1396.

Wallace S. (2004). Remediation marathon style. Environ. Prot. 15: 40-45.

Wang J. L., Xu L. J. (2012). Advanced Oxidation Processes for Wastewater Treatment: Formation of Hydroxyl Radical and Application. Crit. Rev. Environ. Sci. Technol. 42(3): 251-325.

Wang N., Chelme-Ayala P., Perez-Estrada L., Garcia-Garcia E., Pun J., Martin J. W., Belosevic M., Gamal El-Din M. (2013) Impact of ozonation on naphthenic acids speciation and toxicity of oil sands process-affected water to vibrio fischeri and mammalian immune system. Environ. Sci. Technol. 47: 6518-6526

WRF. (2009). Titanium Oxalate Method for Analysis of Hydrogen Peroxide in Water.

Alexandria, VA: Water Resource Foundation.

Wu J. (2005) Ozone Treatment. In: Lee S (Ed.) Encyclopedia of chemical processing, Marcel Dekker, New York, NY, pp. 1993-2001.

Wu J., Doan H., Upreti S. (2008). Decolorization of aqueous textile reactive dye by ozone, Chem. Eng. J. 142: 156-160.

Wu, J., Wang, T. (2001). Ozonation of aqueous azo dye in a semi-batch reactor. Water Res. 35 : 1093-1099.

Yamamoto, Y., Niki E., Shiokawa, H. and Kamiya, Y. (1979). Ozonation of organic compounds 2. Ozonation of phenol in water. J. Org. Chem. 44 (13): 2137-2142.

Yang, L., Hu, C., Nie, Y., Qu, J. (2009). Catalytic ozonation of selected pharmaceuticals over mesoporous alumina-supported manganese oxide. Environ. Sci. Technol. 43: 2525-2529.

Yao C. C. D., Haag W. R. (1991). Rate constants for direct reactions of ozone with several drinking water contaminants. Wat. Res. 25(7): 761-773.

Yen, T., Marsh, W., MacKinnon, M., Fedorak, P., 2004. Measuring naphthenic acids concentrations in aqueous environmental samples by liquid chromatography. J Chromatogr A 1033: 83-90.

Yang L., Hu C., Nie Y., Qu J. (2009). Catalytic ozonation of selected pharmaceuticals over mesoporous alumina-supported manganese oxide. Environ. Sci. Technol. 43: 2525-2529. 
Yong, K., Wu, J., Andrews, S. (2005). Heterogeneous catalytic ozonation of aqueous reactive dye. Ozone Sci. Eng. 27: 257-263.

Zhou S., Huang H., Liu Y. (2008) Biodegradation and origin of oil sands in the western Canada sedimentary basin. Pet. Sci. 5: 87-94. 